ASIPP - IPM Guidelines

\title{
Comprehensive Evidence-Based Guidelines for Interventional Techniques in the Management of Chronic Spinal Pain
}

\begin{abstract}
Laxmaiah Manchikanti, MD1, Mark V. Boswell, MD, PhD², Vijay Singh, MD², Ramsin M. Benyamin, MD4, Bert Fellows, $\mathrm{MA}^{5}$, Salahadin Abdi, MD, PhD ${ }^{6}$, Ricardo M. Buenaventura, MD , Ann Conn, MD ${ }^{8}$, Sukdeb Datta, MD ${ }^{9}$, Richard Derby, MD ${ }^{10}$, Frank JE Falco, MD ${ }^{11}$, Stephanie Erhart, MLIS ${ }^{12}$, Sudhir Diwan, MD ${ }^{13}$, Salim M. Hayek, MD, PhD ${ }^{14}$, Standiford Helm II, MD ${ }^{15}$, Allan T. Parr, MD ${ }^{16}$, David M. Schultz, MD ${ }^{17}$, Howard S. Smith, MD ${ }^{18}$, Lee R. Wolfer, MD, MS ${ }^{19}$, and Joshua A. Hirsch, MD ${ }^{20}$
\end{abstract}

From: ${ }^{1,5}$ Pain Management Center of Paducah, Paducah, KY; ${ }^{2}$ Texas Tech University Health Sciences Center, Lubbock, TX; ${ }^{3}$ Pain Diagnostics Associates, Niagara, WI; ${ }^{4}$ Millennium Pain Center, Bloomington, IL; ${ }^{6}$ University of Miami, Miller School of Medicine,

Miami, FL; ${ }^{7}$ Pain Relief of Dayton, Centerville, $\mathrm{OH}$; ${ }^{8,16}$ Premier Pain Center, Covington, LA; 9 Vanderbilt University Medical Center, Nashville, TN; ${ }^{10,19}$ Spinal

Diagnostics \& Treatment Center, Daly City, CA; ${ }^{11,12}$ Mid Atlantic

Spine \& Pain Specialists, Newark, DE; ${ }^{13}$ University Hospitals of Cleveland and Outcomes Research Consortium, Cleveland, $\mathrm{OH} ;{ }^{14} \mathrm{New}$ York Presbyterian Hospital, Weill Cornell Medical College, New York, NY; ${ }^{15}$ Pacific Coast Pain Management Center, Laguna

Hills, CA; ${ }^{17}$ Medical Advanced Pain Specialists, Minneapolis, MN;

${ }^{18} \mathrm{Albany}$ Medical College, Albany, NY; ${ }^{20}$ Massachusetts General Hospital and Harvard Medical School, Boston, MA.

Address Correspondence: 2831 Lone Oak Road

Paducah, Kentucky 42003

E-mail:drlm@thepainmd.com

Funding: None.

Disclaimer: The authors are solely responsible for the content of this article. No statement in this article should be construed as an official position of ASIPP.

Conflicts of Interest and author affiliation information are listed on page 72 .

Free Full manuscript: www.painphysicianjournal.com
Background: Comprehensive, evidence-based guidelines for interventional techniques in the management of chronic spinal pain are described here to provide recommendations for clinicians.

Objective: To develop evidence-based clinical practice guidelines for interventional techniques in the diagnosis and treatment of chronic spinal pain.

Design: Systematic assessment of the literature.

Methods: Strength of evidence was assessed by the U.S. Preventive Services Task Force (USPSTF) criteria utilizing 5 levels of evidence ranging from Level I to III with 3 subcategories in Level II.

Outcomes: Short-term pain relief was defined as relief lasting at least 6 months and longterm relief was defined as longer than 6 months, except for intradiscal therapies, mechanical disc decompression, spinal cord stimulation and intrathecal infusion systems, wherein up to one year relief was considered as short-term.

Results: The indicated evidence for accuracy of diagnostic facet joint nerve blocks is Level I or II1 in the diagnosis of lumbar, thoracic, and cervical facet joint pain. The evidence for lumbar and cervical provocation discography and sacroiliac joint injections is Level II-2, whereas it is Level II-3 for thoracic provocation discography.

The indicated evidence for therapeutic interventions is Level I for caudal epidural steroid injections in managing disc herniation or radiculitis, and discogenic pain without disc herniation or radiculitis. The evidence is Level II-1 or II-2 for therapeutic cervical, thoracic, and lumbar facet joint nerve blocks; for caudal epidural injections in managing pain of post-lumbar surgery syndrome, and lumbar spinal stenosis, for cervical interlaminar epidural injections in managing cervical pain; for lumbar transforaminal epidural injections; for percutaneous adhesiolysis in management of pain secondary to post-lumbar surgery syndrome; and spinal cord stimulation for post-lumbar surgery syndrome.

The indicated evidence for intradiscal electrothermal therapy (IDET), mechanical disc decompression with automated percutaneous lumbar discectomy (APLD), and percutaneous lumbar laser discectomy (PLDD) is Level II-2.

Limitations: The limitations of these guidelines include a continued paucity of the literature, lack of updates, and conflicts in preparation of systematic reviews and guidelines by various organizations.

Conclusion: The indicated evidence for diagnostic and therapeutic inverventions is variable from Level I to III. These guidelines include the evaluation of evidence for diagnostic and therapeutic procedures in managing chronic spinal pain and recommendations for managing spinal pain. However, these guidelines do not constitute inflexible treatment recommendations. Further, these guidelines also do not represent "standard of care."

Key words: Interventional techniques, chronic spinal pain, diagnostic blocks, therapeutic interventions, facet joint interventions, epidural injections, epidural adhesiolysis, discography, radiofrequency, disc decompression, spinal cord stimulation, intrathecal implantable systems

Pain Physician 2009; 12: 699-802 
1.0 INTRODUCTION

1.1 Chronic Pain

1.2 Interventional Pain Management

1.3 Interventional techniques

1.4 Purpose

1.5 Objectives

1.6 Population and Preferences

1.7 Application

1.8 Rationale

1.9 Importance

1.10 Technology

1.11 Implementation and Review

2.0 METHODOLOGY OF GUIDELINE DEVELOPMENT

2.1 Hierarchy of Strength of Evidence

2.2 Level of Evidence

2.3 Outcomes Assessment Parameters

3.0 EPIDEMIOLOGY, SCOPE, AND IMPACT OF SPINAL PAIN

3.1 Neck Pain

3.2 Thoracic Pain

3.3 Low Back Pain

3.4 Health and Economic Impact

4.0 NEUROPHYSIOLOGIC BASIS OF SPINAL PAIN

5.0 CONTROLLED DIAGNOSTIC INTERVENTIONAL TECHNIQUES

5.1 Diagnosis of Low Back Pain

5.2 Diagnosis of Neck Pain

5.3 Diagnosis of Thoracic Pain

6.0 THERAPEUTIC Interventional techniques
6.1 Facet Joint Interventions

6.2 Epidural Injections

6.3 Lumbar Epidural Adhesiolysis

6.4 Sacroiliac Joint Interventions

6.5 Intradiscal Therapies

6.6 Percutaneous Disc Decompression

6.7 Spinal Cord Stimulation (SCS)

6.8 Implantable Intrathecal Drug Administration Systems

7.0 DOCUMENTATION

7.1 Medical Necessity

7.2 Elements of Documentation

7.3 Types of Documentation

7.4 Documentation of Interventional Procedures

8.0 AN ALGORITHMIC APPROACH

8.1 Comprehensive Algorithm

8.2 Low Back Pain

8.3 Neck Pain

8.4 Thoracic Pain

9.0 DELIVERY OF INTERVENTIONAL TECHNOLOGY

9.1 Indications

9.2 Facet Joint Interventions

9.3 Epidurals Injections

9.4 Percutaneous Adhesiolysis

9.5 Spinal Endoscopic Adhesiolysis

9.6 Intradiscal Procedures

9.7 Mechanical Disc Decompression

9.8 Sacroiliac Joint Injections

\subsection{Introduction}

The American Society of Interventional Pain Physicians (ASIPP) Interventional Pain Management (IPM) guidelines entitled "Comprehensive Evidence-Based Guidelines for spinal interventional techniques in the Management of Chronic Spinal Pain" are systematically developed statements to assist practitioners and patients in making decisions about appropriate health care for specific clinical circumstances. These guidelines present statements of best practice based on a thorough evaluation of the evidence from published studies on the outcomes of treatment (1-6). For further information and detailed analysis, readers may review the related publications, including systematic reviews and individual articles.

\subsection{Chronic Pain}

Chronic pain is defined as a complex and multifactorial phenomenon with pain that persists 6 months after an injury and/or beyond the usual course of an acute disease or a reasonable time for a comparable injury to heal, that is associated with chronic pathologic processes that cause continuous or intermittent pain for months or years, that may continue in the presence or absence of demonstrable pathology and may not be amenable to routine pain control methods with healing never occurring (2).

\subsection{Interventional Pain Management (IPM)}

The National Uniform Claims Committee (NUCC) defined IPM as the discipline of medicine devoted to the diagnosis and treatment of pain and related disorders by the application of spinal interventional techniques in managing subacute, chronic, persistent, and intractable pain, independently or in conjunction with other modalities of treatments.

\subsection{Interventional techniques}

The Medicare Payment Advisory Commission (MedPAC) described spinal interventional techniques as minimally invasive procedures, such as needle placement of drugs in targeted areas, ablation of targeted nerves, and some surgical techniques, such as discectomy and the implantation of intrathecal infusion pumps and spinal cord stimulators (1). 


\subsection{Purpose}

Evidence-based clinical practice guidelines for spinal interventional techniques in the management of chronic spinal pain are statements developed to improve the quality of care, patient access, treatment outcomes, appropriateness of care, efficiency and effectiveness, and achieve cost containment by improving the cost-benefit ratio (7-10).

\subsection{Objectives}

The objectives of the ASIPP guidelines for spinal spinal interventional techniques are to provide a set of recommendations that can support existing and future guidelines by:

1. Focusing on a range of interventions that are the essential elements of effective management of chronic spinal pain.

2. Providing strategies to manage chronic spinal pain and/or its consequences in the general populations and in workers to improve the quality of clinical care.

3. Developing methods that are sound and transparent and highlighting the areas where further research is needed by noting deficiencies in knowledge.

4. Utilizing a process which is valid, reliable, reproducible, clinically applicable, and flexible, providing clarity with a multidisciplinary process with documentation of the process in developing guidelines, along with a scheduled review.

5. Providing recommendations that are generally acceptable to a wide range of specialties and agencies.

6. Increasing compliance, dispelling misconceptions, contributing to appropriate patient expectations, and facilitating the improved relationship between patients, physicians, and payors.

\subsection{Population and Preferences}

The population covered by these guidelines includes all patients suffering with chronic spinal pain eligible to undergo commonly utilized and effective interventional technique(s). The treatment plan must take into consideration the evidence, patient preferences, and risk-benefit ratio.

\subsection{Application}

While these guidelines may be applied by any specialty, they are specifically intended for use by interventional pain physicians. These guidelines do not constitute inflexible treatment recommendations. It is expected that a provider will establish a plan of care on a case-by-case basis, taking into account an individual patient's medical condition, personal needs, and preferences, and the physician's experience. Based on an individual patient's needs, treatment different from that outlined here could be warranted. Consequently, these guidelines do not represent a "standard of care."

The goal of these guidelines is to provide patients, practitioners, regulators and payors information to determine whether the available evidence supports the notion of a "standard" for interventional techniques . "Standard" refers to what is applicable to the majority of patients, with a preference for patient convenience and ease of administration without compromising treatment efficacy or morbidity (11). It is essential to recognize the difference between "standard" and "standard of care," as utilized as a legal definition.

\subsection{Rationale}

Despite advances in biomedical knowledge and the highest per capita health care expenditures in the world, the quality and outcomes of health care vary dramatically across the United States $(12,13)$. Accordingly, the trend to develop and implement research in support of evidence-based practice has been a focus of medical practice for the past decade. For example, in the modern era, the central premise is that decisions about the care of individual patients should be based on "the conscientious, explicit, and judicious use of current best evidence" (14). This means that individual clinical expertise should be integrated with the best information from scientifically based, systematic research, and should be applied in light of the patient's unique values and circumstances (15).

Towards these ends, ASIPP has provided evidencebased guidelines (7-10), methodology for evidence synthesis (16-23), systematic reviews (24-52), and critical analysis (53-55) based on a methodical critical appraisal of existing data using established and uniform criteria.

As an emerging speciality, IPM faces multiple problems which may be disproportionate compared to established medical specialities. IPM is faced with increasing utilization of effective safe techniques due to its emergent nature as well as potentially inappropriate care that may be ineffective or unsafe (56-64). The available evidence at the present time documents a wide degree of variance in the definition and the practice of medicine in general and IPM in particular (6-10,12,13,56-63). The application of spinal interventional techniques by physicians of different specialties is highly variable for even the most commonly performed procedures and treated conditions $(12,13,53-64)$. 
The data for spinal interventional techniques in the Medicare population from 1997 to 2006 shows an increase of $235 \%$ (56). The $22.2 \%$ yearly increase in expenditures in the Medicare population for IPM procedures has been even more significant from 2002 to 2006 . Yet, during the same period, the U.S. population increased by $12 \%$ and the Medicare population increased by $13 \%$ as a proportion of the population (56). The number of patients receiving spinal interventional techniques increased by $169 \%$ from 1997 to 2006 (Fig. 1). This increase in utilization paralleled the rising prevalence of low back pain, advancement of new and innovative fluoroscopic injection techniques and the evolution of IPM into a distinct medical specialty (1-6,56-64).

\subsection{Importance}

Many of the causes of spinal pain and other chronic pain conditions are considered to be either acute recurrent problems characterized by periods of quiescence punctuated by flare-ups or chronic diseases, like diabetes or hypertension, requiring longterm treatment with ongoing care. The importance of spinal interventional techniques in managing chronic spinal pain has been established on the basis of advances in imaging, neuroanatomic findings, the development of precision diagnostic and therapeu- tic injection techniques, and reported non-operative treatment successes. Many guidelines, systematic reviews, Cochrane Reviews, and other articles pertaining to IPM have been published $(6-10,12,24$ 55,65-107). However, most of these guidelines are ambiguous and may not be applicable in managing chronic spinal pain utilizing contemporary IPM. Further, there are quality issues with inclusion or exclusion of significant literature of randomized trials and observational studies.

\subsection{Technology}

Diagnostic and therapeutic spinal interventional techniques in the management of chronic spinal pain have been evaluated. These include facet joint interventions, sacroiliac joint interventions, epidural injections, lumbar epidural adhesiolysis, discography and intradiscal therapies, mechanical disc decompression, and implantable therapies.

\subsection{Implementation and Review}

The dates for implementation and review were established:

- Effective date - August 1, 2009

- Expiration date - July 31, 2012

- Scheduled review - August 1, 2011

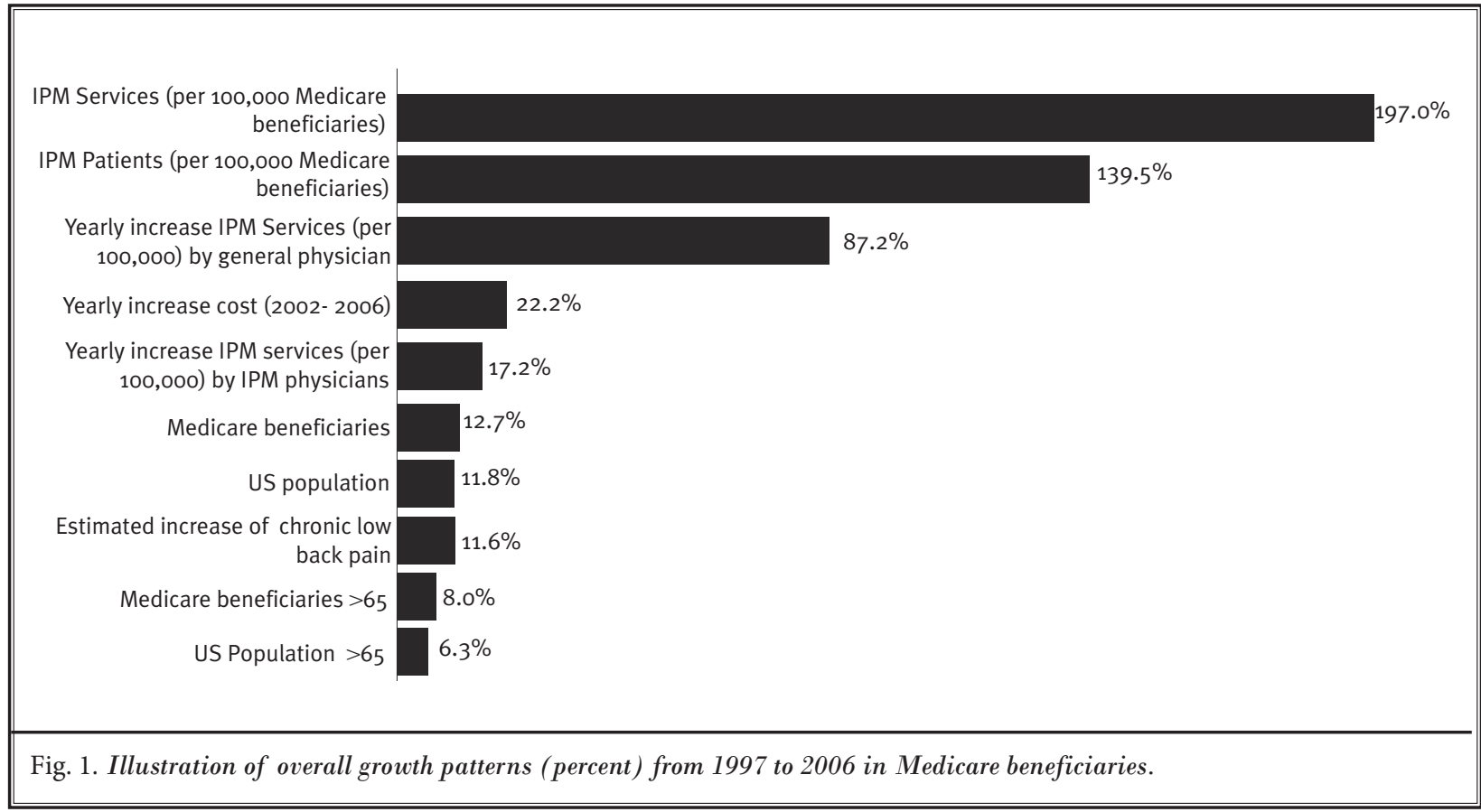




\subsection{Methodology of Guideline DeVelopment}

The methodology of development for the present guidelines is described in an Introduction to EvidenceBased Approach to spinal interventional techniques in the Management of Chronic Spinal Pain (1). Unanimity is strikingly absent when different guidelines are compared, while it is almst always present in individual guidelines (108). The next issue is with regards to lack of independent review, followed by conflict of interests. By favoring one test over another, or one therapy over another, guidelines often create commercial winners and losers, who cannot be disinterested in the result and who therefore must be separated from the process (108). Those who write the guidelines and those who issue them have significant conflicts of interest $(109,110)$.

ASIPP launched the development of practice guidelines for spinal interventional techniques in the management of chronic pain in 1999 and published the first set of guidelines in 2000 (10). These guidelines were started to create a document to help practitioners by synthesizing the available evidence utilizing a combination of evidence and consensus. The synthesis of evidence, committee composition, and the development process have been revised, refined, and expanded with frequent evaluation (6-55,111-116). Further, ASIPP guidelines meet most of the criteria described by Shaneyfelt et al (117), AGREE (118), IOM (119), as well as the majority of recommendations by Sniderman and Furberg (108).

\subsection{Hierarchy of Strength of Evidence}

A hierarchy of strength of evidence for treatment decisions provided by Guyatt and Drummond (120) is as follows:

- N of 1 randomized controlled trial

- Systematic reviews of randomized trials

- Single randomized trial

- Systematic review of observational studies addressing patient-important outcomes

- Single observational study addressing patient-important outcomes

- Physiologic studies (studies of blood pressure, cardiac output, exercise capacity, bone density, and so forth)

- Unsystematic clinical observations

\subsection{Level of Evidence}

The translation of systematic reviews into practice recommendations is not straightforward. The same information can be interpreted in different ways by different panelists, resulting in the provision of different guidance (121). Often, even when there is substantial consensus about what the scientific evidence says, there are disagreements about what the evidence means for clinical practice. Conclusions about clinical effectiveness can vary widely as a result of conflicting viewpoints, such as which outcomes are the most important and which course of action is appropriate given that the evidence is imperfect. Thus, systematic reviews assess the quality of the individual studies and provide the quality and level of evidence. In developing guidelines both are important, that is the quality of evidence and the strength of recommendation which takes into account the balance of the benefits and harms that are associated with the intervention.

The evidence base that supports clinical practice guidelines is often quite limited and guideline developers must often wrestle with what to do when "the irresistible force of the need to offer clinical advice meets with the immovable object of flawed evidence" (122124). The authors of guidelines must consider the best way to address the trade-off between rigor and pragmatism, and between adherence to evidence and broader clinical utility $(122,124,125)$. The authors may nonetheless state their evaluation and recommendations based upon the current best available evidence.

\subsubsection{Determination of Level of Evidence}

Level of evidence is derived from quality assessment and the results of individual studies. While there is no universally accepted approach to presenting levels of evidence, a rigorous approach in widespread use was developed by the United States Preventive Services Task Force (USPSTF) (126). Table 1 illustrates the modiefied quality of evidence developed by the USPSTF, utilized in preparation of the present guidelines.

Methodologic quality assessment of systematic reviews is crucial for guideline preparation and grading recommendations. West et al (127) described a set of high-performing scales or checklists pertaining to systematic reviews, with 7 key domains: study question, search strategy, inclusion and exclusion criteria, data abstraction, study quality and validity, data synthesis and analysis, and funding or sponsorship (Table 2), utilized in preparation of the present guidelines.

Multiple systems are available for the quality assessment and reporting of randomized trials, observational studies, and diagnostic accuracy studies 
Table 1. Quality of evidence developed by USPSTF.

\begin{tabular}{|c|l|}
\hline \hline I: & $\begin{array}{l}\text { Evidence obtained from at least one properly randomized controlled trial or multiple properly conducted diagnostic accuracy } \\
\text { studies. }\end{array}$ \\
\hline II-1: & $\begin{array}{l}\text { Evidence obtained from one well-designed controlled trial without randomization or at least one properly conducted diagnostic } \\
\text { accuracy study of adequate size. }\end{array}$ \\
\hline II-2: & Evidence obtained from at least one properly designed small diagnostic accuracy study. \\
\hline II-3: & $\begin{array}{l}\text { Evidence obtained from multiple time series with or without the intervention. Dramatic results in uncontrolled experiments (such } \\
\text { as the results of the introduction of penicillin treatment in the 1940s) could also be regarded as this type of evidence. }\end{array}$ \\
\hline III: & Opinions of respected authorities, based on clinical experience descriptive studies and case reports or reports of expert committees. \\
\hline \hline
\end{tabular}

Adapted and modified from the U.S. Preventive Services Task Force (USPSTF) (126).

Table 2. Domains in the Agency for Healthcare Research and Quality (AHRQ) criteria for evaluating systematic reviews.

\begin{tabular}{|c|c|}
\hline DOMAIN & ELEMENTS* \\
\hline Study question & - Question clearly specified and appropriate \\
\hline Search strategy & $\begin{array}{l}\text { - Sufficiently comprehensive and rigorous with attention to possible publication biases } \\
\text { - Search restrictions justified (e.g., language or country of origin) } \\
\text { - Documentation of search terms and databases used } \\
\text { - Sufficiently detailed to reproduce study }\end{array}$ \\
\hline Inclusion and exclusion criteria & - Selection methods specified and appropriate, with a priori criteria specified if possible \\
\hline Interventions & - Intervention(s) clearly detailed for all study groups \\
\hline Outcomes & - All potentially important harms and benefits considered \\
\hline Data extraction $\uparrow$ & $\begin{array}{l}\text { - Rigor and consistency of process } \\
\text { - Number and types of reviewers } \\
\text { - Blinding of reviewers } \\
\text { - Measure of agreement or reproducibility } \\
\text { - Extraction of clearly defined interventions/exposures and outcomes for all relevant subjects } \\
\text { and subgroups }\end{array}$ \\
\hline Study quality and validity & $\begin{array}{l}\text { - Assessment method specified and appropriate } \\
\text { - Method of incorporation specified and appropriate }\end{array}$ \\
\hline Data synthesis and analysis & $\begin{array}{l}\text { - Appropriate use of qualitative and/or quantitative synthesis, with consideration of the robustness } \\
\text { of results and heterogeneity issues } \\
\text { - Presentation of key primary study elements sufficient for critical appraisal and replication }\end{array}$ \\
\hline Results & $\begin{array}{l}\text { - Narrative summary and/or quantitative summary statistic and measure of precision, as } \\
\text { appropriate }\end{array}$ \\
\hline Discussion & - Conclusions supported by results with possible biases and limitations taken into consideration \\
\hline Funding or sponsorship & - Type and sources of support for study \\
\hline
\end{tabular}

* Elements appearing in italics are those with an empirical basis. Elements appearing in bold are those considered essential to give a system a Yes rating for the domain.

$\dagger$ Domain for which a Yes rating required that a majority of elements be considered.

Adapted from West $S$ et al. Systems to Rate the Strength of Scientific Evidence, Evidence Report, Technology Assessment No. 47. AHRQ Publication No. 02-E016. Rockville, MD: Agency for Healthcare Research and Quality, 2002. www.thecre.com/pdf/ahrq-system-strength.pdf (127). 
(78,86,127-134). Various methodologic quality assessment instruments were utilized in the evidence synthesis, preparation of systematic reviews, and preparation of ASIPP-IPM guidelines.

Atkins et al (135) evaluated the quality of evidence and strength of recommendations in a pilot study group to examine the Grading of Recommendations, Assessment, Development and Evaluation (GRADE) system. They concluded that judgments about evidence and recommendations are complex with some subjectivity, especially regarding recommendations. Guyatt et al (136) published a description of grading the strength of recommendations and quality of evidence in clinical guidelines as shown in Table 3 that was utilized in the preparation of the ASIPP-IPM guidelines.

\subsection{Outcomes Assessment Parameters}

Short-term pain relief was defined as relief lasting of at least 6 months and long-term relief was defined as longer than 6 months, except for radiofrequency neurotomy procedures, intradiscal procedures, mechanical disc decompression procedures, and implantable therapy with spinal cord stimulation or intrathecal infusion systems, wherein up to one year relief was considered as short-term and longer than one year was considered as long-term.

\subsection{EpIDEMIOLOGY, Scope, ANd Impact of Spinal Pain}

Pain arising from various structures of the spine constitutes the majority of the problems in chronic pain settings. The lifetime prevalence of spinal pain has been reported as $54 \%$ to $80 \%(2,7-$ 10, 137-165).

\subsection{Neck Pain}

The annual prevalence estimates of any neck pain among adults ranged from $12.1 \%$ to $71.5 \%$ with most estimates of annual prevalences between 30\% and $50 \%(157,160-162,164-183)$. Côté et al (160) illustrated various grades of chronic neck pain with $5 \%$ of the patients suffering with grades III and IV neck pain associated with high pain intensity and disability.

Chronic neck pain resulting from whiplash associated disorders (WAD) has been described (184-186). Similarly, the incidence of compensated musculoskeletal disorders such as back and neck pain has been increasing $(156,158,187-203)$. The annual prevalence of neck pain varies among occupations and populations (16.5\% in spinning industry to $74 \%$ in crane operators $(199,204)$. Each year neck pain is responsible for a significant burden of disability in workers $(185,186,188)$.

Table 3. Grading recommendations.

\begin{tabular}{|c|c|c|c|}
\hline $\begin{array}{c}\text { Grade of Recommendation/ } \\
\text { Description }\end{array}$ & $\begin{array}{c}\text { Benefit vs Risk and } \\
\text { Burdens }\end{array}$ & $\begin{array}{l}\text { Methodological Quality of } \\
\text { Supporting Evidence }\end{array}$ & Implications \\
\hline $\begin{array}{l}1 \mathrm{~A} / \text { strong recommendation, } \\
\text { high-quality evidence }\end{array}$ & $\begin{array}{l}\text { Benefits clearly outweigh risk } \\
\text { and burdens, or vice versa }\end{array}$ & $\begin{array}{l}\text { RCTs without important limitations or } \\
\text { overwhelming evidence from observa- } \\
\text { tional studies }\end{array}$ & $\begin{array}{l}\text { Strong recommendation, can ap- } \\
\text { ply to most patients in most cir- } \\
\text { cumstances without reservation }\end{array}$ \\
\hline $\begin{array}{l}1 \mathrm{~B} / \text { strong recommendation, } \\
\text { moderate quality evidence }\end{array}$ & $\begin{array}{l}\text { Benefits clearly outweigh risk } \\
\text { and burdens, or vice versa }\end{array}$ & $\begin{array}{l}\text { RCTs with important limitations (incon- } \\
\text { sistent results, methodological flaws, indi- } \\
\text { rect, or imprecise) or exceptionally strong } \\
\text { evidence from observational studies }\end{array}$ & $\begin{array}{l}\text { Strong recommendation, can ap- } \\
\text { ply to most patients in most cir- } \\
\text { cumstances without reservation }\end{array}$ \\
\hline $\begin{array}{l}1 \mathrm{C} / \text { strong recommendation, } \\
\text { low-quality or very low-qual- } \\
\text { ity evidence }\end{array}$ & $\begin{array}{l}\text { Benefits clearly outweigh risk } \\
\text { and burdens, or vice versa }\end{array}$ & Observational studies or case series & $\begin{array}{l}\text { Strong recommendation but } \\
\text { may change when higher quality } \\
\text { evidence becomes available }\end{array}$ \\
\hline $\begin{array}{l}\text { 2A/weak recommendation, } \\
\text { high-quality evidence }\end{array}$ & $\begin{array}{l}\text { Benefits closely balanced with } \\
\text { risks and burden }\end{array}$ & $\begin{array}{l}\text { RCTs without important limitations or } \\
\text { overwhelming evidence from observa- } \\
\text { tional studies }\end{array}$ & $\begin{array}{l}\text { Weak recommendation, best action } \\
\text { may differ depending on circum- } \\
\text { stances or patients' or societal values }\end{array}$ \\
\hline $\begin{array}{l}\text { 2B/weak recommendation, } \\
\text { moderate-quality evidence }\end{array}$ & $\begin{array}{l}\text { Benefits closely balanced with } \\
\text { risks and burden }\end{array}$ & $\begin{array}{l}\text { RCTs with important limitations (incon- } \\
\text { sistent results, methodological flaws, indi- } \\
\text { rect, or imprecise) or exceptionally strong } \\
\text { evidence from observational studies }\end{array}$ & $\begin{array}{l}\text { Weak recommendation, best } \\
\text { action may differ depending on } \\
\text { circumstances or patients' or } \\
\text { societal values }\end{array}$ \\
\hline $\begin{array}{l}\text { 2C/weak recommendation, } \\
\text { low-quality or very low-qual- } \\
\text { ity evidence }\end{array}$ & $\begin{array}{l}\text { Uncertainty in the estimates } \\
\text { of benefits, risks, and burden; } \\
\text { benefits, risk, and burden may } \\
\text { be closely balanced }\end{array}$ & Observational studies or case series & $\begin{array}{l}\text { Very weak recommendations; } \\
\text { other alternatives may be equally } \\
\text { reasonable }\end{array}$ \\
\hline
\end{tabular}

Adapted from Guyatt $\mathrm{G}$ et al. Grading strength of recommendations and quality of evidence in clinical guidelines. Report from an American College of Chest Physicians task force. Chest 2006; 129:174-181 (136). 
While it is well known that neck pain is a common human phenomenon, what is not known is whether neck pain is likely to improve, reoccur, persist, or worsen. Most of the evidence indicates that between $50 \%$ to $75 \%$ of people who experience neck pain initially report neck pain one to 5 years later $(145,174,179,205-$ 209). Further, evidence also indicates that in adults, recovery of WAD is prolonged, with approximately $50 \%$ of those affected reporting neck pain symptoms one year after the injury (209-213).

\subsection{Thoracic Pain}

A review of epidemiology of thoracic pain showed the incidence ranging from $3 \%$ to $26 \%$ and prevalence ranging from $5 \%$ to $34 \%(162,163,214)$. Despite the lower prevalence compared to low back and neck pain, the degree of disability resulting from thoracic pain disorders was similar to that of the other regions $(215,216)$.

\subsection{Low Back Pain}

The annual prevalence of chronic low back pain ranges from $15 \%$ to $45 \%$, with a point prevalence of $30 \%$ $(139,159,161,217-234)$. The studies evaluating chronic low back pain estimated the average age related prevalence of persistent low back pain to be approximately $15 \%$ in adults and $27 \%$ in the elderly $(139,161,223,224)$. Lawrence et al (139) estimated that among the working population (age 20 to 64), more than 26 million Americans have frequent low back pain, whereas among Americans aged 65 and older, almost 60 million have frequent low back pain. Cassidy et al (159) evaluated pain associated with disability and graded them into Grade I to Grade IV. Based on this, $11 \%$ of the patients had Grade III and Grade IV pain levels with high pain intensity and significant disability. In an extensive review of the international literature on the incidence of disabling low back pain, Nachemson (225) reported that the problem of low back pain was even greater in Canada, Great Britain, Netherlands, and Sweden, in comparison to the United States and Germany. It is estimated that $28 \%$ of the U.S. industrial population will experience disabling low back pain at some time and $8 \%$ of the entire working population will be disabled in any given year, contributing to $40 \%$ of all lost work days (220,226-231).

Remarkably, studies have shown increasing prevalence of chronic pain (147), specifically low back pain (187). Freburger et al (187) reported the rising prevalence of chronic low back pain following an evaluation of North Carolina households conducted in 1992 and repeated in 2006. The results showed an increasing preva- lence of chronic impairing low back pain over the 14year interval from 3.9\% (95\% Cl, 3.4\% - 4.4\%) in 1992 to $10.2 \%(95 \% \mathrm{Cl}, 9.3 \%-11.0 \%)$ in 2006 . The overall prevalence of low back pain increased by $162 \%$ (an annual increase of $11.6 \%$ ), across all demographic groups.

The duration of back pain and its chronicity have been topics of controversy. It is widely believed that most of the episodes will be short-lived with $80 \%$ to $90 \%$ of attacks resolving in about 6 weeks, irrespective of the administration or type of treatment, with only $5 \%$ to $10 \%$ of patients developing persistent back pain $(235,236)$. However, this widely held belief has been frequently questioned as the condition tends to relapse and most patients will experience multiple episodes and long lasting back pain is common (187,237-259). However, Stanton et al (260) reported that the recurrence of low back pain was found to be much less common than previous estimates, ranging from $24 \%$ using 12 months as the definition of recurrence, to $33 \%$ using pain at followup as the definition of recurrence. Even then, this is higher than the conventionally believed proportion of $4 \%$ to $10 \%$.

Bressler et al (261) reported a prevalence of back pain among the elderly within the community ranging from $13 \%$ to $49 \%$; within the medical practice setting, the range was from $24 \%$ to $51 \%$; and in the long-term care setting, the prevalence was $40 \%$, with an overall prevalence of $27 \%$. They suggested that the prevalence of low back pain in the elderly is not known with certainty and is not comparable with that in the younger population.

\subsection{Health and Economic Impact}

Spinal pain is associated with significant economic, societal, and health impact $(156,175,185,222,228,262-322)$. Estimates and patterns of direct health care expenditures among individuals with back pain in the United States have reached $\$ 90.7$ billion for the year 1998 (303). On average, individuals with back pain incurred health care expenditures about $60 \%$ higher than individuals without back pain $(\$ 3,498$ versus $\$ 2,178$ ) (309). In the United States, it was estimated that the cost of treatment in the first year after failed back surgery for pain was approximately \$18,883 in 1997 (312). The majority of these costs are associated with disability compensation, lost productivity, and lost tax revenue. Disability secondary to spinal pain is enormous $(174,265,293-298,303,315,316)$. 


\subsection{Neurophysiologic Basis of Spinal Pain}

The birth and rise of the biopsychosocial model is credited to some difficult and important medical problems which have proven resistant to the biomedical model $(323,324)$. Multiple disease states without a unique underlying pathoanatomic/pathophysiologic lesion have been identified, and the outcomes of treatments even when they are extensive and costly are less than ideal. Along with many of the difficult problems such as pelvic pain, facial pain, myofascial pain syndromes, and some psychiatric illnesses, persistent spinal pain (with its associated societal and health care impact in the billions of dollars) has been included in this category $(13,56,58,278,280-311,325-329)$. The biopsychosocial model of illness was proposed by Engel in 1977 (330). The proponents of this model believe that the complex, multidimensional nature of persistent spinal pain does not lend itself to the clean reductionist program of the biomedical model. Consequently, the clinician is presented with a set of biologic and psychosocial factors, with which to explain why people have persistent spinal pain and a set of alternative tools, addressing these factors, with which to treat patients (331). However, multiple concerns related to the biopsychosocial model have been described (324). These concerns include the reliance on self-report of outcomes, the disconnection between physical pathology and self-report, and the scientific status of the biopsychosocial model.

By definition, "bio" "psycho" "social" underscores the important contribution of various factors in each of the 3 defining domains (324). The rise of the biopsychosocial models' application to spine problems is tied to the disconnection between our current understanding of spinal pathology and back pain/disability and the apparent connections between psychosocial factors and pain-disability (270,324,332-336). Historically, we may find that embracing a biopsychosocial orientation may actually hamper the development of a better understanding of many disease etiologies $(270,324)$. While acknowledging the current shortcomings of the persistent spinal pain biomedical mode, historically, pathoanatomically based biomedical theories of causation have often worked well.

The multi-dimensional mechanism of pain and multidisciplinary management has taken different meanings for different specialties, sometimes ignoring the fundamental facts that pain is not explained by pure theories of either physical or psychological origins. Thus, pain management in some circles has reached a stage of psychosocial reductionism, which has essentially eliminated the bio part from the biopsychosocial approach, leaving "psychosocial," "psychological," or "functional" approaches.

\subsection{Controlled Diagnostic Interventional Techniques}

In contrast to the mixed picture provided by history, physical examination, imaging, and nerve conduction studies in non-radicular pain, controlled diagnostic blocks have been shown to determine the cause of pain in as many as $85 \%$ of the patients in contrast to $15 \%$ of the patients with other available techniques (337-339).

Precision diagnostic blocks are used to clarify multiple challenging situations, in order to determine the pathophysiology of clinical pain, the site of nociception, and the pathway of afferent neural signals.

The theoretical basis of controlled diagnostic blocks is based on the fact that if a patient genuinely has pain from a particular target structure, complete relief of that pain should be obtained consistently whenever that structure is anesthetized, and repeating the diagnostic block can increase the diagnostic accuracy by testing for consistency of response and for the effect of different aesthetic agents.

For a diagnostic block to have face validity it must be shown that the block actually does what it is supposed to do in an anatomical and a physiological sense (340). If a particular structure is said to be the target, it must be shown that the structure is anesthetized and either does or does not produce a result within the distribution of that structure. Face validity can be tested and established either by a study whose results can be replicated or by testing for face validity in each and every case. The face validity may be established by radiographic imaging with injection of a contrast agent or by a physiological approach utilizing a detectable and testable function other than pain (e.g., distal extremity temperature monitoring with a sympathetic block).

Construct validity establishes if the test actually achieves what it is supposed to achieve by measuring the extent to which a test correctly distinguishes the presence, but also the absence, of the condition that the test is supposed to detect. Construct validity measures if the test actually works or not, and how well it works (340).

For diagnostic interventional techniques, there is no conventional criterion standard, such as imaging findings, operative findings, or pathological findings. However, long-term relief may be used to provide a criterion standard for certain type of blocks. Thus, Bogduk (340) has developed testing for construct validity of diagnostic blocks by other means. Features such as the false-positive rate can be estimated by determining how often a diagnostic block is positive 
in patients who should not, or demonstrably do not, have the condition in question. Once the false-positive rate is known, the specificity of the test can be derived as the complement of the false-positive rate.

One form of control involves using a placebo agent in which the protocol requires a sequence of 3 blocks. The first block must involve an active agent, in order to establish, prima facie, that the target structure does appear to be the source of pain. The other 2 agents are administered in randomized double-blind basis. Under these conditions, a true-positive response would be the one in which the patient obtained relief on each occasion that an active agent was used, but no relief when the inactive agent was used.

A second approach, most commonly utilized in the United States because it is also a more pragmatic approach, is to use comparative local anesthetic blocks. The blocks are performed on separate occasions using local anesthetic agents with different durations of action (340-348). In this approach, the consistency of response and the duration of response are tested. Failure to respond to the second block constitutes inconsistency, and indicates that the first response was false-positive. A response concordant with the expected duration of action of the agent used strongly suggests a genuine, physiologic response.

\subsection{Diagnosis of Low Back Pain}

Lumbar intervertebral discs, facet joints, sacroiliac joint, ligaments, fascia, muscles, and nerve root dura have been shown to be capable of transmitting pain in the lumbar spine with resulting symptoms of low back pain and lower extremity pain $(3,4)$. The diagnostic blocks applied in the precision diagnosis of chronic low back pain include lumbar facet joint nerve blocks, lumbar provocation discography, and sacroiliac joint blocks $(40,45,46)$.

\subsubsection{Lumbar Facet or Zygapophysial Joint Blocks}

Controlled diagnostic blocks of a lumbar facet or zygapophysial joint can be performed by anesthetizing the joint via injection of local anesthetics intraarticularly or in close proximity to the medial branches of the dorsal rami that innervate the target joint.

The rationale for using facet joint blocks for diagnosis is based on the fact that lumbar facet joints are capable of causing pain and they have a nerve supply (349-360). Facet joints have been shown to be a source of pain in patients using diagnostic techniques of known reliability and validity $(29,361-373)$. The value, validity, and clinical effectiveness of diagnostic facet joint nerve blocks has also been illustrated by the application of therapeutic modalities based on the diagnosis with controlled comparative local anesthetic blocks $(7,8,29,80,361,362,374-377)$.

The face validity of lumbar medial branch or facet joint nerve blocks has been established by injecting small volumes of local anesthetic and contrast material onto the target points for these structures and by determining the spread of contrast medium in the posteroanterior and lateral radiographs $(340,351,352,363)$. Construct validity of facet joint blocks is important to eliminate placebo effect as the source of confounding results and to secure truepositive results $(340,346,348,363)$. The hypothesis that testing a patient first with lidocaine and subsequently with bupivacaine provides a means of identifying the placebo response has been tested and proven $(342,347,378)$.

The specificity of the effect of lumbar facet joint blocks was demonstrated in controlled trials $(351,352)$. Provocation response of facet joint pain was shown to be unreliable in one study (378). The false-negative rate of diagnostic facet joint blocks was shown to be $8 \%$ due to unrecognized intravascular injection of local anesthetic (351).

The validity of comparative local anesthetic blocks was determined not only by short-term relief with controlled diagnostic blocks, and ability to perform movements which were painful prior to the blocks, but also with application of another appropriate reference standard (long-term follow-up) as described in the literature (376). Utilizing the modified criteria established by the International Association for the Study of Pain (IASP) (379), false-positive rates varying from $17 \%$ to $50 \%$ were demonstrated. Minimal effect of sedation $(380,381)$ and lack of influence of psychological factors on the validity of controlled lumbar diagnostic local anesthetic blocks of facet joints was demonstrated $(382,383)$. Other variables includding prior opioid exposure were also evaluated (384-386).

\subsubsection{Cost Effectiveness}

Diagnostic lumbar facet joint nerve blocks were not evaluated for cost effectiveness systematically. However, the feasibility and cost-effectiveness of appropriately performed controlled comparative local anesthetic blocks has been described (267,338,387-389). 


\subsubsection{Safety and Complications}

The common reported complications of facet joint injections or nerve blocks though rare, include hemorrhage, dural puncture, spinal cord trauma, infection, intraarterial or intravenous injection, chemical meningitis, neural trauma, paralysis, radiation exposure, facet capsule rupture, hematoma formation, steroid side effects, and epidural, subdural, or subarachnoid spread $(6,29,40,361,362,390-408)$.

\subsubsection{Evidence Assessment}

Our search yielded 5 systematic reviews $(29,40,361,362,409)$ and multiple other manuscripts (338,351,352,361-369,371,373,376,378,383-386,410).

The recent systematic review by Datta et al (40) utilized 7 studies $(338,364,365,368,369,372,373)$ meeting inclusion criteria with $80 \%$ pain relief and ability to perform previously painful movements with controlled diagnostic blocks of lumbar facet joint nerves.

\subsubsection{Prevalence}

Based on the systematic review by Datta et al (40), prevalence is $21 \%$ to $40 \%$ in heterogenous population with chronic low back pain and $16 \%$ in post lumbar surgery syndrome with confidence intervals (Cls) ranging from $9 \%$ to $23 \%$ in post surgery syndrome and $14 \%$ to $53 \%$ in heterogenous population (Table 4). The overall prevalence is $31 \%(95 \% \mathrm{Cl} ; 28 \%-33 \%)$.

\subsubsection{False-Positive Rate}

Based on Datta et al's (40) systematic review, falsepositive rates of $17 \%$ to $49 \%$ are demonstrated with Cls ranging from $10 \%$ to $59 \%$ with overall false-positive rate of $30 \%$ (95\% Cl 27\%-33\%) (Table 4).

\subsubsection{Level of Evidence}

Evidence is Level I or II-1 based on the (USPSTF) criteria (126).

Rubinstein and van Tulder (411) in a best-evidence review of diagnostic procedures for low-back pain concluded that there is strong evidence for the diagnostic accuracy of lumbar facet joint blocks in evaluating spinal pain.

\subsubsection{Recommendations}

Based on the present comprehensive evaluation and other described guidelines $(3,29,40,53,338,361$ $365,368,369,372,379,412,413)$, diagnostic lumbar facet joint nerve blocks are recommended in patients with suspected facet joint pain.
- Indications include:

- Patients suffering with somatic or non-radicular low back and lower extremity pain, with duration of pain of at least 3 months.

- Average pain levels are of greater than 6 on a scale of 0 to 10 .

- Pain is at least intermittent or continuous causing functional disability.

- Condition has failed to respond to more conservative management, including physical therapy modalities with exercises, chiropractic management, and non-steroidal anti-inflammatory agents.

- Lack of preponderance of evidence of either discogenic or sacroiliac joint pain and lack of disc herniation or evidence of radiculitis.

- No evidence of contraindications is present for the needle placement and injection of local anesthetics.

- Presence of contraindications or inability to undergo physical therapy, chiropractic management, or inability to tolerate non-steroidal anti-inflammatory drugs.

- A positive response is based on the following evidence:

- Patient has met the above indications.

- Patient responds positively to controlled local anesthetic blocks either with placebo control or comparative local anesthetic blocks with appropriate response to each local anesthetic (< $1 \mathrm{~mL}$ per level).

- At least $80 \%$ relief as criterion standard with ability to perform previously painful movement without deterioration of the relief (i.e., extension, lateral rotation, flexion, etc.).

- The patient's response should be recorded independently by the assessor - generally a registered nurse familiar with patient or another physician.

\subsubsection{Lumbar Provocation Discography}

Discography is a procedure that is used to characterize the pathoanatomy/architecture of the intervertebral disc and to determine if the intervertebral disc is a source of chronic low back pain. Implicitly, discography is an invasive diagnostic test that should only be applied to those chronic low back pain patients in whom one suspects a discogenic etiology. Discography literally means the opacification of the nucleus pulposus of an intervertebral disc to render it visible under radiogra- 
Pain Physician: July/August 2009:12: 699-802

Table 4. Data of prevalence with controlled diagnostic blocks and false-positive rates in the lumbar region.

\begin{tabular}{|l|c|c|c|c|}
\hline \multicolumn{1}{|c|}{ Study } & $\begin{array}{c}\text { Methodological } \\
\text { Criteria * }\end{array}$ & Participants & Prevalence & False-Positive Rate \\
\hline Manchikanti et al 2002 (369) & 75 & 120 & $40 \%(95 \%$ CI 31\%-49\%) & $30 \%(95 \%$ CI 20\%-40\%) \\
\hline Manchikanti et al 2004 (365) & 75 & 397 & $31 \%(95 \%$ CI 27\%-36\%) & $27 \%(95 \%$ CI 22\%-32\%) \\
\hline Manchukonda et al 2007 (364) & 75 & 303 & $27 \%(95 \%$ CI 22\%-33\%) & $45 \%(95 \%$ CI 36\%-53\%) \\
\hline Schwarzer et al 1995 \# (372) & 75 & 63 & $40 \%(95 \%$ CI 29\%-53\%) & NA \\
\hline Manchikanti et al 2001 (338) & 75 & 120 & $40 \%(95 \%$ CI 31\%-49\%) & $47 \%(95 \%$ CI 35\%-59\%) \\
\hline Manchikanti et al 2003 (368) & 75 & 300 & $\begin{array}{c}\text { I. 21\% (95\% CI 14\%-27\%) } \\
\text { II. 41\% (95\% CI 33\%-49\%) }\end{array}$ & $\begin{array}{c}\text { I. 17\% (95\% CI 10\%-24\%) } \\
\text { II. 27\% (95\% CI 18\%-36\%) }\end{array}$ \\
\hline Manchikanti et al 2007 (373) & 75 & 117 & $16 \%(95 \%$ CI 9\%-23\%) & $49 \%(95 \%$ CI 39\%-59\%) \\
\hline Overall & & 1,420 & $31 \%(95 \%$ CI; 28\%-33\%) & $30 \% \#(95 \%$ CI; 27\%-33\%) \\
\hline
\end{tabular}

$\mathrm{CI}=$ confidence interval; NA =not available; \# Schwarzer et al (372) was without evaluation of false-positive rates.

${ }^{\star}$ Methodologic quality assessment adapted and modified from West S, et al. Systems to Rate the Strength of Scientific Evidence, Evidence Report, Technology Assessment No. 47. AHRQ Publication No. 02-E016 (127).

Adapted with permission from Datta S et al. Systematic assessment of diagnostic accuracy and therapeutic utility of lumbar facet joint interventions. Pain Physician 2009; 12:437-460 (40).

phy (414-416). The commonly practiced technical and evaluative components of discography include sterile needle placement into the center of the intervertebral disc (nucleus pulposus), radiopaque contrast injection to provoke pain, radiological assessment of disc morphology, and clinical assessment of the intensity and concordance of evoked pain in relation to baseline pain.

Basic and clinical studies have shown that the lumbar discs are innervated and can be a source of pain that has pathomorphologic correlates (354,417-486). Even though the specific neurobiological events involved in how discography causes pain have not been elucidated, sound anatomic, histopathological, radiological, and biomechanical evidence suggests that lumbar discography may help to identify symptomatic and pathological intervertebral discs $(28,46,114,487,488)$.

The rationale is well established for lumbar discography $(28,46,114,414,488)$. Discography is helpful in patients with low back or lower extremity pain to acquire information about the structure and sensitivity of their lumbar intervertebral discs and to make informed decisions about treatment and modifications of activity. Although the clinical exam may demonstrate a favorable correlation with discography or disc-related pain $(451,489-498)$, this information may not be sufficient to guide invasive treatment for discogenic pain.

Examinations of cadaver lumbar discs typically confirm the presence of annular tears and disc de- generation, as revealed by discograms (499-503). Multiple authors also have investigated the accuracy of lumbar discographic and CT/discographic findings based on the ability to demonstrate accurate pathology confirmed at the time of surgery. There is a high inter- and intra-observer agreement in assessing discographic morphology, i.e., the Adams classification $(499,504,505)$. It was reported that the exact reproduction of pain was more likely in ruptured or fissured discs and less likely in degenerative discs; based on the Adams classification (499).

Lumbar discography was compared with myelography, computed tomography (CT), magnetic resonance imaging (MRI), and results of surgical and conservative management. CT discography was reported to be more accurate than myelography (506-516). On similar grounds, discography was shown to be superior to plain CT $(517,518)$. While comparing the results of lumbar discography with MRI, some found discography to be as good as MRI, even though MRI was preferable as it was non-invasive and allowed assessment of more levels with one test, with minimal risk of complications and minimal discomfort $(519,520)$. However, others have identified advantages of discography with pain provocation, when MRIs were normal or equivocal $(487,518,521)$. Strong correlation was demonstrated between MR/discography and CT/discography in as- 
sessing annular tears and degeneration of lumbar discs $(518,522,523)$. A good correlation between MRI, discography, and the high intensity zone has been established by some (522-528), while others have reported poor correlation and limited value of discography (529-536).

The technique of lumbar discography is standardized by the IASP criteria (415) and has been well studied $(28,46,105,114,414,488,537-543)$. The definition of a positive discogram, per International Spine Intervention Society (ISIS) guidelines (416) is pain > $7 / 10$, concordance, pressure $<50$ psi above opening pressure, Grade III anular tear, and a painless control disc. ASIPP guidelines (3) have defined a positive discogram only if the target disc produces concordant pain with an intensity of at least 7 on a 10-point pain measurement scale or $70 \%$ of the highest reported pain (i.e., worst spontaneous pain of $7=7 \times 70 \%=$ 5), and 2 adjacent discs with provocation discography do not produce any pain at all or only one disc in the case of L5/S1 with low volume and low pressure injection.

In an ideal situation, a gold standard or criterion is obtained by tissue confirmation of the presence or absence of a disease; however, surgical inspection of a degenerated disc cannot determine if discogenic pain is present or not. Thus, the greatest challenge concerning discography continues to be the gold standard problem. Three systematic reviews exhaustively discussed these issues $(28,46,114)$. However, the gold standard problem is not unique to discography. Knottnerus et al (543) stated that there are several methodological challenges that must be addressed in diagnostic accuracy studies. These include the gold standard problem, spectrum and selection bias, "soft" measures (subjective phenomena), observer variability and bias, complex relations, clinical impact, sample size, and the rapid progress of knowledge (543). In systematic reviews $(28,46,105,114)$, these concerns have been explored.

\subsubsection{Cost Effectiveness}

There are no cost effectiveness studies of lumbar provocation discography available in the literature.

\subsubsection{Safety and Complications}

Complications related to discography include discitis, subdural abscess, spinal cord injury, vascular injury, annular strains, epidural and paravertebral abscess $(6,28,46,114,414-416,544-555)$.

\subsubsection{Evidence Assessment}

The literature search provided 5 systematic reviews $(28,46,53,105,114,409)$. All of the systematic reviews met the inclusion criteria. Hancock et al (409) focused on the diagnostic criteria comparing discography with other tests. Wolfer et al (105) evaluated false-positive rates. Shah et al (114), Buenaventura et al (28), and Manchikanti et al (46) performed the systematic assessment of value of provocation discography utilizing West et al's AHRQ criteria for systematic reviews. Manchikanti et al (46) utilized modified IASP criteria (415). For a disc to be judged positive, stimulation of the target disc produces concordant pain with an intensity of at least 6 on a 10 point pain measurement scale and 2 adjacent discs with provocation discography do not produce any pain at all except for L5-S1 disc wherein only one negative disc is required. Manchikanti et al (46) utilized 9 studies meeting strict inclusion criteria and considered all other studies performed under controlled conditions. Wolfer et al (105) utilized multiple studies with methodologic quality evaluation and scoring of lumbar discographic studies in their evaluations.

Thus, the 2 latest systematic reviews by Manchikanti et al (46) and Wolfer et al (105) were utilized in the evidence synthesis for the guidelines.

\subsubsection{Prevalence of Lumbar Discogenic Pain}

Prevalence of pain due to internal disc disruption (IDD) was reported as $39 \%$ of patients suffering with chronic low back pain in the United States (451). In contrast, primary discogenic pain was reported in $26 \%$ of patients suffering with chronic low back pain in the United States (338). Table 5 illustrates the data of prevalence of lumbar discogenic pain utilizing IASP criteria.

\subsubsection{False-Positive Rate}

A series of published studies specifically investigated the potential false-positive rate of lumbar discography $(539,555-567)$. The Holt study (560) was performed on prisoners, with outdated techniques and noxious, irritating contrast dye (561). Falsepositive rate meta-analysis by Wolfer et al (105) pooled all extrctable data from high quality studies performed in subjcts asymptomatic of low back pain and reported the following false-positive rates: $3 \%$ in subjects without confounding factors, $0 \%$ in the pain-free group, $10 \%$ in the low pressure positive chronic pain group, $15 \%$ in prior discectomy patients, and $12.5 \%$ in patients with residual pain after iliac crest bone harvesting. If all patients from all 
subgroups are combined, a total false-positive rate of $9.3 \%(95 \% \mathrm{Cl}, 3 \%, 16 \%)$ is obtained in contrast to the high false-positive rates of $40 \%$ to $83 \%$ described by Carragee et al $(562,563)$.

\subsubsection{Level of Evidence}

Based on USPSTF (126) criteria, the indicated evidence is Level II-2 for lumbar discography.

\subsubsection{Recommendations}

The recommendations for lumbar provocation discography include appropriate indications with patients with low back pain to prove the diagnostic hypothesis of the discogenic pain specifically after exclusion of other sources of lumbar pain and identification of the disc that should be targeted for treatment, or to establish either that no disc or too many discs are symptomatic, in which case surgery may not be indicated.

\subsubsection{Sacroiliac Joint Blocks}

Due to the inability to make the diagnosis of sacroiliac joint-mediated pain with non-invasive tests, sacroiliac joint blocks appear to be the evaluation of choice to provide appropriate diagnosis. Further, controlled studies have established sacroiliac joints as a potential source of low back and lower extremity pain $(6,27,45,116,338,568-575)$. Based on the controlled diagnostic blocks, the sacroiliac joint block has been implicated as the primary source of pain $(6,27,45,116,338,569,570,576,577)$.

The face validity of sacroiliac joint blocks has been established by injecting small volumes of local anesthetic with contrast into the joint and determining contrast spread. Construct validity of sacroiliac joint blocks has been established by determining the false-positive rate of single, uncontrolled, sacroiliac joint injections of $20 \%$ to $54 \%(338,569,570,577)$. Positive responses may occur with extravasation of an anesthetic agent out of the joint due to defects in the joint capsule (578). Negative results may occur from faulty needle placement, intravascular injection, or inability of the local anesthetic to reach the painful portion of the joint due to loculations $(27,45,116,568,574,575,579-583)$.

\subsubsection{Cost Effectiveness}

There are no studies evaluating the cost effectiveness of diagnostic sacroiliac joint blocks.

\subsubsection{Safety and Complications}

Complications of sacroiliac joint injection include infection, trauma to the sciatic nerve and complications related to drug administration $(6,27,45,116)$.

\subsubsection{Evidence Assessment}

Rupert et al (45) provided the latest evidence with consideration of 13 manuscripts for inclusion and having 5 studies which met methodologic quality assessment $(338,569,570,577,578)$.

\subsubsection{Prevalence}

The prevalence of sacroiliac joint pain is estimated to range between $10 \%$ and $38 \%$ with $95 \%$ confidence intervals of $0 \%-51 \%(338,569,570,577,578)$ (Table $6)$.

\subsubsection{False-Positive Rate}

The false-positive rate of a single block is estimated to range between $20 \%$ and $54 \%$ with $95 \%$ Cls of $3 \%-64 \%(338,569,570,578)$. However, in one study (577), the false-positive rate was $0 \%$.

Table 5. Data of prevalence of lumbar discogenic pain utilizing IASP criteria.

\begin{tabular}{||l|c|l|l||}
\hline \multicolumn{1}{|c||}{ Study } & $\begin{array}{l}\text { Methodological } \\
\text { Quality Scoring }\end{array}$ & \multicolumn{1}{||}{ Participants } & Prevalence \\
\hline $\begin{array}{l}\text { Schwarzer et al 1995 } \\
(451)\end{array}$ & 70 & $\begin{array}{l}92 \text { consecutive patients with chronic low } \\
\text { back pain and no history of previous lum- } \\
\text { bar surgery referred for discography. }\end{array}$ & $\begin{array}{l}\text { The diagnostic criteria for internal disc } \\
\text { disruption were fully satisfied in 39\% of the } \\
\text { patients, most commonly at L5/S1 and L4/5. }\end{array}$ \\
\hline $\begin{array}{l}\text { Manchikanti et al 2001 } \\
\text { (338) }\end{array}$ & 70 & $\begin{array}{l}\text { From a group of } 120 \text { patients with low back } \\
\text { pain, 72 patients negative for facet joint } \\
\text { pain underwent discography. }\end{array}$ & $\begin{array}{l}\text { The prevalence of discogenic pain was estab- } \\
\text { lished in 26\% of total patient sample and 43\% } \\
\text { of patients negative for facet joint pain. }\end{array}$ \\
\hline
\end{tabular}

Adapted from Manchikanti L et al. Systematic review of lumbar discography as a diagnostic test for chronic low back pain. Pain Physician 2009; $12: 541-560(46)$ 


\subsubsection{Level of Evidence}

The indicated evidence for the accuracy of sacroiliac joint diagnostic injections is Level II-2 for the diagnosis of sacroiliac joint pain utilizing controlled diagnostic blocks.

Rubinstein and van Tulder (411) in a best-evidence review of diagnostic procedures for low-back pain concluded that there is moderate evidence for the diagnostic accuracy of sacrioliac joint injections in evaluating spinal pain.

\subsubsection{Recommendations}

Controlled sacroiliac joint blocks with placebo or controlled comparative local anesthetic blocks are recommended when indications are satisfied. A positive response is considered $\geq 80 \%$ relief with ability to perform previously painful movements.

- The primary indication for sacroiliac joint blocks is the need to know if a patient's pain is arising from the sacroiliac joint or not.

- Sacroiliac joint injections are indicated in patients

- with chronic low back pain that is maximal below the level of $L 5$ vertebra

- with or without somatic referred pain in the lower limb, in whom no other diagnosis is readily apparent

- no other possible diagnosis is more likely

- a diagnosis has been made or cannot be made using less invasive options

- lack of resolution of pain with the passage of time or conservative therapy.

\subsection{Diagnosis of Neck Pain}

Cervical intervertebral discs, facet joints, atlantoaxial and atlanto-occipital joints, ligaments, fascia, muscles, and nerve root dura have been shown to be capable of transmitting pain in the cervical spine with resulting symptoms of neck pain, upper extremity pain, and headache $(3,4,584-586)$. Cervical facet joint nerve blocks and cervical provocation discography are the commonly practiced interventional diagnostic techniques $(39,45)$.

\subsubsection{Cervical Facet or Zygapophysial Joint Blocks}

Diagnostic blocks of a cervical facet or zygapophysial joint can be performed by anesthetizing the joint or the medial branches of the dorsal rami that innervate the target joint, to test whether the joint is the source of pain. Valid information is obtained by performing controlled blocks, either in the form of placebo injections of normal saline or comparative local anesthetic blocks.

The rationale for using cervical facet joint blocks for diagnosis is based on the fact that facet joints are capable of causing pain and they have a nerve supply $(353,587-591)$. They have been shown to be a source of pain in patients using diagnostic techniques of known reliability and validity $(339,364,365,369,383$, 385). Conventional clinical and radiologic techniques are unreliable in diagnosing cervical facet or zygapophysial joint pain $(3,41)$.

The value, validity, and clinical effectiveness of cervical diagnostic facet joint nerve blocks was also illus-

Table 6. Data of prevalence of sacroiliac joint pain based on controlled diagnostic blocks.

\begin{tabular}{|l|c|c|c|c||}
\hline \multicolumn{1}{|c|}{ Study } & $\begin{array}{c}\text { Methodologic } \\
\text { Quality Assessment } \\
\text { Score }\end{array}$ & \# of Subjects & Prevalence Estimates & False-Positive Rate \\
\hline Manchikanti et al 2001 (338) & 65 & 20 & $10 \%(95 \%$ CI, 0\% - 23\%) & $22 \%(95 \%$ CI, 3\%- 42\%) \\
\hline Maigne et al 1996 (569) & 65 & 54 & $18.5 \%(95 \%$ CI, 8\% - 29\%) & $20 \%(95 \%$ CI, 8\% - 33\%) \\
\hline Irwin e et al 2007 (570) & 65 & 158 & $26.6 \%(95 \%$ CI, 20\% - 34\%) & $53.8 \%(95 \%$ CI, 43\%- 64\%) \\
\hline Laslett et al 2003 (577) & 65 & $43 / 48$ & $25.6 \%(95 \%$ CI, 12\% - 39\%) & $0 \%$ \\
\hline van der Wurff et al 2006 (578) & 65 & 60 & $38 \%(95 \%$ CI, 26\% - 51\%) & $21 \%(95 \%$ CI, 7\% - 35\%) \\
\hline
\end{tabular}

$\mathrm{CI}=$ confidence interval

Methodological criteria and scoring adapted from West S et al. Systems to Rate the Strength of Scientific Evidence, Evidence Report, Technology Assessment No. 47. AHRQ Publication No. E016 (127).

Adapted from Rupert MP et al. Evaluation of sacroiliac joint interventions: A systematic appraisal of the literature. Pain Physician 2009; 12:399418 (45). 
trated by application of therapeutic modalities based on the diagnosis with controlled comparative local anesthetic blocks $(6,24,30,41,112,361-363,592-599)$.

Controlled diagnostic blocks of cervical facet joints with 2 local anesthetics (or placebo-controlled) are the major means of confirming the diagnosis of facet joint pain. The face validity of cervical medial branch blocks has been established by injecting small volumes of local anesthetic and contrast material onto the target points for these structures and by determining the spread of contrast medium in posteroanterior and lateral radiographs (589). Construct validity of cervical facet joint blocks is important to eliminate placebo effect as the source of confounding results and to secure true-positive results $(3,41,339,364,365,369,600-605)$. Potential and real confounding factors were assessed in several studies. Influence of age, surgery, psychopathology, and prior opioid exposure were evaluated in 3 reports and found not to have significant impact on the prevalence of cervical facet joint related chronic neck pain $(381,383,385,386,602,606)$.

\subsubsection{Cost Effectiveness}

Diagnostic cervical facet joint nerve blocks were not evaluated for cost effectiveness systematically. However, multiple authors $(267,338,388)$ have described the feasibility and cost-effectiveness of appropriately performed controlled local anesthetic blocks.

\subsubsection{Safety and Complications}

Though rare and minor, the commonly reported complications of cervical facet joint injections or nerve blocks include hemorrhage, dural puncture, spinal cord trauma, infection, intraarterial or intravenous injection, chemical meningitis, neural trauma, paralysis, pneumothorax, radiation exposure, facet capsule rupture, hematoma formation, steroid side effects, and epidural subdural or subarachnoid spread $(6,7,29,30,41,112,361-363,390,393-400)$.

\subsubsection{Evidence Assessment}

Our search yielded 4 systematic reviews $(29,41,361,362)$ and multiple other publications (339,364,365,369,600-605). The recent systematic review by Falco et al (41) utilized 9 studies $(339,364,365,369,601$ 605 ) meeting inclusion criteria with $80 \%$ pain relief and ability to perform previously painful movements with controlled diagnostic blocks.

\subsubsection{Prevalence}

The estimated prevalence is $36 \%$ to $67 \%$ with Cls ranging from $27 \%$ to $75 \%$ in patients in heterogenous population with an average of $49 \%$ with $95 \% \mathrm{Cl}$ of $45 \%$ to $52 \%$. In addition, the prevalence was shown to be $36 \%$ with $95 \% \mathrm{Cl}$ of $22 \%$ to $51 \%$ in patients after surgical intervention (602) (Table 7).

\subsubsection{False-Positive Rate}

Based on the systematic review by Falco et al (41), false-positive rates with a single block are $27 \%$ to $63 \%$ with Cls ranging from $15 \%$ to $78 \%$ with an average of $49 \%$ with $95 \% \mathrm{Cl}$ of $44 \%$ to $54 \%$ (Table 7 ).

\subsubsection{Level of Evidence}

The evidence for diagnosis of cervical facet joint pain is Level I or II-1 based on the USPSTF criteria (126).

Rubinstein and van Tulder (411) in a best-evidence review of diagnostic procedures for neck pain concluded that there is strong evidence for the diagnostic accuracy of cervical facet joint blocks in evaluating spinal pain.

\subsubsection{Recommendations}

Based on the present comprehensive evaluation and other described evaluations $(3,29,41,361$ $363,607,608)$, diagnostic cervical facet joint nerve blocks are recommended in patients with the following criteria:

- Patients suffering with somatic or non-radicular neck pain or headache and upper extremity pain, with duration of pain of at least 3 months.

- Average pain levels of greater than 6 on a scale of 0 to 10 .

- Pain is at least intermittent or continuous causing functional disability.

- Problem has failed to respond and has not resolved with more conservative management, including physical therapy modalities with exercises, chiropractic management, and non-steroidal anti-inflammatory agents.

- Lack of preponderance of evidence of discogenic pain, disc herniation, or evidence of radiculitis.

- There is no evidence of contraindications for the needle placement and injection of local anesthetics.

- Contraindications or inability to undergo physical therapy, chiropractic management, or inability to 
Table 7. Data of prevalence and false-positive rates of cervical diagnostic facet joint blocks.

\begin{tabular}{|c|c|c|c|c|}
\hline Study & $\begin{array}{l}\text { Methodologic } \\
\text { Criteria }\end{array}$ & \# of Subjects & Prevalence Estimates & False-Positive Rate \\
\hline Barnsley et al 1995 (604) & 75 & 50 & $54 \%(95 \%$ CI, 40\%, 68\%). & NA \\
\hline Barnsley et al 1993 (605) & 75 & 55 & NA & $27 \%(95 \%$ CI, $15 \%, 38 \%)$ \\
\hline Lord et al 1996 (603) & 75 & 68 & $60 \%$ (95\% CI, 46\%, 73\%) & NA \\
\hline Manchikanti et al 2002 (369) & 75 & 120 & $67 \%$ (95\% CI, 58\%,75\%) & $63 \%(95 \%$ CI $48 \%, 78 \%)$ \\
\hline Manchikanti et al 2004 (365) & 75 & 255 of 500 & $55 \%$ (95\% CI, 49\%, 61\%) & $63 \%(95 \%$ CI $54 \%, 72 \%)$ \\
\hline Manchukonda et al 2007 (364) & 65 & 251 of 500 & $39 \%(95 \%$ CI, $32 \%, 45 \%)$ & $45 \%$ (95\% CI 37\%, 52\%) \\
\hline Manchikanti et al 2008 (602) & 65 & $\begin{array}{l}\text { Non-Surgery: } \\
206 \\
\text { Post-Surgery: } \\
\quad 45\end{array}$ & $\begin{array}{c}\text { Non-Surgery } \\
39 \%(95 \% \text { CI, 33\%, 46\%) } \\
\text { Post-Surgery } \\
36 \%(95 \% \text { CI, } 22 \%, 51 \%)\end{array}$ & $\begin{array}{c}\text { Non-Surgery } \\
43 \%(95 \% \text { CI 35\%, 52\%) } \\
\text { Post-Surgery } \\
50 \%(95 \% \text { CI } 32 \%, 68 \%)\end{array}$ \\
\hline Speldewinde et al 2001 (601) & 50 & 97 & $36 \%$ (95\% CI, 27\%, 45\%) & NA \\
\hline Yin and Bogduk 2008 (339) & 60 & 84 of 143 & $42 \% \#(95 \%$ CI, $31 \%, 52 \%)$ & NA \\
\hline OVERALL & & 980 & $49 \%$ (95\% CI, 45\%, 52\%) & $49 \%(95 \%$ CI, $44 \%, 54 \%)$ \\
\hline
\end{tabular}

\# Authors reported adjusted prevalence as $55 \%$ (95\% CI, 38\%, 62\%) and crude prevalence as $24 \%$.

$\mathrm{NA}=$ not available or not applicable; $\mathrm{CI}=$ confidence interval

Adapted from Falco FJE et al. Systematic review of diagnostic utility and therapeutic effectiveness of cervical facet joint interventions. Pain Physician 2009; 12:323-344 (41).

tolerate non-steroidal anti-inflammatory drugs.

- A positive response is based on the following evidence:

- Patient has met the above indications.

- Patient responds positively to controlled local anesthetic blocks either with placebo control or comparative local anesthetic blocks with appropriate response to each local anesthetic with $<1 \mathrm{~mL}$ of local anesthetic.

- At least $80 \%$ relief as criterion standard with ability to perform previously painful movement without deterioration of the relief (i.e., extension, overhead activity, lateral rotation, flexion, etc.).

- The patient's response should be recorded independently by the assessor - generally a registered nurse familiar with patient or another physician.

\subsubsection{Cervical Provocation Discography}

Cervical provocation discography is intended to both identify a painful cervical intervertebral disc and depict internal derangements (609-611).

Imaging studies such as radiographs, myelog- raphy, CT, CT-myelography, and MRI are incapable of identifying a cervical degenerated disc as painful $(28,114,612-618)$. Thus, it appears that cervical provocation discography can diagnose discogenic pain without disc herniation and radiculitis.

Over 50 years ago, Smith and Nichols $(619,620)$ emphasized pain reproduction as the principal feature of cervical discography. Cloward (621-623) described 2 types of pain during cervical disc stimulation: pain arising from IDD (i.e., discogenic pain) and neurogenic pain that stems from a herniated disc fragment causing nerve root or dural irritation.

In a report published in 1964, Holt (624) questioned the validity and role of cervical discography, citing a high false-positive rate in asymptomatic subjects. He based this assumption on the contention that fissures and pain provocation were normal features in people without neck pain. Klafta and Collis $(625,626)$ also found that cervical discography was less accurate than myelography in predicting surgical findings.

Studies conducted in cadavers and patients have re-examined Holt's conclusions $(561,612)$. These studies have established fissures to be normal age-related findings that do not necessarily indicate symptomatol- 
ogy, and that demonstrating them with discography is immaterial $(609,627,628)$. Supporting this assertion, Schellhas et al (612) found that pressurizing normal discs failed to provoke pain in both symptomatic and asymptomatic patients, whereas abnormal discs tended to produce concordant pain. Roth (629) and Kofoed (630) proposed the concept of analgesic discography.

The major obstacle confronting proponents of cervical discography is the lack of consensus as to what constitutes a positive response. Widespread variations in criteria exist not only for pain provocation (i.e., designation of concordance and threshold for a positive response), but also for morphological classification. While some investigators have interpreted certain patterns of contrast dispersion as being indicative of disc pathology, others have found a lack of correlation between morphology and pain reproduction (28,39,114,609-613,628-633).

Multiple questions have been raised regarding the utility of cervical discography, including the high reported false-positive rate, the lack of standardization; the discrepancies regarding the need for "control levels," pain concordance, and pain intensity threshold; and utilization $(28,39,53,58,105,114,608-611,618,634-636)$.

Validity is exemplified by disc stimulation symptom mapping $(114,612)$ in patients with pain and asymptomatic volunteers. Ohnmeiss et al (637) found a significant relationship between imaging and symptom provocation, with $86 \%$ of normal-looking discs either producing no pain $(60 \%)$ or atypical pain (26\%). Conversely, $78 \%$ of disrupted discs were clinically painful on injection. Viikari-Juntura et al (503) demonstrated that discography provides additional information regarding structural changes not available by any other non-invasive methods of examination. In general, nuclear signal changes observed on $\mathrm{MRI}$ in cadavers tended to underestimate the degree of pathology appreciated with discography or gross examination. Parfenchuck and Janssen (631) found that while certain MRI patterns correlated well with positive and negative cervical discography responses, many other patterns revealed equivocal responses. They concluded that MRI is a useful adjunct to cervical discography, but that some MRI patterns should not be considered pathologic, and discography is necessary to identify a painful disc(s).

The proportion of cervical discs identified as symptomatic varies among studies. Grubb and Kelly
(638) found that $50 \%$ of discs are capable of producing concordant pain upon injection. Schellhas et al (612) reported that among 11 discs that appeared normal on MRI in pain patients, 10 proved to have annular tears discographically. Discographically normal discs $(n=8)$ were never painful in either pain patients or an asymptomatic cohort, whereas intensely painful discs all exhibited tears of both the inner and outer annulus.

Holt's 1964 study (624) in asymptomatic prisoners reflected negatively on cervical discography. But these studies $(560,625)$ have been repeatedly refuted and better overriding data have since been generated. Holt utilized an irritant contrast and failed to employ fluoroscopic guidance. Even aside from these significant flaws, the technique itself was suspect. Extravasation of contrast material was noted with every injection, which continued even after reducing the volume.

\subsubsection{Cost Effectiveness}

There are no cost effectiveness studies of provocation discography available in the literature.

\subsubsection{Safety and Complications}

Complications related to cervical discography include discitis, subdural abscess, spinal cord injury, vascular injury, epidural and paravertebral abscess (544-551,639-643).

\subsubsection{Evidence Assessment}

Three systematic reviews were identified evaluating cervical discography. Of these, the recent systematic review of cervical discography (39) utilized 3 evaluations meeting inclusion criteria $(339,644,645)$. This systematic review also included various outcome studies comparing surgical outcomes.

\subsubsection{Prevalence}

Based on IASP criteria (608) and systematic review (39), the data show a prevalence rate ranging between $16 \%$ and $20 \%(339,644,645)$.

\subsubsection{False-Positive Rate}

Overall, false-positive results with cervical provocation discography are a serious concern, with cited prevalence rates exceeding $50 \%$. Schellhas et al (612) found that the numerical rating pain score produced by discography in asymptomatic subjects was significantly lower $(P \leq 0.0001)$ than in patients with neck 
pain. Schellhas et al (612) recommended adding an operational criterion whereby the patient must rate the intensity of produced pain as $\geq 7$ on a 10-point numerical pain rating scale or an equivalent magnitude on another suitable scale.

\subsubsection{Level of Evidence}

The indicated level of evidence is Level II-2 based on the modified USPSTF criteria (126).

\subsubsection{Recommendations}

Based on the systematic review (39), IASP criteria (608), ISIS criteria (609), and ASIPP criteria (3) the following recommendations are made:

1) Cervical discography is indicated to test the diagnostic hypothesis of discogenic pain of the cervical spine in individuals who have been properly selected and screened to eliminate other sources of cervical pain.

2) The discography should be performed utilizing appropriate criteria and results are considered positive only if the stimulation of the target disc produces concordant pain with an intensity of at least 7 on a 10-point pain measurement scale or reproduces at least $70 \%$ of the most severe pain the patient has experienced (i.e., 5 of 7) and 2 adjacent discs with low volume contrast injection with low pressure discography do not produce any pain at all.

\subsection{Diagnosis of Thoracic Pain}

The multiple structures which may be responsible for chronic thoracic pain include thoracic facet joints and intervertebral discs. Thoracic facet joints have been evaluated with controlled diagnostic techniques.

\subsubsection{Facet or Zygapophysial Joint Blocks}

Controlled diagnostic blocks of thoracic medial branch blocks that innervate the target joint provide valid information whether the facet joints are the source of pain. The rationale for using thoracic facet joint blocks for diagnosis is based on the fact that facet joints are capable of causing pain and they have a nerve supply $(363,646-657)$. Further, they have been shown to be a source of pain in patients using diagnostic techniques of known reliability and validity $(364,365,658)$. Conventional clinical and radiologic techniques are unreliable in diagnosing thoracic facet joint pain.
The value, validity, and clinical effectiveness of thoracic diagnostic facet joint nerve blocks was illustrated by application of therapeutic modalities based on the diagnosis with controlled, comparative local anesthetic blocks $(29,361,362,659,660)$

The face validity of thoracic medial branch blocks is extrapolated from cervical and lumbar facet joint nerve blocks $(351,352,589)$. The construct validity of thoracic facet joint blocks to eliminate placebo effect as the source of confounding results and to secure true-positive results, controlled, comparative local anesthetic blocks have been performed $(361-365,658)$.

\subsubsection{Cost Effectiveness}

Diagnostic thoracic facet joint nerve blocks were not evaluated for cost effectiveness systematically. However, multiple authors (338,387-390) have described the feasibility and cost-effectiveness of appropriately performed controlled local anesthetic blocks.

\subsubsection{Safety and Complications}

Complications from facet joint nerve blocks or intraarticular injections in the thoracic spine may include pneumothorax, dural puncture, spinal cord trauma, subdural injection, neural trauma, hematoma formation, iepidural abscess, meningitis; and side effects related to the administration of steroids, local anesthetics, and other drugs $(30,80,390,397,408,661-665)$.

\subsubsection{Evidence Assessment}

Our search yielded 4 systematic reviews $(29,31,361,362)$. The recent systematic review by Atluri et al (31) utilized 3 studies $(364,365,658)$.

\subsubsection{Prevalence}

Based on the controlled local anesthetic blocks, utilizing $80 \%$ pain relief, the prevalence is estimated as $34 \%$ to $42 \%$ with $95 \%$ Cls ranging from $22 \%$ to $53 \%$. (Table 8 ).

\subsubsection{False-Positive Rate}

Based on the controlled local anesthetic block with $80 \%$ pain relief, false-positive rates of single local anesthetic blocks range from $42 \%$ to $55 \%$ with Cls ranging from $26 \%$ to $78 \%$. (Table 8 ).

\subsubsection{Level of Evidence}

The evidence for the diagnosis of thoracic facet joint pain with controlled comparative local an- 
esthetic blocks is Level II-1 based on USPSTF criteria (126).

\subsubsection{Recommendations}

Based on the systematic review (31), IASP criteria (666), ISIS criteria (667), and ASIPP criteria (3) the following recommendations are made.

- Somatic or nonradicular upper back or mid back pain.

- Duration of pain at least of 3 months.

- Average pain levels of greater than 6 on a scale of 0 to 10 .

- Intermittent or continuous pain causing functional disability.

- Failure to respond to more conservative management, including physical therapy modalities with exercises, chiropractic management, and nonsteroidal anti-inflammatory agents.

- Lack of obvious evidence for discogenic pain.

- Lack of disc herniation or evidence of radiculitis.

- No contraindications with understanding of consent, nature of the procedure, needle placement, or sedation.

- No history of allergy to contrast administration, local anesthetics, steroids, Sarapin, or other drugs potentially utilized.

- Contraindications or inability to undergo physical therapy, chiropractic management, or inability to tolerate nonsteroidal anti-inflammatory drugs.

- A positive response is based on the following evidence:

- Patient has met the above indications.

- Patient responds positively to controlled local anesthetic blocks either with placebo control or comparative local anesthetic blocks with appropriate response to each local anesthet- ic with ( $<1 \mathrm{~mL}$ of local anesthetic).

- At least $80 \%$ relief as criterion standard with ability to perform previously painful movement without deterioration of the relief (i.e., extension, overhead activity, lateral rotation, flexion, etc.).

- The patient's response should be recorded independently by the assessor - generally a registered nurse familiar with patient or another physician.

\subsubsection{Thoracic Provocation Discography}

Provocation thoracic discography has been studied by very few authors and there is a paucity of literature (511,668-671). Wood et al (669) evaluated the validity of concordant pain and the role of false-positive responses. They reported the mean pain response in the asymptomatic volunteers as 2.4/10 even though 3 discs exhibiting prominent endplate irregularities and annular tears typical of thoracolumbar Scheuermann's disease were intensely painful. Further, of the 48 discs studied, only 21 appeared normal on MRI and only 10 were judged as normal after provocation discography. The discs which exhibited concordant pain (24 of 48 or $50 \%$ ) exhibited a pain response of $8.5 / 10$, statistically higher pain levels than the 17 discs that exhibited non-concordant pain pressure with an average pain of $4.8 / 10$, and 5 discs with no pain response at all. Schellhas et al (668) evaluated concordant pain and also at least one nearby controlled level disc. They demonstrated clinical concordance in approximately $50 \%$ of the discs, with controlled levels being painless.

\subsubsection{Cost Effectiveness}

There are no cost effectiveness studies of tho-

Table 8. Data of prevalence with controlled diagnostic blocks and false-positive rates in thoracic region.

\begin{tabular}{|c|c|c|c|c|}
\hline Study & $\begin{array}{c}\text { Methodological } \\
\text { Quality Scoring (AHRQ) }\end{array}$ & Participants & Prevalence & False-Positive Rate \\
\hline Manchikanti et al 2004 (365) & 70 & 72 & $42 \%(95 \%$ CI 30\%-53\%) & $55 \%(95 \%$ CI 39\%-78\%) \\
\hline Manchukonda et al 2007 (364) & 60 & 65 & $34 \%(95 \%$ CI 22\%-47\%) & $42 \%(95 \%$ CI $26 \%-59 \%)$ \\
\hline
\end{tabular}

AHRQ=Agency for Healthcare Research and Quality; CI = confidence interval

Source: Atluri S et al. Systematic review of diagnostic utility and therapeutic effectiveness of thoracic facet joint interventions. Pain Physician 2008; 11:611-629 (31). 
racic provocation discography available in the literature.

\subsubsection{Safety and Complications}

Complications relating to thoracic discography include discitis, nerve root injury, epidural abscess, allergic contrast reaction, subarachnoid puncture, meningitis, direct trauma to the spinal cord, pneumothorax, and trauma to retroperitoneal structures including the kidney and the spleen $(32,668-672)$.

\subsubsection{Evidence Assessment}

While there were 3 systematic reviews $(28,32,114)$ evaluating thoracic discography, only one systematic review (32) evaluated thoracic discography as a diagnostic test separately. This review utilized IASP criteria and methodologic quality assessment criteria.

\subsubsection{Prevalence}

The prevalence of thoracic discography has not been determined.

\subsubsection{False-Positive Rate}

Utilizing the data by Wood et al (669), it appears that the false-positive rate with thoracic discograms is 0 if a pain response of 7 or above is considered as positive with concordant pain with negative contiguous discs. However the evidence is preliminary.

\subsubsection{Level of Evidence}

The indicated level of evidence is Level II-3 for thoracic discography.

\subsubsection{Recommendations}

The recommendations based on IASP criteria (666), ISIS criteria (670), and ASIPP criteria (3) are as follows:

1) The thoracic discography is indicated to decide if an intervertebral disc is painful or not.

2) The discography should be performed utilizing appropriate criteria and results are considered positive only if the stimulation of the target disc produces concordant pain with an intensity of at least 7 on a 10-point pain measurement scale or reproduces at least $70 \%$ of the most severe pain the patient has experienced (i.e., 5 of 7) and 2 adjacent discs with low volume contrast injection with low pressure provocation discography do not produce any pain at all.

\subsection{Therapeutic Interventional TECHNIQUES}

Multiple therapeutic spinal interventional techniques are applied in managing chronic spinal pain. The rationale includes the commonality and complexity of spinal pain problems and ability of diagnostic blocks to identify sources of chronic spinal pain. Facet joints, discs and sacroiliac joints are proven sources of chronic spinal pain and are accessible to neural blockade $\quad(1-3,7-9,24-31,33-43,45-47,64,96,105,112$ $116,137,362,673-681)$. Removal or correction of structural abnormalities of the spine may fail to cure and may even worsen painful spinal conditions $(1,2,7$ $9,13,33,34,42,43,47,96,98,113,270,271,275,280,325$, $326,572,586,682-706)$. The degenerative processes of the spine and the origin of the spinal pain are complex without correlation of radiographic changes to clinical picture and prognosis $(1,2,7-9,24-31,34$ $41,43,45,46,96,105,112-116,270,362,409,411,458,680$ ,681). The effectiveness of a large variety of therapeutic interventions used to manage chronic spinal pain has not been demonstrated conclusively $(1,2,7-9,24$ $31,34-41,43,45,46,96,105,112-116,270,362,680,681)$. Finally there is increasing evidence supporting the use of spinal interventional techniques in managing spinal pain $(1,2,7-9,24-31,34-41,43,45,46,96,105,112$ $116,270,362,680,681)$.

\subsection{Facet Joint Interventions}

Based on a detailed review of the literature, the general consensus appears to be that facet joint pain can be diagnosed with reasonable certainty on the basis of controlled diagnostic local anesthetic blocks (29, $30,31,40,41,361,363,379,391,409,411,413,606,607,646$ $666,667,707,708)$. Therefore, assessment of the efficacy of interventional procedures for the treatment of facet joint pain requires that studies only employ controlled diagnostic medial branch blocks or intraarticular injections as selection criteria for such studies.

Facet joint pain may be managed by intraarticular injections, medial branch blocks, or neurolysis of medial branches $(1,2,7-9,30,31,40,41,112,391,646,708)$.

\subsubsection{Intraarticular Injections}

\subsubsection{Evidence Assessment}

The comprehensive search identified 9 systematic reviews and 2 other publications evaluating the therapeutic role of intraarticular facet joint injections (30, 
$31,40,41,53,78,103,112,709-711)$. Recent reviews of cervical, thoracic, and lumbar facet joint interventions met inclusion criteria $(31,40,41)$.

Staal et al (103) utilized 6 weeks of relief as shortterm and longer than 6 weeks as long-term, whereas Atluri et al (31), Falco et al (41), and Datta et al (40) utilized 6 months of relief as short-term and over 6 months as long-term. Further, the 2 systematic reviews $(40,41)$ utilized $80 \%$ pain relief with controlled diagnostic blocks as the inclusion criteria, whereas one systematic review (31) utilized $50 \%$ relief with controlled diagnostic blocks. In contrast, Staal et al (103) had no inclusion criteria based on the validity of diagnosis. In addition, there were 6 studies (712-717) either considered or included in one or more systematic reviews.

Staal et al (103) included the studies by Carette et al (712) and Lilius et al (715) in their analysis and qualified them as one high quality (712) and one low quality study (715) comparing the effects of facet joint injections with corticosteroids to placebo injections. They concluded that there was moderate evidence with 2 trials including 210 patients that facet joint injections with corticosteroids are not significantly different from placebo injections for short-term pain relief and improvement of disability. Datta et al (40) considered 5 randomized trials and 15 observational studies for inclusion and concluded that none of them met inclusion criteria with appropriate diagnosis and duration of follow-up. Atluri et al (31) and Falco et al (41) concluded that there were no studies meeting the criteria for inclusion in the cervical and lumbar spine.

\subsubsection{Cost Effectiveness}

No studies were performed evaluating cost effectiveness of therapeutic intraarticular facet joint injections.

\subsubsection{Safety and Complications}

Complications of intraarticular injections are rare but can be serious $(30,31,40,41,53,78,90,103,112,390,39$ 7,399,401-404,406,408,718-721). Complications include infection, intraarterial or intravenous injection, spinal anesthesia, chemical meningitis, neural trauma, spinal cord injury, dural puncture, pneumothorax, radiation exposure, facet capsule rupture, hematoma formation, and steroid side effects.

\subsubsection{Indications}

Due to lack of evidence of effectiveness, no specific indications are identified for therapeutic intraarticular injections.

\subsubsection{Level of Evidence}

The evidence for lumbar intraarticular injections is Level III (limited) with 2C/very weak recommendation. The evidence for cervical intraarticular injections is lacking. There was no evidence available for thoracic intraarticular facet joint injections.

\subsubsection{Recommendations}

Based on the available evidence, therapeutic intraarticular facet joint injections are not recommended.

\subsubsection{Medial Branch Blocks}

\subsubsection{Evidence Assessment}

Six systematic reviews $(30,31,40,41,103,112)$ evaluating the effectiveness of therapeutic medial branch injections included one update (30) of an original publication (112), whereas 3 publications $(31,40,41)$ were current with application of strict methodologic inclusion criteria, with controlled diagnostic blocks as a prerequisite, along with assessment of 6 months of relief as short-term and longer than 6 months as long-term. In addition, 6 randomized clinical trials $(375,596,659,722$ 724) and 2 observational studies $(660,725)$ evaluating the effectiveness of the therapeutic role of medial branch blocks were considered.

Following the comprehensive review of all the available systematic reviews, 4 systematic reviews $(31,40,41,103)$, met the inclusion criteria (127). Staal et al (103) utilized more than 6 weeks of relief as longterm, whereas others $(31,40,41)$ utilized over 6 months of relief as long-term. Further, 3 systematic reviews utilized strict diagnostic criteria. Staal et al (103) included one study by Manchikanti et al (722). Staal et al (103) concluded that there was no difference; however, they failed to take into consideration the design of the study - non-inferiority or equivalence trial versus efficacy trial $(20,130)$.

All of the 4 randomized trials evaluating the effectiveness of facet joint nerve blocks and meeting the inclusion criteria were performed by Manchikanti et al $(375,596,659,722)$ utilizing an active control design. These studies are referred to as non-inferiority or equivalence trials. Consequently, they lack placebo. However, active control designs show the existence of effect and compare therapies. These studies also were conducted based on consolidated standards of reporting trials (CONSORT criteria) (130). All the studies except the earliest one (722) were double-blind, ran- 
domized, and controlled trials with inclusion of outcome assessments with numeric pain scores, Oswestry or Neck Pain Disability Index, opioid intake, and work status reported at baseline, 3 months, 6 months, and 12 months. They considered significant relief as $50 \%$ or greater and significant functional status improvement as $40 \%$ or more. Their inclusion criteria involved confirmation of the existence of facet joint pain based on $80 \%$ relief with controlled local anesthetic blocks. All the studies showed positive results with $71 \%$ to $92 \%$ of the patients showing positive results on a long-term basis (i.e., 6 months). The limitations of these studies include lack of placebo, non-academic setting, and single center studies.

Manchikanti et al also published 2 prospective evaluations on therapeutic effectiveness of cervical and thoracic facet joint nerve blocks in managing chronic spinal pain. Both studies showed positive results with cervical facet joint nerve blocks (725), showing positive response in $82 \%$ of the patients at 6 months and $56 \%$ at 12 months. In contrast, thoracic facet joint nerve blocks showed improvement in $71 \%$ of the patients at 6 months, $76 \%$ at 12 months, $71 \%$ at 24 months, and $69 \%$ at 36 months (660).

\subsubsection{Cost Effectiveness}

The cost effectiveness of lumbar facet joint nerve blocks was evaluated by Manchikanti et al (722) with 1-year improvement of quality of life (QOL) at $\$ 3,461$.

\subsubsection{Safety and Complications}

Complications of medial branch blocks include infection, intraarterial or intravenous injection, spinal anesthesia, chemical meningitis, dural puncture, neural trauma, spinal cord trauma, pneumothorax, radiation exposure, hematoma formation, and steroid side effects $(390,397,399,401-404,406,718-721,726)$.

\subsubsection{Indications}

Indications are described for diagnostic facet joint nerve blocks. For therapeutic interventions, the diagnosis must be established with a positive response to controlled local anesthetic blocks with $80 \%$ relief.

\subsubsection{Level of Evidence}

Table 9 illustrates the results of published reports of effectiveness of cervical, thoracic, and lumbar medial branch blocks.

Based on the quality of evidence using the USPSTF criteria (126) the indicated level of evidence for lumbar, thoracic, and cervical facet joint nerve blocks is Level II-1 or II-2.

\subsubsection{Recommendations}

Based on Guyatt et al's criteria (136) the recommendation is strong (1B or 1C) for the use of therapeutic cervical, thoracic, and lumbar facet joint nerve blocks to provide both short-term and long-term relief in the treatment of chronic facet joint pain.

\subsubsection{Medial Branch Neurotomy}

Percutaneous neurotomy of medial branches may be performed by radiofrequency thermoneurolysis utilizing a thermal or pulsed mode, cryoneurolysis, or laser denervation. However, in these guidelines, due to the paucity of the literature and emerging nature of multiple modalities of treatments, we have considered only thermal radiofrequency neurotomy.

\subsubsection{Evidence Assessment}

Among the 9 systematic reviews $(30,31,40,41,79$ $81,112,709)$ of medial branch radiofrequency neurotomy available only 3 systematic reviews $(31,40,41)$ which included inclusion criteria of controlled local anesthetic blocks and appropriate outcome parameters were included in this review. The description of multiple systematic reviews is provided briefly to illustrate the deficiencies.

Geurts et al (79) concluded that there was moderate evidence that radiofrequency lumbar facet denervation was more effective for chronic low back pain than placebo, and there was only limited evidence existent for the effectiveness of radiofrequency neurotomy for chronic cervical zygapophysial joint pain after flexion/extension injury. Niemesto et al (81), within the framework of the Cochrane Collaboration Back Review Group, concluded that there was limited evidence that radiofrequency denervation had a positive short-term effect on chronic cervical zygapophysial joint pain, and a conflicting short-term effect on chronic low back pain. Slipman et al (709) concluded that the evidence for radiofrequency denervation is Level III or moderate. The systematic reviews by Manchikanti et al (80) and Boswell et al $(30,112)$ concluded that the evidence for pain relief with radiofrequency neurotomy of medial branch nerves was moderate to strong in cervical and lumbar spine.

The therapeutic role of medial branch neurotomy was evaluated in 9 randomized trials 
(374,597,727-733), and in 21 observational studies (593-595,598,648,662,734-748).

For cervical and lumbar medial branch neurotomy, 2 randomized trials $(374,597)$ and 5 observational studies $(593,595,598,741,749)$ met inclusion criteria with methodologic quality assessment for evidence synthesis, with none of the studies meeting inclusion criteria for radiofrequency thermal neurotomy. The manuscripts meeting the diagnostic criteria of $80 \%$ relief with ability to perform previously painful maneuvers were included in methodologic quality assessment $(31,40,41)$.

Nath et al (374), in a randomized controlled trial (RCT) of 40 patients with chronic low back pain (20 active and 20 controls), found that the active treatment group showed significantly greater improvements with pain and analgesic use. The pain relief was however, only monitored for 6 months, as it was felt that patients who received placebo treatment could not be left untreated for longer than 6 months. Bogduk (749) provided a favorable opinion and highlighted the selection criteria, generalizability, and relief of index pain.
In 1996, Lord et al (597) evaluated the effectiveness of percutaneous radiofrequency neurotomy for chronic cervical zygapophyseal joint pain in a randomized, double-blind clinical trial with strict diagnostic selection criteria in 24 patients. At 3 months all patients were interviewed by completing the visual-analogue scale, the McGill Pain Questionnaire (MPQ), side effects, complications, and any sensation of numbness. At 27 weeks, one patient in the control group and 7 in the active treatment group remained free of pain. The median time for return of pain to at least $50 \%$ of the pre-operative level was 263 days in the active group and 8 days in the placebo group. This study found that radiofrequency neurotomy can provide pain relief for a moderate proportion of patients lasting from months to over a year.

Among the 2 observational studies, Sapir and Gorup (593) evaluated patients with neck pain after whiplash and showed no significant difference among the patients with or without litigation. The second study was by Barnsley (598) assessing outcomes in a series of con-

Table 9. Results of published reports of effectiveness of cervical, thoracic, and lumbar medial branch blocks.

\begin{tabular}{|c|c|c|c|c|c|c|c|c|}
\hline \multirow[b]{2}{*}{ Study } & \multirow[b]{2}{*}{$\begin{array}{c}\text { Study } \\
\text { Characteristics }\end{array}$} & \multirow[b]{2}{*}{$\begin{array}{l}\text { Methodological } \\
\text { Quality Score(s) }\end{array}$} & \multirow[b]{2}{*}{ No. of Patients } & & \multicolumn{2}{|c|}{ Long-term Relief } & \multicolumn{2}{|c|}{ Results } \\
\hline & & & & 3 mos. & 6 mos. & 12 mos. & $\begin{array}{c}\text { Short- } \\
\text { term } \\
\text { relief } \\
\leq 6 \mathrm{mos} \text {. }\end{array}$ & $\begin{array}{c}\text { Long- } \\
\text { term } \\
\text { relief } \\
>66 \mathrm{mos} .\end{array}$ \\
\hline \multicolumn{9}{|l|}{ Cervical } \\
\hline $\begin{array}{l}\text { Manchikanti et } \\
\text { al } 2008 \text { (596) }\end{array}$ & RA, DB & 76 & 76 & $\begin{array}{c}83 \% \text { vs } \\
85 \% \\
\end{array}$ & $\begin{array}{c}87 \% \text { vs } \\
95 \%\end{array}$ & $\begin{array}{c}85 \% \text { vs } \\
92 \% \\
\end{array}$ & $\mathrm{P}$ & $\mathrm{P}$ \\
\hline $\begin{array}{l}\text { Manchikanti et } \\
\text { al } 2004 \text { (725) }\end{array}$ & $\mathrm{O}$ & 69 & 100 & $92 \%$ & $82 \%$ & $56 \%$ & $\mathrm{P}$ & $\mathrm{P}$ \\
\hline \multicolumn{9}{|l|}{ Thoracic } \\
\hline $\begin{array}{l}\text { Manchikanti et } \\
\text { al } 2008(659)\end{array}$ & RA, DB & 60 & $\begin{array}{c}\text { Group I - no steroid }=24 \\
\text { Group II - steroid }=24\end{array}$ & $\begin{array}{l}79 \% \text { vs } \\
83 \%\end{array}$ & $\begin{array}{c}79 \% \text { vs } \\
81 \%\end{array}$ & $\begin{array}{c}79 \% \text { vs } \\
79 \%\end{array}$ & $\mathrm{P}$ & $\mathrm{P}$ \\
\hline $\begin{array}{l}\text { Manchikanti et } \\
\text { al } 2006(660)\end{array}$ & $\mathrm{O}$ & 69 & 55 & $71 \%$ & $71 \%$ & $76 \%$ & $\mathrm{P}$ & $\mathrm{P}$ \\
\hline \multicolumn{9}{|l|}{ LUMBAR } \\
\hline $\begin{array}{l}\text { Manchikanti et } \\
\text { al } 2008 \text { (375) }\end{array}$ & RA, DB & 73 & $\begin{array}{c}\text { Group I - no steroid }=60 \\
\text { Group II - steroid }=60\end{array}$ & $\begin{array}{c}83 \% \text { vs } \\
82 \% \\
\end{array}$ & $\begin{array}{c}83 \% \text { vs } \\
93 \%\end{array}$ & $\begin{array}{c}82 \% \text { vs } \\
85 \%\end{array}$ & $\mathrm{P}$ & $\mathrm{P}$ \\
\hline $\begin{array}{l}\text { Manchikanti et } \\
\text { al } 2001 \text { (722) }\end{array}$ & RA & 59 & 73 & $100 \%$ & $82 \%$ & $21 \%$ & P & P \\
\hline
\end{tabular}

$\mathrm{RA}=$ randomized; $\mathrm{DB}=$ Double-blind; $\mathrm{O}=$ observational; vs = versus; $\mathrm{P}=$ positive; $\mathrm{N}$ = negative

Adapted and modified from:

Falco FJE et al. Systematic review of diagnostic utility and therapeutic effectiveness of cervical facet joint interventions. Pain Physician 2009; 12:323-344 (41).

Atluri S et al. Systematic review of diagnostic utility and therapeutic effectiveness of thoracic facet joint interventions. Pain Physician 2008; 11:611$629(31)$.

Datta S et al. Systematic assessment of diagnostic accuracy and therapeutic utility of lumbar facet joint interventions. Pain Physician 2009; 12:437$460(40)$. 
secutive patients with percutaneous radiofrequency neurotomy of chronic neck pain showing positive results. A third study was performed by McDonald et al (595), and similar to the one performed by Barnsley (598) produced positive results. There were 2 studies evaluating lumbar facet joint nerve neurotomy by Dreyfuss et al (741) and Gofeld et al (739). Dreyfuss et al (741) prospectively evaluated 15 patients with $87 \%$ of patients reporting $60 \%$ pain relief at 12 months status post-radiofrequency neurotomy, whereas Gofeld et al (739) reported long-term improvement in $68.4 \%$ of the patients.

\subsubsection{Cost Effectiveness}

No cost effectiveness evaluations were performed with medial branch neurotomy.

\subsubsection{Safety and Complications}

Complications include dural puncture, spinal cord trauma, infection, intraarterial or intravenous injec- tion, spinal anesthesia, chemical meningitis, neural trauma, pneumothorax, radiation exposure, hematoma formation, painful cutaneous dysesthesias, increased pain due to neuritis or neurogenic inflammation, anesthesia dolorosa, cutaneous hyperesthesia, pneumothorax, and deafferentation pain $((390,397,399$ $402,403,406,718,719,750-752)$.

\subsubsection{Indications}

Indications are the same as described for diagnostic facet joint nerve blocks. For therapeutic interventions, the diagnosis must be established with a positive response to controlled local anesthetic blocks with $80 \%$ relief.

\subsubsection{Level of Evidence}

Table 10 illustrates the results of published studies of cervical and lumbar facet nerve neurotomy. There were no studies meeting inclusion criteria in the thoracic spine.

Table 10. Published results of studies of cervical and lumbar facet joint nerve neurotomy.

\begin{tabular}{|c|c|c|c|c|c|c|c|}
\hline \multirow[b]{2}{*}{ Study } & \multirow{2}{*}{$\begin{array}{c}\text { Study } \\
\text { Characteristics }\end{array}$} & \multirow{2}{*}{$\begin{array}{c}\text { Methodological } \\
\text { Quality } \\
\text { Score(s) }\end{array}$} & \multirow{2}{*}{$\begin{array}{l}\text { Number of } \\
\text { Patients }\end{array}$} & \multicolumn{2}{|c|}{$\begin{array}{c}\text { Pain Relief } \\
\text { (months) }\end{array}$} & \multicolumn{2}{|c|}{ Results } \\
\hline & & & & 6 mos. & 12 mos. & $\begin{array}{l}\text { Short-term } \\
\text { relief } \\
\leq 6 \mathrm{mos} .\end{array}$ & $\begin{array}{c}\text { Long-term } \\
\text { relief } \\
>6 \mathrm{mos} .\end{array}$ \\
\hline \multicolumn{8}{|l|}{ Cerrvical } \\
\hline $\begin{array}{l}\text { Lord et al } 1996 \\
\text { (597) }\end{array}$ & RA, DB & 67 & $\begin{array}{l}\text { 24-control } \\
24 \text {-active }\end{array}$ & $\begin{array}{l}1 \text { of sham } \\
7 \text { of active }\end{array}$ & $\begin{array}{c}58 \% \\
\text { in active treatment } \\
\text { group }\end{array}$ & $\mathrm{P}$ & $\mathrm{P}$ \\
\hline $\begin{array}{l}\text { Sapir and Gorup } \\
2001 \text { (593) }\end{array}$ & $\mathrm{O}$ & 87 & 46 & NA & $\begin{array}{c}\text { Mean VAS change } \\
4.6 \pm 1.8\end{array}$ & $P$ & $\mathrm{P}$ \\
\hline $\begin{array}{l}\text { McDonald et al } \\
1999 \text { (595) }\end{array}$ & $\mathrm{O}$ & 65 & 28 & NA & $71 \%$ & $\mathrm{P}$ & $\mathrm{P}$ \\
\hline $\begin{array}{l}\text { Barnsley } 2005 \\
\text { (598) }\end{array}$ & $\mathrm{O}$ & 54 & 35 & NA & $74 \%$ & $\mathrm{P}$ & $\mathrm{P}$ \\
\hline \multicolumn{8}{|l|}{ Lumbar } \\
\hline $\begin{array}{l}\text { Nath et al } 2008 \\
\text { (374) }\end{array}$ & RA, DB & 50 & $\begin{array}{l}20 \text {-control } \\
20 \text {-active }\end{array}$ & SI & NA & $\mathrm{P}$ & NA \\
\hline $\begin{array}{l}\text { Gofeld et al } 2007 \\
\text { (739) }\end{array}$ & $\mathrm{O}$ & 63 & 174 & $68 \%$ & NA & $\mathrm{P}$ & $\mathrm{P}$ \\
\hline $\begin{array}{l}\text { Dreyfuss et al } 2000 \\
\text { (741) }\end{array}$ & $\mathrm{O}$ & 73 & 15 & $87 \%$ & $87 \%$ & $\mathrm{P}$ & $\mathrm{P}$ \\
\hline
\end{tabular}

$\mathrm{RA}=$ randomized $\mathrm{DB}=$ double blind $\mathrm{O}=$ Observational; $\mathrm{NA}=$ not available; $\mathrm{SI}=$ significant improvement; $\mathrm{VAS}=$ visual analog scale; $\mathrm{P}=$ positive; $\mathrm{N}=$ negative

Adapted and modified from:

Falco FJE et al. Systematic review of diagnostic utility and therapeutic effectiveness of cervical facet joint interventions. Pain Physician 2009; 12:323344 (41).

Datta $S$ et al. Systematic assessment of diagnostic accuracy and therapeutic utility of lumbar facet joint interventions. Pain Physician 2009; 12:437460 (40). 
Based on USPSTF criteria (126), the indicated evidence for cervical medial branch radiofrequency neurotomy is Level II-1 to Level II-2, Level II-2 to II-3 for lumbar radiofrequency neurotomy, and with no evidence available for thoracic medial branch radiofrequency neurotomy.

\subsubsection{Recommendations}

Based on Guyatt et al's (136) criteria for cervical radiofrequency neurotomy and lumbar radiofrequency neurotomy, the recommendation is $1 \mathrm{C} / \mathrm{strong}$ recommendation.

\subsection{Epidural Injections}

Access to the epidural space is available by caudal, interlaminar, and transforaminal approaches (4,7-10,24$26,34-37,111,753-762)$. Substantial differences with the technique and outcomes have been described among the 3 approaches. Thus, due to the inherent variations, differences, advantages, and disadvantages applicable to each technique (including the effectiveness and outcomes), caudal epidural injections, interlaminar epidural injections (cervical, thoracic, and lumbar epidural injections), and transforaminal epidural injections (lumbosacral) are considered as separate entities.

In addition, the response to epidural injections for various pathological conditions (disc herniation and/or radiculitis, discogenic pain without disc herniation, spinal stenosis, and post surgery syndrome) is variable.

\subsubsection{Caudal Epidural Injections}

Several systematic reviews have evaluated the effectiveness of epidural steroids including caudal epidural injections $(34,78,86,88,103,763-766)$. However, they failed to separate caudal and interlaminar techniques, arriving often at erroneous conclusions. Of importance are systematic reviews performed by Nelemans et al (78), updated by Staal et al (103), Koes et al (763), van Tulder et al (88), and Armon et al (766). All these reviews included essentially similar criteria as well as the same studies, uniformly arriving at inaccurate conclusions. In contrast, Abdi et al $(24,111)$ and Boswell et al (767), Singh et al (50), and Bogduk et al (753) evaluated caudal epidural steroid injections as separate procedures, reaching opposite conclusions. They concluded that the effectiveness of caudal epidural injections in managing lumbar radiculopathy was moderate.

Conn et al (34) in a systematic review evaluating the effect of caudal epidural injections with or without steroids in managing various types of chronic low back and lower extremity pain emanating as a result of disc herniation or radiculitis, post lumbar surgery syndrome, spinal stenosis, and chronic discogenic pain without disc herniation or radiculitis has shown Level I evidence for short- and long-term relief of chronic pain secondary to disc herniation or radiculitis and discogenic pain without disc herniation or radiculitis. Further, the systematic review by Conn et al (34) also provides an indicated level of evidence II-1 or II-2 for caudal epidural injections in managing chronic pain of post lumbar surgery syndrome and spinal stenosis. The results of the systematic review were provided utilizing contemporary systematic review methodology utilizing randomized trials and observational studies, even though most of the evidence was derived from randomized trials.

\subsubsection{Disc Herniation and Radiculitis}

\subsection{Evidence Assessment}

Six randomized trials (768-773) were used in evidence synthesis. Dashfield et al (770) and Manchikanti et al (769) utilized fluoroscopy.

Of the 2 studies utilizing fluoroscopy, Dashfield et al (770) compared the effectiveness of caudal steroid epidural with targeted steroid placement during spinal endoscopy for chronic sciatica in a prospective, randomized, double-blind trial. Patients in the caudal group underwent caudal epidural corticosteroid injection with a total of $10 \mathrm{~mL}$ of lidocaine $1 \%$ with 40 $\mathrm{mg}$ of triamcinolone being injected into the epidural space. Patients in the epiduroscopy group underwent epiduroscopy performed by an experienced epiduroscopist with placement of steroid over the nerve root, which included $10 \mathrm{~mL}$ of lidocaine $1 \%$ with triamcinolone $40 \mathrm{mg}$. The epiduroscopy group also received infusion of 50 to $150 \mathrm{mg} \mathrm{mL}$ of sodium chloride solution. No significant differences were found between the groups for any of the measures at any time. There were significant differences within both groups compared with pretreatment values. For the caudal group, significant improvements were found for descriptive pain at 6 months; visual analog scale (VAS) at 6 weeks, 3 months, and 6 months; present pain intensity at 3 months and 6 months; anxiety at 6 weeks, 3 months, and 6 months; and depression at 6 months only.

Manchikanti et al (769) in a preliminary report of a randomized, double-blind, equivalence trial, published results in 84 patients with 42 patients in each group of local anesthetic with or without steroid. 
The study consists of 60 patients in each group with Group I patients receiving caudal epidural injections with local anesthetic of lidocaine $0.5 \%$ preservative free, whereas Group II patients received caudal epidural injections with $0.5 \%$ lidocaine, $9 \mathrm{~mL}$, mixed with 1 $\mathrm{mL}$ of steroid. Repeat caudal epidural injections were provided based on the response to prior caudal epidural injections evaluated by improvement in physical and functional status. Multiple outcome measures were utilized with measurements of pain outcomes, employment status, and opioid intake assessed at 3 months, 6 months, and 12 months post-treatment. Sample size justification was provided for preliminary analysis and intent-to-treat analysis was performed. This report showed significant pain relief $(\geq 50 \%)$ in $79 \%$ to $81 \%$ of the patients with significant improvement in functional status $(40 \%$ or greater reduction in Oswestry scores) in $83 \%$ to $91 \%$ of the patients at the end of one-year follow-up with no significant differences noted with or without steroids. The overall average procedures per year were 3 to 4 with an average total relief per year of 35 to 36 weeks over a period of 52 weeks. Opioid intake and employment also showed significant improvement. The importance of this study lies in the fact that it was performed under fluoroscopy in a private practice setting with a randomized, double-blind design as an equivalence trial. The results of this study are generalizable to IPM settings in the United States.

\subsection{Effectiveness}

Of the 6 randomized trials, 5 were judged to be positive for short-term relief (768-772). Of the 4 trials, 3 reported positive results with long-term follow-up of more than 6 months $(769,771,773)$. The results in 2 studies utilizing fluoroscopy $(769,770)$ were superior to blind epidural injections. Table 11 illustrates results of effectiveness of randomized trials in disc herniation and radiculitis.

\subsubsection{Post Surgery Syndrome}

\subsection{Evidence Assessment}

Three studies were identified evaluating the effectiveness of caudal epidural injections in post surgery syndrome (773-775). Only one study by Manchikanti et al (774) was performed under fluoroscopy. Of these, 2 studies $(773,774)$ provided outcomes of longer than 6 months.
The only fluoroscopic study by Manchikanti et al (774) evaluated 40 patients in a randomized, doubleblind equivalence trial with an objective to evaluate the effectiveness of caudal epidural injections in patients with chronic low back and lower extremity pain after surgical intervention with post lumbar surgery syndrome. The results were preliminary from an expected study of 120 patients including 40 patients completing one year follow-up with justification of sample size in the subgroup analysis. They assigned patients into one of 2 groups with Group I patients receiving caudal epidural injections of local anesthetic (lidocaine $0.5 \%$ preservative free), whereas Group II patients received caudal epidural injections with $0.5 \%$ lidocaine, $9 \mathrm{~mL}$, mixed with $1 \mathrm{~mL}$ of non-particulate Celestone, $6 \mathrm{mg}$, under fluoroscopy. Multiple outcome measures were utilized including measurement of pain and disability, employment status, and opioid intake. In this study utilizing contemporary practice with fluoroscopy and in a private practice setting in a double-blind equivalence trial, preliminary results of one year showed significant pain relief ( $\geq 50 \%$ ) in $60 \%$ to $65 \%$ of the patients and functional improvement (greater than $40 \%$ reduction in ODI) in $55 \%$ to $70 \%$ of the patients with no significant differences between the groups at oneyear follow-up. Patients in the study received overall 3 to 4 procedures in a year with an average total relief of 26 to 32 weeks of 52 weeks. There were significant withdrawals due to failure to improve. Thus, separation into successful and failed groups showed results different from overall results. In the successful group, the total relief per year ranged from 35 to 44 weeks with poor response in the failed subjects. Average relief per procedure was 10 to 14 weeks. Opioid intake was also reduced significantly at one-year follow-up. The advantages of this study include the fact that it is an equivalence trial performed in a private practice setting with the results generalizable to the interventional pain patient population across the country when performed fluoroscopically.

\subsection{Effectiveness}

Of the 3 randomized trials studying the effectiveness of caudal epidural steroid injections in post-surgery syndrome, all of them were shown to be positive for short and long-term relief (773-775). Table 12 illustrates the results of randomized trials in managing chronic pain of post surgery syndrome with caudal epidural injections. 


\subsubsection{Spinal Stenosis}

\subsection{Evidence Assessment}

One randomized trial (776) and 2 observational studies $(777,778)$ evaluating the role of caudal epidural injections in spinal stenosis met inclusion criteria.

Manchikanti et al (776) published preliminary results of a randomized equivalence trial of fluoroscopic caudal epidural injections in managing chronic low back pain secondary to spinal stenosis. The study included 40 patients with 20 patients in each group with justification of sample size.

Patients were assigned randomly into 2 groups, with Group I patients receiving caudal epidural injections of local anesthetic (lidocaine $0.5 \%$ ), whereas Group II patients received caudal epidural injections with $0.5 \%$ lidocaine, $9 \mathrm{~mL}$, mixed with $1 \mathrm{~mL}$ of nonparticulate Celestone.

Multiple outcome measures were utilized including NRS, ODI, employment status, and opioid intake with assessment at 3 months, 6 months, and
12 months post-treatment. They defined significant pain relief as $50 \%$ more.

Significant pain relief ( $\geq 50 \%$ ) was demonstrated in $55 \%$ to $65 \%$ of patients with functional status improvement with at least a $40 \%$ reduction in ODI scores in $55 \%$ to $80 \%$ of the patients. The overall average procedures ranged from 3 to 4 with an average total relief of 23 to 30 weeks over a period of 52 weeks. However, when the groups were separated into failed groups and successful groups, the results improved somewhat with average relief ranging from 38 to 43 weeks over a period of one year with an average relief of 10 to 15 weeks per procedure in the overall population. There was also a reduction of opioid intake. Even though this is a small study, it was performed utilizing contemporary IPM techniques under fluoroscopic evaluation with appropriate outcome parameters in a private practice setting, yet utilizing a randomization and double-blind design in an equivalence trial comparing local anesthetic and steroid. Thus, these results can be applied to populations across the United States. Further, this is the first randomized trial evalu-

Table 11. Results of randomized trials of effectiveness of caudal epidural steroid injections in managing pain of lumbar disc herniation/radiculitis.

\begin{tabular}{|c|c|c|c|c|c|c|c|c|}
\hline \multirow[b]{2}{*}{ Study } & \multirow[b]{2}{*}{$\begin{array}{c}\text { Study } \\
\text { Characteristics }\end{array}$} & \multirow[b]{2}{*}{$\begin{array}{l}\text { Methodological } \\
\text { Quality Scoring }\end{array}$} & \multirow[b]{2}{*}{ Participants } & \multicolumn{3}{|c|}{ Pain Relief } & \multicolumn{2}{|c|}{ Results } \\
\hline & & & & 3 mos. & 6 mos. & 12 mos. & $\begin{array}{c}\text { Short-term } \\
\text { relief } \leq 6 \\
\text { mos. }\end{array}$ & $\begin{array}{c}\begin{array}{c}\text { Long- } \\
\text { term }\end{array} \\
\text { relief }> \\
6 \text { mos. }\end{array}$ \\
\hline $\begin{array}{l}\text { Manchikanti et al } \\
2008(769)^{*}\end{array}$ & RA, DB & 72 & 84 & $81 \%$ & $86 \%$ & $\begin{array}{l}79 \% \text { to } \\
81 \%\end{array}$ & $\mathrm{P}$ & $\mathrm{P}$ \\
\hline $\begin{array}{l}\text { Dashfield et al } 2005 \\
(770)^{*}\end{array}$ & RA, DB & 50 & $\begin{array}{c}\text { Caudal }=30 \\
\text { Endoscopy }=30\end{array}$ & SI & SI & NA & $\mathrm{P}$ & NA \\
\hline $\begin{array}{l}\text { Bush and Hillier } \\
1991(768)\end{array}$ & RA, DB & 55 & 23 & SI & NSI & NSI & $\mathrm{P}$ & $\mathrm{N}$ \\
\hline $\begin{array}{l}\text { Mathews et al } 1987 \\
\text { (771) }\end{array}$ & $\mathrm{RA}, \mathrm{DB}$ & 62 & $\begin{array}{l}\mathrm{C}=34 \\
\mathrm{~T}=23\end{array}$ & SI & SI & SI & $\mathrm{N}$ & $\mathrm{P}$ \\
\hline $\begin{array}{l}\text { Hesla and Breivik } \\
1979(773)\end{array}$ & RA, DB & 58 & $\begin{array}{l}69 \text { patients: } \\
\text { crossover } \\
\text { design }\end{array}$ & $\begin{array}{l}77 \% \text { vs } \\
29 \%\end{array}$ & $\begin{array}{l}59 \% \text { vs } \\
25 \%\end{array}$ & $\begin{array}{l}59 \% \text { vs } \\
25 \%\end{array}$ & $\mathrm{P}$ & $P$ \\
\hline $\begin{array}{l}\text { Breivik et al } 1976 \\
(772)\end{array}$ & RA, DB & 68 & $\begin{array}{l}\mathrm{C}=19 \\
\mathrm{~T}=16\end{array}$ & $\begin{array}{l}20 \% \text { vs } \\
50 \%\end{array}$ & $\begin{array}{l}20 \% \text { vs } \\
50 \%\end{array}$ & NA & $\mathrm{P}$ & NA \\
\hline
\end{tabular}

${ }^{\star}$ Indicates use of fluoroscopy

$R A=$ randomized $; D B=$ double blind $; C=$ control $; T=$ treatment $; \mathrm{N} A=$ not available $; S I=$ significant improvement $; \mathrm{NSI}=$ no significant improvement; $v$ s = versus; $P=$ positive; $N=$ negative

Adapted and modified from Conn A et al. Systematic review of caudal epidural injections in the management of chronic low back pain. Pain Physician 2009; 12:109-135 (34). 
ating the role of caudal epidural injections in spinal stenosis.

\subsection{Effectiveness}

The one randomized trial evaluating spinal stenosis with or without steroids with local anesthetic (776) and 2 observational studies $(777,778)$ showed positive results for short- and long-term relief (Table 13). Huntoon and Burgher (779) concluded in an editorial that results of caudal epidural were similar to surgery.

\subsubsection{Discogenic Pain}

\subsection{Evidence Assessment}

One randomized trial (780) and 2 observational studies $(781,782)$ met inclusion criteria.

Manchikanti et al (780) in a randomized, doubleblind, equivalence trial evaluated the effectiveness of caudal epidural injections with or without steroids in managing chronic low back pain without disc herniation or radiculitis in providing effective and long last-

Table 12. Results of randomized trials in managing low back pain of post-surgery syndrome with caudal epidural injections.

\begin{tabular}{|c|c|c|c|c|c|c|c|c|}
\hline \multirow[b]{2}{*}{ Study } & \multirow[b]{2}{*}{$\begin{array}{c}\text { Study } \\
\text { Characteristics }\end{array}$} & \multirow[b]{2}{*}{$\begin{array}{l}\text { Methodological } \\
\text { Quality Scoring }\end{array}$} & \multirow[b]{2}{*}{ Participants } & \multicolumn{3}{|c|}{ Pain Relief } & \multicolumn{2}{|c|}{ Results } \\
\hline & & & & 3 mos. & 6 mos. & 12 mos. & $\begin{array}{c}\text { Short-term } \\
\text { relief } \leq 6 \\
\text { mos. }\end{array}$ & $\begin{array}{c}\text { Long- } \\
\text { term } \\
\text { relief }>6 \\
\text { mos. }\end{array}$ \\
\hline $\begin{array}{l}\text { Manchikanti et } \\
\text { al } 2008(774)^{\star}\end{array}$ & RA, DB & 70 & 40 & $\begin{array}{c}65 \% \text { to. } \\
70 \%\end{array}$ & $60 \%$ & $\begin{array}{l}60 \% \text { to } \\
65 \%\end{array}$ & $\mathrm{P}$ & $\mathrm{P}$ \\
\hline $\begin{array}{l}\text { Revel et al } \\
1996(775)\end{array}$ & RA & 62 & $\begin{array}{c}\text { Forceful injec- } \\
\text { tion }=29 \\
\text { Regular }=31\end{array}$ & NA & $\begin{array}{c}49 \% \text { vs } \\
19 \%\end{array}$ & NA & $\mathrm{P}$ & $\mathrm{P}$ \\
\hline $\begin{array}{l}\text { Hesla and } \\
\text { Breivik } 1979 \\
\text { (773) }\end{array}$ & $\mathrm{RA}, \mathrm{DB}$ & 58 & $\begin{array}{l}69 \text { patients: } \\
\text { crossover } \\
\text { design }\end{array}$ & $\begin{array}{c}77 \% \text { vs } \\
29 \%\end{array}$ & $\begin{array}{l}59 \% \text { vs } \\
25 \%\end{array}$ & $59 \%$ vs $25 \%$ & $\mathrm{P}$ & $\mathrm{P}$ \\
\hline
\end{tabular}

${ }^{\star}$ Indicates use of fluoroscopy

$R A=$ randomized $; D B=$ double blind $; \mathrm{NA}=$ not available $;$ vs $=$ versus $; P=$ positive $; \mathrm{N}=$ negative

Adapted and modified from Conn A et al. Systematic review of caudal epidural injections in the management of chronic low back pain. Pain Physician 2009; 12:109-135 (34).

Table 13. Results of effectiveness in evaluation in managing spinal stenosis.

\begin{tabular}{|l|c|c|c|c|c|c|c|c||}
\hline \multicolumn{1}{|c|}{ Study } & $\begin{array}{c}\text { Study } \\
\text { Characteristics }\end{array}$ & $\begin{array}{c}\text { Methodological } \\
\text { Quality Scoring }\end{array}$ & Participants & $\mathbf{3 ~ m o s .}$ & $\mathbf{6}$ mos. & $\mathbf{1 2}$ mos. & $\begin{array}{c}\text { Phort- } \\
\text { term relief } \\
\leq \mathbf{6} \text { mos. }\end{array}$ & $\begin{array}{c}\text { Long-term } \\
\text { relief }>\mathbf{6} \\
\text { mos. }\end{array}$ \\
\hline $\begin{array}{l}\text { Manchikanti } \\
\text { et al 2008 } \\
(776)^{*}\end{array}$ & RA, DB & 70 & 40 & $\begin{array}{c}50 \% \text { to } \\
65 \%\end{array}$ & $\begin{array}{c}60 \% \text { to } \\
65 \%\end{array}$ & $55 \%$ to $65 \%$ & $\mathrm{P}$ & $\mathrm{P}$ \\
\hline $\begin{array}{l}\text { Ciocon et al } \\
1994(777)\end{array}$ & $\mathrm{O}$ & 57 & 30 & SI & SI & NA & P & NA \\
\hline $\begin{array}{l}\text { Botwin et al } \\
2007(778)^{*}\end{array}$ & $\mathrm{O}$ & 61 & 34 & $65 \%$ & $62 \%$ & $54 \%$ & $\mathrm{P}$ & $\mathrm{P}$ \\
\hline
\end{tabular}

*Indicates use of fluoroscopy

$\mathrm{RA}=$ randomized $; \mathrm{DB}=$ double blind $; \mathrm{O}=$ observational; $\mathrm{NA}=$ not available $; \mathrm{SI}=$ significant improvement $; \mathrm{vs}=$ versus; $\mathrm{P}=$ positive $;$ $\mathrm{N}=$ negative

Adapted and modified from Conn A et al. Systematic review of caudal epidural injections in the management of chronic low back pain. Pain Physician 2009; 12:109-135 (34). 
ing pain relief and to evaluate the differences between local anesthetic with or without steroids. Inclusion criteria consisted of lack of disc herniation and symptoms of radiculitis, negative response to controlled diagnostic facet joint nerve blocks and sacroiliac joint blocks, and failure of conservative management. Patients were randomly assigned to one of 2 groups, Group I patients received caudal epidural injections with local anesthetic (lidocaine $0.5 \%$ ), whereas Group II patients received caudal epidural injections with $0.5 \%$ lidocaine, $9 \mathrm{~mL}$, mixed with $1 \mathrm{~mL}$ of steroid. Multiple outcome measures were utilized which included the NRS, the ODI 2.0, employment status, and opioid intake with assessment at 3 months, 6 months, and 12 months post-treatment. Significant pain relief ( $\geq 50 \%$ ) was demonstrated in at least $72 \%$ to $81 \%$ of patients and functional status improvement was demonstrated by a reduction of $40 \%$ in the ODI scores in $81 \%$ of the patients. The overall average procedures per year were $3.6 \pm 1.05$ in Group I and $3.9 \pm 1.33$ in Group II with an average total relief per year of $32.3 \pm 16.93$ weeks in Group I and $30.7 \pm 17.94$ weeks in Group II over a period of 52 weeks. Limitations of the study were lack of a placebo group and a preliminary report of 36 patients in each group. They concluded that caudal epidural injections with or without steroids may be effective in patients with chronic function-limiting low back pain without facet joint pain, disc herniation, and/or radiculitis in over $70 \%$ of the patients.

Manchikanti et al (782) in a randomized trial evaluated the effectiveness of caudal epidural steroid injections with Sarapin or steroids for chronic low back pain. The study included 65 patients who underwent diagnostic facet joint nerve blocks utilizing comparative local anesthetic blocks and were shown to be negative for facet joint pain and other problems such as sacroiliac joint pain before enrollment into the study. They were randomly selected from 105 patients negative for facet joint pain allocated into three groups, with Group I consisting of 15 patients comprising a convenience control sample treated conservatively; Group II, consisting of 22 patients treated with caudal epidural with local anesthetic and Sarapin; and Group III, consisting of 33 patients treated with caudal epidural with a mixture of local anesthetic and betamethasone. The study period lasted for 3 years. Results showed that there was significant improvement in patients receiving caudal epidural injections, with a decrease in pain associated with improved physical, functional, and mental status; and decreased narcotic intake combined with return to work. The study showed that at one-month $96 \%$ of the patients evaluated showed significant improvement, which declined to $56 \%$ at 3 months and $16 \%$ at 6 months, with administration of one to 3 injections. The study also showed cost effectiveness of this treatment, with a cost of $\$ 2550$ for 1-year improvement of QOL. They concluded that the treatment is not only effective clinically, but also is cost effective.

Manchikanti et al (781) in a prospective evaluation of the effectiveness of caudal epidural injections in discogram positive and negative chronic low back pain evaluated 100 consecutive patients, without evidence of disc herniation or radiculitis. Patients underwent discography utilizing strict criteria of concordant pain, and negative adjacent discs, after being judged to be negative for facet joint and/or sacroiliac joint pain utilizing comparative local anesthetic blocks. They included Group I, comprised of 45 of 55 patients negative on provocative discography; and Group II, with 17 of 45 patients with positive provocative discography. Results showed that there was significant improvement in patients receiving caudal epidural injections, with a decrease in pain associated with improved physical, functional, and mental status; decreased narcotic intake; and increased return to work. The study showed that at one-month, $100 \%$ of the patients evaluated showed significant improvement in both groups; this declined to $86 \%$ at 3 months in Group I, but remained at $100 \%$ in Group II, declining to $60 \%$ and $64 \%$ at 6 months in Group I and Group II, with administration of one to 3 injections. Analysis with one to 3 injections, which included all ( $n=62$ ) patients showed significant relief in $71 \%$ and $65 \%$ of the patients at one-month, in $67 \%$ and $65 \%$ at 3 months, and in $47 \%$ and $41 \%$ at 6 months, in Group I and Group II, respectively.

\subsection{Effectiveness}

Table 14 illustrates the results of effectiveness of caudal epidural injections in managing discogenic pain without disc herniation or radiculitis. One randomized trial (780) and one observational study (782) showed positive long-term results, whereas one study (781) evaluated only short-term relief of 6 months or less.

\subsubsection{Cost Effectiveness}

The cost effectiveness of fluoroscopically directed caudal epidural steroids was $\$ 3,635$ and that of transforaminal steroids $\$ 2,927$ per year, whereas for inter- 
laminar epidural steroids the cost was $\$ 6,024$ (783). In another study, the cost for one-year improvement for QOL was $\$ 2,550$ in patients treated with caudal epidural with local anesthetic and/or steroids under fluoroscopy (782).

\subsubsection{Safety and Complications}

Various complications of caudal epidural injections have been reported $(24,111,390,401,406,665,720,753$, $760,767,784-797)$. Suppression of pituitary adrenal axis, hypercorticism, Cushing's syndrome, osteoporosis, avascular necrosis of the bone, steroid myopathy, steroid psychosis, osteomyelitis, epidural lipomatosis, weight gain, fluid retention, and hyperglycemia have been reported. However, it has been shown that at therapeutic doses of epidural steroids administered, complications were not noted related to procedure (798-800).

Complications and side effects include infection, intravascular injection, extra epidural placement, hematoma formation, abscess formation, subdural injection, intracranial air injection, epidural lipomatosis, dural puncture, nerve damage, headache, increased intracranial pressure, vascular injury, cerebrovascular or pulmonary embolism. Other less common complications include transient blindness (801), retinal necrosis (802), central serous chorioretinopathy $(791,803)$, retinal hemorrhage (790), persistent recurrent intractable hiccups (804), flushing (805), chemical meningitis, discitis $(786,794)$, epidural hematoma (806-809), epidural abscess (794), and arachnoiditis $(810,811)$.

\subsubsection{Indications}

Caudal epidural steroid injections are indicated in patients with chronic low back pain who have failed to respond to conservative modalities of treatments. While caudal epidural steroid injections may be performed for any type of low back pain with or without lower extremity pain nonresponsive to conservative modalities of treatments, they are properly indicated in patients negative for facet or sacroiliac joint pain or patients who have at least a combination of discogenic component with facet joint pain. Caudal epidural steroids are the preferred modality of treatment for lower lumbar and sacral involvement, in postsurgical patients, and in patients with bilateral involvement or multilevel involvement for which transforaminal epidurals will require multiple procedures at multiple levels.

\subsubsection{Level of Evidence}

The level of evidence is variable for the 4 condi- tions evaluated. The evidence is based on randomized trials and observational studies utilizing the USPSTF criteria (126). Tables 11 to 14 illustrate the results of effectiveness of caudal epidural injections.

- The evidence is Level I for short- and long-term relief in managing chronic low back and lower extremity pain secondary to lumbar disc herniation and/or radiculitis and discogenic pain without disc herniation or radiculitis.

- The indicated evidence is Level II-1 or II-2 for caudal epidural injections in managing low back pain of post-surgery syndrome and spinal stenosis.

\subsubsection{Recommendations}

Based on grading recommendations by Guyatt et al (136), the recommendation for caudal epidural steroid injections is as follows:

- In managing lumbar spinal pain with disc herniation and radiculitis or discogenic pain without disc herniation or radiculitis, the recommendation is $1 \mathrm{~A}$ or $1 \mathrm{~B} /$ strong.

- The recommendation for caudal epidural injections in managing patients with post-lumbar laminectomy syndrome and spinal stenosis is $1 \mathrm{~B}$ or $1 \mathrm{C} /$ strong.

\subsubsection{Interlaminar Epidural Injections}

Multiple systematic reviews provided negative opinions for lumbar interlaminar epidural injections $(24,35,78,88,103,111,763,764,766,767)$. Recently, 2 systematic reviews were performed evaluating lumbar and cervical interlaminar epidurals $(35,36)$. They arrived at conflicting conclusions with the systematic review of the effectiveness of the cervical epidurals in the management of chronic neck pain illustrating a Level II-1 evidence in managing chronic neck and upper extremity pain (36); whereas, the evidence is Level II-2 for short-term relief of pain of disc herniation or radiculitis utilizing blind interlaminar epidural steroid injections with lack of evidence for long-term relief (35). Staal et al (103) updated Neleman et al's (78) systematic review, concluding that there was insufficient evidence to support the use of injection therapy in subacute and chronic low back pain.

\subsubsection{Lumbar Interlaminar Epidural Injections}

Lumbar interlaminar epidural injections were evaluated separately for disc herniation and radiculitis, spinal stenosis, and discogenic pain. 
Table 14. Results of randomized and observational studies of effectiveness of caudal epidural steroid injections in managing discogenic pain.

\begin{tabular}{|c|c|c|c|c|c|c|c|c|}
\hline \multirow[b]{2}{*}{ Study } & \multirow[b]{2}{*}{$\begin{array}{c}\text { Study } \\
\text { Characteristics }\end{array}$} & \multirow[b]{2}{*}{$\begin{array}{l}\text { Methodological } \\
\text { Quality Scoring }\end{array}$} & \multirow[b]{2}{*}{ Participants } & \multicolumn{3}{|c|}{ Pain Relief } & \multicolumn{2}{|c|}{ Results } \\
\hline & & & & 3 mos. & 6 mos. & 12 mos. & $\begin{array}{c}\text { Short-term } \\
\text { relief } \leq 6 \\
\text { mos. }\end{array}$ & $\begin{array}{c}\text { Long- } \\
\text { term } \\
\text { relief }>6 \\
\text { mos. }\end{array}$ \\
\hline $\begin{array}{l}\text { Manchikanti et } \\
\text { al } 2008(780)\end{array}$ & RA, DB & 72 & 64 & $78 \%$ & $\begin{array}{c}75 \% \text { to } \\
81 \%\end{array}$ & $72 \%$ & $\mathrm{P}$ & $\mathrm{P}$ \\
\hline $\begin{array}{l}\text { Manchikanti et } \\
\text { al } 2001(782)^{*}\end{array}$ & $\mathrm{O}$ & 76 & 70 & $95 \%$ & $85 \%$ & $\begin{array}{l}61 \% \text { to } \\
73 \%\end{array}$ & $\mathrm{P}$ & $\mathrm{P}$ \\
\hline $\begin{array}{l}\text { Manchikanti et } \\
\text { al } 2002(781)^{*}\end{array}$ & $\mathrm{O}$ & 73 & 62 & $86 \%$ & $60 \%$ & NA & $\mathrm{P}$ & NA \\
\hline
\end{tabular}

*Indicates use of fluoroscopy

$\mathrm{RA}=$ randomized $; \mathrm{DB}=$ double blind $; \mathrm{O}=$ observational $\mathrm{NA}=$ not available; $\mathrm{P}=$ positive $\mathrm{N}=$ negative

Adapted and modified from Conn A et al. Systematic review of caudal epidural injections in the management of chronic low back pain. Pain Physician 2009; 12:109-135 (34).

\subsection{Disc Herniation and Radiculitis}

Five blind lumbar interlaminar studies met inclusion criteria (812-816). However, most studies incorporated flawed methodology without fluoroscopy. The authors utilized a flawed process by considering local anesthetic injection as a placebo along with a small sample size, and also used poor methodology, and inadequate outcome assessments (813). Widely applauded, Carette et al's study (812) also contained numerous deficiencies including lack of fluoroscopy, performance of the procedure in the lateral decubitus position and injection of isotonic saline as placebo into the epidural space. Arden et al (815) utilized an unrealistic outcome expectation of reduction of ODI by $75 \%$ from the baseline, performed without fluoroscopy, and repeated the injections without concern about return of the pain for a total of 3 injections. Snoek et al (814) in a study of 51 patients with lumbar root compression found no significant differences between the 2 groups. Wilson-MacDonald et al (816) also showed no significant differences.

As shown in Table 15, of the 5 randomized trials (blind lumbar interlaminar epidurals) included in the evidence synthesis, 2 were positive for short-term and all 5 of them were negative for long-term relief of more than 6 months.

\subsection{Spinal Stenosis}

Two blind lumbar interlaminar randomized trials $(813,816)$ and one observational study $(817)$ evaluating spinal stenosis were identified.
Cuckler et al (813) and Wilson-MacDonald et al (816) utilized flawed methodologic processes as described earlier and further, the number of patients studied was also small. The observational study by Campbell et al (817) showed significant confusion, basically demonstrating that epidural steroid injections performed blindly with an interlaminar approach in a series of 3 injections may still be effective.

Three evaluations studying the effectiveness of blind lumbar interlaminar studied injections in spinal stenosis (Table 16).

\subsection{Chronic Low Back Pain of Discogenic Origin without Radiculitis or Disc Herniation}

Only one observational study was available evaluating the effect of spinal steroid injections for degenerative disc disease under fluoroscopy, which included intradiscal injections as well as epidural injections (818).

Butterman (818) reported epidural steroid injections were performed in 93 patients with degenerative disc disease and inflammatory endplate changes and in 139 patients without inflammatory endplate changes. Patients received either interlaminar or transforaminal epidural steroid injections, all of which were performed under fluoroscopy; however, the proportion of patients receiving interlaminar epidural steroid injections is not described. Over a period of 2 years, this study had an extensive dropout rate of $60 \%$. 
Table 15. Results of randomized trials of effectiveness of blind lumbar interlaminar epidural steroid injections in managing disc herniation and radiculitis.

\begin{tabular}{|c|c|c|c|c|c|c|c|c|c|}
\hline \multirow[b]{2}{*}{ Study } & \multirow[b]{2}{*}{$\begin{array}{c}\text { Study } \\
\text { Characteristics }\end{array}$} & \multirow[b]{2}{*}{$\begin{array}{l}\text { Methodological } \\
\text { Quality Scoring }\end{array}$} & \multirow[b]{2}{*}{ Participants } & \multicolumn{4}{|c|}{ Pain Relief } & \multicolumn{2}{|c|}{ Results } \\
\hline & & & & $\begin{array}{c}<3 \\
\text { mos. }\end{array}$ & 3 mos. & 6 mos. & 12 mos. & $\begin{array}{l}\text { Short-term } \\
\text { relief } \\
\leq 6 \mathrm{mos} .\end{array}$ & $\begin{array}{c}\text { Long-term } \\
\text { relief } \\
>6 \mathrm{mos} .\end{array}$ \\
\hline $\begin{array}{l}\text { Wilson- } \\
\text { MacDonald } \\
\text { et al } 2005 \\
(816)\end{array}$ & RA & 68 & 43 & SI & NSD & NSD & NSD & $\mathrm{P}$ & $\mathrm{N}$ \\
\hline \begin{tabular}{|l} 
Arden et al \\
$2005(815)$
\end{tabular} & $\mathrm{RA}, \mathrm{DB}, \mathrm{PC}$ & 86 & 228 & $75 \%$ & NSD & NSD & NSD & $\mathrm{N}$ & $\mathrm{N}$ \\
\hline $\begin{array}{l}\text { Carette et al } \\
1997(812)\end{array}$ & RA,DB,PC & 77 & $\begin{array}{l}\mathrm{C}=80 \\
\mathrm{~T}=78\end{array}$ & SIT & NSD & NSD & NSD & $\mathrm{P}$ & $\mathrm{N}$ \\
\hline $\begin{array}{l}\text { Cuckler et al } \\
1985(813)\end{array}$ & RA,DB & 60 & $\begin{array}{l}\mathrm{C}=31 \\
\mathrm{~T}=42\end{array}$ & NSD & NSD & NSD & NSD & $\mathrm{N}$ & $\mathrm{N}$ \\
\hline $\begin{array}{l}\text { Snoek et al } \\
1977(814)\end{array}$ & RA & 72 & $\begin{array}{l}\mathrm{C}=24 \\
\mathrm{~T}=27\end{array}$ & NSD & NSD & NSD & NSD & $\mathrm{N}$ & $\mathrm{N}$ \\
\hline
\end{tabular}

$\mathrm{RA}=$ randomized; $\mathrm{DB}=$ double blind; $\mathrm{PC}=$ placebo controlled $\mathrm{C}=$ control $\mathrm{T}=$ treatment; $\mathrm{SI}=$ significant improvement; $\mathrm{SIT}=$ significant improvement in treatment group; $\mathrm{NSD}=$ no significant difference; $\mathrm{P}=$ positive; $\mathrm{N}=$ negative

Adapted and modified from Parr AT et al. Lumbar interlaminar epidural injections in managing chronic low back and lower extremity pain: A systematic review. Pain Physician 2009; 12:163-188 (35).

Approximately one-half of the patients expressed a positive opinion as to whether the epidural steroid injection was successful in the treatment of their symptoms during the first 3 months. Of the 139 patients who did not have inflammatory endplate changes and were treated with epidural steroid injections, 98 had not changed treatment after 3 month follow-up. Patients' self assessment of success slowly declined over time so that after one year, only 32 of the original 139 patients in this group considered their injection therapy to have been successful. However, a significant improvement in all outcome scales was found at all follow-up periods for those patients who did not drop out $(P<0.001)$. A comparison of the 2 epidural steroid groups (inflammatory versus non-inflammatory endplates) revealed greater improvement for ODI scores for the patients with inflammatory endplates at one to 3 and 4 to 6 month follow-up periods and pain drawing at the 4 to 6 month follow-up period. The authors concluded that patients may have short-term benefit by epidural steroid injection without disc herniation or stenosis. Overall, $25 \%$ to $35 \%$ of patients with chronic low back pain resulting from degenerative disc disease had improved pain and function after epidural steroid injection at 2-year follow-up.
Only one observational study (818) showed moderate results with short-term positive results and with negative long-term results in patients with chronic low back pain of discogenic origin without radiculitis or disc herniation.

\subsubsection{Cervical Interlaminar Epidural Injections}

\subsubsection{Evidence Assessment}

Only 3 systematic reviews evaluated the role of cervical interlaminar epidural injections $(24,36,111)$. The recent systematic review of cervical epidural injections met inclusion criteria (24). Three blind cervical epidural studies met the inclusion criteria (819-821).

Castagnera et al (820) randomly allocated 24 patients into 2 groups with the steroid group treated with $0.5 \%$ lidocaine plus triamcinolone acetonide $10 \mathrm{mg} / \mathrm{mL}$, whereas the morphine group received the same combination of $0.5 \%$ lidocaine and steroid plus $2.5 \% \mathrm{mg}$ of morphine. Pain relief was assessed as the percentage of pain decrease on a VAS at months 3, 6, 8, and 12 after cervical epidural steroid injection, up to 48 months. They reported a success rate of $78.5 \%$ in the steroid group and $80 \%$ in the steroid and morphine group with pain relief 
Table 16. Results of published studies of effectiveness of blind lumbar interlaminar epidural steroid injections in managing spinal stenosis.

\begin{tabular}{|c|c|c|c|c|c|c|c|c|c|}
\hline \multirow[b]{2}{*}{ Study } & \multirow[b]{2}{*}{$\begin{array}{c}\text { Study } \\
\text { Characteristics }\end{array}$} & \multirow[b]{2}{*}{$\begin{array}{l}\text { Methodological } \\
\text { Quality Scoring }\end{array}$} & \multirow[b]{2}{*}{ Participants } & \multicolumn{4}{|c|}{ Pain Relief } & \multicolumn{2}{|c|}{ Results } \\
\hline & & & & $\begin{array}{l}<3 \\
\text { mos. }\end{array}$ & $\begin{array}{c}3 \\
\text { mos. }\end{array}$ & $\begin{array}{c}6 \\
\operatorname{mos} .\end{array}$ & $\begin{array}{c}12 \\
\text { mos. }\end{array}$ & $\begin{array}{c}\text { Short- } \\
\text { term } \\
\text { relief } \\
\leq 6 \mathrm{mos} .\end{array}$ & $\begin{array}{c}\text { Long- } \\
\text { term } \\
\text { relief }> \\
6 \text { mos. }\end{array}$ \\
\hline $\begin{array}{l}\text { Cuckler et al } \\
1985(813)\end{array}$ & RA,DB & 60 & 37 & NSD & NSD & NSD & NSD & $\mathrm{N}$ & $\mathrm{N}$ \\
\hline $\begin{array}{l}\text { Wilson- } \\
\text { MacDonald et al } \\
2005 \text { (816) }\end{array}$ & RA & 68 & 32 & SI & NSD & NSD & NSD & $\mathrm{P}$ & $\mathrm{N}$ \\
\hline $\begin{array}{l}\text { Campbell et al } \\
2007(817)\end{array}$ & $\mathrm{O}$ & 53 & 84 & NA & NA & NA & $40 \%$ & NA & $\mathrm{N}$ \\
\hline
\end{tabular}

$\mathrm{RA}=$ randomized $\mathrm{DB}=$ double blind $\mathrm{O}=$ observational $\mathrm{C}=$ control $\mathrm{T}$ = treatment $\mathrm{SI}=$ significant improvement $\mathrm{NSD}=$ no significant differ ence; $\mathrm{P}=$ positive; $\mathrm{N}$ = negative; $\mathrm{NA}$ = not available

Adapted and modified from Parr AT et al. Lumbar interlaminar epidural injections in managing chronic low back and lower extremity pain: A systematic review. Pain Physician 2009; 12:163-188 (35).

which was stable, with a mean follow-up of $43 \pm$ 18.1 months.

This is a well performed study; however, the authors attempted to evaluate the pain by increasing the volume of sodium chloride solution injection into the cervical epidural space, not to exceed $10 \mathrm{~mL}$ to exacerbate the patient's radicular pain. The mean volume injected in the epidural space was $6.6 \pm 2.1$ and $6.3 \pm$ $1.9 \mathrm{~mL}$ in the respective groups. This report however showed results much superior to any other study reported in the literature. They also showed that pain relief remained stable for 48 months and in some cases for more than 60 months. The intensity of medical treatment also decreased significantly 3 months after cervical epidural steroid injection and remained unchanged over subsequent periods. They also showed return to work in all the patients who were working prior to the cervical epidural steroid injections. However, there was no correlation found between pain relief and absenteeism. Furthermore, the addition of morphine to lidocaine and triamcinolone has not been shown to be superior to epidural lidocaine and triamcinolone in this study. Even though significant differences were observed, this study was limited by the small sample sizes of 14 and 10 in the 2 groups.

Stav et al (819) treated 25 patients with epidural steroid and lidocaine injections and 17 patients with steroid and lidocaine injections into the posterior neck muscles. They administered one to 3 injections at 2 week intervals based on the clinical response. Pain relief was evaluated by the VAS one week after the last injection and then one year later. One week after the last injection, good pain relief was reported in $76 \%$ of the patients receiving epidural steroids and local anesthetic as compared to $35.5 \%$ of the patients receiving extra-epidural steroids and local anesthetic. One year after the treatment, $68 \%$ of the patients in the epidural steroid group still had very good pain relief, whereas only $11.8 \%$ of the patients receiving intramuscular or extra-epidural with local anesthetic reported good pain relief. The study also reported that patients were able to increase range of motion, a few of them reduced their daily dose of analgesics, and recovery of the capacity for work was significantly better in the epidural steroid group.

The disadvantages of this study include lack of fluoroscopic visualization, epidural entry at multiple levels with some between C4 and C5, and lack of patient blinding with administration of intramuscular steroid lidocaine injection.

Pasqualucci et al (821) evaluated the efficacy of epidural local anesthetics plus steroids for the treatment of cervicobrachial pain in 160 patients randomized based on the duration of the pain and administering 2 types of treatments with a maximum of 9 blocks of single injections or 30 days of continuous epidural with 
the achievement of pain control of $80 \%$ or greater. Patients in the single injection group were administered a series of epidural blocks every 4 to 5 days with administration of $0.25 \%$ bupivacaine $6 \mathrm{~mL}$, with $80 \mathrm{mg}$ of methylprednisolone for a maximum of 9 blocks. In the continuous epidural group, catheterization was carried out and bupivacaine, a volume of $6 \mathrm{~mL}$, combined with $80 \mathrm{mg}$ of methylprednisolone was administered initially, followed by bupivacaine $6 \mathrm{~mL}$ every 6,12 , or 24 hours, along with methylprednisolone 40 mg every 4 to 5 days for a period of 30 days. They evaluated pain control and pain-free sleep status. Of the 160 enrolled patients, 19 were excluded due to various reasons. None of the patients had any major complications. The results of this evaluation showed a statistically significant efficacy of the treatment of cervicobrachial pain with epidural local anesthetic plus corticosteroids in continuous infusion rather than in single injection, in patients with chronic pain who did not respond to conservative therapies with pain duration of 6 months or longer. However, there was no statistically significant difference between the 2 treatments in patients with pain of less than 6 months. This data suggested that continuous epidural local anesthetic plus corticosteroid has greater efficacy than single injection of these drugs for the treatment of chronic cervicobrachial pain of greater than 6 months.

Although this study provides important information; it has several drawbacks: lack of long-term fol- low-up, lack of fluoroscopy, and inadequate blinding of patients and physicians.

Of the 3 randomized trials evaluating cervical interlaminar epidural steroid injections, all showed positive results for short-term relief (819-821), 2 were positive for long-term relief $(819,820)$, and the results of long-term relief were not available for one study (821). Table 17 illustrates results of effectiveness of blind cervical interlaminar epidural steroid injections.

\subsubsection{Cost Effectiveness}

In the evaluation of cost effectiveness, Manchikanti et al (783) and Price et al (822) concluded that lumbar interlaminar epidural steroid injections were not cost effective. There were no studies evaluating the cost effectiveness of cervical interlaminar epidural injections.

\subsubsection{Safety and Complications}

The common complications of lumbar interlaminar epidural injections are related to either the needle placement or the drug administration as described for caudal epidural injections $(7,24,111,405,407,665,753,7$ $67,785,786,788-794,801-811,822-852)$.

In the cervical spine, additional or specific complications include spinal cord trauma, spinal cord or epidural hematoma formation, subarachnoid or subdural injections, intravascular injection, vascular injury, or vascular embolism (827-846).

Table 17. Results of published studies of effectiveness of cervical interlaminar epidural steroid injections.

\begin{tabular}{|c|c|c|c|c|c|c|c|c|}
\hline \multirow[b]{2}{*}{ Study } & \multirow[b]{2}{*}{$\begin{array}{c}\text { Study } \\
\text { Characteristics }\end{array}$} & \multirow[b]{2}{*}{$\begin{array}{l}\text { Methodological } \\
\text { Quality Scoring }\end{array}$} & \multirow[b]{2}{*}{ Participants } & \multicolumn{3}{|c|}{ Pain Relief } & \multicolumn{2}{|c|}{ Results } \\
\hline & & & & 3 mos. & $6 \mathrm{mos}$. & 12 mos. & $\begin{array}{c}\text { Short-term } \\
\text { relief } \leq 6 \\
\text { months }\end{array}$ & $\begin{array}{c}\text { Long-term } \\
\text { relief }>6 \\
\text { months }\end{array}$ \\
\hline $\begin{array}{l}\text { Castagnera } \\
\text { et al } 1994 \\
(820)\end{array}$ & RA & 55 & $\begin{array}{l}\text { Local anesthetic with } \\
\text { steroids }=14 \\
\text { Local anesthetic with } \\
\text { steroids and morphine } \\
\quad=10\end{array}$ & $79 \%$ & $79 \%$ & $79 \%$ & $P$ & $\mathrm{P}$ \\
\hline $\begin{array}{l}\text { Stav et al } \\
1993(819)\end{array}$ & RA & 50 & $\begin{array}{l}\mathrm{C}=17 \\
\mathrm{~T}=25\end{array}$ & $\begin{array}{c}12 \% \text { vs } \\
68 \%\end{array}$ & $\begin{array}{c}12 \% \text { vs } \\
68 \%\end{array}$ & $\begin{array}{c}12 \% \text { vs } \\
68 \%\end{array}$ & $\mathrm{P}$ & $\mathrm{P}$ \\
\hline $\begin{array}{l}\text { Pasqualucci } \\
\text { et al } 2007 \\
(821)\end{array}$ & RA & 56 & $\begin{array}{c}\text { Single }=20 \\
\text { Continuous }=20 \\
\text { Over } 180 \text { days }\end{array}$ & NA & $\begin{array}{c}58 \% \text { vs } \\
74 \%\end{array}$ & NA & $\mathrm{P}$ & NA \\
\hline
\end{tabular}

$\mathrm{RA}=$ randomized $\mathrm{C}=$ control $\mathrm{T}=$ treatment vs = versus $\mathrm{P}=$ positive $\mathrm{N}=$ negative $\mathrm{NA}=$ not available

Adapted from Benyamin RM et al. Systematic review of the effectiveness of cervical epidurals in the management of chronic neck pain. Pain Physician 2009; 12:137-157 (36). 


\subsubsection{Indications}

Indications include disc herniation, radiculopathy, and spinal stenosis. Caudal epidural injection is the preferred mode of delivery for post lumbar surgery syndrome.

\subsubsection{Level of Evidence}

The evidence based on USPSTF critera (126) is Levle II-2. The indicated evidence for cervical interlaminar epidural steroid injections is Level II-1.

The indicated level of evidence for blind lumbar interlaminar epidural injections for short-term relief in managing chronic low back and lower extremity pain secondary to lumbar disc herniation and/or radiculitis is Level II-2. The evidence is Level III for blind lumbar interlaminar epidural injections in managing low back pain of spinal stenosis and chronic low back pain of discogenic origin without disc herniation or radiculitis.

\subsubsection{Recommendations}

Based on Guyatt et al's criteria (136), the recommendation for cervical interlaminar epidurals is $1 \mathrm{C} /$ strong.

The recommendation for disc herniation and radiculitis for blind lumbar interlaminar epidural injections is $1 C$, a strong recommendation which may change when higher quality evidence becomes available for short-term relief. However, for long-term relief, the recommendation is $2 B$, with weak recommendation, with best action differing depending on circumstances or patients' or societal values. For spinal stenosis and discogenic pain without disc herniation and radiculitis, the recommendation is $2 \mathrm{C} / v e r y$ weak.

\subsubsection{Lumbar Transforaminal Epidural Injections}

\subsubsection{Evidence Assessment}

Two systematic reviews $(24,111)$ showed the evidence of lumbar transforaminal epidural steroid injections for lumbar nerve root pain was strong for shortterm and moderate for long-term improvement. The evidence is limited for lumbar radicular pain in post surgery syndrome. DePalma et al (853) performed a critical appraisal of the evidence for selective nerve root injection in the treatment of lumbosacral radiculopathy.

The recent systematic review by Buenaventura et al (37) indicated the evidence is Level II-1 for shortterm relief and Level II-2 for long-term relief in managing chronic low back and lower extremity pain. They evaluated methodologic quality assessment, relief of longer than 6 months as long-term relief, and appropriate outcomes. Thus, this systematic review met all the criteria for inclusion in the guideline synthesis.

Jeong et al (854) compared transforaminal epidural injections to themselves and only altered the level (preganglionic vs. ganglionic) injected. The drugs injected were triamcinolone and bupivacaine. At the short-term the pre-ganglionic injection group did better than the ganglionic group. At long-term follow-up there was no statistically significant difference between the groups but a majority of the patients in both groups rated their outcomes as good to excellent ( $79 \%$ at short-term and $63.9 \%$ at long-term).

Karppinen et al (855) evaluated transforaminal epidural steroid injections in patients with sciatica. Eighty patients received transforaminal epidural injections of methylprednisolone and bupivacaine and another 80 received saline injections via a transforaminal injection. Pain and Oswestry scores were recorded. Both groups showed improvement with the steroid group doing better than the saline at 2 weeks and the saline group doing better at the 3 and 6 month points. Interestingly, the steroid and local anesthetic infiltration seemed to be associated with a rebound phenomenon at 3 and 6 months. This was manifested by little or no improvement in pain and disability between 3 and 6 months but then equal pain and disability scores at 12 months. Karppinen et al (856) in their subgroup analysis of the randomized trial (855) showed significantly positive results for contained herniations at one-year.

Riew et al $(857,858)$ evaluated whether selective nerve root injections might help patients with lumbar radicular pain to avoid spine surgery. Fifty-five patients who were deemed surgical candidates were treated and randomized to receive either a selective nerve root injection of betamethasone $6 \mathrm{mg}$ with bupivacaine or a selective nerve root injection of bupivacaine alone. The patients were allowed up to 4 injections of the same study medicine during the evaluation. The patients were followed for between 13 and 28 months. There was no set follow-up evaluation at a short- or long-term point. At the end of the period, 18 of the 27 patients receiving only bupivacaine had chosen to undergo surgery. Of the 28 patients receiving the combination of betamethasone and bupivacaine, only 8 had undergone surgery. The difference was highly significant. In the follow-up study, Riew et al (857) showed positive long-term results with or without steroids. 
Vad et al (859) studied the effect of transforaminal epidural betamethasone $9 \mathrm{mg}$ and lidocaine and compared it to a lumbar paraspinal muscle trigger point injection of saline. Forty-eight patients were included. Outcomes included pain score, patient satisfaction, and other measures of function. The patients were followed for an average of 1.4 years but no set shortor long-term follow-up evaluations were scheduled. Patients improved in both groups but the transforaminal group did significantly better with a much lower pain score at the end and a larger percentage of patients ( $84 \%$ vs. $48 \%$ ) achieving a successful outcome in a shorter period of time than the trigger point group (6 weeks vs. 12 weeks).

\subsubsection{Cost Effectiveness}

In the management of chronic low back pain, cost per one-year improvement of QOL was \$2,927 per year with transforaminal epidural steroid injections (783). Furthermore, in patients treated with transforaminal steroids, operations were avoided for contained herniations, costing $\$ 12,666$ less per responder in the steroid group (854). Cost effectiveness was also demonstrated by others by avoiding surgical intervention $(857,858)$.

\subsubsection{Safety and Complications}

The most common and worrisome complications of transforaminal epidural steroid injections in the lumbar spine are related to neural trauma, vascular trauma, intravascular injection, and infection $(7,24$, $111,405,407,665,767,788-794,798,801-811,822,853-$ $856,860-871)$. Complications including spinal cord injury and infarction $(847,860)$, and paraplegia (864), have been reported. Side effects related to the administration of steroids are generally attributed either to the chemistry or to the pharmacology of steroids $(24,111,665,753,767,798-800,868-871)$.

\subsubsection{Indications}

The indications for therapeutic lumbar transforaminal epidural injections include chronic low back and/or lower extremity pain resulting from herniated discs and radiculopathy, spinal stenosis, and failed back surgery syndrome (FBSS).

\subsubsection{Level of Evidence}

Table 18 illustrates the results of randomized trials of the effectiveness of lumbar transforaminal epidural injections. evidence for lumbar transforaminal epidural steroid injections is Level II-1 for short-term relief and Level II-2 for long-term relief in managing chronic low back and lower extremity pain based on the USPSTF criteria (126).

\subsubsection{Recommendations}

Based on the criteria by Guyatt et al (136), the recommendation for lumbar transforaminal epidural injections, in managing chronic low back and lower extremity pain, is $1 \mathrm{C} /$ strong recommendation.

\subsection{Lumbar Epidural Adhesiolysis}

The purpose of percutaneous epidural lysis of adhesions is to minimize the deleterious effects of epidural scarring, which can physically prevent direct application of drugs to nerves and other spinal tissues and to treat chronic back pain (872-875). Epidural lysis of adhesions and direct deposition of corticosteroids in the spinal canal can also be achieved with a 3-dimensional view provided by epiduroscopy or spinal endoscopy.

\subsubsection{Percutaneous Adhesiolysis}

\subsubsection{Evidence Assessment}

Clinical effectiveness of percutaneous adhesiolysis was evaluated in 3 systematic reviews $(43,46,113)$, and one health technology assessment (872). Epter et al (43) concluded that the indicated level of evidence is I or II-1 for short- and long-term relief for percutaneous adhesiolysis in post lumbar surgery syndrome.

Three randomized trials (876-878) and 4 observational studies (879-882) met inclusion criteria for percutaneous adhesiolysis.

Of the 3 randomized trials (876-878), 2 studies had similar patient characteristics $(877,878)$. Manchikanti et al (878) reported that patients in all 3 studies failed multiple conservative modalities of treatments including fluoroscopically directed epidural steroid injections. They (878) also reported the proportion of patients included with a history of previous surgery ranged from $64 \%$ to $72 \%$ in all intervention groups.

Heavner et al (877) compared various types of solutions used after mechanical adhesiolysis; Group A received a combination of hyaluronidase and hypertonic saline; Group B, hypertonic saline solution; Group C, isotonic saline solution; and Group $D$, hyaluronidase and isotonic saline solution. Heavner et al (877) evaluated a 3-day procedure where the catheter was inserted on the first day and the drugs were injected on the second and third day, whereas Manchikanti et al 
$(878,882)$ evaluated one-day adhesiolysis. Veihelmann et al (876) and Gerdesmeyer et al (879) used a 3-day protocol in both studies. They also used hyaluronidase as part of the treatment protocol. The outcome parameters by Heavner et al (877) included the short-form MPQ and VAS for back pain and leg pain. Manchikanti et al (878) utilized VAS pain scale, ODI 2.0, work status, opioid intake, range of motion measurement, and psychological evaluation by Pain Patient Profile (P-3). Veihelmann et al (876) used VAS scores for back pain and leg pain, ODI score, Gerbershagen score, and a quantified score for the use of analgesics. They also used a blinded observer.

Manchikanti et al (878) divided 75 patients randomly into 3 groups, with Group I consisting of a control group without adhesiolysis, with injection of local anesthetic, steroid, and normal saline; Group II consisting of patients undergoing adhesiolysis, with injection of local anesthetic, steroid, and normal saline; and Group III consisting of patients undergoing adhesiolysis, with an injection of $10 \%$ sodium chloride solution, in addition to local anesthetic and steroid.

The descriptive characteristics of observational studies are well described in the systematic review by Epter et al (43).

\subsubsection{Cost Effectiveness}

Cost effectiveness of percutaneous adhesiolysis for 1-year of improvement in the QOL varied from $\$ 2,028$ to $\$ 5,564$ (880-882).

\subsubsection{Safety and Complications}

The most commonly reported complications of percutaneous adhesiolysis were dural puncture, catheter shearing, and infection $(7,46,113,874,876-886)$. Other potential complications include intravascular injection; vascular injury; cerebral vascular or pulmonary embolus; reaction to the steroids; hypertonic saline, or hyaluronidase, and administration of high volumes of fluids potentially resulting in excessive epidural hydrostatic pressures; death; and brain damage $(7,46,113,874,885-888)$.

\subsubsection{Indications}

Indications for lysis of epidural adhesions are chronic low back and/or lower extremity pain resulting from post surgery syndrome, epidural fibrosis, and spinal stenosis.

\subsubsection{Level of Evidence}

Table 19 illustrates the results of published studies of effectiveness of percutaneous adhesiolysis.

The effectiveness of percutaneous adhesiolysis in the management of chronic low back pain in post lumbar surgery syndrome indicated Level I to II-1 evidence based on the USPSTF criteria (126).

Table 18. Results of randomized trials of effectiveness of lumbar transforaminal epidural injections.

\begin{tabular}{|c|c|c|c|c|c|c|c|c|}
\hline \multirow[b]{2}{*}{ Study } & \multirow[b]{2}{*}{$\begin{array}{c}\text { Study } \\
\text { Characteristics }\end{array}$} & \multirow[b]{2}{*}{$\begin{array}{l}\text { Methodological } \\
\text { Quality Scoring }\end{array}$} & \multirow[b]{2}{*}{ Participants } & \multicolumn{3}{|c|}{ Pain Relief } & \multicolumn{2}{|c|}{ Results } \\
\hline & & & & 3 mos. & 6 mos. & 12 mos. & $\begin{array}{c}\text { Short- } \\
\text { term } \\
\text { relief } \leq 6 \\
\text { mos. }\end{array}$ & $\begin{array}{c}\text { Long- } \\
\text { term } \\
\text { relief }>6 \\
\text { mos. }\end{array}$ \\
\hline $\begin{array}{l}\text { Karppinen et } \\
\text { al 2001/2001 } \\
(855,856)\end{array}$ & RA, DB & 81 & $\begin{array}{l}\mathrm{C}=80 \\
\mathrm{~T}=80\end{array}$ & $\mathrm{SICH}$ & NSI & NSI & $\mathrm{P}$ & $\mathrm{N}$ \\
\hline $\begin{array}{l}\text { Riew et al 2000/ } \\
2006(857,858)\end{array}$ & $\mathrm{P}, \mathrm{RA}, \mathrm{DB}$ & 68 & 55 & NA & NA & $\begin{array}{l}33 \% \text { vs. } 71 \% \\
\text { (avoided } \\
\text { surgery) }\end{array}$ & $\mathrm{P}$ & $\mathrm{P}$ \\
\hline $\begin{array}{l}\text { Jeong et al } 2007 \\
(854)\end{array}$ & RA, DB & 63 & 239 & $\begin{array}{l}\text { PG } 99 \text { of } 112 \\
\text { G } 90 \text { of } 127\end{array}$ & $\begin{array}{l}\text { PG } 64 \text { of } 106 \\
\text { G } 78 \text { of } 116\end{array}$ & NA & $\mathrm{P}$ & NA \\
\hline $\begin{array}{l}\text { Vad et al } 2002 \\
(859)\end{array}$ & RA & 58 & 48 & NA & NA & $48 \%$ vs. $84 \%$ & $\mathrm{P}$ & $\mathrm{P}$ \\
\hline
\end{tabular}

$\mathrm{RA}=$ randomized; $\mathrm{DB}=$ double blind $\mathrm{P}=$ prospective $\mathrm{C}=$ control $\mathrm{T}$ = treatment $\mathrm{PG}=$ pre-ganglionic $\mathrm{G}=$ ganglionic $; \mathrm{SICH}=$ significant improvement in contained disc herniation; NSI = no significant improvement; vs. = versus; $\mathrm{NA}=$ not available; $\mathrm{P}=$ positive; $\mathrm{N}=$ negative.

Adapted from Buenaventura RM et al. Systematic review of therapeutic lumbar transforaminal epidural steroid injections. Pain Physician 2009; 12:233-251 (37). 
Evidence-Based Guidelines for Spinal Interventional Techniques

Table 19. Results of published studies effectiveness of percutaneous lysis of lumbar epidural adhesions.

\begin{tabular}{|c|c|c|c|c|c|c|c|c|}
\hline \multirow[b]{2}{*}{ Study } & \multirow[b]{2}{*}{$\begin{array}{c}\text { Study } \\
\text { Characteristics }\end{array}$} & \multirow[b]{2}{*}{ Participants } & \multicolumn{4}{|c|}{ Pain Relief } & \multicolumn{2}{|c|}{ Results } \\
\hline & & & $\leq \mathbf{3}$ mos. & 3 mos. & 6 mos. & 12 mos. & $\begin{array}{l}\text { Short- } \\
\text { term } \leq \\
6 \text { mos. }\end{array}$ & $\begin{array}{c}\text { Long- } \\
\text { term }>6 \\
\text { mos. }\end{array}$ \\
\hline $\begin{array}{l}\text { Manchikanti et al } 2004 \\
\text { (878) }\end{array}$ & RA, DB & $\begin{aligned} \mathrm{G} 1 & =25 \\
\mathrm{G} 2 & =25 \\
\mathrm{G} 3 & =25\end{aligned}$ & $\begin{array}{l}\mathrm{G} 1=33 \% \\
\mathrm{G} 2=64 \% \\
\mathrm{G} 2=72 \%\end{array}$ & $\begin{aligned} \mathrm{G} 1 & =0 \% \\
\mathrm{G} 2 & =64 \% \\
\mathrm{G} 3 & =72 \%\end{aligned}$ & $\begin{aligned} \mathrm{G} 1 & =0 \% \\
\mathrm{G} 2 & =60 \% \\
\mathrm{G} 3 & =72 \%\end{aligned}$ & $\begin{aligned} \mathrm{G} 1 & =0 \% \\
\mathrm{G} 2 & =60 \% \\
\mathrm{G} 3 & =72 \%\end{aligned}$ & $\mathrm{P}$ & $\mathrm{P}$ \\
\hline Heavner et al 1999 (877) & RA, DB & 59 & $83 \%$ & $49 \%$ & $43 \%$ & $49 \%$ & $\mathrm{P}$ & $\mathrm{P}$ \\
\hline $\begin{array}{l}\text { Veihelmann et al } 2006 \\
(876)\end{array}$ & RA & 99 & SI & SI & SI & SI & $\mathrm{P}$ & $\mathrm{P}$ \\
\hline $\begin{array}{l}\text { Manchikanti et al } 2001 \\
(882)\end{array}$ & $\mathrm{O}$ & $\begin{aligned} \mathrm{G} 1 & =15 \\
\mathrm{G} 2 & =30\end{aligned}$ & & $97 \%$ & $93 \%$ & $47 \%$ & $\mathrm{P}$ & $\mathrm{P}$ \\
\hline $\begin{array}{l}\text { Manchikanti et al } 1999 \\
(881)\end{array}$ & $\mathrm{O}$ & 60 & $100 \%$ & $90 \%$ & $72 \%$ & $52 \%$ & $P$ & $\mathrm{P}$ \\
\hline $\begin{array}{l}\text { Manchikanti et al } 1999 \\
(880)\end{array}$ & $\mathrm{O}$ & 129 & $79 \%$ & $68 \%$ & $36 \%$ & $13 \%$ & $\mathrm{P}$ & $\mathrm{N}$ \\
\hline $\begin{array}{l}\text { Gerdesmeyer et al } 2005 \\
\text { (879) }\end{array}$ & $\mathrm{O}$ & 61 & SI & SI & SI & SI & P & $\mathrm{P}$ \\
\hline
\end{tabular}

$\mathrm{RA}=$ randomized; $\mathrm{DB}$ = double blind; $\mathrm{O}=$ observational; $\mathrm{G}$ = group; $\mathrm{SI}$ = significant improvement $\mathrm{P}$ = positive; $\mathrm{N}=$ negative

Adapted from Epter RS et al. Systematic review of percutaneous adhesiolysis and management of chronic low back pain in post lumbar surgery syndrome. Pain Physician 2009; 12:361-378 (43).

\subsubsection{Recommendations}

The recommendation is strong, with $1 \mathrm{~B}$ or $1 \mathrm{C}$ for percutaneous adhesiolysis in post lumbar surgery syndrome.

\subsubsection{Spinal Endoscopic Adhesiolysis}

\subsubsection{Evidence Assessment}

Spinal endoscopic adhesiolysis was evaluated in 3 systematic reviews $(46,47,113)$, and one health technology assessment (872). Hayek et al (47) concluded that spinal endoscopic adhesiolysis may be used as an effective treatment modality for chronic refractory low back pain and lower extremity pain of post lumbar surgery syndrome.

There was only one randomized trial (889) and 5 observational studies $(881,890-893)$ that met inclusion criteria.

Manchikanti et al (889) evaluated the effectiveness of spinal endoscopic adhesiolysis in chronic refractory low back and lower extremity pain in an RCT. A total of 83 patients were evaluated, with 33 patients in Group I and 50 patients in Group II. Group I served as an active control, with endoscopy into the sacral level without adhesiolysis, followed by injection of local anesthetic and steroid. In contrast, Group II received spinal endoscopic adhesiolysis, followed by an injection of local anesthetic and steroid. Among the 50 patients in the treatment group receiving spinal endoscopic adhesiolysis, significant improvement without adverse effects were shown in $80 \%$ at 2 months, $56 \%$ at 6 months, and $48 \%$ at 12 months. The control group showed improvement in $33 \%$ of patients at one-month and none thereafter.

Based on the definition that less than 6 months of relief is considered short-term and longer than 6 months of relief is considered long-term, a significant number of patients obtained long-term relief with improvement in pain, functional status, and psychological status. In this study, the authors performed an intention-to-treat analysis. Outcome assessments included VAS, ODI 2.0, work status, opioid intake, range of motion, and psychological evaluation.

Table 20 illustrates the description of observational studies included in the evidence synthesis for spinal endoscopic adhesiolysis. 
Pain Physician: July/August 2009:12: 699-802

Table 20. Summary description of observational studies for spinal endoscopic adhesiolysis.

\begin{tabular}{|c|c|c|c|c|c|c|}
\hline $\begin{array}{l}\text { Study I } \\
\text { Methods }\end{array}$ & Participants & Intervention & Outcome & Results & $\begin{array}{c}\text { Conclusion(s) } \\
\text { Short-term } \leq 6 \\
\text { mos. } \\
\text { Long-term }>6 \\
\text { mos. } \\
\end{array}$ & Complications \\
\hline $\begin{array}{l}\text { Manchikanti } \\
\text { et al } 1999 \\
(881)\end{array}$ & $\begin{array}{l}60 \text { FBSS patients } \\
\text { - excluded facet } \\
\text { and SI joint pain }\end{array}$ & $\begin{array}{l}\text { Epiduroscope to } \\
\text { level of pathology, } \\
\text { adhesiolysis, } 10 \\
\text { mL } 1 \% \text { lidocaine + } \\
\text { steroid injection }\end{array}$ & $\begin{array}{l}\text { Pain relief: } \\
\text { 1) none } \\
\text { 2) }<50 \% \\
\text { 3) } 50 \% \\
\text { (successful) } \\
\text { Duration: }<1 \\
\text { month, } 1,2,3,6 \text {, } \\
\text { and } 12 \text { months }\end{array}$ & $\begin{array}{l}\text { Initial success (> } \\
50 \% \text { relief) in } 100 \% \\
\text { of patients declining } \\
\text { to } 80 \% \text { at } 3 \text { months, } \\
52 \% \text { at } 6 \text { months, and } \\
22 \% \text { at one year }\end{array}$ & $\begin{array}{l}\text { Safe and possibly } \\
\text { cost effective } \\
\text { procedure in pa- } \\
\text { tients with FBSS } \\
\text { (long-term) }\end{array}$ & $\begin{array}{l}\text { Dural puncture in } 7 \\
\text { procedures. } \\
\text { "Suspected" infec- } \\
\text { tion in } 8 \text { patients } \\
\text { who were given } \\
\text { antibiotics but no } \\
\text { "obvious" infection } \\
\text { was noted }\end{array}$ \\
\hline $\begin{array}{l}\text { Manchikanti } \\
\text { et al } 2000 \\
(893)\end{array}$ & $\begin{array}{l}85 \text { consecutive } \\
\text { patients ( } 86 \% \\
\text { with FBSS) } \\
\text { underwent } \\
112 \text { epiduros- } \\
\text { copic adhesiolysis } \\
\text { procedures (27 } \\
\text { patients had a } \\
\text { second proce- } \\
\text { dure). Follow up } \\
\text { for } 1-2 \text { years }\end{array}$ & $\begin{array}{l}\text { Epiduroscopic } \\
\text { adhesiolysis and } \\
\text { application of } 10 \mathrm{~mL} \\
1 \% \text { lidocaine }+6 \mathrm{mg} \\
\text { betamethasone }\end{array}$ & $\begin{array}{l}\text { Pain relief: } \\
\text { 1) none } \\
\text { 2) }<50 \% \\
\text { 3) }>50 \% \\
\text { (significant) } \\
\text { Duration: }<1 \\
\text { month, } 1,2,3,6 \text {, } \\
\text { and } 12 \text { months }\end{array}$ & $\begin{array}{l}\text { Significant (> } 50 \%) \\
\text { relief for a mean of } 19 \\
\pm 1.79 \text { weeks. After } \\
\text { one procedure, initial } \\
\text { relief in } 100 \% \text { of } \\
\text { patients, declined to } \\
94 \% \text { at } 1-2 \text { months, } \\
77 \% \text { at } 2-3 \text { months, } \\
52 \% \text { at } 3-6 \text { months, } \\
21 \% \text { at } 6-12 \text { months, } \\
\text { and } 7 \% \text { after one year }\end{array}$ & $\begin{array}{l}\text { Relatively safe } \\
\text { and possibly cost } \\
\text { effective proce- } \\
\text { dure in patients } \\
\text { who have failed } \\
\text { other modali- } \\
\text { ties of treatment } \\
\text { (long-term) }\end{array}$ & $\begin{array}{l}\text { Dural puncture in } 8 \\
\text { patients. Subarach- } \\
\text { noid block in } 4 \text { pa- } \\
\text { tients. } 2 \text { documented } \\
\text { infections (one } \\
\text { requiring skin graft- } \\
\text { ing and prolonged } \\
\text { antibiotics) and } \\
6 \text { "SUSPECTED" } \\
\text { infections. }\end{array}$ \\
\hline $\begin{array}{l}\text { Richardson } \\
\text { et al } 2001 \\
(892)\end{array}$ & $\begin{array}{l}38 \text { patients with } \\
\text { lumbar radicular } \\
\text { pain who failed } \\
\text { analgesics, TENS, } \\
\text { and epidural } \\
\text { injections were } \\
\text { recruited; } 19 \text { had } \\
\text { FBSS. Procedure. } \\
\text { Aborted in } 4 \\
\text { patients }\end{array}$ & $\begin{array}{l}34 \text { patients under- } \\
\text { went mechanical } \\
\text { adhesiolysis }+5 \mathrm{~mL} \\
\text { bupivacaine } 0.25 \%+ \\
80 \mathrm{mg} \text { methyl-pred- } \\
\text { nisolone }+100 \mathrm{mcg} \\
\text { clonidine. }\end{array}$ & $\begin{array}{l}\text { VAS + func- } \\
\text { tional activity } \\
\text { score at } 2,6 \text {, and } \\
12 \text { months post } \\
\text { procedure }\end{array}$ & $\begin{array}{l}\text { Preoperative VAS } 8.2 \\
\rightarrow 5.6,6.8 \text {, and } 6.7 \text { at } \\
2,6 \text {, and } 12 \text { months } \\
\text { respectively. A } \\
\text { similarly significant } \\
\text { functional improve- } \\
\text { ment was noted }\end{array}$ & $\begin{array}{l}\text { Epiduroscopic } \\
\text { adhesiolysis } \\
\text { achieved moder- } \\
\text { ate but sustained } \\
\text { reduction in } \\
\text { chronic lumbar } \\
\text { radicular pain as } \\
\text { well as improve- } \\
\text { ment in func- } \\
\text { tional status } \\
\end{array}$ & $\begin{array}{l}\text { Transient low back } \\
\text { pain in some and } \\
\text { transient lower } \\
\text { limb paresthesiae } \\
\text { in } 2 \text { patients. None } \\
\text { required hospital } \\
\text { admission. }\end{array}$ \\
\hline $\begin{array}{l}\text { Geurts et al } \\
2002(891)\end{array}$ & $\begin{array}{l}24 \text { patients were } \\
\text { recruited: radicu- } \\
\text { lar pain below } \\
\text { knee }+ \text { evidence } \\
\text { of radiculopathy } \\
\text { by exam; leg pain } \\
\text { > back pain } \\
2 \text { patients unable } \\
\text { to enter caudal } \\
\text { space (excluded); } \\
14 \text { of the remain- } \\
\text { ing } 22 \text { were FBSS } \\
\text { patients }\end{array}$ & $\begin{array}{l}\text { Mechanical } \\
\text { adhesiolysis + } 120 \\
\text { mg methyl-pred- } \\
\text { nisolone + } 600 \mathrm{IU} \\
\text { hyaluronidase + } 150 \\
\text { mcg clonidine. } \\
2 \text { patients had no } \\
\text { injection and were } \\
\text { excluded: one with } \\
\text { no adhesions and } \\
\text { another because of } \\
\text { dural puncture }\end{array}$ & $\begin{array}{l}\text { Median VAS } \\
\text { score from } 12 \\
\text { recordings over } \\
\text { a } 4 \text { day period } \\
\text { one week before } \\
\text { intervention } \\
\text { and assessment } \\
\text { at } 3,6,9 \text { and } 12 \\
\text { months. Global } \\
\text { subjective } \\
\text { efficacy rating } \\
\text { (GSER) at } 12 \\
\text { months. }\end{array}$ & $\begin{array}{l}19 / 20 \text { patients } \\
\text { showed adhesions } \\
\text { by epiduroscopy vs. } \\
11 / 20 \text { by MRI } \\
\text { Significant pain } \\
\text { relief at } 3,6,9 \text {, and } \\
12 \text { months occurred } \\
\text { in } 55 \%, 40 \%, 35 \% \\
\text { and } 35 \% \text { of patients } \\
\text { respectively Similar } \\
\text { findings by GSER at } \\
12 \text { months }\end{array}$ & $\begin{array}{l}\text { Epiduroscopy is } \\
\text { useful in diagnos- } \\
\text { ing spinal root } \\
\text { pathology and } \\
\text { targeted applica- } \\
\text { tion of epidu- } \\
\text { ral medications } \\
\text { can result in } \\
\text { substantial and } \\
\text { prolonged pain } \\
\text { relief }\end{array}$ & $\begin{array}{l}\text { One accidental dural } \\
\text { puncture noted; pro- } \\
\text { cedure aborted and } \\
\text { patient was excluded } \\
\text { from analysis. How- } \\
\text { ever, } 3 \text { patients had } \\
\text { post-dural puncture } \\
\text { headache and } 2 \\
\text { required epidural } \\
\text { blood patches. } \\
\text { Transient intra-op- } \\
\text { erative discomfort in } \\
\text { some patients. }\end{array}$ \\
\hline $\begin{array}{l}\text { Avellanal and } \\
\text { Diaz- } \\
\text { Reganon } \\
2008(890)\end{array}$ & $\begin{array}{l}19 \text { patients with h/ } \\
\text { o FBSS and severe } \\
\text { sciatica (VAS } \geq 7 \text { ) } \\
\text { who have failed } \\
\text { multiple treatment } \\
\text { modalities includ- } \\
\text { ing adhesiolysis } \\
\text { with a Racz cath- } \\
\text { eter. All patients } \\
\text { had X-rays, MRI, } \\
\text { and EMG within } \\
2 \text { months of } \\
\text { enrollment }\end{array}$ & $\begin{array}{l}\text { Interlaminar epidur- } \\
\text { oscopic adhesiolysis } \\
\text { at L5/S1 and oc- } \\
\text { casionally at L4/L5 } \\
\text { or L3/L4. } \\
6 \mathrm{~mL} \text { mixture of tri- } \\
\text { amcinolone, } 40 \mathrm{mg} \text {, } \\
\text { hyaluronidase } 600 \\
\text { IU, and bupivacaine } \\
0.0625 \% \text { was } \\
\text { injected }\end{array}$ & $\begin{array}{l}\text { VAS at } 1,2,3 \text {, } \\
\text { and } 6 \text { months. }\end{array}$ & $\begin{array}{l}\text { Compared to VAS at } \\
\text { baseline, there was } \\
\text { significant reduc- } \\
\text { tion in pain at } 1,2 \text {, } \\
3 \text {, and } 6 \text { months. } \\
\text { Six patients had no } \\
\text { improvement at } 3 \\
\text { months or later, } 7 \\
\text { experienced mild } \\
\text { improvement, and } 6 \\
\text { improved markedly } \\
(>3 \text { points on the } \\
\text { VAS) }\end{array}$ & $\begin{array}{l}\text { A } 50 \% \text { smaller } \\
\text { diameter } \\
\text { endoscope is ef- } \\
\text { fective in pain } \\
\text { relief through } \\
\text { adhesiolysis in } \\
\text { patients with } \\
\text { FBSS }\end{array}$ & $\begin{array}{l}4 \text { dural punctures } \\
(21 \%) \text {, one neces- } \\
\text { sitating admission } \\
\text { to the hospital for } \\
5 \text { days; transient } \\
\text { headache and hypo- } \\
\text { tension during the } \\
\text { procedure lasting } \\
<30 \text { sec; some low } \\
\text { back and leg pain re- } \\
\text { lieved spontaneously } \\
\text { within } 2 \text { days }\end{array}$ \\
\hline
\end{tabular}

Adapted from Hayek SM et al. Effectiveness of spinal endoscopic adhesiolysis in post lumbar surgery syndrome: A systematic review. Pain Physician 2009; 12:419-435 (47). 


\subsubsection{Cost Effectiveness}

The cost effectiveness of spinal endoscopy in patients failing to respond to all conservative modalities of treatments including percutaneous adhesiolysis with a spring-guided catheter, was shown to be $\$ 7,020$ to $\$ 8,127(881,893)$.

\subsubsection{Safety and Complications}

Common complications reported following spinal endoscopic adhesiolysis include pain at the site of the procedure/low back pain, dural puncture headache and cerebrospinal fluid leak, infection, paresthesiae, and transient subarachnoid block. However, despite characterization of spinal endoscopic adhesiolysis as a generally safe procedure several case reports describe serious potential complications $(881,888-898)$. Severe visual impairment following epiduroscopy has been reported (888).

\subsubsection{Indications}

Endoscopic epidural adhesiolysis is indicated for patients whose chronic low back and lower extremity pain secondary to postlumbar laminectomy syndrome and epidural adhesiolysis resulting in chronic, intractable pain, nonresponsive or poorly responsive, to other modalities of treatment $(889,894)$.

\subsubsection{Level of Evidence}

The indicated level of evidence is II-1 or II-2 for short- and long-term relief for endoscopic adhesiolysis in post lumbar laminectomy syndrome, based on one randomized trial. (Table 21 ).

\subsubsection{Recommendations}

Based on Guyatt et al's grading strength of recommendations and quality of evidence in clinical guidelines, the recommendation is $1 \mathrm{C} /$ strong for endoscopic adhesiolysis in post lumbar laminectomy syndrome.

\subsection{Sacroiliac Joint Interventions}

Sacroiliac joint pain may be managed by intraarticular injections or neurolysis of the sacroiliac joint $(27,45,116)$. Three systematic reviews have been conducted to evaluate the effectiveness of sacroiliac joint interventions $(27,45,116)$. All of them illustrated either lack of evidence or limited evidence for both intraarticular sacroiliac joint injections and radiofrequency neurotomy of the nerve supply of the sacroiliac joint. Rupert et al (45) evaluated the role of intraarticular injections and radiofrequency neurotomy with inclusion criteria of diagnosis of sacroiliac joint pain by controlled diagnostic blocks and outcome parameters of 6 months or longer. There was limited evidence (Level II-3) for radiofrequency neurotomy.

\subsubsection{Intraarticular Sacroiliac Joint Injections}

\subsubsection{Evidence Assessment}

Despite the availability of 17 publications with 4 randomized trials and 14 observational reports as shown by Rupert et al (45), there were no studies meeting inclusion criteria.

While 2 previous systematic reviews $(27,116)$ showed limited evidence for intraarticular injections, utilizing more stringent criteria, Rupert et al (45) reported a lack of studies meeting the inclusion criteria.

\subsubsection{Safety and Complications}

Potential complications include infection, hematoma formation, neural damage, trauma to the sciatic nerve, gas and vascular particulate embolism, leakage of the drug from the joint, complications related to drug administration, and radiation exposure $(7,27,116,404,572,665,817)$.

Side effects related to the administration of steroids are generally attributed to the chemistry or to the pharmacology of the steroids (665).

\subsubsection{Indications}

Common indications for sacroiliac joint injections are the same as for diagnostict sacroiliac joint. In addition, the joint should have been positive utilizing controlled diagnostic blocks with $80 \%$ relief.

\subsubsection{Level of Evidence}

Based on the available literature, evidence is unavailable for intraarticular sacroiliac joint injections for therapeutic purposes.

\subsubsection{Recommendations}

Based on the available literature and evidence no recommendation is provided.

\subsubsection{Radiofrequency Neurotomy}

\subsubsection{Evidence Assessment}

The effectiveness of radiofrequency neurotomy was evaluated in 3 systematic reviews. Two systematic reviews $(27,116)$ showed limited evidence for radio- 
Pain Physician: July/August 2009:12: 699-802

Table 21. Summary results of eligible studies of endoscopic adhesiolysis included in this systematic review.

\begin{tabular}{|c|c|c|c|c|c|c|c|}
\hline \multirow{2}{*}{ Study } & \multirow{2}{*}{$\begin{array}{c}\text { Study } \\
\text { Characteristics }\end{array}$} & \multirow{2}{*}{$\begin{array}{l}\text { Methodological } \\
\text { Quality Scoring }\end{array}$} & \multirow{2}{*}{$\begin{array}{l}\text { Number of } \\
\text { Participants }\end{array}$} & \multicolumn{2}{|c|}{ Significant Pain Relief } & \multicolumn{2}{|c|}{ Results } \\
\hline & & & & $\leq 6 \mathrm{mos}$ & $>6$ mos. & $\begin{array}{l}\text { Short-term } \\
\leq 6 \text { mos. }\end{array}$ & $\begin{array}{l}\text { Long-term } \\
>6 \text { mos. }\end{array}$ \\
\hline $\begin{array}{l}\text { Manchikanti et al } \\
2005(889)\end{array}$ & RA,DB & 69 & 83 & $56 \% *$ & $48 \%{ }^{*}$ & $\mathrm{P}$ & $\mathrm{P}$ \\
\hline $\begin{array}{l}\text { Manchikanti et al } \\
1999(881)\end{array}$ & $\mathrm{O}$ & 62 & 60 & $52 \% *$ & $22 \%^{*}$ & $\mathrm{P}$ & $\mathrm{P}$ \\
\hline $\begin{array}{l}\text { Manchikanti et al } \\
2000 \text { (893) }\end{array}$ & $\mathrm{O}$ & 58 & 85 & $\begin{array}{c}21 \% * 6-12 \\
\text { mos. }\end{array}$ & $\begin{array}{c}7 \%^{*}>12 \\
\text { mos. }\end{array}$ & $\mathrm{P}$ & $\mathrm{N}$ \\
\hline \begin{tabular}{|l|}
$\begin{array}{l}\text { Richardson et al } \\
2001(892)\end{array}$ \\
\end{tabular} & $\mathrm{O}$ & 67 & 38 & Yes & Yes & $\mathrm{P}$ & $\mathrm{P}$ \\
\hline $\begin{array}{l}\text { Geurts et al } 2002 \\
(891)\end{array}$ & $\mathrm{O}$ & 77 & 24 & Yes & Yes & $\mathrm{P}$ & $\mathrm{P}$ \\
\hline $\begin{array}{l}\text { Avellanal and Diaz- } \\
\text { Reganon } 2008 \text { (890) } \\
\end{array}$ & $\mathrm{O}$ & 53 & 19 & Yes & N/A & $\mathrm{P}$ & $\mathrm{N}$ \\
\hline
\end{tabular}

${ }^{\star}$ Denotes percentage of patients with $>50 \%$ pain relief

$\mathrm{RA}=$ randomized; $\mathrm{DB}=$ double blind $\mathrm{O}=$ observational; $\mathrm{P}=$ positive $\mathrm{N}=$ negative $\mathrm{NA}=$ not applicable .

Adapted from Hayek SM et al. Effectiveness of spinal endoscopic adhesiolysis in post lumbar surgery syndrome: A systematic review. Pain Physician 2009; 12:419-435 (47)

frequency neurotomy in managing chronic sacroiliac joint pain. The recent systematic review (45) with more stringent criteria showed evidence of Level II-3 with inclusion criteria of controlled diagnostic blocks and long-term relief considered as longer than 6 months.

Three observational studies (899-901) met inclusion criteria in the systematic review by Rupert et al (45).

Vallejo et al (899) tested the hypothesis that pulsed radiofrequency of the posterior rami from $L 4$ to S3 would provide therapeutic benefit to patients with intractable sacroiliac joint dysfunction. This study consisted of 22 patients with confirmed SI joint pain were evaluated following dual diagnostic blocks with local anesthetic and corticosteroid using $\geq 75 \%$ relief as the success criterion. The follow-up period was 6 months and outcome measures included VAS scoring and a QOL assessment tool. Sixteen of the 22 were found to have good ( $\geq 50 \%$ ) to excellent $(\geq 80 \%$ ) results; however, in only 7 patients did this improvement exceed 17 weeks. This study is limited by its observational nature, and the small number of patients. In addition, only 7 of 22 patients experienced between 17 and 32 weeks worth of relief, which is similar to the duration of benefit obtained from local anesthetic blocks with or without steroids $(375,596,659,665,788,793,814)$.

Burnham and Yasui (901) evaluated 9 subjects with sacroiliac joint pain confirmed by local anesthetic joint and lateral branch nerve blocks with bipolar radiofrequency neurotomy. These subjects were treated with a series of radiofrequency strip lesions performed adjacent to the lateral dorsal foraminal aperture plus conventional monopolar lesioning at the L5 dorsal ramus. Significant reductions in back and leg pain frequency and severity, and analgesic intake were demonstrated at 3, 6, 9, and 12 months. The median improvement in pain intensity was 4.1 on a $0-10$ NRS and the reduction in disability were 17.8 on the ODI. Overall satisfaction was $67 \%$ at 12 month follow-up. Limitations include the small number of patients $(n=9)$ recruited from one practice.

Cohen and Abdi (900) performed radiofrequency lesioning on 9 patients who experienced greater than $80 \%$ pain relief following intraarticular joint injection(s) and greater than $50 \%$ relief following L4-5 primary dorsal rami and S1-3 lateral branches blocks. Eight of 9 patients (89\%) obtained $50 \%$ or greater pain relief from this procedure that persisted at their 9-month follow-up. The authors concluded that in patients with injection confirmed sacroiliac joint pain who respond to L4-L5 dorsal rami and S1-3 lateral branch blocks, radiofrequency denervation can be an effective treatment. Limitations of this study include the observational nature and small number of patients.

Among the studies failing to meet the strict criteria for this evaluation was a randomized, placebo-controlled study evaluating lateral branch radiofrequency 
denervation by Cohen et al (902). Except for dual blocks, the study meets all the criteria for randomized trials and the reporting guidelines of CONSORT (130). This study was also the first to utilize cooled probe radiofrequency technology, which can increase the lesion size by a factor of 8 . The authors randomized $28 \mathrm{pa}-$ tients from amongst 90 potential candidates with predominantly axial low back pain to receive either cooled radiofrequency denervation from L4-S3 or sham lesioning. The main inclusion criterion was $>75 \%$ pain relief lasting at least 3 hours following a single intraarticular block performed with a $3 \mathrm{~mL}$ solution containing $2 \mathrm{~mL}$ of bupivacaine and $40 \mathrm{mg}$ of depomethylprednisolone. Those patient's allocated to the placebo group who failed to obtain significant benefit were eligible to crossover to an open-label parallel group that received conventional radiofrequency denervation. Three and 6 months after the procedure, $64 \%(n=9)$ and $57 \%(n=$ 8) of patients respectively undergoing cooled radiofrequency lesioning experienced $>50 \%$ pain relief accompanied by significant functional improvement.

In contrast, none of the sham-treated patients experienced significant improvement 3 months after the procedure. In the crossover treatment group $(n=11)$, $6(55 \%)$ and $4(36 \%)$ patients experienced a positive outcome 3 and 6 months post-procedure. However, one year after treatment, only 2 patients $(14 \%)$ in the treatment group continued to demonstrate persistent pain relief. The authors concluded that these results furnished preliminary evidence that $L 4$ and $L 5$ primary dorsal rami and S1 to S3 lateral branch radiofrequency denervation may provide intermediate-term pain relief and functional benefit in well-selected patients with suspected sacroiliac joint pain. They also conceded that larger studies were needed to confirm these results and identify the optimal candidates and treatment parameters for this therapy.

This study provides strong evidence that response to radiofrequency denervation is superior to placebo. The limitations of the study include the small number of patients, the failure to exclude false-positive responders with a single uncontrolled sacroiliac joint block, the utilization of different types of radiofrequency technology, and the abridged outcome measures after 6 months.

\subsubsection{Cost Effectiveness}

No cost effectiveness evaluations were performed with radiofrequency neurotomy of sacroiliac joint innervation.

\subsubsection{Safety and Complications}

Reported complications of radiofrequency thermoneurolysis include a worsening of the usual pain, burning or dysesthesias, decreased sensation and allodynia in the skin overlying the joint, transient leg pain, persistent leg weakness, inadvertent lesioning of the spinal nerve, ventral ramus, or sciatic nerve resulting in motor deficits, sensory loss, and possible deafferentation pain. $(390,397,399,402,403,406,418,719,726,750,751)$.

\subsubsection{Indications}

Indications for sacroiliac joint interventions are illustrated under intraarticular sacroiliac joint injections.

\subsubsection{Level of Evidence}

Based on the available literature and the USPSTF criteria (126), the indicated evidence is Level II-3 (limited) for radiofrequency neurotomy of sacroiliac joint nerve supply.

\subsubsection{Recommendations}

The recommendations based on Guyatt et al's (136) criteria is $2 \mathrm{~B}$, a weak recommendation for radiofrequency neurotomy for sacroiliac joint pain.

\subsection{Intradiscal Therapies}

Multiple intradiscal therapies described to manage either discogenic pain or IDD includes intradiscal electrothermal therapy (IDET), radiofrequency annuloplasty, and intradiscal biacuplasty (IDB). Percutaneous intradiscal treatment of low back pain has been the subject of several reviews $(38,53,65,96-98,903,904)$. The CMS has issued a non-certification for these procedures (68). CMS referred to them collectively as thermal intradiscal procedures, including IDET, percutaneous intradiscal radiofrequency thermocoagulation (PIRFT), radiofrequency annuloplasty, IDB, percutaneous (or plasma) disc decompression (PDD) or coblation, or targeted disc decompression.

\subsubsection{Intradiscal Electrothermal Therapy}

\subsubsection{Evidence Assessment}

The evidence for IDET includes 5 systematic reviews $(38,53,96-98)$, a technology assessment update (100), critical appraisal of the evidence (64), and multiple other reviews

Appleby et al (97) in a systematic review reviewed the literature from all the available studies and con- 
cluded that there was compelling evidence for the relative efficacy and safety of IDET. This metaanalysis showed an overall mean improvement in pain intensity of 2.9 points, physical function of 21.1 points as measured by Short-Form 36 (SF-36) and disability of 7.0 points as measured by the ODI, however, the lead author was an employee of the device manufacturer. Andersson et al (96) performed a systematic review of spinal fusion and IDET in the treatment of intractable discogenic low back pain. They concluded that the majority of patients reported improvement in symptoms following both spinal fusion and IDET procedure. However, the IDET procedure appeared to offer sufficiently similar symptom amelioration to spinal fusion without attendant complications. Gibson and Waddell (98) concluded that the preliminary results of 3 similar trials of intradiscal electrotherapy suggest it is ineffective, except possibly in highly selected patients. Freeman (903) performed a critical appraisal of the evidence of IDET and concluded that the evidence for the efficacy of IDET remains weak and has not passed the standard of scientific proof.
Helm et al (38) in a recent systematic review evaluating IDET indicated the evidence of Level II-2. Two randomized trials $(905,906)$ and 22 observational studies $(448,907-927)$ met inclusion criteria. Descriptive characteristics of both randomized trials are illustrated in Table 22. Helm et al (38) provided descriptions of these studies.

Both studies were sponsored by device manufacters and have been criticized $(907,908)$. Despite these criticisms, both describe patients in sufficient detail for a practitioner to identify them in a clinical setting. Both describe IDET sufficiently that the procedure can be provided outside of the academic setting. Both measured and reported clinically relevant effects. Pauza et al (905) did meet all the criteria for clinically important improvement, including a greater than $30 \%$ improvement in pain scores, a 2-point reduction in VAS in about $50 \%$ of patients, and a greater than $10 \%$ improvement in functioning scores, although the functioning score improvement was not clinically significant. According to Pauza et al (905), but not according to Freeman et al (906), the benefits of IDET are worth the potential harms.

Table 22. Description of randomized controlled trials of intradiscal electrothermal therapy.

\begin{tabular}{|c|c|c|c|c|c|c|}
\hline Study/Methods & Participants & Inclusion/Exclusion & Interventions & Outcomes & Results & $\begin{array}{c}\text { Conclusion } \\
\text { Short-term } \leq \\
12 \text { mos. } \\
\text { Long-term }> \\
12 \text { mos. }\end{array}$ \\
\hline $\begin{array}{l}\text { Pauza et al } 2004 \\
\text { (905) } \\
\text { Randomized, } \\
\text { placebo-controlled, } \\
\text { double-blind, } \\
\text { prospective trial. }\end{array}$ & $\begin{array}{l}\text { Of the } 37 \text { treat- } \\
\text { ed patients, } 32 \\
\text { were included } \\
\text { in the analysis; } \\
\text { of the } 27 \text { sham } \\
\text { patients, } 24 \\
\text { were included } \\
\text { in the analysis. }\end{array}$ & $\begin{array}{l}\text { Inclusion: age } 18-65 \text { years; low } \\
\text { back pain > leg pain of }>6 \\
\text { months duration; less than } 20 \% \\
\text { loss of disc height; Positive dis- } \\
\text { cography and posterior annular } \\
\text { tears on CT scan. } \\
\text { Exclusion: abnormal neurologi- } \\
\text { cal exam; Workers' Compensa- } \\
\text { tion; personal injury litigation } \\
\text { or receiving disability. }\end{array}$ & $\begin{array}{l}\text { IDET } \\
37 \text { had IDET; } 27 \\
\text { had a sham pro- } \\
\text { cedure in which } \\
\text { the introducer } \\
\text { needle was } \\
\text { advanced to the } \\
\text { outer annulus, } \\
\text { but no catheter } \\
\text { placed. }\end{array}$ & $\begin{array}{l}\text { SF-36 and VAS } \\
\text { Unblinded at } \\
\text { 6-months }\end{array}$ & $\begin{array}{l}\text { The improve- } \\
\text { ment in the } \\
\text { IDET group was } \\
\text { significantly } \\
\text { better than the } \\
\text { sham. } \\
40 \% \text { of patients } \\
\text { treated with } \\
\text { IDET obtained } \\
50 \% \text { relief at } 6 \\
\text { months. }\end{array}$ & $\begin{array}{l}\text { Positive } \\
\text { short-term. }\end{array}$ \\
\hline $\begin{array}{l}\text { Freeman et al } 2005 \\
(906) \\
\text { Randomized, pla- } \\
\text { cebo- controlled, } \\
\text { double-blind, } \\
\text { prospective trial. }\end{array}$ & $\begin{array}{l}57 \text { subjects } \\
\text { from } 3 \text { spine } \\
\text { practices in } \\
\text { Australia. }\end{array}$ & $\begin{array}{l}\text { Inclusion: symptoms of MRI } \\
\text { documented degenerative } \\
\text { disease; one or } 2 \text { positive levels } \\
\text { on discography; dye spread on } \\
\text { post discography CT scan to } \\
\text { or beyond the outer annulus; } \\
\text { age > 18. } \\
\text { Exclusion: loss of more than } \\
50 \% \text { disc height; severely } \\
\text { disrupted disc; } 3 \text { or more } \\
\text { symptomatic lumbar discs; } \\
\text { previous back surgery; current } \\
\text { injury litigation. }\end{array}$ & $\begin{array}{l}\text { IDET } \\
\text { Treated group } \\
\text { had IDET, with } \\
\text { catheter cover- } \\
\text { ing at least } 75 \% \\
\text { of the annular } \\
\text { tear. } \\
\text { The control } \\
\text { had a catheter } \\
\text { placed in the } \\
\text { annulus and the } \\
\text { cable attached } \\
\text { to it. }\end{array}$ & $\begin{array}{l}\text { VAS, Low Back } \\
\text { Pain Outcome } \\
\text { Score, Oswes- } \\
\text { try Disability } \\
\text { Index, SF-36, } \\
\text { Zung Depres- } \\
\text { sion Index and } \\
\text { the Modi- } \\
\text { fied Somatic } \\
\text { Perception } \\
\text { Questionnaire. }\end{array}$ & $\begin{array}{l}\text { At six months, } \\
\text { neither group } \\
\text { showed any } \\
\text { benefit in any } \\
\text { parameter. }\end{array}$ & $\begin{array}{l}\text { Negative } \\
\text { short-term }\end{array}$ \\
\hline
\end{tabular}

Adapted from Helm S et al. Systematic review of the effectiveness of thermal annular procedures in treating discogenic low back pain. Pain Physician 2009; 12:207-232 (38). 


\subsubsection{Cost Effectiveness}

Andersson et al (96) in their systematic review of intractable low back pain treatment with IDET versus spinal fusion surgery concluded that more than half of patients treated with IDET can avoid surgery and therefore spare the cost of surgery and its complications.

\subsubsection{Safety and Complications}

Complications of IDET include catheter breakage, nerve root injuries, post-IDET disc herniation, progressive disc degeneration, cauda equina syndrome, infection, vertebral endplate osteonecrosis, epidural abscess, radiculopathy, disc herniation, and spinal cord damage $(97,551,928-940)$.

\subsubsection{Indications}

The indications have been described as follows (941):

1) Axial low back pain of at least 6 months duration.

2) Failure to respond to conservative treatment.

3) $\geq 60 \%$ residual disc height.

4) Positive concordant discogram at low pressure.

5) Normal neurologic exam (or at least no new deficits attributable to level to be treated).

6) Negative straight-leg raise.

7) Results of MRI with no evidence of root compression, tumor, or infection.

\subsubsection{Level of Evidence}

Table 23 illustrates the results of published studies of effectiveness of IDET, which includes randomized and observational studies. The evidence for IDET is Level II-2 based on USPSTF criteria (126).

\subsubsection{Recommendations}

A recommendation of $2 \mathrm{~A} /$ weak recommendation is provided based on Guyatt et al's (136) recommendation.

\subsubsection{Intradiscal Biacuplasty}

One systematic review of the evidence for IDB (38) and one pilot study $(942,943)$ was identified. Kapural et al evaluated 15 patients undergoing one or two-level IDB treatments of their painful lumbar discs. All had chronic low back pain $>6$ months, back pain exceeding leg pain, concordant pain on provocation discography, disc height $>50 \%$ of control, and evidence of single or 2-level degenerative disc disease without evidence of additional changes on MRI. IDB was performed under fluoroscopy using 2 radiofrequency probes positioned bilaterally in the intervertebral disc. Thirteen patients completed followup questionnaires, at 1, 3, and 6 months.

Median visual analo scale pain scores were reduces from $7(95 \% C 6,8)$ to $4(2,5) \mathrm{cm}$ at 1 month, and remained at $3(2,5) \mathrm{cm}$ at 6 months. The Oswestry improved from 23.3 (SD 7.0) to 16.5 (6.8) points at 1 month and remained similar after 6 months. The SF-36 Physical Functioning scores improved from 51 (18) to 70 (16) points after 6 months, while the SF-36 Bodily Pain Score improved from 38 (15) to 54 (23) points. Daily opioid use did not change significantly from baseline.

\subsubsection{Safety and Complications}

No complications of biacuplasty have been reported thus far. However, expected potential complications are similar to IDET.

\subsubsection{Indications}

Indications are the same as for IDET as described above.

\subsubsection{Level of Evidence}

Based on the quality of evidence using the USPSTF criteria (126) the level of evidence for IDB is Level III (limited).

\subsubsection{Recommendations}

No recommendation is provided based on the available evidence.

\subsubsection{Radiofrequency Posterior Annuloplasty}

One systematic review (38) and 2 studies dealt with radiofrequency annuloplasty $(927,944)$. Finch et al (944), in a case series, found the procedure to be effective. Kapural et al (927), in an observational study, found radiofrequency annuloplasty to be less effective than IDET. Table 24 describes effectiveness based on 2 published studies.

\subsubsection{Indications}

The indications are similar to IDET.

\subsubsection{Safety and Complications}

Potential complications are expected to be similar to those of IDET. 
Pain Physician: July/August 2009:12: 699-802

Table 23. Results of published studies of effectiveness of IDET.

\begin{tabular}{|c|c|c|c|c|c|c|c|}
\hline \multirow[b]{2}{*}{ Study } & \multirow[b]{2}{*}{$\begin{array}{c}\text { Study } \\
\text { Characteristics }\end{array}$} & \multirow[b]{2}{*}{$\begin{array}{l}\text { Methodological } \\
\text { Quality Scoring }\end{array}$} & \multirow[b]{2}{*}{ Participants } & \multicolumn{2}{|c|}{ Pain Relief } & \multicolumn{2}{|c|}{ Results } \\
\hline & & & & $\leq 12 \mathrm{mos}$ & $>12 \mathrm{mos}$. & $\begin{array}{c}\text { Short-term } \\
\text { relief } \leq 12 \\
\text { mos. }\end{array}$ & $\begin{array}{c}\text { Long-term } \\
\text { relief }>12 \\
\text { mos. }\end{array}$ \\
\hline $\begin{array}{l}\text { Pauza et al } 2004 \\
(905)\end{array}$ & RA & 68 & 64 & $\begin{array}{c}56 \% \text { had } 2 \text { point } \\
\text { decrease } \\
40 \% \text { had }>50 \% \\
\text { decrease }\end{array}$ & NA & Yes & NA \\
\hline $\begin{array}{l}\text { Freeman et al } \\
2005 \text { (906) }\end{array}$ & RA & 61 & 57 & No change & NA & No & NA \\
\hline $\begin{array}{l}\text { Karasek and } \\
\text { Bogduk 2000 and } \\
2002(909,910)\end{array}$ & $\mathrm{O}$ & 85 & 53 & $70 \%$ & $57 \%$ & Yes & Yes \\
\hline $\begin{array}{l}\text { Gerszten et al } \\
2002(911)\end{array}$ & $\mathrm{O}$ & 50 & 27 & $75 \%$ & $75 \%$ & Yes & Yes \\
\hline $\begin{array}{l}\text { Saal and Saal } \\
2000 \& 2002 \\
(912-914)\end{array}$ & $\mathrm{O}$ & 52 & 53 & SI & SI & Yes & Yes \\
\hline $\begin{array}{l}\text { Cohen et al } 2003 \\
\text { (915) }\end{array}$ & $\mathrm{O}$ & 80 & 70 & $48 \%$ & NA & Yes & NA \\
\hline $\begin{array}{l}\text { Freedman et al } \\
2002(916)\end{array}$ & $\mathrm{O}$ & 66 & 41 & $47 \%$ & $\begin{array}{c}16 \%>50 \% \\
\text { decrease }\end{array}$ & Yes & No \\
\hline $\begin{array}{l}\text { Lee et al } 2003 \\
\text { (917) }\end{array}$ & $\mathrm{O}$ & 53 & 62 & NA & $53 \%$ & Yes & Yes \\
\hline $\begin{array}{l}\text { Lutz et al } 2003 \\
\text { (918) }\end{array}$ & $\mathrm{O}$ & 58 & 33 & NA & $70 \%$ & Yes & Yes \\
\hline $\begin{array}{l}\text { Davis et al } 2004 \\
\text { (919) }\end{array}$ & $\mathrm{O}$ & 52 & 60 & NA & $37 \%$ & No & No \\
\hline $\begin{array}{l}\text { Derby et al } 2004 \\
(448)\end{array}$ & $\mathrm{O}$ & 61 & $\begin{array}{l}34 \text { Injection } \\
74 \text { IDET }\end{array}$ & $\begin{array}{c}2.2 \text { point } \\
\text { decrease for } \\
\text { injection } \\
1.27 \text { for IDET }\end{array}$ & NA & Yes & No \\
\hline $\begin{array}{l}\text { Derby et al } 2004 \\
(920)\end{array}$ & $\mathrm{O}$ & 52 & 99 & NA & $\begin{array}{c}52 \% \\
1.56 \text { point } \\
\text { decrease } \\
\text { back pain }\end{array}$ & Yes & Yes \\
\hline $\begin{array}{l}\text { Mekhail and } \\
\text { Kapural } 2004 \\
\text { (921) }\end{array}$ & $\mathrm{O}$ & 58 & 34 & SI & SI & Yes & Yes \\
\hline $\begin{array}{l}\text { Kapural et al } 2004 \\
(922)\end{array}$ & $\mathrm{O}$ & 74 & 34 & SI & SI & Yes & Yes \\
\hline $\begin{array}{l}\text { Kapural et al } 2005 \\
\text { (927) }\end{array}$ & $\mathrm{O}$ & 81 & 21 & SI & SI & Yes & Yes \\
\hline $\begin{array}{l}\text { Bryce et al } 2005 \\
(923)\end{array}$ & $\mathrm{O}$ & 58 & 86 & SI & SI & Yes & Yes \\
\hline $\begin{array}{l}\text { Maurer et al } 2008 \\
(924)\end{array}$ & $\mathrm{O}$ & 62 & 56 & SI & SI & Yes & Yes \\
\hline $\begin{array}{l}\text { Nunley et al } 2008 \\
(925)\end{array}$ & $\mathrm{O}$ & 60 & 53 & SI & NA & Yes & NA \\
\hline $\begin{array}{l}\text { Ergun et al } 2008 \\
\text { (926) }\end{array}$ & $\mathrm{O}$ & 56 & 39 & NA & $79 \%$ & NA & Yes \\
\hline
\end{tabular}

$\mathrm{O}=$ observational; $\mathrm{RA}$ = randomized; $\mathrm{VAS}=$ visual analog scale; $\mathrm{SI}=$ significant improvement; $\mathrm{NSI}$ = no significant improvement; NA = not available Adapted from Helm S et al. Systematic review of the effectiveness of thermal annular procedures in treating discogenic low back pain. Pain Physician 2009; 12:207-232 (38). 
Table 24. Results of published studies of effectiveness of radiofrequency annuloplasty.

\begin{tabular}{|c|c|c|c|c|c|c|c|}
\hline \multirow[b]{2}{*}{ Study } & \multirow[b]{2}{*}{$\begin{array}{c}\text { Study } \\
\text { Characteristics }\end{array}$} & \multirow[b]{2}{*}{$\begin{array}{l}\text { Methodological } \\
\text { Quality Scoring }\end{array}$} & \multirow[b]{2}{*}{ Participants } & \multicolumn{2}{|c|}{ "Pain Relief (VAS) } & \multicolumn{2}{|c|}{ Results } \\
\hline & & & & $\leq 12$ mos. & $>12$ mos. & $\begin{array}{c}\text { Short-term } \\
\text { relief } \leq 12 \text { mos. }\end{array}$ & $\begin{array}{c}\text { Long-term } \\
\text { relief }>12 \\
\text { mos. }\end{array}$ \\
\hline $\begin{array}{l}\text { Finch et al } \\
2005 \text { (944) }\end{array}$ & $\mathrm{O}$ & 69 & 46 & $37 \%$ & NA & No & NA \\
\hline $\begin{array}{l}\text { Kapural et al } \\
2005 \text { (927) }\end{array}$ & $\mathrm{O}$ & 81 & 21 & NSI & NA & No & NA \\
\hline
\end{tabular}

$\mathrm{O}=$ observational; $\mathrm{RA}=$ randomized; $\mathrm{NSI}=$ no significant improvement; $\mathrm{NA}=$ not available

Adapted from Helm S et al. Systematic review of the effectiveness of thermal annular procedures in treating discogenic low back pain. Pain Physician 2009; 12:207-232 (38).

\subsubsection{Level of Evidence}

The indicated level of evidence for radiofrequency annuloplasty is II-3 based on USPSTF criteria (126).

\subsubsection{Recommendations}

No recommendation is provided.

\subsection{Percutaneous Disc Decompression}

The primary goal of surgical treatment of a disc prolapse, protrusion, or extrusion is the relief of nerve root compression by removing the herniated nuclear material (945-947). Several alternative techniques to open discectomy and microdiscectomy include automated percutaneous lumbar discectomy (APLD), percutaneous lumbar laser discectomy (PLLD), mechanical disc decompression with a high rotation per minute device or DeKompressor ${ }^{\circledR}$, and nucleoplasty. All the techniques were assessed systematically (49-52).

\subsubsection{Automated Percutaneous Lumbar Discectomy (APLD)}

APLD is performed with a pneumatically driven, suction-cutting probe in a cannula with a $2.8 \mathrm{~mm}$ outer diameter with removal of one to 3 grams of disc material to reduce intradiscal pressure and decompress the nerve roots $(49,99,948-963)$.

\subsubsection{Evidence Assessment}

Gibson and Waddell (945) in a Cochrane collaboration review indicated that the place for forms of discectomy other than traditional open discectomy is unresolved. They concluded that trials of percutaneous discectomy suggest that clinical outcomes following treatment are at best fair and certainly worse than after microdiscec- tomy, although the importance of patient selection is acknowledged. They concluded that there is considerable evidence that surgical discectomy provides effective clinical relief for carefully selected patients with sciatica due to lumbar disc prolapse that fails to resolve with conservative management. These authors noted that unless or until better scientific evidence is available, APLD should be regarded as a research technique.

In a technology assessment report (99), negative evidence was illustrated. The systematic review by Hirsch et al (49) utilizing a combination of randomized trials and observational studies with only one randomized trial meeting inclusion criteria for evidence synthesis (948) and with 10 observational studies meeting inclusion criteria for evidence synthesis $(952-959,962,963)$ concluded that the indicated level of evidence is II-2 in properly selected patients with contained lumbar disc prolapse.

Of the 2 published randomized trials $(948,949)$, Revel et al (948) met the inclusion criteria for evidence synthesis. Revel et al (948) randomized patients with sciatica caused by a disc herniation to undergo as an APLD or chemonucleolysis. The trial included 72 chemonucleolysis and 69 APLD patients of whom $43 \%$ of chemonucleolysis patients and $26 \%$ of APLD patients were considered sedentary subjects and the disc appeared degenerated more often in the chemonucleolysis group (92\%) than in the APLD group (76\%). The study had 32 patients withdrawing during trial as therapeutic failures. At one-year follow-up, overall success rates were $66 \%$ in the chemonucleolysis group and $37 \%$ in the APLD group.

Many aspects of the Revel et al's study (948), such as patient selection criteria, which led to poor results, have been criticized (49). The size of the disc hernia- 
tion was an issue because for APLD it should not occupy more than $30 \%$ of the spinal canal, whereas in Revel et al's study (948) in 59\% of APLD and $64 \%$ of chemonucleolysis patients the disc herniation covered between $25 \%$ and $50 \%$ of the spinal canal. Further, in $71 \%$ of the APLD patients and $79 \%$ of chemonucleolysis patients, the disc herniation had migrated up to $5 \mathrm{~mm}$ cranially or caudally to the endplate levels, considered a contraindication of APLD. Other factors included that at discography, 39\% of the tested discs showed epidural leakage, $76 \%$ of the discs were severely degenerated (APLD is not effective in diffuse annular bulging), 9\% had marked disc space narrowing, and $21 \%$ of patients had severe back pain, but no correlation to leg pain was made.

Multiple observational studies meeting inclusion criteria have been described in detail by Hirsch et al (49) and a summary of the results of eligible studies of APLD is provided in Table 25.

\subsubsection{Cost Effectiveness}

No cost effectiveness studies are available for APLD.

\subsubsection{Indications}

Indications of percutaneous mechanical disc decompression include the following:

1) Unilateral leg pain greater than back pain.

2) Radicular symptoms in a specific dermatomal distribution that correlates with MRI findings.

3) Positive straight leg raising test or positive bowstring sign, or both.

4) Neurologic findings or radicular symptoms.

5) No improvement after 6 weeks of conservative therapy.

6) Imaging studies (CT, MRI, discography) indicating a subligamentous contained disc herniation.

7) Well maintained disc height of $60 \%$.

Table 25. Summary results of eligible studies of automated percutaneous lumbar discectomy included in this systematic review.

\begin{tabular}{|c|c|c|c|c|c|}
\hline \multirow{2}{*}{ Study } & \multirow{2}{*}{$\begin{array}{c}\text { Study } \\
\text { Characteristics }\end{array}$} & \multirow{2}{*}{$\begin{array}{l}\text { Methodological } \\
\text { Quality Scoring }\end{array}$} & \multirow{2}{*}{$\begin{array}{l}\text { Number of } \\
\text { Participants }\end{array}$} & Pain Relief & Results \\
\hline & & & & $>12$ mos. & $\begin{array}{l}\text { Long-term } \\
>12 \mathrm{mos} .\end{array}$ \\
\hline Revel et al (948) & RA & 70 & $\begin{array}{c}69 \text { APLD } \\
72 \text { Chemonucleolysis }\end{array}$ & $\begin{array}{c}37 \% \text { APLD } \\
66 \% \text { Chemonucleolysis }\end{array}$ & $\mathrm{N}$ \\
\hline Shapiro (952) & $\mathrm{O}$ & 55 & 57 & $58 \%$ & $\mathrm{P}$ \\
\hline Grevitt et al (953) & $\mathrm{O}$ & 70 & $\begin{array}{c}137 \text { (115 remained } \\
\text { at final follow-up } \\
\text { interview) }\end{array}$ & $72 \%$ & $\mathrm{P}$ \\
\hline Onik et al (954) & $\mathrm{O}$ & 68 & 506 & $75 \%$ & $\mathrm{P}$ \\
\hline Davis et al (955) & $\mathrm{O}$ & 59 & 518 & $85 \%$ & $\mathrm{P}$ \\
\hline $\begin{array}{l}\text { Maroon \& Allen } \\
(956)\end{array}$ & $\mathrm{O}$ & 54 & 1054 & $85 \%$ & $\mathrm{P}$ \\
\hline Teng et al (957) & $\mathrm{O}$ & 71 & 1,582 & $83 \%$ & $\mathrm{P}$ \\
\hline Bonaldi et al (958) & $\mathrm{O}$ & 58 & 234 & $75 \%$ & $\mathrm{P}$ \\
\hline Degobbis et al (959) & $\mathrm{O}$ & 55 & 50 & NA & NA \\
\hline Marks (962) & $\mathrm{O}$ & 66 & 103 & $63 \%$ & $\mathrm{P}$ \\
\hline Bernd et al (963) & $\mathrm{O}$ & 68 & 238 & $60 \%$ & $\mathrm{P}$ \\
\hline
\end{tabular}

$\mathrm{RA}=$ randomized; $\mathrm{O}=$ observational $\mathrm{P}=$ positive; $\mathrm{N}=$ negative; $\mathrm{N} / \mathrm{A}=$ not available.

Adapted from Hirsch JA et al. Automated percutaneous lumbar discectomy for the contained herniated lumbar disc: A systematic assessment of evidence. Pain Physician 2009; 12:601-620 (49). 


\subsubsection{Safety and Complications}

Percutaneous discectomy is associated with risks which include nerve injury, infection, bleeding, development of spinal instability, damage to endplate, and disc space collapse.

\subsubsection{Level of Evidence}

The indicated level of evidence based on USPSTF criteria (126) is Level II-2 for short- and long-term relief for APLD.

\subsubsection{Recommendations}

The recommendation is $1 \mathrm{C} /$ strong recommendation based on Guyatt et al's (136) criteria.

\subsubsection{Percutaneous Lumbar Laser Discectomy (PLLD)}

In percutaneous lumbar laser discectomy or PLLD, laser energy is used to reduce pressure by vaporizing a small volume of the nucleus pulposus. It is hypothesized that the change in pressure between the nucleus pulposus and the peridiscal tissue causes retraction of the herniation away from the nerve root $(50,99,945)$.

\subsubsection{Evidence Assessment}

Based on the systematic review by Waddell et al (946) there is no acceptable evidence for laser discectomy. However, Singh et al (50) in a systematic review of current evidence, which included observational studies, indicated the level of evidence for
PLLD as Level II-2 for short- and long-term relief. The evidence was based on multiple observational studies (964-973).

Singh et al (50) described the characteristics of multiple studies included in the evidence synthesis and the details including methodologic quality scoring, and results are illustrated in Table 26.

\subsubsection{Cost Effectiveness} PLLD.

No cost effectiveness studies are available for

\subsubsection{Indications} APLD.

The indications for PLLD are the same as for

\subsubsection{Safety and Complications}

Complications of APLD include instrument failures, nerve damage, reflex sympathetic dystrophy (RSD), sigmoid artery injury, anomalous iliolumbar artery injury, spondylodiscitis, and cauda equina syndrome (974-977).

\subsubsection{Level of Evidence}

The indicated level of evidence based on USPSTF criteria (126) is II-2 for short- and long-term relief.

\subsubsection{Recommendations}

The recommendation based on Guyatt et al's (136) criteria is 1 C/strong recommendation for PLLD.

Table 26. Results of percutaneous disc decompression with laser assisted disc removal.

\begin{tabular}{|l|c|c|c|c|c||}
\hline \multicolumn{1}{|c|}{ Study } & Study Characteristics & $\begin{array}{c}\text { Methodological } \\
\text { Quality Scoring }\end{array}$ & $\begin{array}{c}\text { Number of } \\
\text { Participants }\end{array}$ & $\begin{array}{c}\text { Pain Relief } \\
>\text { 12 mos }\end{array}$ & Results \\
\hline Knight \& Goswami (970) & O & 69 & 576 & $56 \%$ & $\mathrm{P}$ \\
\hline Bosacco et al (964) & $\mathrm{O}$ & 58 & 63 & $66 \%$ & $\mathrm{P}$ \\
\hline Choy (965) & $\mathrm{O}$ & 55 & 518 & $75 \%$ & $\mathrm{P}$ \\
\hline Zhao et al (972) & $\mathrm{O}$ & 80 & 139 & $82 \%$ & $\mathrm{P}$ \\
\hline Tassi (973) & $\mathrm{O}$ & 61 & 419 & $84 \%$ & $\mathrm{P}$ \\
\hline Grönemeyer et al (971) & $\mathrm{O}$ & 75 & 200 & $73 \%$ & $\mathrm{P}$ \\
\hline Nerubay et al (966) & $\mathrm{O}$ & 55 & 50 & $74 \%$ & $\mathrm{P}$ \\
\hline Ascher (967) & $\mathrm{O}$ & 50 & 90 & $74 \%$ & $\mathrm{P}$ \\
\hline Botsford (969) & $\mathrm{O}$ & 63 & 292 & $75 \%$ & $\mathrm{P}$ \\
\hline Casper et al (968) & O & 72 & 100 & $87 \%$ & $\mathrm{P}$ \\
\hline
\end{tabular}

$\mathrm{O}=$ observational; $\mathrm{P}=$ positive; $\mathrm{N} / \mathrm{A}=$ not applicable.

Adapted from Singh V et al. Percutaneous lumbar laser disc decompression: A systematic review of current evidence. Pain Physician 2009; 12:573-588 (50). 


\subsubsection{Nucleoplasty}

\subsubsection{Evidence Assessment}

PDD with nucleoplasty (coblation technology) is performed with radiofrequency energy to dissolve nuclear material through molecular dissociation. Bipolar radiofrequency coagulation denatures proteoglycans, changing the internal environment of the affected nucleus pulposus with reduction in intradiscal pressure (978-982). The proposed advantage of the coblation technology is that the procedure provides for a controlled and highly localized ablation, resulting in minimal thermal damage to surrounding tissues.

Gibson and Waddell (945) concluded that multiple minimally invasive decompression techniques including coblation therapy should be regarded as research techniques. Manchikanti et al (52) in a systematic review showed the indicated evidence for nucleoplasty as Level II-3 in managing predominantly lower extremity pain due to contained disc herniation. In this systematic review, 5 of 7 studies met inclusion criteria $(980,983-$ 988). Manchikanti et al (52) described the characteristics of 5 studies included in the evidence synthesis (Table 27). All the studies showed improvement; however, no randomized trials were available for inclusion. The described complications of nucleoplasty include nerve damage, needle breakage, infection, and other complications similar to intradiscal therapies and percutaneous lumbar discectomy procedures $(979,988)$.

\subsubsection{Cost Effectiveness}

Cost effectiveness of PDD with coblation nucleoplasty has not been evaluated.

\subsubsection{Indications}

The indications are the same as for APLD.

\subsubsection{Safety and Complications}

Side effects and complications after percutaneous disc decompression with coblation technology include nerve injury, infection, bleeding, development of spinal instability, and progressive degenerative changes $(984,985)$.

\subsubsection{Level of Evidence}

Based on USPSTF criteria (126), the indicated evidence for nucleoplasty is Level II-3 in managing predominantly lower extremity pain due to contained disc herniation. There is no evidence available for axial low back pain.

\subsubsection{Recommendations}

The recommendation based on Guyatt et al's (136) criteria is $2 B /$ weak recommendation in managing radicular pain due to contained disc herniation No recommendation is available in managing axial low back pain.

\subsubsection{Mechanical High RPM Device}

The Dekompressor probe is a mechanical high rotation per minute device designed to extract the nuclear material through an introducer cannula using an auger-like device that rotates at high speeds $(51,99)$.

\subsubsection{Evidence Assessment}

Gibson and Waddell (945) have described all newer alternative minimally invasive techniques should

Table 27. Results of published evaluations of nucleoplasty.

\begin{tabular}{|c|c|c|c|c|c|c|c|}
\hline \multirow[b]{2}{*}{ Study } & \multirow{2}{*}{$\begin{array}{c}\text { Study } \\
\text { Characteristics }\end{array}$} & \multirow{2}{*}{$\begin{array}{l}\text { Methodological } \\
\text { Quality Score }\end{array}$} & \multirow{2}{*}{$\begin{array}{l}\text { No. of } \\
\text { patients }\end{array}$} & \multicolumn{2}{|c|}{ Pain Relief } & \multicolumn{2}{|c|}{ Results } \\
\hline & & & & $6 \mathrm{mos}$ & 1 year & $\begin{array}{c}\text { Short-term } \\
\text { relief } \leq 12 \mathrm{mos}\end{array}$ & $\begin{array}{l}\text { Long-term } \\
\text { relief >12 mos }\end{array}$ \\
\hline Singh et al (980) & $\mathrm{O}$ & 62 & 67 & $59 \%$ & $56 \%$ & $\mathrm{P}$ & $\mathrm{P}$ \\
\hline Singh et al (984) & $\mathrm{O}$ & 62 & 80 & $76 \%$ & $77 \%$ & $\mathrm{P}$ & $\mathrm{P}$ \\
\hline Marin (985) & $\mathrm{O}$ & 61 & 64 & $80 \%$ & $80 \%$ & $\mathrm{P}$ & $\mathrm{P}$ \\
\hline Mirzai et al (986) & $\mathrm{O}$ & 77 & 52 & $85 \%$ & $88 \%$ & $\mathrm{P}$ & $\mathrm{P}$ \\
\hline Al-Zain et al (987) & $\mathrm{O}$ & 74 & 69 & $61 \%$ & $58 \%$ & $\mathrm{P}$ & $\mathrm{P}$ \\
\hline
\end{tabular}

$\mathrm{O}=$ Observational; $P$ = positive

Adapted and modified from Manchikanti L et al. A systematic review of mechanical lumbar disc decompression with nucleoplasty. Pain Physician 2009; 12:561-572. (52). 
be regarded as research techniques (989-992). Singh et al (51) in a systematic review utilizing 2 observational studies $(990,991)$ meeting the inclusion criteria showed the indicated evidence as Level III for shortand long-term relief.

The studies by Alo et al $(989,990)$ from a single study, Lierz et al (991), and Amoretti et al (992) all showed positive results. However, the number of participants was small in 2 studies meeting the inclusion criteria $(990,991)$. Table 28 illustrates the results of published studies meeting inclusion criteria with $65 \%$ positive results by Alo et al at one year and $80 \%$ by Lierz et al. However, the total number of patients included in both studies is only 114 .

\subsubsection{Cost Effectiveness}

Cost effectiveness studies were not available.

\subsubsection{Indications}

The indications are the same as for APLD.

\subsubsection{Safety and Complications}

The potential complications of Dekompressor include the same complications with either APLD or nucleoplasty. However, a critical failure of a Dekompressor probe was reported (993).

Other complications are similar to other intradiscal and mechanical disc decompression procedures, including nerve damage, infection, etc.

\subsubsection{Level of Evidence}

Based on USPSTF criteria (126), the indicated evidence for Dekompressor is Level III for short- and longterm relief.

\subsubsection{Recommendations}

No recommendation is provided for Dekompressor.

\subsection{Spinal Cord Stimulation}

Spinal cord stimulation (SCS) is primarily implanted in the United States for FBSS and complex regional pain syndrome (CRPS) $(85,89,91-95,98,994-1000)$.

\subsubsection{Evidence Assesment}

Multiple systematic reviews have been performed with the first review published in 1995 (93). Taylor et al (85) concluded that the level of evidence for the efficacy of SCS in chronic back and leg pain secondary to FBSS was moderate. In another systematic study, Taylor (94) in evaluating neuropathic back and leg pain secondary to FBSS concluded that the evidence was of Grade B. A Cochrane review for SCS (91) concluded that evidence was limited for SCS for FBSS. Frey et al (42) indicated the evidence to be Level II-1 or II-2 for clinical use on a long-term basis in relieving chronic intractable pain of FBSS.

Kumar et al $(1001,1002)$ compared SCS with conventional medical management (CMM) in patients with neuropathic pain secondary to FBSS with predominant leg pain of neuropathic radicular origin. By 12 months, the protocol analysis showed $48 \%$ of the SCS group and $9 \%$ of the medical management group achieving at least $50 \%$ pain relief. By 24 -month follow-up, 42 out of 52 randomized patients continuing SCS reported significantly improved leg pain relief, QOL, and functional capacity; and 13 patients (31\%) required a device-related surgical revision (1001). At 24 months, of 46 out of 52 patients randomized to SCS and 41 of the 48 patients randomized to CMM who were available, the primary outcome was achieved by $34(47 \%)$ out of 72 patients who received SCS as final treatment versus one $(7 \%)$ of 15 for CMM. The authors concluded that compared with the medical management group, the spinal cord group experienced improved leg and back pain relief, QOL, and functional capacity, as well as greater treatment satisfaction.

Table 28. Results of published studies of Dekompressor meeting inclusion criteria.

\begin{tabular}{|c|c|c|c|c|c|c|c|}
\hline \multirow[b]{2}{*}{ Study } & \multirow{2}{*}{$\begin{array}{c}\text { Study } \\
\text { Characteristics }\end{array}$} & \multirow{2}{*}{$\begin{array}{l}\text { Methodological } \\
\text { Quality Score }\end{array}$} & \multirow{2}{*}{$\begin{array}{c}\text { No. of } \\
\text { patients }\end{array}$} & \multicolumn{2}{|c|}{ Pain relief } & \multicolumn{2}{|c|}{ Results } \\
\hline & & & & $6 \mathrm{mos}$ & 12 mos. & $\begin{array}{c}\text { Short-term } \\
\text { relief } \leq 12 \mathrm{mos}\end{array}$ & $\begin{array}{c}\text { Long-term } \\
\text { relief }>12 \mathrm{mos} .\end{array}$ \\
\hline Alo et al (990) & $\mathrm{O}$ & 52 & 50 & $74 \%$ & $65 \%$ & $P$ & $\mathrm{P}$ \\
\hline Lierz et al (991) & $\mathrm{O}$ & 52 & 64 & $80 \%$ & $80 \%$ & $\mathrm{P}$ & $\mathrm{P}$ \\
\hline
\end{tabular}

$\mathrm{O}=$ Observational; $P$ = positive

Adapted from Singh V. Systematic review of percutaneous lumbar mechanical disc decompression utilizing Dekompressor冈. Pain Physician 2009; 12:589-600 (51). 
North et al (1003) presented results of SCS versus repeated lumbosacral spine surgery for chronic pain in an RCT. Of the 99 patients from a consecutive series invited to participate in the study, 60 candidates consented to randomization and 50 proceeded to a treatment. Among 45 patients (90\%) available for follow-up, SCS was more successful than reoperation (9 of 19 patients versus 3 of 26 patients, $P \leq 0.01$ ). The long-term success rates at $2.9 \pm 1.1$ years were for SCS, $47 \%$ versus reoperation $12 \%(P \leq 0.01)$.

Multiple observational studies showed positive results. Frey et al (42) included 9 observational studies (1004-1012) in the evidence synthesis as illustrated in Table 29.

\subsubsection{Cost Effectiveness}

Cost effectiveness of SCS has been performed in FBSS $(995,996)$. Taylor et al $(995)$ found that initial health care acquisition costs were offset by a reduction in post implant health care resource demands and costs. Mean 5-year costs were $\$ 29,123$ in the intervention group compared to $\$ 38,029$ in the control group for FBSS. Other investigators also showed similar find- ings illustrating cost effectiveness of spinal cord stimulation even though initial health care acquisition costs are higher than other treatments $(996-999,1006)$.

\subsubsection{Safety and Complications}

The most common adverse event reported in the literature is lead migration followed by lead fracture and infection at the incision site of implantable pulse generator or in the surgical pocket $(1000,1013,1014)$. Overall up to $34 \%$ of SCS patients may experience an adverse event (89).

\subsubsection{Indications}

While multiple indications are available, the indications in the United States are related to neuropathic pain of FBSS or CRPS.

\subsubsection{Level of Evidence}

The indicated evidence for SCS is Level II-1 or II-2 for long-term relief in managing patients with FBSS.

\subsubsection{Recommendations}

Based on Guyatt et al's (136) criteria, the recom-

Table 29. Results of published studies of effectiveness of spinal cord stimulation in post lumbar surgery syndrome.

\begin{tabular}{|c|c|c|c|c|c|c|c|}
\hline \multirow[b]{2}{*}{ Study } & \multirow{2}{*}{$\begin{array}{c}\text { Study } \\
\text { Characteristics }\end{array}$} & \multirow{2}{*}{$\begin{array}{l}\text { Methodological } \\
\text { Quality Scoring }\end{array}$} & \multirow[b]{2}{*}{ Patients } & \multicolumn{2}{|c|}{ Pain Relief } & \multicolumn{2}{|c|}{ Results } \\
\hline & & & & $\leq 12$ mos. & $>12 \mathrm{mos}$. & $\begin{array}{c}\text { Short-term } \\
\leq 12 \text { mos. }\end{array}$ & $\begin{array}{l}\text { Long-term } \\
>12 \mathrm{mos} .\end{array}$ \\
\hline Kumar et al (1001) & RA & 55 & $\begin{array}{c}\mathrm{SCS}=52 \\
\mathrm{CMM}=48\end{array}$ & $48 \%$ vs $9 \%$ & $58 \%$ vs $17 \%$ & $\mathrm{P}$ & $\mathrm{P}$ \\
\hline North et al (1003) & RA & 56 & $\begin{array}{c}\text { SCS }=24 \\
\text { Reoperation }=26\end{array}$ & $\begin{array}{c}\text { SCS 9/19 } \\
\text { Reoperation } \\
3 / 26\end{array}$ & $\begin{array}{c}\text { SCS } 9 / 19 \\
\text { Reoperation } \\
3 / 26\end{array}$ & $\mathrm{P}$ & $\mathrm{P}$ \\
\hline $\begin{array}{l}\text { Van Buyten et al } \\
\text { (1004) }\end{array}$ & $\mathrm{O}$ & 53 & 254 & - & $68 \%$ & $\mathrm{P}$ & $\mathrm{P}$ \\
\hline $\begin{array}{l}\text { Kumar and Toth } \\
\text { (1005) }\end{array}$ & $\mathrm{O}$ & 58 & 182 & - & $48 \%$ & $\mathrm{P}$ & $\mathrm{N}$ \\
\hline $\begin{array}{l}\text { De La Porte and Van } \\
\text { de Kelft (1006) }\end{array}$ & $\mathrm{O}$ & 56 & 78 & - & $58 \%$ & $\mathrm{P}$ & $\mathrm{P}$ \\
\hline Devulder et al (1007) & $\mathrm{O}$ & 56 & 69 & - & $77 \%$ & $\mathrm{P}$ & $\mathrm{P}$ \\
\hline North et al (1008) & $\mathrm{O}$ & 62 & 50 & - & $53 \%$ & $\mathrm{P}$ & $\mathrm{P}$ \\
\hline Dario (1009) & $\mathrm{O}$ & 56 & 49 & - & $71 \%$ & $\mathrm{P}$ & $\mathrm{P}$ \\
\hline $\begin{array}{l}\text { De La Porte and } \\
\text { Siegfried (1010) }\end{array}$ & $\mathrm{O}$ & 50 & 94 & - & $60 \%$ & $\mathrm{P}$ & $\mathrm{P}$ \\
\hline Burchiel et al (1011) & $\mathrm{O}$ & 57 & 219 & - & $55 \%$ & $\mathrm{P}$ & $\mathrm{P}$ \\
\hline $\begin{array}{l}\text { Ohnmeiss et al } \\
(1012)\end{array}$ & $\mathrm{O}$ & 57 & 40 & - & $70 \%$ & $\mathrm{P}$ & P \\
\hline
\end{tabular}

$R A=$ randomized $; \mathrm{O}=$ observational; $\mathrm{SCS}=$ spinal cord stimulation; $\mathrm{CMM}=$ conventional medical management; $;$ vs = versus; $P=$ positive Adapted from Frey ME et al. Spinal cord stimulation for patients with failed back surgery syndrome: A systematic review. Pain Physician 2009; 12:379-397 (42). 
mendation is $1 \mathrm{~B}$ or $1 \mathrm{C} /$ strong recommendation for clinical use on a long-term basis.

\subsection{Implantable Intrathecal Drug Administration Systems}

Continuous infusion of intrathecal medication is used for control of chronic, refractory, malignant and non-malignant pain $(7,33,53,92)$.

\subsubsection{Evidence Assessment}

Turner et al (92), in a systematic review of effectiveness and complications of programmable intrathecal opioid delivery systems for chronic non-cancer pain, found improvement in pain among patients who received a permanent intrathecal drug delivery system. Recently, Patel et al (33) indicated the level of evidence for intrathecal infusion systems of either Level II-3 or III (limited). There were 5 observational studies which met inclusion criteria (1015-1019).

Three of the 5 observational studies $(1015,1016,1019)$ with availability of outcomes showed positive results with only 232 patients (Table 30 ).

\subsubsection{Cost Effectiveness}

In post lumbar surgery syndrome, it was shown that intrathecal morphine delivery resulted in lower cumulative 60 -month costs of $\$ 16,579$ per year and
$\$ 1,382$ per month versus medical management at $\$ 17,037$ per year or $\$ 1,420$ per month (1020).

\subsubsection{Safety and Complications}

The complications include post-dural puncture headache, infection, nausea, urinary retention, pruritus, catheter and pump failure, pedal edema, hormonal changes, granuloma formation, and decreased libido (1021-1027).

\subsubsection{Indications}

The most common indication for the use of intrathecal pumps is disease of the spine (1020). Common specific diseases include adhesive arachnoiditis, postlaminectomy syndrome, spinal stenosis, and intractable low back and lower extremity pain.

\subsubsection{Level of Evidence}

The indicated evidence for intrathecal infusion systems (Table 30) is either Level II-3 or Level III, for long-term relief of chronic non-cancer pain of longer than one-year based on USPSTF criteria (126).

\subsubsection{Recommendations}

Based on Guyatt et al's criteria (136), the recommendation for intrathecal infusion systems is $1 \mathrm{Cl}$ strong, with proper selection criteria.

Table 30. Results of published studies of effectiveness of intrathecal infusion systems.

\begin{tabular}{|c|c|c|c|c|c|c|c|}
\hline \multirow[b]{2}{*}{ Study } & \multirow[b]{2}{*}{$\begin{array}{c}\text { Study } \\
\text { Characteristics }\end{array}$} & \multirow[b]{2}{*}{$\begin{array}{l}\text { Methodological } \\
\text { Quality Scoring }\end{array}$} & \multirow[b]{2}{*}{ Participants } & \multicolumn{2}{|c|}{ Pain Relief } & \multicolumn{2}{|c|}{ Results } \\
\hline & & & & $\leq 12 \mathrm{mos}$ & $>12 \mathrm{mos}$ & $\begin{array}{c}\text { Short-term } \\
\text { relief } \leq 12 \\
\text { months }\end{array}$ & $\begin{array}{c}\text { Long-term } \\
\text { relief }>12 \\
\text { months }\end{array}$ \\
\hline $\begin{array}{l}\text { Winkelmüller } \\
\text { \& Winkelmüller } \\
1996(1015)\end{array}$ & $\mathrm{O}$ & 53 & 120 & $74 \%$ & $74 \%$ & $\mathrm{P}$ & $\mathrm{P}$ \\
\hline $\begin{array}{l}\text { Roberts et al } 2001 \\
(1016)\end{array}$ & $\mathrm{O}$ & 50 & 88 & $82 \%$ & $82 \%$ & $\mathrm{P}$ & $\mathrm{P}$ \\
\hline $\begin{array}{l}\text { Shaladi et al } 2007 \\
(1019)\end{array}$ & $\mathrm{O}$ & 55 & 24 & $100 \%$ & $100 \%$ & $\mathrm{P}$ & $\mathrm{P}$ \\
\hline
\end{tabular}

$\mathrm{O}=$ observational; $\mathrm{P}$ = positive; $\mathrm{N}$ = negative; $\mathrm{NA}$ = not applicable

Adapted from Patel VB et al. Systematic review of intrathecal infusion systems for long-term management of chronic non-cancer pain. Pain Physician 2009; 12:345-360 (33). 


\subsection{DOCUMENTATION}

Documentation is to provide evidence or information. Documentation includes evaluation and management services, procedural services, and billing and coding. While the purpose of documentation is to provide information, it reflects the competency and character of the physician.

\subsection{Medical Necessity}

Medical necessity requires appropriate diagnosis and coding by the International Classification of Diseases, Ninth Revision, Clinical Modification (ICD-9-CM) to justify services rendered and indicates the severity of a patient's condition (1028). The Balanced Budget Act (HR 2015, Section 4317) requires all physicians to provide diagnostic information for all Medicare/Medicaid patients starting from January 1, $1998(1029,1030)$. Medical necessity is defined in numerous ways (1031-1035):

- The CMS (1033) defines medical necessity as ..."no payment may be made under Part A or Part B for any expense incurred for items or services which . . .are not reasonable and necessary for the diagnosis or treatment of illness or injury or to improve the functioning of a participant."

- The American Medical Association (AMA) (1035) defines medical necessity as, "health care services or procedures that a prudent physician would provide to a patient for the purpose of preventing, diagnosing or treating an illness, injury, disease or its symptoms in a manner that is:

- In accordance with generally accepted standards of medical practice.

- Clinically appropriate in terms of type, frequency, extent, site, and duration.

- Not primarily for the convenience of the patient, physician or other healthcare provider."

\subsection{Elements of Documentation}

Federal, state, third party payor, and managed care plans rely heavily on provider documentation when assessing the claims for various parameters. These include:

- Was the billed service actually rendered or provided to the patient?

- Was the level of service or extent of the service accurately reported?

- Was the service or procedure medically necessary?

- Was the claim sent to the correct primary insurer for the service or procedure performed?

\subsection{Types of Documentation}

Documentation includes evaluation and management services and interventional techniques. Documentation for spinal interventional techniques may vary based on whether the procedure was performed in a facility setting such as hospital outpatient department or ambulatory surgery center versus in a physician's office.

\subsection{Documentation of Interventional Procedures}

All spinal interventional techniques are considered surgical procedures. Documentation requirements are as follows:

- History and physical.

- Indications and medical necessity.

- Intra-operative procedural description.

- Post-operative monitoring and ambulation.

- Discharge/disposition.

\subsubsection{History and Physical}

The physician's history should include the following elements:

- Documentation of the signs and symptoms warranting the interventional procedure.

- A listing of the patient's current medications including dosages, route, and frequency of admission.

- Any existing co-morbid conditions and previous surgeries.

- Documentation of any social history or conditions which would have an impact on the patient's care upon discharge from the facility following the procedure.

The physician's physical examination should not only reflect the relevance to interventional procedure, but also the type of anesthesia planned. Generally, for interventional techniques, if no anesthesia is to be administered, the physical examination is limited to the assessment of the patient's mental status and an examination specific to the proposed procedure, including any co-morbid conditions.

However, if intravenous sedation or any other type of anesthesia is planned, the physical examination should also include documentation of the results of an auscultatory examination of the heart and lungs, and an assessment and written statement about the patient's general health, in addition to the assessment of mental status and an examination specific to the proposed procedure and any co-morbid conditions. 


\subsubsection{Indications and Medical Necessity}

Medical necessity must be established for each and every procedure and encounter. General documentation requirements for spinal interventional techniques for indications and medical necessity are as follows:

1. Complete initial evaluation including history and physical examination.

2. Physiological and functional assessment, as necessary and feasible.

3. Definition of indications and medical necessity, as follows:

- Suspected organic problem.

- Non-responsiveness to conservative modalities of treatment.

- Pain and disability of moderate-to-severe degree.

- No evidence of contraindications such as severe spinal stenosis resulting in intraspinal obstruction, infection, or predominantly psychogenic pain.

- Responsiveness to prior interventions with improvement in physical and functional status for repeat blocks or other interventions.

- Repeating interventions only upon return of pain and deterioration in functional status.

\subsubsection{Procedural Documentation}

This includes a description of the procedure, postoperative monitoring, and discharge/disposition (Table 31).

Table 31. Key components of documentation of an interventional procedure.

1. History and physical examination

2. Informed consent

3. Description of intravenous access, sedation, and physiologic monitoring (if utilized)

4. Appropriate patient positioning and sterile preparation

5. Anatomic needle placement

- Size, etc

- Local Anesthetic / Steroids / Other Solutions

- Volume

- Concentration

- Fluoroscopy

- Contrast

- Volume

- Spread

- Pain Provocation

6. Operating room staff

7. Description of complications (if any) and if none stated as such

8. Listing of post injection instructions to patient, including symptom monitoring as appropriate

9. Patient status at discharge

10. Post follow-up

\subsection{An Algorithmic Approach}

The algorithmic approach described here is based on the best available evidence on the epidemiology of various identifiable sources of chronic spinal pain. This algorithmic approach is designed to promote the efficient use of IPM techniques based on the best available evidence. However, this may not be applicable in each and every patient. The purpose of the described algorithmic approach is to provide a disciplined approach to the use of spinal interventional techniques in managing spinal pain. This approach includes evaluation, diagnostic, and therapeutic approaches which in turn avoid unnecessary care as well as poorly documented practices.

This algorithmic approach does not dictate standard of care-these are guidelines. Further, with space constraints, comprehensive initial evaluation and all the findings are not provided. Thus, this should not be construed as the entire evaluation. Only relevant descriptions are provided. Further, changes in physical functional and psychological status are not described for each encounter.

\subsection{Comprehensive Algorithm}

Figure 2 illustrates an algorithmic approach for evaluation and management of a chronic pain patient. Appropriate history, physical examination, and medical decision-making are essential to provide appropriate documentation and patient care. Not covered in this algorithm are socioeconomic issues and psychosocial factors that may be important in the clinical decision-making process. A comprehensive and complete evaluation will assist in complying with the regulations and providing appropriate care and also fulfilling an algorithmic approach.

\subsection{Low Back Pain}

\subsubsection{Diagnosis}

Figure 3 illustrates a diagnostic algorithmic approach for chronic low back pain without disc herniation. This algorithm for the investigation of low back pain is based on the best available evidence on the epidemiology of various identifiable sources of chronic low back pain. Facet joint pain, discogenic pain, nerve root pain, and sacroiliac joint pain have been proven to be common causes of pain with proven diagnostic techniques $(25,27,29,40,45,46,116,361-363)$.

If there is evidence of radiculitis, spinal stenosis, or other demonstrable causes resulting in radiculitis, 
one may proceed with diagnostic transforaminal or therapeutic epidural injections (25). Otherwise an algorithmic approach should include the diagnostic interventions with facet joint blocks and sacroiliac joint injections, followed by discography. Lumbar discography at the present time suffers from significant controversy with Level II-2 evidence (46). In contrast, facet joint nerve blocks in the diagnosis of lumbar facet joint pain provide higher evidence with Level I or Level II-1 (40), whereas sacroiliac joint injections provide Level II-2 evidence (45).

An algorithm for investigating chronic low back pain without disc herniation commences with clinical questions, physical findings, and findings of radiological investigations. Controlled studies have illustrated the prevalence of lumbar facet joint pain in $21 \%$ to $41 \%$ of patients with chronic low back pain $(29,40,338,361-365,368,369,372)$ and $16 \%$ in post laminectomy syndrome (373). The average prevalence of $31 \%(95 \% \mathrm{Cl} 28 \%-33 \%)$ and false-positive rate of $30 \%$ ( $95 \% \mathrm{Cl} 27 \%-33 \%)$ was shown by Datta et al (40). Thus, facet joints are entertained first in the algorithm because of their commonality as a source of chronic low back pain, available treatment, and ease of performance of the blocks. Further, among all the diagnostic approaches in the lumbosacral spine, medial branch blocks have the best evidence (Level I) with ability to rule out false-positives (27\% to $47 \%$ ) and demonstrated validity with multiple compounding factors, including psychological factors $(382,383)$, exposure to opioids (1036), and sedation $(44,380,1037)$. In this approach, investigation of facet joint pain is considered as a prime investigation, ahead of disc provocation and sacroiliac joint blocks. Multiple studies have indicated that facet joint pain may be bilateral in $60 \%$ to $79 \%$ of cases and involving 3 joints in $21 \%$ to $37 \%$ of patients $(364,365,369)$.

The diagnostic blocks must be performed under controlled conditions. In the United States, commonly performed diagnostic blocks are often accomplished with 2 separate local anesthetics - in what is referred to as controlled comparative local anesthetic blocks with a small volume of local anesthetic. If a patient experiences at least $80 \%$ relief with the ability to perform previously painful movements within a timeframe that is appropriate for the duration of the local anesthetic used and the duration of relief with the second block relative to the first block is commensurate with the respective local anesthetic employed in each block, then, a positive diagnosis is made.
In this algorithm, to pursue the sacroiliac joint as the pain generator, pain must be caudal to L5 and must be positive for at least some provocative tests, along with tenderness over the sacroiliac joint $(3,45,409)$. Sacroiliac joint blocks have a Level II-2 evidence in the diagnosis of sacroiliac joint pain utilizing comparative controlled local anesthetic blocks. The prevalence of sacroiliac joint pain is estimated to range between $2 \%$ and $38 \%$ using a double block paradigm in specific study populations $(27,45,116,338,409,411,569,570,577$, 578). The false-positive rates of single, uncontrolled, sacroiliac joint injections have been shown to be $20 \%$ to $54 \%(45)$. However, there has been a paucity of evidence in the evaluation of the effectiveness of sacroiliac joint blocks in the diagnosis of sacroiliac joint pain $(27,45,116)$.

One or both sacroiliac joints may be blocked utilizing controlled comparative local anesthetic block paradigms in the United States. The relief obtained should be $80 \%$ with the ability to perform previously painful movements and also should be concordant based on the local anesthetic injection with a bupivacaine injection outlasting a lidocaine injection $(3,45)$.

If pain is not suggestive of facet joint or sacroiliac joint origin, then the epidural injection algorithm is followed. Caudal and lumbar interlaminar epidurals are non-specific as far as identifying the source of pain. If a patient fails to respond to epidural injections, the discogenic approach may be undertaken.

Lumbar provocation discography is seldom performed as an initial test in the present algorithm. Provocative lumbar discography is performed as the first test in only specific settings of suspected discogenic pain and availability of a definitive treatment is offered or solely for diagnostic purposes prior to fusion. Otherwise, once facet joint pain, and if applicable sacroiliac joint pain, is ruled out and the patient fails to respond to at least 2 fluoroscopically directed epidural injections, discography may be pursued if determination of the disc as the source of pain is crucial. MRI will assist in ruling out any red flags and disc herniation, but will not determine if the disc is the cause of the pain. Hancock et al (409) in a systematic review of tests designed to identify the disc as a pain generator concluded that centralization was the only clinical feature associated with a discogenic pain etiology (1038). Provocation discography continues to be controversial with respect to diagnostic accuracy $(28,46,105,114)$, utilization $(13,56,58-60,278,327,328)$, and its impact on surgical volume $(63,636)$. Lumbar discography has 


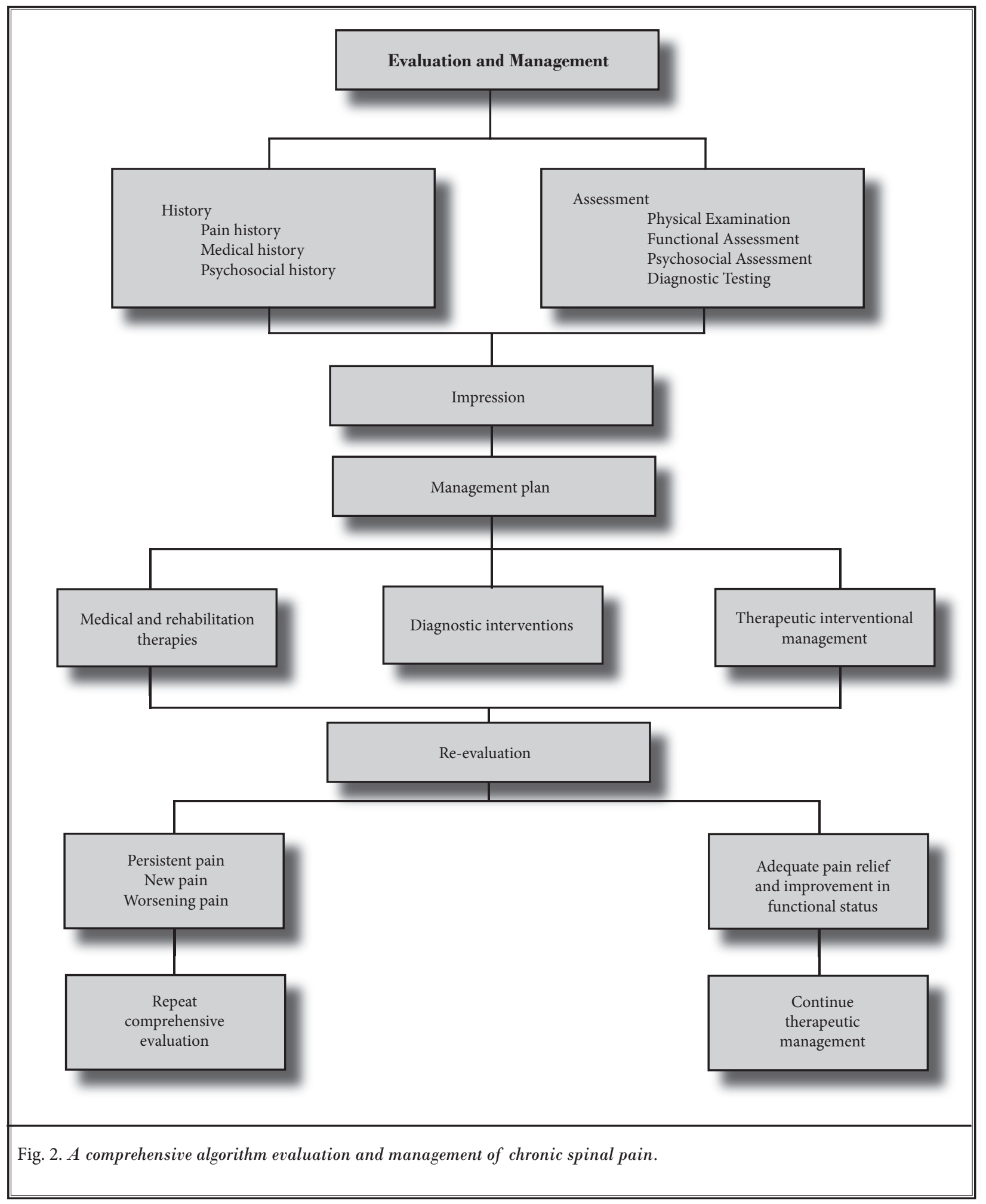




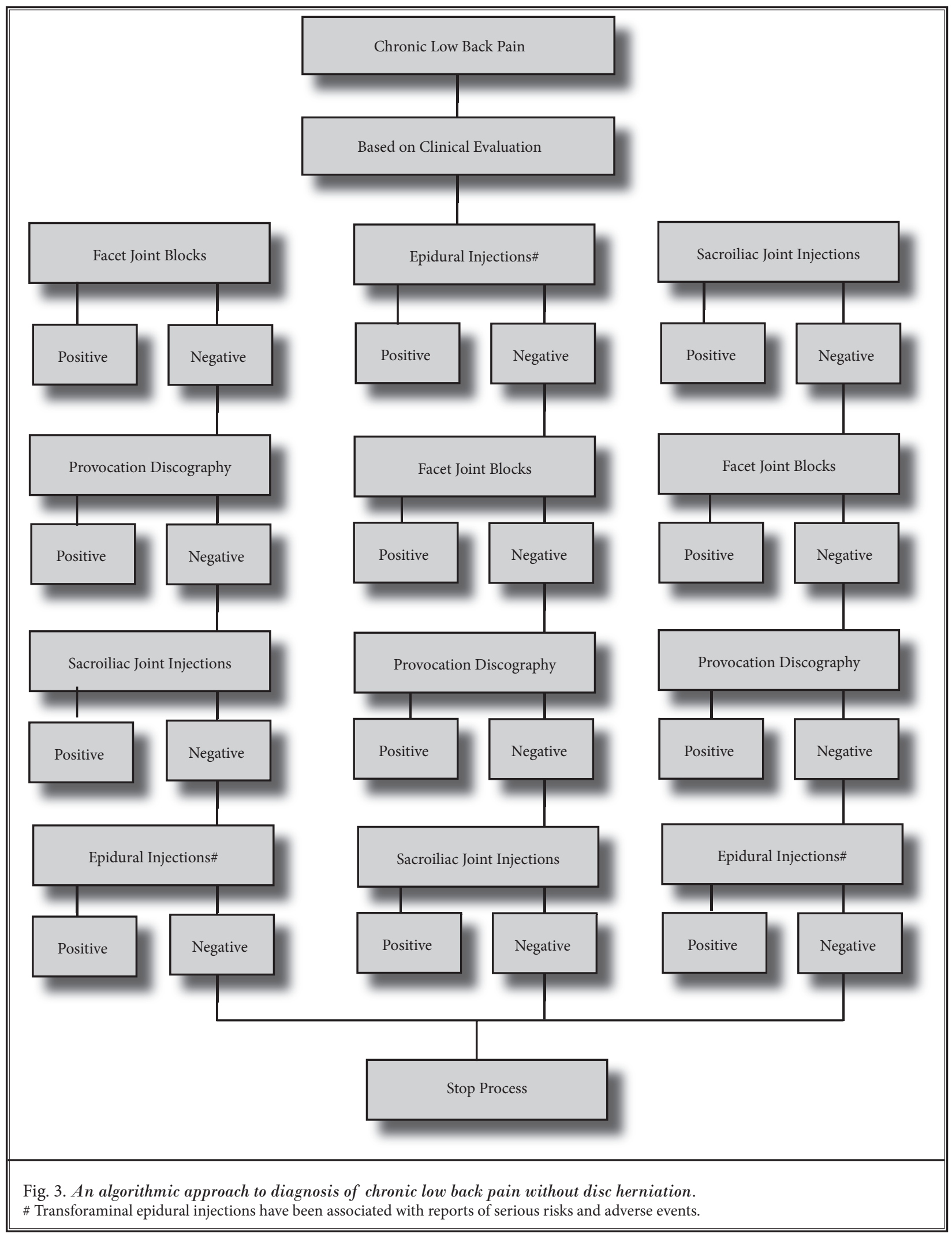


been refined substantially since its inception and its diagnostic accuracy has been established as Level II$2(3,46,53,105)$. However, to be valid, the provocation discography must be performed utilizing strict criteria of having concordant pain in one disc with at least 2 negative discs, one above and one below except when the $L 5 / S 1$ is involved. In that case, only one negative disc is needed along with the suspect disc (L5/S1 in this case) displaying evoked intensity of a pain score of 7 on a scale of 0 to 10 or $70 \%$ of worst spontaneous pain (i.e., worst pain of $7=7 \times 70 \%=5$ ) $(3,46)$.

\subsubsection{Diagnostic Efficiency}

Under the present algorithmic approach, once facet joint pain is excluded, the patient may be treated with epidural injections or sacroiliac joint blocks may be pursued provided the patient meets the criteria for sacroiliac joint blocks. Lumbar provocation discography is the last step in the diagnostic algorithm and is utilized only when appropriate treatment can be performed if disc abnormality is noted. The only other indication is to satisfy patients' impressions if the patient does not improve with any other modalities of treatments.

Given the realities of health care in the United States and the available evidence from the literature, it appears that lumbar facet joints account for $30 \%$ of cases of chronic low back pain, sacroiliac joint pain accounts for less than $10 \%$ of cases, and discogenic pain accounts for $25 \%$ of the patients.

\subsubsection{Management Algorithm}

\subsubsection{Somatic Pain Algorithm}

Figure 4 illustrates therapeutic algorithmic management. The patients testing positive for facet joint pain may undergo either therapeutic facet joint nerve blocks or radiofrequency neurotomy based on the patients' preferences, values, and physician expertise. However, there is no evidence for lumbar intraarticular facet joint injections (40). In contrast, based on the review of included therapeutic studies $(374,375,722)$, Level II-1 to II-2 evidence is presented for lumbar facet joint nerve blocks with an indicated level of evidence of II-2 to II-3 for lumbar radiofrequency neurotomy $(40,374,375,722,741,739)$.

The next modality of treatment is epidural injections. Epidural injections have been shown to present with variable evidence. A recent systematic review of caudal epidural injections in the management of chronic low back pain (34) showed Level I evidence for relief of chronic pain secondary to disc herniation or radiculitis and discogenic pain without disc herniation or radiculitis $(769,780,781)$. Further, the indicated evidence is Level II-1 or II-2 for caudal epidural injections in managing chronic pain of post lumbar surgery syndrome and spinal stenosis $(34,774,776)$. A systematic review of therapeutic lumbar transforaminal epidural steroid injections (37) showed an indicated level of evidence of Level II-1 for short-term relief and Level II-2 for long-term relief in managing chronic lumbar radicular pain. The majority of the patients derived from the diagnostic algorithmic approach do not have radicular pain or disc herniation, thus, transforaminal epidural injections are applied with the proper indications for patients with radiculitis (37). In contrast, the evidence for lumbar interlaminar epidurals is lacking (35) with a paucity of contemporary literature and lack of fluoroscopically directed studies, and an indicated evidence of Level II-2 for short-term relief of pain of disc herniation or radiculitis with limited or lack of evidence for other conditions.

The indicated evidence for therapeutic sacroiliac joint interventions $(27,45,116)$ is unavailable. Finally, the evidence for intradiscal procedures with thermal annular technology is also limited. The systematic review of the effectiveness of thermal annular procedures in treating discogenic low back pain (38) showed an indicated Level of evidence of II-2 for IDET, II-3 for radiofrequency annuloplasty, and limited or lack of evidence for IDB.

\subsubsection{Radicular Pain Algorithm}

While disc protrusion, herniation, and prolapse resulting in sciatica are seen in less than $5 \%$ of the patients with low back pain (945), approximately $30 \%$ of the patients presenting to IPM clinics will require either caudal, interlaminar, or transforaminal epidural injections as their initial treatment. Many patients with post-surgery syndrome, spinal stenosis, and radiculitis without disc protrusion may respond to epidural injections $(24,26,34-37,111,113)$. Patients non-responsive to epidural injections will require either mechanical disc decompression (49-52), percutaneous adhesiolysis $(26,43,113)$, spinal endoscopic adhesiolysis $(26,48,113)$, or implantation of a spinal cord stimulator (42) or intrathecal infusion systems (33) depending on the clinical presentation, pathology, and other biopsychosocial factors. Transforaminal epidural injections may be performed for diagnostic purposes; however, these also lead to therapeutic improvement. 
Buenaventura et al (37) in a systematic review of therapeutic lumbar transforaminal epidural steroid injections showed the indicated level of evidence as II-1 for short-term relief of 6 months or less and Level II-2 for long-term relief of longer than 6 months in managing chronic low back and lower extremity pain. Conn et al (34) in a systematic review of caudal epidural injections in the management of chronic low back pain showed variable evidence for various conditions causing low back and lower extremity pain. The evidence level shown is Level I for short- and long-term relief in managing chronic low back and lower extremity pain secondary to lumbar disc herniation and radiculitis, and discogenic pain without disc herniation or radiculitis. However, the indicated level of evidence is Level II-1 or II-2 for caudal epidural injections in managing low back pain of post-lumbar laminectomy syndrome and spinal stenosis.

In contrast to lumbar transforaminal epidural and caudal epidural injections, the evidence for lumbar interlaminar epidural injections in managing chronic low back and lower extremity pain is limited due to the lack of availability of studies utilizing fluoroscopy. The evidence is delivered from blind interlaminar epidural injections. Based on Parr et al's (35) systematic review, the indicated evidence is Level II-2 for short-term relief of pain of disc herniation or radiculitis utilizing blind interlaminar epidural steroid injections with a lack of evidence and Level III for long-term relief of disc herniation and radiculitis. Furthermore, the evidence at present is lacking for short- and long-term relief of spinal stenosis and discogenic pain without radiculitis or disc herniation utilizing blind epidural injections.

Consequently, if a patient presents with unilateral, single, or 2 level involvement, one may proceed with transforaminal epidural injections (diagnostic and therapeutic). Bilateral or extensive involvement of multiple segments will lead to either interlaminar or caudal epidurals based on the upper or lower levels being involved, extensive stenosis (central or foraminal) and lack of response to caudal or interlaminar approaches. Except in specific documented circumstances with spinal stenosis also is based on the same philosophy as described above for transforaminal epidurals. For postsurgery syndrome, a caudal epidural is preferred and one may consider a transforaminal epidural if essential in patients without obstructing hardware.

\subsubsection{Algorithm for Chronic Non-Responsive Pain}

Patients non-responsive to epidural injections, may be considered for mechanical disc decompression, percutaneous adhesiolysis, spinal endoscopic adhesiolysis, spinal cord stimulation, or implantation of intrathecal infusion systems.

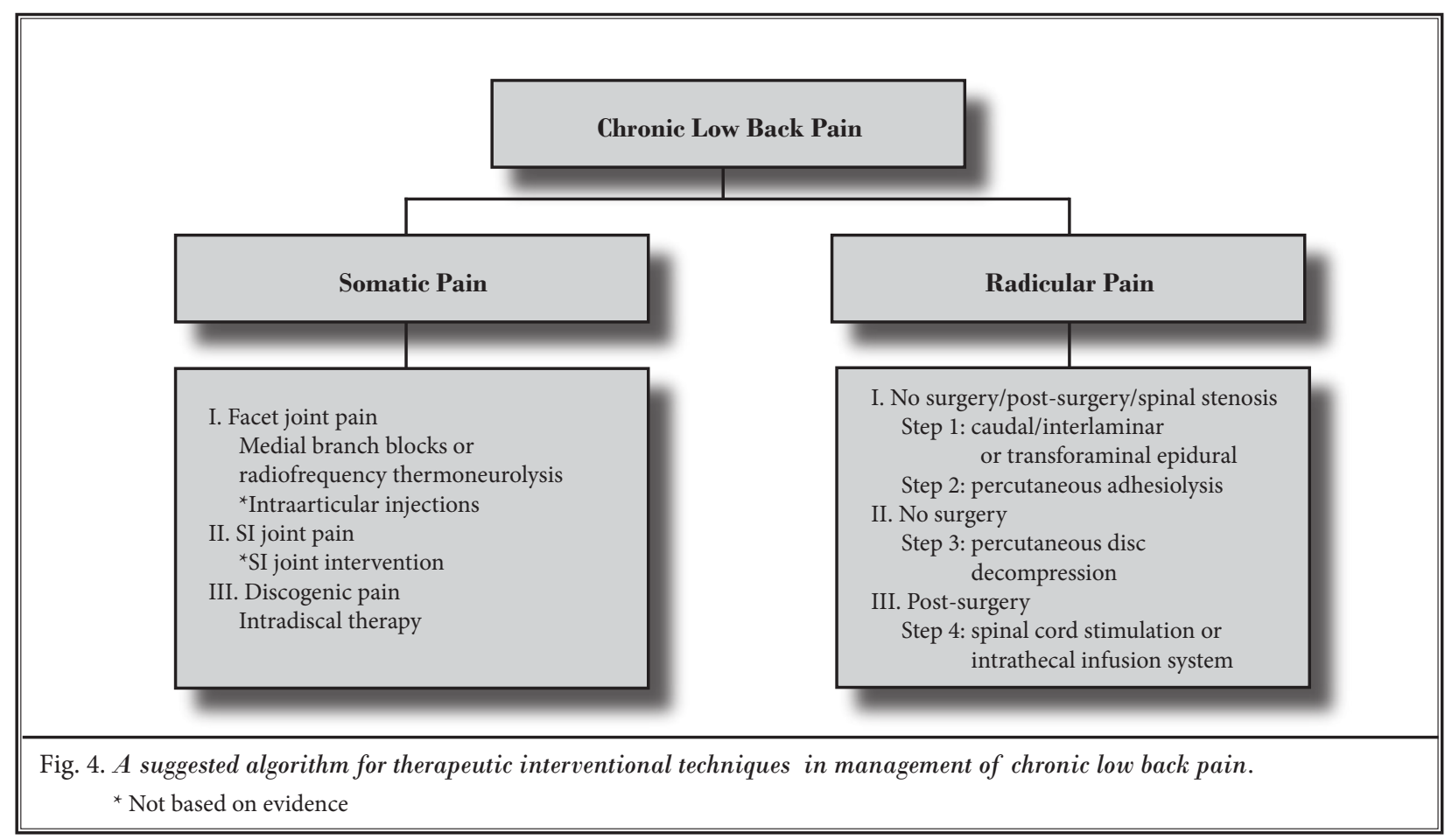


Percutaneous mechanical disc decompression (PMDD) is riddled with a lack of evidence even though there are 4 modalities, namely APLD, PLD, a mechanical high RPM device utilizing an Archimides' screw (DeKompressor $\left.{ }^{\circledR}\right)$, and coblation nucleoplasty or plasma decompression. Recent systematic reviews (49-52) showed the evidence to be Level II-2 for short- and long-term (> one year) improvement for percutaneous automated lumbar discectomy and laser discectomy. The evidence for coblation nucleoplasty (Level II-3) and Dekompressor (Level III) is only emerging.

In patients with post-lumbar surgery syndrome after failure to respond to fluoroscopically directed epidural injections, percutaneous adhesiolysis is considered (43). Despite a paucity of efficacy and pragmatic trials, the systematic review by Epter et al (43) indicated the level of evidence as Level I or II-1 with short-term relief being considered as 6 months or less and long-term longer than 6 months (876-882), in managing post-lumbar laminectomy syndrome. Another type of adhesiolysis, spinal endoscopic adhesiolysis, which is considered to be an experimental procedure, also showed the indicated level of evidence of II-1 or II-2 for short-term and long-term ( $\leq 6$ months or $>6$ months) (30).

The next step in the radicular pain algorithm is implantable therapy. Frey et al (42) in a systematic review of SCS for patients with FBSS indicated the level of evidence as II-1 or II-2 for long-term relief (> one year) in managing patients with FBSS. In this systematic review (42), 2 randomized trials $(1001,1003)$ and 8 observational studies were included (1004,1006-1012). Despite early increased expense, cost-effectiveness has been demonstrated for SCS (995-999).

Finally, long-term management of chronic non-cancer pain may be achieved with intrathecal infusion systems (33). Intrathecal infusion systems are also utilized for non-cancer pain in FBSS as an advanced stage intervention. While there is a lack of conclusive evidence, Patel et al (33), due to the paucity of quality literature concluded that the level of evidence for intrathecal infusion systems was indicated as Level II-3 or Level III with longer than one-year improvement considered as long-term response. There were no randomized trials meeting inclusion criteria for this systematic review (56).

\subsection{Neck Pain}

\subsubsection{Diagnosis}

Figure 5 illustrates an algorithmic approach to the diagnosis of chronic neck pain without disc hernia- tion. This represents an algorithmic approach for the investigation of neck pain based on the best available evidence on the epidemiology of various identifiable sources of chronic neck pain. In a systematic review of diagnostic utility and therapeutic effectiveness of cervical facet joint interventions, Falco et al (41), based on the controlled diagnostic blocks, determined the prevalence to be $36 \%$ to $67 \%$ with an average prevalence of $49 \%$ based on 8 studies $(339,364,365,369,601$ 604) with a false-positive rate of $27 \%$ to $63 \%$ (average $49 \%$ ) with single diagnostic blocks. In a systematic review of cervical discography as a diagnostic test for chronic spinal pain (39), the prevalence of cervical discogenic pain utilizing IASP criteria ranged between $16 \%$ and $20 \%$ based on 3 studies $(339,644,645)$.

If there is evidence of radiculitis, spinal stenosis, post-surgery syndrome, or other demonstrable causes resulting in radiculitis, an interventionist may proceed with therapeutic epidural injections. For diagnostic purposes one may proceed with diagnostic cervical selective nerve root blocks or transforaminal epidural injections in rare circumstances. However, diagnostic accuracy of cervical selective nerve root blocks has not been established $(25,115)$. Cervical transforaminal epidural injections have been associated with substantial risk (762,825,1039-1050). In contrast, therapeutic cervical interlaminar epidural injections have been shown with an indicated level of evidence of II-1 in managing chronic neck and upper extremity pain (36). Otherwise an algorithmic approach should include the diagnostic interventions with facet joint blocks, epidural injections, followed by discography. Discography at the present time suffers from significant controversy with Level II-2 evidence (39). In contrast, facet joint nerve blocks in the diagnosis of cervical facet joint pain provide evidence of Level I or Level II-1 (41).

An algorithm of investigation of chronic neck pain without disc herniation or radiculitis commences with clinical questions and physical and imaging findings. The controlled studies have illustrated the presence of facet joint pain on average in $40 \%$ to $50 \%$ of cases, ranging from $36 \%$ to $67 \%$ of the patients and $39 \%$ in a large recent study. Thus, the facet joints are entertained first in the algorithm in patients without radicular symptoms because of their commonality as a causative factor for chronic neck pain and headache and ease of performance. Consequently, the investigation of facet joint pain is considered as a prime investigation ahead of disc stimulation. Multiple studies have indicated the facet joint pain to be bilateral in 


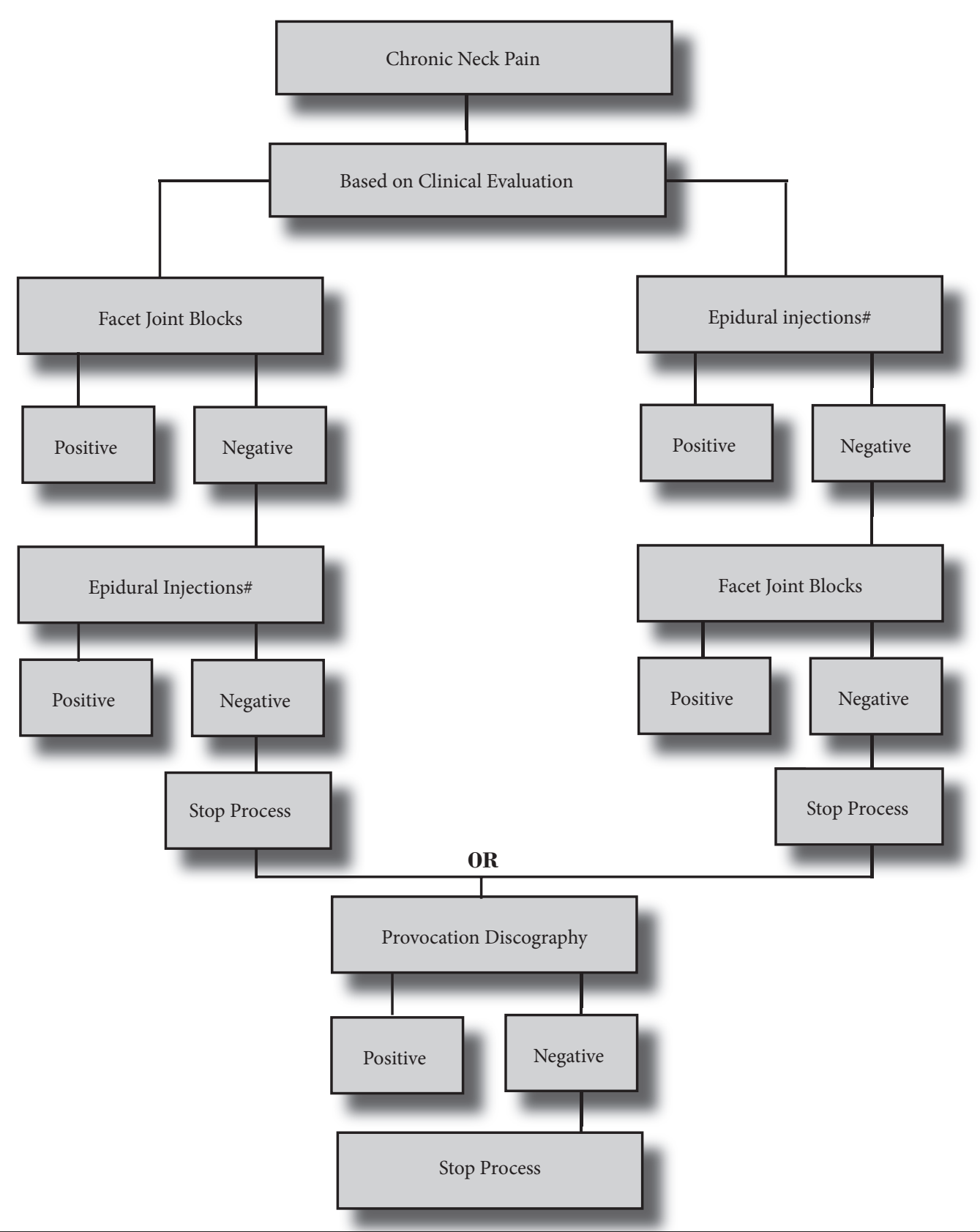

Fig. 5. An algorithmic approach to diagnosis of chronic neck pain without disc herniation.

\# Transforaminal epidural injections have been associated with reports of serious risks and adverse events

$69 \%$ to $72 \%$ of cases and involving at least 3 joints in $50 \%$ to $85 \%$ of patients $(364,365,369)$.

The diagnostic blocks must be performed under controlled conditions. In the United States, commonly performed diagnostic blocks are often achieved using 2 separate local anesthetics - controlled comparative lo- cal anesthetic blocks with a small volume of injectate.

If the facet joints are shown to be causative of chronic neck pain with $80 \%$ relief and the ability to perform previously painful movements with concordant response with 2 different local anesthetics, a positive diagnosis is made. 
Cervical interlaminar injections are indicated if the facet joints are not suspected as a source for neck pain. However, if the patient fails to respond to epidural injections, further diagnostic interventions evaluating the disc may be undertaken provided a treatment can be offered.

Cervical provocation discography is seldom performed as an initial test in the present algorithmic approach. Once the facet joint pain is ruled out and the patient fails to respond to at least 2 fluoroscopically directed epidural injections, discography may be pursued if the determination of the disc as the source of pain is crucial. However, to be valid, the provocation discography must be performed utilizing criteria with concordant pain in one disc with at least 2 negative discs, with evoked intensity of pain of 7 of 10 or $70 \%$ of worst spontaneous pain (e.g., worst pain of $7=>7$ $x 70 \%=5$, being the pain score that would be significant upon disc provocation) $(3,39)$.

\subsubsection{Diagnostic Efficiency}

Under the present algorithmic approach, which is simple, efficient, and cost-effective, once facet joint pain is excluded, the patient may be treated with epidural injections. Essentially, cervical provocation dis- cography is the last step in the diagnostic algorithm and is utilized only when appropriate treatment can be offered if the disc abnormality is demonstrated. However, a rare but justifiable indication is to satisfy the patients' impressions if the patient does not improve with any other modalities of treatment. Thus far, studies have demonstrated the effectiveness of epidural injections in the cervical region as well as specifically in discogenic pain in the lumbar region $(34,36,769,774,776,780,781,819,820,1051-1055)$.

In the United States, based on available literature, cervical facet joints account for $40 \%$ to $50 \%$ of cases of chronic neck pain without disc herniation, while discogenic pain accounts for approximately $20 \%$ of the cases.

\subsubsection{Management Algorithm}

\subsubsection{Somatic Pain Algorithm}

As illustrated in Fig. 6 showing the therapeutic algorithmic management of chronic neck pain, patients testing positive for facet joint pain may undergo either therapeutic facet joint nerve blocks or radiofrequency neurotomy based on patients' preferences, values, and physician expertise. However, there is no evidence for

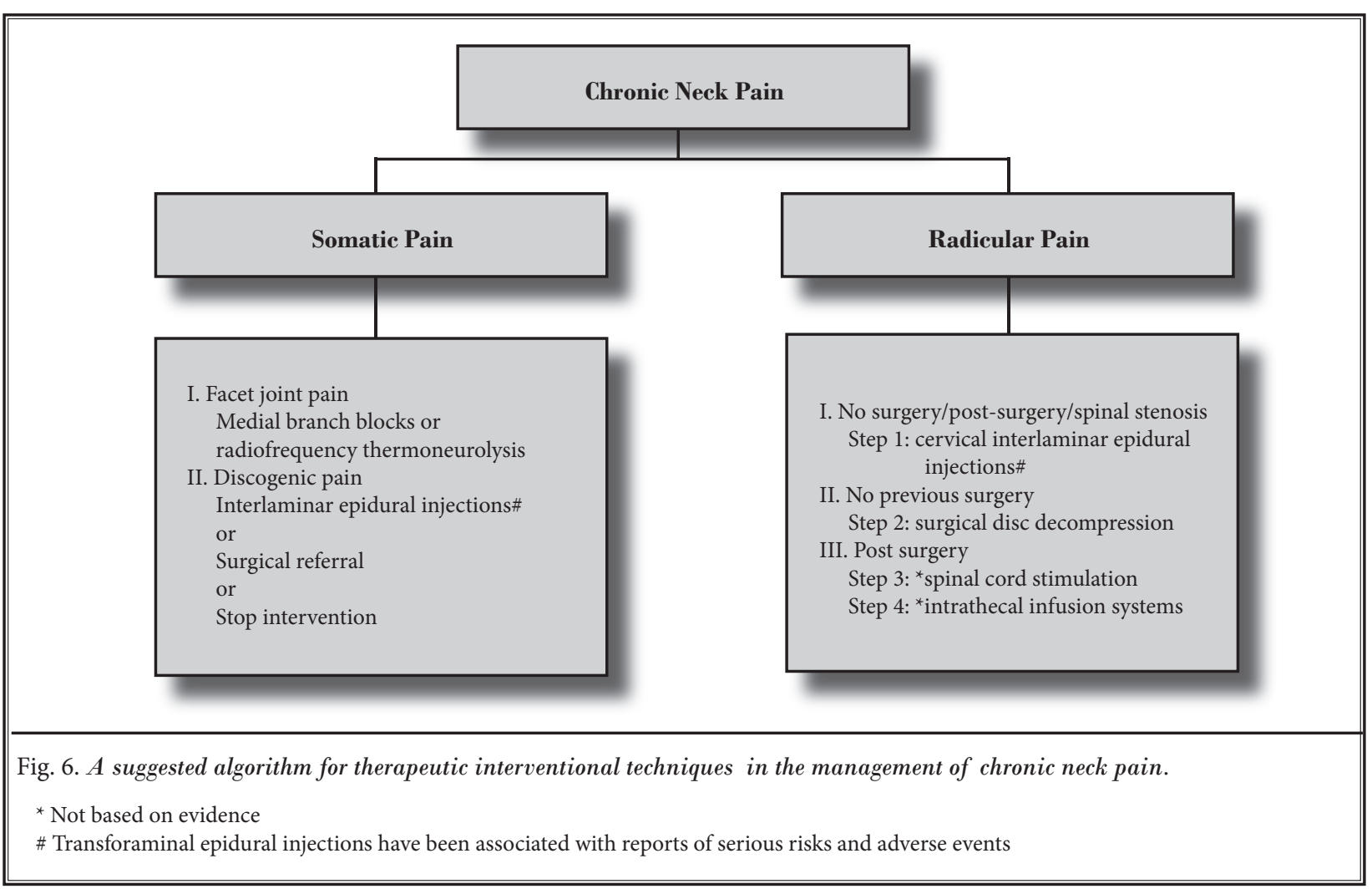


cervical intraarticular facet joint injections (41). In contrast to lack of evidence for intraarticular injections, Falco et al (41) have shown evidence for cervical medial branch blocks of II-1 or II-2 for cervical medial branch radiofrequency neurotomy based studies utilizing appropriate diagnostic criteria $(575,592-594,596-598)$.

\subsubsection{Radicular Pain Algorithm}

Disc protrusions, herniations, or prolapses are less common in the cervical spine than in the lumbar spine. Radiculitis may also result from cervical spinal stenosis, spondylolisthesis, post-surgery syndrome, and discogenic pain without disc herniation. Approximately $30 \%$ of the patients presenting to IPM will require interlaminar epidural injections as their initial treatment. Transforaminal epidurals may be performed for diagnostic purposes, but they lack evidence and have increased risks $(25,115,762,825,1039-1050)$.

\subsubsection{Chronic Non-Responsive Pain Algorithm}

Given a failure to respond to less invasive modalities of treatments, the consideration is then for SCS and intrathecal infusion systems. Evidence of these modalities in managing chronic intractable neck pain has not been evaluated. The evidence in the lumbar spine (42) is Level II-1 or II-2 for long-term relief in managing patients with FBSS. However, the evidence for intrathecal infusion systems is Level II-3 or Level III with one-year long-term improvement (33).

\subsection{Thoracic Pain}

\subsubsection{Diagnosis}

Figure 7 illustrates diagnostic algorithmic approach for chronic thoracic pain without disc herniation or radiculitis.

This algorithm for investigation of thoracic pain is based on the best available evidence on the epidemiology of various identifiable sources of chronic mid back and upper back pain. Facet joint pain has been proven to be one of the common causes of pain with proven diagnostic techniques $(31,364,365,658)$. Based on the controlled, comparative local anesthetic blocks, thoracic facet joint pain has been shown to be present in approximately $40 \%$ of patients with mid-upper back pain when data from 3 studies were combined ( $34 \%$ to $48 \%$ ) with false-positive rates of $42 \%$. In contrast, the prevalence, as well as diagnostic accuracy of thoracic discogenic pain has not been well demonstrated (32).

Consequently, if a patient has any signs of radiculitis or disc herniation or other demonstrable causes resulting in radiculitis, one may proceed with therapeutic epidural injections. Otherwise, an algorithmic approach should include diagnostic interventions with facet joint blocks, epidural injections, and in rare circumstances, provocation thoracic discography and transforaminal epidural injections. Thoracic discography suffers from substantial controversy with low levels of evidence compared to cervical and lumbar discography. Thoracic transforaminal epidural injections are associated with high risk (860).

An algorithm for investigating chronic mid back or upper back pain without disc herniation commences with clinical questions, clinical findings, and findings of imaging. In this approach, investigation of facet joint pain is considered as the prime investigation, ahead of disc stimulation. Facet joint pain is bilateral in $64 \%$ to $84 \%$ of cases and involving 3 joints or more in $81 \%$ to $94 \%$ of patients $(364,365,658)$.

The diagnostic blocks must be performed under controlled conditions. If a patient experiences at least $80 \%$ relief with the ability to perform previously painful movements with a concordant response in relation to duration of local anesthetics, a positive diagnosis is made.

Thoracic provocation discography is seldom performed, not only as an initial test, but in the settings of IPM. Once facet joint pain is ruled out and the patient fails to respond to at least 2 fluoroscopically directed epidural injections, investigations may cease or, under rare circumstances, discography may be pursued.

\subsubsection{Diagnostic Efficiency}

Under the present algorithmic approach, once facet joint pain is excluded, the patient may be treated with epidural injections. Thoracic provocation discography is an extremely rare and last step in the diagnostic algorithm and is utilized only when appropriate treatment can be performed if the disc abnormality is noted. The only very rare exception may be to perform discography to satisfy the patient's impressions if the patient does not improve with any other modalities of treatment.

Given the frequency of involvement of thoracic spine and the practice of medicine in the United States as well as the lack of significant pertinent literature, 


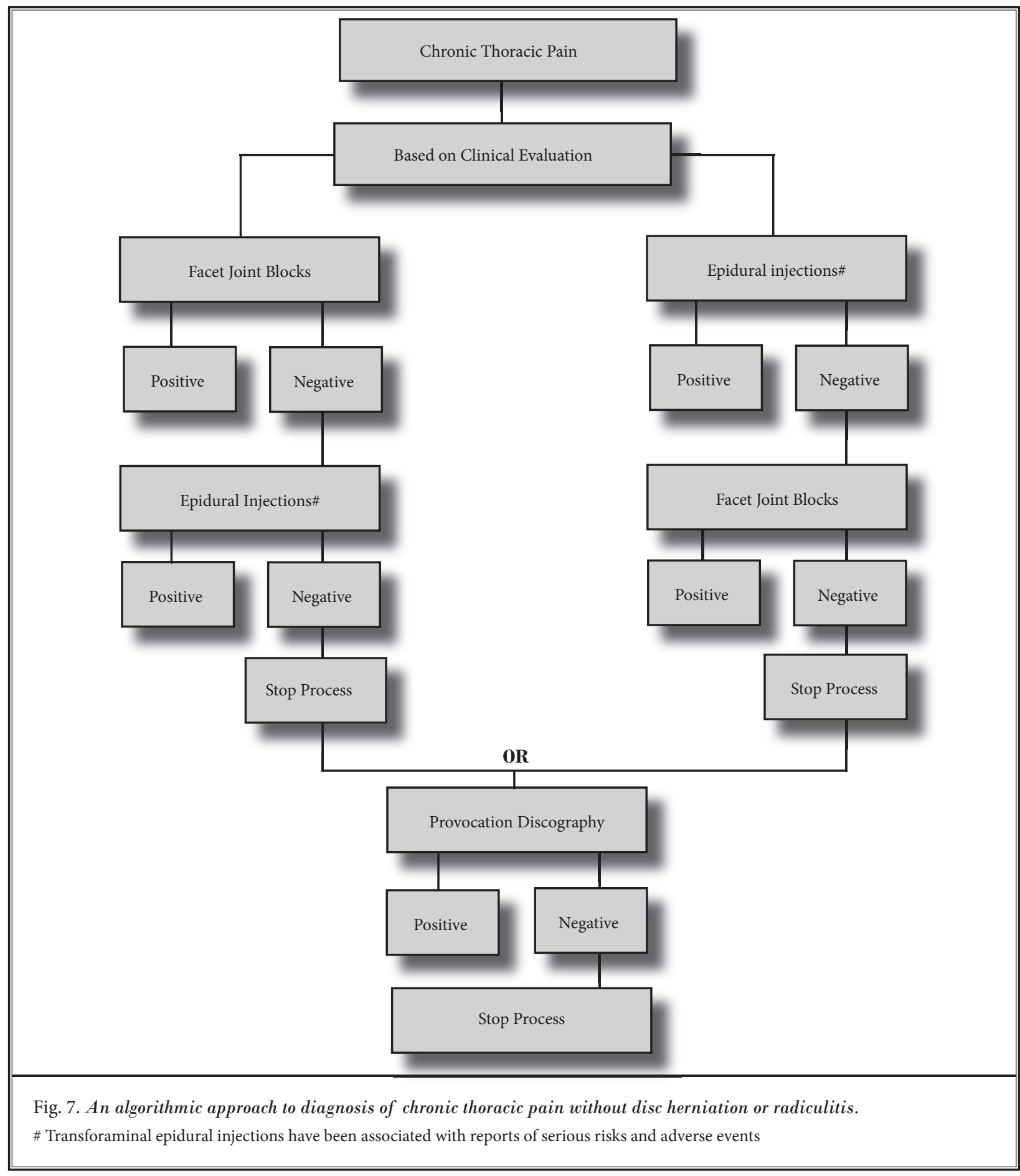

it appears that thoracic facet joints account for $40 \%$ of the cases of chronic mid back and upper back pain, whereas the remaining are considered to be discogenic pain or without specific diagnosis.

\subsubsection{Management Algorithm}

Figure 8 illustrates therapeutic algorithmic management. The patients testing positive for facet joint pain may undergo either therapeutic facet joint nerve 
blocks or radiofrequency neurotomy based on the patient's preferences, values, and physician expertise. However, there is no evidence for either thoracic intraarticular facet joint injections or radiofrequency neurotomy (31). The only available evidence is for therapeutic thoracic medial branch blocks with a Level II-1 for short-term and long-term relief (31).

\subsubsection{Somatic Pain Algorithm}

As illustrated in Fig. 8 displaying the therapeutic algorithmic management of chronic thoracic pain, patients testing positive for facet joint pain may undergo therapeutic facet joint nerve blocks, however radiofrequency neurotomy may be offered based on the patients' preferences, values, and physician expertise. At present there is no evidence for either thoracic intraarticular facet joint injections or radiofrequency neurotomy. In contrast, based on the review of included therapeutic studies $(31,659,660)$, Level II-1 or II-2 evidence is presented for thoracic facet joint nerve blocks.

The next modality of treatment is epidural injections. Epidural injections have been shown to have variable evidence in the cervical and lumbar regions with no analyzable evidence in the thoracic spine (34-37).

\subsubsection{Radicular Pain Algorithm}

Disc protrusions and herniations are much less common in the thoracic spine than the lumbar or cervical spine. Nonetheless, very few patients who present with thoracic radiculitis, post-surgery syndrome, spinal stenosis, and radiculitis without disc protrusion, and patients failing to show evidence of facet joint pain are candidates for epidural injections. Epidural injections are most commonly provided through an interlaminar route rather than transforaminal which is associated with high risk. Thoracic interlaminar epidural injections have not been evaluated or proven as to their effectiveness.

\subsubsection{Algorithm for Chronic Non-Responsive Pain}

Patients non-responsive to facet joint interventions and epidural interventions in the thoracic spine, in rare circumstances, may be considered for disc decompression or intrathecal implantables either with SCS or intrathecal infusion systems. However, there is no evidence available for any of the management modalities. Consequently, management is based on physician experience and patients' values and beliefs.

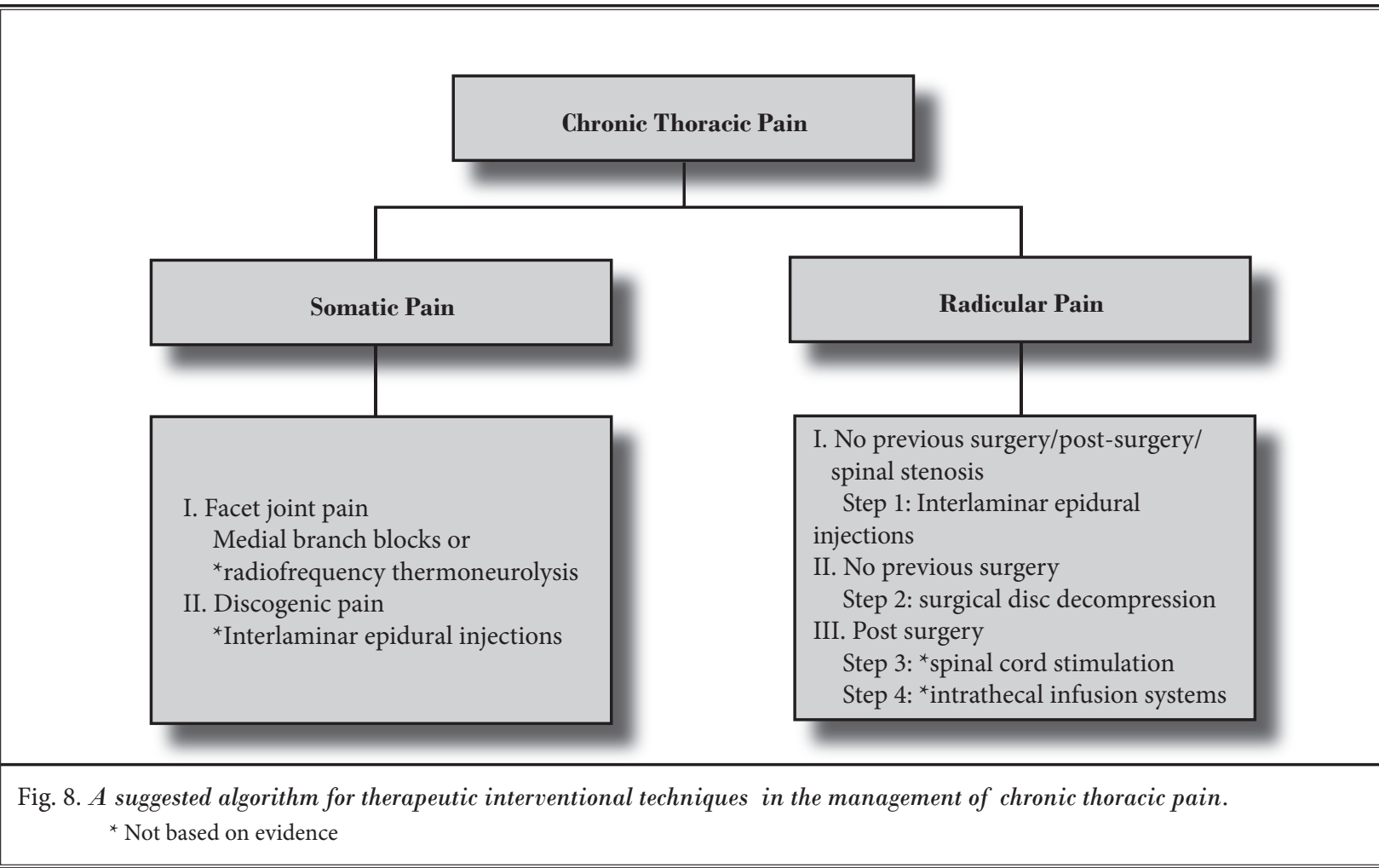




\subsection{Delivery of Interventional TECHNOLOGY}

There is no consensus among IPM specialists with regards to type, dosage, frequency, total number of injections, or other interventions. Fortunately, the recent literature provides some guidance even though it is not conclusive. Based on the principles of EBM, the average relief per procedure is considered as the recommended duration if it is safely performed without complications.

The recent literature shows no significant difference in the outcomes with or without steroids with medial branch blocks $(31,40,41,375)$ and epidural injections $(34-37,659,660,769,774,776,780)$. Further many of the techniques including radiofrequency neurolysis and disc decompressions do not require any steroids.

The most commonly used formulations of longacting steroids include methylprednisolone (Depo-Medrol), triamcinolone acetonide (Aristocort or Kenalog), and betamethasone acetate and phosphate mixture (Celestone Soluspan) (401,810,868,871, 1056-1077).

The chemistry of neuraxial steroids has taken center stage in recent years due to the devastating complications following epidural injections, specifically transforaminals. Steroid particle embolization of small radicular arteries is believed to be an important causative factor (1076-1079). Tiso et al (1073) and Benzon et al (1074) extensively evaluated chemical properties and their relationship to IPM.
Data from Tiso et al (1073) and Benzon et al (1074) regarding particle sizes were in general agreement with regards to methylprednisolone, triamcinolone, and commercial betamethasone. Though all formulations of steroids may be considered safe, formulations of betamethasone appear to be safer with no significant difference in the effectiveness (810). Formulations of commonly used epidural steroids are shown in Table 32 and the pharmacologic profile of commonly used epidural steroids is shown in Table 33 $(659,660,1056,1057,1074,1080-1082)$.

Consistent with the present literature of the pharmacology of steroids, it appears that non-particulate steroids may be the agents of choice for transforaminal epidural injections, though no trials have compared particulate to non-particulate steroids. However, particulate steroids may be safely utilized for interlaminar or caudal epidural injections. Caution must be exercised in the use of particulate steroids in transforaminal epidural injections and specifically for cervical transforaminal epidural injections, particularly if sharp needles are used.

The frequency and total number of injections have been considered important issues, even though controversial and poorly addressed. These are based on flawed assumptions from non-existing evidence. Over the years, some authors have recommended one injection for diagnostic as well as therapeutic purposes.

Table 32. Formulations of commonly used epidural steroids.

\begin{tabular}{|c|c|c|c|c|c|c|}
\hline & \multicolumn{2}{|c|}{ Depo-Medrol } & Kenalog & Celestone & Decadron & $\begin{array}{c}\text { Non-particulate } \\
\text { Celestone }\end{array}$ \\
\hline & \multicolumn{2}{|c|}{ Methylprednisolone } & \multirow{2}{*}{$\begin{array}{c}\begin{array}{c}\text { Triamcinolone } \\
\text { acetonide }\end{array} \\
40 \mathrm{mg} / \mathrm{mL}\end{array}$} & \multirow{2}{*}{$\begin{array}{c}\begin{array}{c}\text { Betamethasone } \\
\text { preservative free }\end{array} \\
6 \mathrm{mg} / \mathrm{mL}\end{array}$} & \multirow{2}{*}{$\begin{array}{c}\begin{array}{c}\text { Dexamethasone } \\
\text { sodium phosphate }\end{array} \\
4 \mathrm{mg} / \mathrm{mL} \\
\end{array}$} & \multirow{2}{*}{$\begin{array}{c}\begin{array}{c}\text { Betamethasone } \\
\text { sodium } \\
\text { phosphate }\end{array} \\
6 \mathrm{mg} / \mathrm{mL}\end{array}$} \\
\hline Amount of steroid & $40 \mathrm{mg} / \mathrm{mL}$ & $\begin{array}{c}80 \\
\mathrm{mg} / \mathrm{mL}\end{array}$ & & & & \\
\hline Polyethylene glycol 3350 & 29.1 & 28.2 & - & - & - & - \\
\hline Polysorbate 80 & 1.94 & 1.88 & 0.4 & - & - & - \\
\hline Monobasic sodium phosphate & 6.8 & 6.59 & - & 3.4 & - & 3.0 \\
\hline Benzyl alcohol & 9.16 & 8.8 & 9 & - & - & - \\
\hline Diabasic sodium phosphate & - & - & - & 7.1 & - & 6.0 \\
\hline Edetate disodium & - & - & - & 0.1 & - & - \\
\hline Benzalkonium chloride & - & - & - & 0.2 & - & - \\
\hline Sodium sulfite & - & - & - & - & $1 \mathrm{mg}$ & - \\
\hline
\end{tabular}


Table 33. Profile of commonly used epidural steroids.

\begin{tabular}{|c|c|c|c|c|c|c|c|}
\hline \multirow[b]{2}{*}{ Drug } & \multirow{2}{*}{$\begin{array}{c}\text { Equivalent } \\
\text { Dose }\end{array}$} & \multirow{2}{*}{$\begin{array}{c}\text { Epidural } \\
\text { Dose }\end{array}$} & \multirow{2}{*}{$\begin{array}{c}\text { Anti- } \\
\text { Inflammatory } \\
\text { Potency }\end{array}$} & \multirow{2}{*}{$\begin{array}{c}\text { Sodium } \\
\text { Retention } \\
\text { Capacity }\end{array}$} & \multicolumn{3}{|c|}{ Duration of Adrenal Suppression } \\
\hline & & & & & IM & $\begin{array}{c}\text { Single } \\
\text { Epidural }\end{array}$ & $\begin{array}{c}\text { Three } \\
\text { Epidurals }\end{array}$ \\
\hline Hydrocortisone & $20 \mathrm{mg}$ & N/A & 1 & 1 & N/A & N/A & N/A \\
\hline $\begin{array}{l}\text { Depo-Methylprednisolone } \\
\text { (Depo-Medrol) }\end{array}$ & $4 \mathrm{mg}$ & $40-80 \mathrm{mg}$ & 5 & 0.5 & 1-6 weeks & $1-3$ weeks & N/A \\
\hline $\begin{array}{l}\text { Triamcinolone acetonide } \\
\text { (Kenalog) }\end{array}$ & $4 \mathrm{mg}$ & $40-80 \mathrm{mg}$ & 5 & 0 & $2-6$ weeks & N/A & 2-3 months \\
\hline $\begin{array}{l}\text { Betamethasone (Celestone } \\
\text { Soluspan) }\end{array}$ & $0.6 \mathrm{mg}$ & $6-12 \mathrm{mg}$ & 33 & 0 & 1-2 weeks & N/A & N/A \\
\hline $\begin{array}{l}\text { Dexamethasone } \\
\text { (Decadron) }\end{array}$ & $0.75 \mathrm{mg}$ & 8-16 mg & 27 & 1 & N/A & N/A & N/A \\
\hline
\end{tabular}

$\mathrm{N} / \mathrm{A}=$ Not available

Data adapted and modified from McEvoy et al (1057), Jacobs et al (1080) Kay et al (1081), Hsu et al (1082), Mikhail et al (871) Schimmer and Parker (1056) and Benzon et al (1074).

Some have preached 3 injections in a series irrespective of a patient's progress or lack thereof, whereas others suggest 3 injections followed by a repeat course of 3 injections after 3-, 6-, or 12-month intervals. There are also proponents who propose that an unlimited number of injections with no established goals or parameters should be available. A limitation of $3 \mathrm{mg}$ per kilogram of body weight of steroid or $210 \mathrm{mg}$ per year in an average person and a lifetime dose of $420 \mathrm{mg}$ of steroid also has been advocated; however, with no scientific basis. The comprehensive review of the literature in preparation of these guidelines and review of all the systematic reviews has not shown any basis for the above reported assumptions and limitations. The administration must be based solely on patients' response, safety profile of the drug, experience of the patient, and pharmacological and chemical properties such as duration of action and suppression of adrenals.

\subsection{Indications}

Indications are variable for various types of interventional techniques.

\subsection{Facet Joint Interventions}

These guidelines apply for cervical, thoracic, and lumbar facet joint interventions.

- Common indications for diagnostic facet joint interventions are as follows:

- Somatic or nonradicular neck, mid back, upper back or low back and headache, upper extremity pain, chest wall pain or lower ex- tremity pain.

- Duration of pain of at least 3 months.

- Average pain levels of $\geq 6$ on a scale of 0 to 10.

- Intermittent or continuous pain causing functional disability.

- Failure to respond to more conservative management, including physical therapy modalities with exercises, chiropractic management, and nonsteroidal anti-inflammatory agents.

- Lack of evidence, either for discogenic or sacroiliac joint pain.

- Lack of disc herniation or evidence of radiculitis.

- No contraindications with understanding of consent, nature of the procedure, needle placement, or sedation.

- No history of allergy to contrast administration, local anesthetics, steroids, Sarapin, or other drugs potentially utilized.

- Contraindications or inability to undergo physical therapy, chiropractic management, or inability to tolerate nonsteroidal anti-inflammatory drugs.

- Common indications for therapeutic facet joint interventions are based on the above indications and positive response to controlled local anesthetic blocks ( $<1 \mathrm{~mL}$ per nerve) with a criterion standard of $80 \%$ pain relief with ability to perform prior painful movements without any significant pain. 


\subsubsection{Frequency of Interventions}

- In the diagnostic phase, a patient may receive 2 procedures at intervals of no sooner than one week or preferably 2 weeks, with careful judgment of response.

- In the therapeutic phase (after the diagnostic phase is completed), the suggested frequency would be 2-3 months or longer between injections, provided that $\geq 50 \%$ relief is obtained for 8 weeks.

- If the interventional procedures are applied for different regions, they may be performed at intervals of no sooner than one week or preferably 2 weeks for most types of procedures.

- It is suggested that therapeutic frequency remain at least a minimum of 2 months for each region, it is further suggested that all the regions be treated at the same time provided that all procedures can be performed safely.

- In the treatment or therapeutic phase, the interventional procedures should be repeated only as necessary according to the medical necessity criteria, and it is suggested that these be limited to a maximum of 4 to 6 times for local anesthetic and steroid blocks over a period of one year, per region.

- Under unusual circumstances with a recurrent injury or cervicogenic headache, procedures may be repeated at intervals of 6 weeks after stabilization in the treatment phase.

- For medial branch neurotomy, the suggested frequency would be 6 months or longer (maximum of 2 times per year) between each procedure, provided that $50 \%$ or greater relief is obtained for 10 to 12 weeks.

- The therapeutic frequency for medial branch neurotomy should remain at intervals of at least 6 months per each region with multiple regions involved. It is further suggested that all regions be treated at the same time, provided all procedures are performed safely.

- Cervical and thoracic are considered as one region and lumbar and sacral are considered as one region for billing purposes.

\subsection{Epidural Injections}

Epidural injections include caudal, interlaminar, and transforaminal in cervical, thoracic, lumbar and sacral regions.
These guidelines apply to all epidural injections including caudal, interlaminar, and transforaminal.

\subsubsection{Caudal}

- Common indications are as follows:

- Chronic low back and/or lower extremity pain which has failed to respond or poorly responded to noninterventional and nonsurgical conservative management resulting from:

- Disc herniation/lumbar radiculitis

- Lumbar spinal stenosis

- Post lumbar surgery syndrome

- Epidural fibrosis

- Degenerative disc disease/discogenic low back pain

- Other causes

- Absence of facet joint pain determined by controlled local anesthetic blocks.

- Intermittent or continuous pain causing functional disability.

- Average pain level of $\geq 6$ on a scale of 0 to 10 .

\subsubsection{Lumbar Interlaminar}

- Indications are same as for caudal epidural injections, except for post-surgery syndrome.

- Caudal epidural is the modality of choice for post-surgery syndrome.

\subsubsection{Cervical Interlaminar}

- Common indications are as follows:|

- Chronic neck and/or upper extremity pain which has failed to respond or poorly responded to non-interventional and non-surgical conservative management resulting from:

- Herniated, protruded, or extruded disc with or without radiculitis

- Cervical spinal stenosis

- Post cervical surgery syndrome

- Degenerative disc disease

- Other causes

- Absence of facet joint pain determined by controlled local anesthetic blocks.

- Intermittent or continuous pain causing functional disability.

- Average pain level of $\geq 6$ on a scale of 0 to 10 .

\subsubsection{Thoracic Interlaminar}

- Common indications are as follows:|

- Chronic mid back or upper back pain which 
has failed to respond or poorly responded to non-interventional and non-surgical conservative management resulting from:

- Herniated, protruded, or extruded disc with or without radiculitis

- Thoracic spinal stenosis

- Thoracic post-surgery syndrome

- Degenerative disc disease

- Other causes

\subsubsection{Lumbar Transforaminal}

Lumbar transforaminal epidurals are provided for diagnostic and therapeutic purposes.

- Diagnostic indications:

- To identify an inflamed nerve root in a patient with a history of radicular pain when results of visual anatomic studies and neurophysiologic studies are not collaborative.

- $\quad$ To identify the pain generator when patients have multiple abnormalities on visual anatomic studies.

- To determine the symptomatic level in multilevel disc herniation.

- To determine a primary pain generator in the spine-hip syndrome.

- To determine a previously undocumented nerve root irritation as a result of spondylolisthesis.

- To determine the symptomatic level in multilevel stenosis.

- To determine the symptomatic root in patients with documented postoperative fibrosis.

- Therapeutic indications:

- Average pain levels of $\geq 6$ on a scale of 0 to 10

- Intermittent or continuous pain causing functional disability

- Chronic low back and/or lower extremity pain which has failed to respond or poorly responded to non-interventional and non-surgical conservative management

- Chronic low back and/or lower extremity pain resulting from:

- Disc herniation

- FBSS without extensive scar tissue and hardware

- Spinal stenosis with radiculitis

- Discogenic pain with radiculitis

\subsubsection{Frequency of Interventions}

- Guidelines of frequency of interventions apply to epidural injections caudal, interlaminar, and transforaminal.

- In the diagnostic phase, a patient may receive 2 procedures at intervals of no sooner than one week or preferably 2 weeks except in cancer-related pain or when a continuous administration of local anesthetic is employed for CRPS.

- In the therapeutic phase (after the diagnostic phase is completed), the suggested frequency of interventional techniques should be 2 months or longer between each injection, provided that > $50 \%$ relief is obtained for 6 to 8 weeks.

- If the neural blockade is applied for different regions, they may be performed at intervals of no sooner than one week and preferably 2 weeks for most types of procedures. The therapeutic frequency may remain at intervals of at least 2 months for each region. It is further suggested that all regions be treated at the same time, provided all procedures can be performed safely.

- In the treatment or therapeutic phase, the epidural injections should be repeated only as necessary according to medical necessity criteria, and it is suggested that these be limited to a maximum of 4-6 times per year.

- Under unusual circumstances with a recurrent injury, cancer-related pain, or CRPS, blocks may be repeated at intervals of 6 weeks or less after diagnosis/stabilization in the treatment phase.

- Cervical and thoracic regions are considered as one region and lumbar and sacral are considered as one region.

\subsection{Percutaneous Adhesiolysis}

- Common indications are as follows:

- Chronic low back and/or lower extremity pain resulting from:

- Failed back surgery syndrome/epidural fibrosis

- Spinal stenosis

- Disc herniation with radiculitis

- Duration of pain of at least 6 months.

- Intermittent or continuous pain causing functional disability.

- Average pain levels of $\geq 6$ on a scale of 0 to 10 .

- Failure to respond or poor response to non-interventional and non-surgical conservative management and fluoroscopically-directed epidural injections

- Absence of facet joint pain determined by con- 
has failed to respond or poorly responded to non-interventional and non-surgical conservative management resulting from:

- Herniated, protruded, or extruded disc with or without radiculitis

- Thoracic spinal stenosis

- Thoracic post-surgery syndrome

- Degenerative disc disease

- Other causes

\subsubsection{Lumbar Transforaminal}

Lumbar transforaminal epidurals are provided for diagnostic and therapeutic purposes.

- Diagnostic indications:

- To identify an inflamed nerve root in a patient with a history of radicular pain when results of visual anatomic studies and neurophysiologic studies are not collaborative.

- $\quad$ To identify the pain generator when patients have multiple abnormalities on visual anatomic studies.

- $\quad$ To determine the symptomatic level in multilevel disc herniation.

- To determine a primary pain generator in the spine-hip syndrome.

- To determine a previously undocumented nerve root irritation as a result of spondylolisthesis.

- To determine the symptomatic level in multilevel stenosis.

- $\quad$ To determine the symptomatic root in patients with documented postoperative fibrosis.

- Therapeutic indications:

- Average pain levels of $\geq 6$ on a scale of 0 to 10

- Intermittent or continuous pain causing functional disability

- Chronic low back and/or lower extremity pain which has failed to respond or poorly responded to non-interventional and non-surgical conservative management

- Chronic low back and/or lower extremity pain resulting from:

- Disc herniation

- FBSS without extensive scar tissue and hardware

- Spinal stenosis with radiculitis

- Discogenic pain with radiculitis

\subsubsection{Frequency of Interventions}

- Guidelines of frequency of interventions apply to epidural injections caudal, interlaminar, and transforaminal.

- In the diagnostic phase, a patient may receive 2 procedures at intervals of no sooner than one week or preferably 2 weeks except in cancer-related pain or when a continuous administration of local anesthetic is employed for CRPS.

- In the therapeutic phase (after the diagnostic phase is completed), the suggested frequency of interventional techniques should be 2 months or longer between each injection, provided that > $50 \%$ relief is obtained for 6 to 8 weeks.

- If the neural blockade is applied for different regions, they may be performed at intervals of no sooner than one week and preferably 2 weeks for most types of procedures. The therapeutic frequency may remain at intervals of at least 2 months for each region. It is further suggested that all regions be treated at the same time, provided all procedures can be performed safely.

- In the treatment or therapeutic phase, the epidural injections should be repeated only as necessary according to medical necessity criteria, and it is suggested that these be limited to a maximum of 4-6 times per year.

- Under unusual circumstances with a recurrent injury, cancer-related pain, or CRPS, blocks may be repeated at intervals of 6 weeks or less after diagnosis/stabilization in the treatment phase.

- Cervical and thoracic regions are considered as one region and lumbar and sacral are considered as one region.

\subsection{Percutaneous Adhesiolysis}

- Common indications are as follows:

- Chronic low back and/or lower extremity pain resulting from:

- Failed back surgery syndrome/epidural fibrosis

- Spinal stenosis

- $\quad$ Disc herniation with radiculitis

- Duration of pain of at least 6 months.

- Intermittent or continuous pain causing functional disability.

- Average pain levels of $\geq 6$ on a scale of 0 to 10 .

- Failure to respond or poor response to non-interventional and non-surgical conservative management and fluoroscopically-directed epidural injections 
- Absence of facet joint pain determined by controlled local anesthetic blocks

\subsubsection{Frequency of Interventions}

- The number of procedures are preferably limited to:

- 2 interventions per year, with a 3-day protocol.

- 4 interventions per year, with a one-day protocol.

\subsection{Spinal Endoscopic Adhesiolysis}

- Common indications are as follows:

- Chronic low back and lower extremity pain nonresponsive or poorly responsive to conservative treatment, including fluoroscopically directed epidural injections and percutaneous adhesiolysis with hypertonic saline neurolysis.

- Moderate to severe disability.

- Absence of facet joint pain determined by controlled local anesthetic blocks.

\subsubsection{Frequency of Interventions}

- The procedures are preferably limited to a maximum of 2 per year provided the relief was $>50 \%$ for $>4$ months.

\subsection{Intradiscal Procedures}

- Axial low back pain of at least 6 months duration.

- Failure to respond to conservative treatment.

- Abnormal nucleus signal on T2-weighed MRI images with $>60 \%$ residual disc height.

- Positive concordant discogram at low pressure.

- Normal neurologic exam (or at least no new deficits attributable to the level to be treated).

- Negative straight-leg raise.

- MRI with no evidence of root compression, tumor, or infection (if root compression is present, consider PMDD).

\subsection{Mechanical Disc Decompression}

- Common indications are as follows:

- Unilateral leg pain greater than back pain

- Radicular symptoms in a specific dermatomal distribution that correlates with MRI findings

- Positive straight leg raising test or positive bowstring sign, or both

- Neurologic findings or radicular symptoms
- No improvement after 6 weeks of conservative therapy

- Imaging studies (CT, MRI, discography) indicating a subligamentous contained disc herniation

- Well maintained disc height of $60 \%$

\subsection{Sacroiliac Joint Injections}

- Common indications are as follows:

- Somatic or nonradicular low back and lower extremity pain below the level of L5 vertebra.

- Duration of pain of at least 3 months.

- Average pain levels of $\geq 6$ on a scale of 0 to 10

- Intermittent or continuous pain causing functional disability.

- Failure to respond to more conservative management, including physical therapy modalities with exercises, chiropractic management, and non-steroidal anti-inflammatory agents.

- Lack of obvious evidence for disc-related or facet joint pain.

- No contraindications with understanding of consent, nature of the procedure, needle placement, or sedation.

- No history of allergy to contrast administration, local anesthetics, steroids, Sarapin, or other drugs potentially utilized.

- Contraindications or inability to undergo physical therapy, chiropractic management, or inability to tolerate nonsteroidal anti-inflammatory drugs.

- For therapeutic sacroiliac joint interventions with intraarticular injections or radiofrequency neurotomy, the joint should have been positive utilizing controlled diagnostic blocks.

\subsubsection{Frequency of Interventions}

- In the diagnostic phase, a patient may receive 2 procedures at intervals of no sooner than one week or preferably 2 weeks.

- In the therapeutic phase (after the diagnostic phase is completed), the suggested frequency would be 2 months or longer between injections, provided that $>50 \%$ relief is obtained for 6 weeks.

- If the procedures are done for different joints, they should be performed at intervals of no sooner than one week or preferably 2 weeks. It is suggested that therapeutic frequency remain at 2 
months for each joint. It is further suggested that both joints be treated at the same time, provided the injections can be performed safely.

- In the treatment or therapeutic phase, the interventional procedures should be repeated only as necessary according to the medical necessity criteria, and it is suggested that they be limited to a maximum of 4-6 times for local anesthetic and steroid blocks over a period of one year, per region.

- Under unusual circumstances with a recurrent injury, procedures may be repeated at intervals of 6 weeks after stabilization in the treatment phase.

- For sacroiliac joint radiofrequency neurotomy, the suggested frequency is 3 months or longer between each procedure (maximum of 3 times per year), provided that $>50 \%$ relief is obtained for 10 to 12 weeks.

\section{Acknowledgments}

The authors wish to thank the editorial board of Pain Physician, for review and criticism in improving the manuscript; Sekar Edem for his assistance in the literature search; and Tonie M. Hatton and Diane E. Neihoff, transcriptionists (Pain Management Center of Paducah), for their assistance in preparation of this manuscript.

\section{Author Affiliatons}

${ }^{1}$ Dr. Manchikanti is Medical Director of the Pain Management Center of Paducah, Paducah, KY.

${ }^{2}$ Dr. Boswell is Chairman of Department of Anesthesiology and Director of the International Pain Center, Texas Tech University Health Sciences Center, Lubbock, TX.

${ }^{3} \mathrm{Dr}$. Singh is Medical Director of Pain Diagnostics Associates, Niagara, WI.

${ }^{4}$ Dr. Benyamin is Medical Director, Millennium Pain Center, Clinical Associate Professor, Department of Surgery, College of Medicine, University of Illinois, Urbana-Champaign, IL.

5 Mr. Fellows is Director Emeritus of Psychological Services at the Pain Management Center of Paducah, Paducah, KY.

${ }^{6} \mathrm{Dr}$. Abdi is Professor and Chief, Division of Pain Medicine, Department of Anesthesiology, Perioperative Medicine and Pain Management, University of Miami, Miller School of Medicine, Miami, FL.

${ }^{7}$ Dr. Buenaventura is Medical Director, Pain Relief of Dayton, Centerville, $\mathrm{OH}$, and Clinical Associate Professor, Department of Surgery, Wright State University School of Medicine, Dayton, $\mathrm{OH}$ ${ }^{8} \mathrm{Dr}$. Conn is staff physician, Premier Pain Relief, Covington, LA. Dr. Datta is Director, Vanderbilt University Interventional Pain Program, Associate Professor, Dept. of Anesthesiology, Vanderbilt University Medical Center, Nashville, TN.

${ }^{10}$ Dr. Derby is Medical Director of Spinal Diagnostics \& Treatment Center, Daly City, CA, and Associate Professor, Department of Physical Medicine and Rehabilitation, Stanford University, Stanford, CA.

${ }^{11}$ Dr. Falco is Medical Director of the Mid Atlantic Spine \& Pain Specialists of Newark, DE, and Clinical Assistant Professor, Temple University Medical School, Philadelphia, PA.
${ }^{12} \mathrm{Ms}$. Erhart is Educational/Research Coordinator; Librarian for Mid Atlantic Spine \& Pain Specialists of Newark, DE

${ }^{13} \mathrm{Dr}$. Diwan is Director of Pain Medicine in the Department of Anesthesiology, New York Presbyterian Hospital, and the Director of the Tri-Institutional Pain Fellowship Program, Weill Cornell Medical College, New York, NY.

${ }^{14} \mathrm{Dr}$. Hayek is Chief of the Division of Pain Medicine, Department of Anesthesiology, University Hospitals of Cleveland, Cleveland, $\mathrm{OH}$, and a member of the Outcomes Research Consortium, Cleveland, $\mathrm{OH}$.

${ }^{15}$ Dr. Helm is a Medical Director, Pacific Coast Pain Management Center, Laguna Hills, CA.

${ }^{16} \mathrm{Dr}$. Parr is Medical Director of Premier Pain Center, Covington, LA. ${ }^{17} \mathrm{Dr}$. Schultz is the Medical Director and President of Medical Advanced Pain Specialists, Minneapolis, MN.

${ }^{18} \mathrm{Dr}$. Smith is Associate Professor and Academic Director of Pain Management for Albany Medical College Department of Anesthesiology, Albany, NY.

${ }^{19} \mathrm{Dr}$. Wolfer is with the Spinal Diagnostics \& Treatment Center, Daly City, CA.

${ }^{20} \mathrm{Dr}$. Hirsch is Chief of Minimally Invasive Spine Surgery, Depts. of Radiology and Neurosurgery, Massachusetts General Hospital and Assistant Professor of Radiology, Harvard Medical School, Boston, MA.

Dr. Manchikanti, Dr. Singh, Dr. Benyamin, Dr. Abdi, Dr. Datta, Dr. Falco, Dr. Helm, Dr. Parr, Dr. Shah, Dr. Schultz, and Dr. Hirsch are members of the American Society of Interventional Pain Physicians board of directors.

Conflicts of interest: Dr. Datta receives research support from Sucampo Pharmaceuticals and an honorarium from Smith and Nephew

Dr. Schultz is a paid consultant for Medtronic.

Dr. Hayek is a consultant for Boston Scientific, Valencia, CA

Dr. Hirsch is a consultant for Cardinal Healthcare and Medtronic, he has previously served as a consultant for Arthrocare, he serves on the Steering Committee for KAVIAR trial (volunteer position), and on the Data and Safety Monitoring Board (DSMB): CEEP trial (volunteer position).

Dr. Derby has stock options with Laurimed and Kyphon. 


\section{References}

1. Manchikanti L, Singh V, Helm S, Schultz DM, Datta S, Hirsch J. An Introduction to an Evidence-Based Approach to Interventional Techniques in the Management of Chronic Spinal Pain. Pain Physician 2009; 12: E1-E33.

2. Manchikanti L. Singh V, Datta S, , Cohen SP, Hirsch JA. Comprehensive Review of Epidemiology, Scope, and Impact of Spinal Pain. Pain Physician 2009: 12: E35-E70.

3. Manchikanti L, Boswell MV, Singh V, Derby R, Fellows B, Falco FJE, Datta S, Smith HS, Hirsch JA. Comprehensive Review of Neurophysiologic Basis and Diagnostic Interventions in Managing Chronic Spinal Pain. Pain Physician 2009; 12:E71-E120.

4. Manchikanti L, Boswell MV, Datta S, Fellows B, Abdi S, Singh V, Benyamin RM, Falco FJE, Helm S, Hayek S, Smith HS. Comprehensive Review of Therapeutic Interventions in Managing Chronic Spinal Pain. Pain Physician 2009: 12:E123E198.

5. Manchikanti L, Singh V, Pampati V, Boswell MF, Benyamin RM, Hirsch JA. Description of Documentation in the Management of Chronic Spinal Pain. Pain Physician 2009: 12:E199-E224

6. Manchikanti L, Helm S, Singh V, Benyamin RM, Datta S, Hayek S, Fellows B, Boswell MV. An Algorithmic Approach for Clinical Management of Chronic Spinal Pain. Pain Physician 2009: 12:E225264.

7. Boswell MV, Trescot AM, Datta S, Schultz DM, Hansen HC, Abdi S, Sehgal N, Shah RV, Singh V, Benyamin RM, Patel VB, Buenaventura RM, Colson JD, Cordner HJ, Epter RS, Jasper JF, Dunbar EE, Atluri SL, Bowman RC, Deer TR, Swicegood JR, Staats PS, Smith HS, Burton AW, Kloth DS, Giordano J, Manchikant L. Interventional techniques: Evidencebased practice guidelines in the management of chronic spinal pain. Pain Physician 2007; 10:7-111.

8. Boswell MV, Shah RV, Everett CR, Sehgal N, McKenzie-Brown AM, Abdi S, Bowman RC, Deer TR, Datta S, Colson ID, Spillane WF, Smith HS, LucasLevin LF, Burton AW, Chopra P, Staats PS, Wasserman RA, Manchikanti L. Interventional techniques in the management of chronic spinal pain: Evidencebased practice guidelines. Pain Physician 2005; 8:1-47.

9. Manchikanti L, Staats PS, Singh V, Schultz DM, Vilims BD, Jasper JF, Kloth
DS, Trescot AM, Hansen HC, Falasca TD, Racz GB, Deer T, Burton AW, Helm S, Lou L, Bakhit CE, Dunbar EE, Atluri SL, Calodney AK, Hassenbusch S, Feler CA. Evidence-based practice guidelines for interventional techniques in the management of chronic spinal pain. Pain Physician 2003; 6:3-80.

10. Manchikanti L, Singh V, Bakhit CE, Fellows $B$. Interventional techniques in the management of chronic pain. Part 1.0. Pain Physician 2000; 3:7-42.

11. Wu JS, Wong RK, Lloyd NS, Johnston M, Bezjak A, Whelan T; Supportive Care Guidelines Group of Cancer Care Ontario. Radiotherapy fractionation for the palliation of uncomplicated painful bone metastases - An evidence-based practice guideline. BMC Cancer 2004; 4:71.

12. Eden J, Wheatley B, McNeil B, Sox H. Knowing What Works in Health Care: $A$ Roadmap for the Nation. National Academies Press, Washington, DC, 2008.

13. Manchikanti L. Health care reform in the United States: Radical surgery needed now more than ever. Pain Physician 2008; 11:13-42.

14. Sackett DL, Rosenberg WM, Gray JA, Haynes RB, Richardson WS. Evidence based medicine: What it is and what it isn't. $B M J$ 1996; 312:71-72.

15. Straus SE, Glasziou P, Richardson WS, Haynes RB. Evidence-Based Medicine: How to Practice and Teach EBM, 3rd ed. Churchill Livingstone, London, UK, 2005.

16. Manchikanti L, Heavner J, Racz GB, Mekhail NA, Schultz DM, Hansen HC, Singh V. Methods for evidence synthesis in interventional pain management. Pain Physician 2003; 6:89-111.

17. Manchikanti L, Abdi S, Lucas LF. Evidence synthesis and development of guidelines in interventional pain management. Pain Physician 2005; 8:7386.

18. Manchikanti L, Boswell MV, Giordano J. Evidence-based interventional pain management: Principles, problems, potential, and applications. Pain Physician 2007; 10:329-356.

19. Manchikanti L. Evidence-based medicine, systematic reviews, and guidelines in interventional pain management: Part 1: Introduction and general considerations. Pain Physician 2008; 11:161-186.

20. Manchikanti L, Hirsch JA, Smith HS. Ev- idence-based medicine, systematic reviews, and guidelines in interventional pain management: Part 2: Randomized controlled trials. Pain Physician 2008; 11:717-773.

21. Manchikanti L, Benyamin RM, Helm S, Hirsch JA. Evidence-based medicine, systematic reviews, and guidelines in interventional pain management: Part 3: Systematic reviews and meta-analysis of randomized trials. Pain Physician 2009; 12:35-72

22. Manchikanti L, Singh V, Smith HS, Hirsch JA. Evidence-based medicine, systematic reviews, and guidelines in interventional pain management: Part 4: Observational studies. Pain Physician 2009; 12:73-108.

23. Manchikanti L, Derby R, Wolfer L, Singh V, Datta S, Hirsch JA. Evidence-based medicine, systematic reviews, and guidelines in interventional pain management: Part 5. Diagnostic accuracy studies. Pain Physician 2009; 12:517540.

24. Abdi S, Datta S, Trescot AM, Schultz DM, Adlaka R, Atluri SL, Smith HS, Manchikanti L. Epidural steroids in the management of chronic spinal pain: A systematic review. Pain Physician 2007; 10:185-212.

25. Datta S, Everett CR, Trescot AM, Schultz DM, Adlaka R, Abdi S, Atluri SL, Smith HS, Shah RV. An updated systematic review of the diagnostic utility of selective nerve root blocks. Pain Physician 2007; 10:113-128.

26. Trescot AM, Chopra P, Abdi S, Datta S, Schultz DM. Systematic review of the effectiveness and complications of adhesiolysis in the management of chronic spinal pain: An update. Pain Physician 2007; 10:129-146.

27. Hansen HC, McKenzie-Brown AM, Cohen SP, Swicegood JR, Colson JD, Manchikanti L. Sacroiliac joint interventions: A systematic review. Pain Physician 2007; 10:165-184.

28. Buenaventura RM, Shah RV, Patel V, Benyamin RM, Singh V. Systematic review of discography as a diagnostic test for spinal pain: An update. Pain Physician 2007; 10:147-164.

29. Sehgal N, Dunbar EE, Shah RV, Colson JD. Systematic review of the diagnostic utility of facet (zygapophysial) joint injections in chronic spinal pain: An update. Pain Physician 2007; 10:213-228.

30. Boswell MV, Colson JD, Sehgal N, Dun- 
bar E, Epter R. A systematic review of therapeutic facet joint interventions in chronic spinal pain. Pain Physician 2007; 10:229-253.

31. Atluri S, Datta S, Falco FJ, Lee M. Systematic review of diagnostic utility and therapeutic effectiveness of thoracic facet joint interventions. Pain Physician 2008; 11:611-629.

32. Singh V, Manchikanti L, Shah RV, Dunbar EE, Glaser SE. Systematic review of thoracic discography as a diagnostic test for chronic spinal pain. Pain Physician 2008; 11:631-642.

33. Patel VB, Manchikanti L, Singh V, Schultz DM, Hayek SM, Smith HS. Systematic review of intrathecal infusion systems for long-term management of chronic non-cancer pain. Pain Physician 2009; 12:345-360.

34. Conn A, Buenaventura R, Datta S, Abdi S, Diwan S. Systematic review of caudal epidural injections in the management of chronic low back pain. Pain Physician 2009; 12:109-135.

35. Parr AT, Diwan S, Abdi S. Lumbar interlaminar epidural injections in managing chronic low back and lower extremity pain: A systematic review. Pain Physician 2009; 12:163-188.

36. Benyamin RM, Singh V, Parr AT, Conn A, Diwan S, Abdi S. Systematic review of the effectiveness of cervical epidurals in the management of chronic neck pain. Pain Physician 2009; 12:137-157.

37. Buenaventura RM, Datta S, Abdi S, Smith HS. Systematic review of therapeutic lumbar transforaminal epidural steroid injections. Pain Physician 2009; 12:233-251.

38. Helm S, Hayek S, Benyamin RM, Manchikanti L. Systematic review of the effectiveness of thermal annular procedures in treating discogenic low back pain. Pain Physician 2009; 12:207-232.

39. Manchikanti L, Dunbar EE, Wargo BW, Shah RV, Derby R, Cohen SP. Systematic review of cervical discography as a diagnostic test for chronic spinal pain. Pain Physician 2009; 12:305-321.

40. Datta S, Lee M, Falco FJE, Bryce DA, Hayek SM. Systematic assessment of diagnostic accuracy and therapeutic utility of lumbar facet joint interventions. Pain Physician 2009; 12:437460.

41. Falco FJE, Erhart S, Wargo BW, Bryce DA, Atluri S, Datta S, Hayek SM. Systematic review of diagnostic utility and therapeutic effectiveness of cervical facet joint interventions. Pain Physician 2009; 12:323-344.

42. Frey ME, Manchikanti L, Benyamin RM, Schultz DM, Smith HS, Cohen SP. Spinal cord stimulation for patients with failed back surgery syndrome: A systematic review. Pain Physician 2009; 12:379-397.

43. Epter RS, Helm S, Hayek SM, Benyamin RM, Smith HS, Abdi S. Systematic review of percutaneous adhesiolysis and management of chronic low back pain in post lumbar surgery syndrome. Pain Physician 2009; 12:361-378.

44. Smith HS, Chopra P, Patel VB, Frey ME, Rastogi R. Systematic review on the role of sedation in diagnostic spinal interventional techniques. Pain Physician 2009; 12:195-206.

45. Rupert MP, Lee M, Manchikanti L, Datta S, Cohen SP. Evaluation of sacroiliac joint interventions: A systematic appraisal of the literature. Pain Physician 2009; 12:399-418.

46. Manchikanti L, Glaser S, Wolfer L, Derby $R$, Cohen SP. Systematic review of lumbar discography as a diagnostic test for chronic low back pain. Pain Physician 2009; 12:541-560.

47. Hayek SM, Helm S, Benyamin RM, Singh V, Bryce DA, Smith HS. Effectiveness of spinal endoscopic adhesiolysis in post lumbar surgery syndrome: A systematic review. Pain Physician 2009; 12:419-435.

48. Trescot AM, Helm S, Hansen H, Benyamin RM, Adlaka R, Patel S, Manchikanti L. Opioids in the management of chronic non-cancer pain: An update of American Society of Interventional Pain Physicians' (ASIPP) guidelines. Pain Physician 2008; 11:S5-S62.

49. Hirsch JA, Singh V, Falco FJE, Benyamin RM, Manchikanti L. Automated percutaneous lumbar discectomy for the contained herniated lumbar disc: A systematic assessment of evidence. Pain Physician 2009; 12:601-620.

50. Singh V, Manchikanti L, Benyamin RM, Helm S, Hirsch JA. Percutaneous lumbar laser disc decompression: A systematic review of current evidence. Pain Physician 2009; 12:573-588.

51. Singh V, Benyamin RM, Datta S, Falco FJE, Helm S, Manchikanti L. Systematic review of percutaneous lumbar mechanical disc decompression utilizing Dekompressor. Pain Physician 2009; 12:589-600.

52. Manchikanti L, Derby R, Benyamin RM, Helm S, Hirsch JA. A systematic review of mechanical lumbar disc decompression with nucleoplasty. Pain Physician 2009; 12:561-572.

53. Manchikanti L, Singh V, Derby R, Schultz DM, Benyamin RM, Prager JP, Hirsch JA. Reassessment of evidence synthesis of occupational medicine practice guidelines for interventional pain management. Pain Physician 2008; 11:393482.

54. Manchikanti L, Singh V, Derby R, Helm S, Trescot AM, Staats PS, Prager JP, Hirsch JA. Review of occupational medicine practice guidelines for interventional pain management and potential implications. Pain Physician 2008; 11:271-289.

55. Manchikanti L, Singh V, Helm S, Trescot AM, Hirsch JA. A critical appraisal of 2007 American College of Occupational and Environmental Medicine (ACOEM) practice guidelines for interventional pain management: An independent review utilizing AGREE, AMA, IOM, and other criteria. Pain Physician 2008; 11:291-310.

56. Manchikanti L, Singh V, Pampati V, Smith HS, Hirsch J. Analysis of growth of interventional techniques in managing chronic pain in the medicare population: A 10-year evaluation from 1997 to 2006. Pain Physician 2009; 12:9-34.

57. Manchikanti L. Medicare in interventional pain management: A critical analysis. Pain Physician 2006; 9:171198.

58. Manchikanti L, Boswell MV. Interventional techniques in ambulatory surgical centers: A look at the new payment system. Pain Physician 2007; 10:627650.

59. Manchikanti L, Giordano J. Physician payment 2008 for interventionalists: Current state of health care policy. Pain Physician 2007; 10:607-626.

6o. Friedly J, Chan L, Deyo R. Increases in lumbosacral injections in the Medicare population: 1994 to 2001. Spine 2007; 32:1754-1760.

61. US Department of Health and Human Services. Office of Inspector General (OIG). Medicare Payments for Facet Joint Injection Services (OEl-0507-00200). September 2008. www. oig.hhs.gov/oei/reports/oei-05-0700200.pdf

62. Manchikanti L, Hirsch JA. Issues in health care: Interventional pain management at the crossroads. Health policy update. Pain Physician 2007; 10:261-284. 
63. Specialty Utilization data files from CMS: www.cms.hhs.gov

64. Manchikanti L. Interventional pain management: Past, present, and future. The Prithvi Raj lecture: Presented at the 4 th World Congress-World Institute of Pain, Budapest, 2007. Pain Pract 2007; 7:357-371.

65. American College of Occupational and Environmental Medicine. Low Back Disorders Chapter. In: Occupational Medicine Practice Guidelines: Evaluation and Management of Common Health Problems and Functional Recovery of Workers, Second Edition. American College of Occupational and Environmental Medicine, Elk Grove Village, 2007.

66. American College of Occupational and Environmental Medicine. Chronic Pain Chapter (revised 2008). In: Occupational Medicine Practice Guidelines: Evaluation and Management of Common Health Problems and Functional Recovery of Workers, Second Edition. American College of Occupational and Environmental Medicine, Elk Grove Village, 2008.

67. Dennison PL. Official Disability Guidelines, 13th ed. Work Loss Data Institute, 2008.

68. Phurrough S, Salive M, O'Connor D, Schafer J. Decision Memo for Thermal Intradiscal Procedures. 2008 [cited September 30, 2008]. www.cms.hhs. $\mathrm{gov} / \mathrm{mcd} / \mathrm{viewdecisionmemo.asp?fro}$ $\mathrm{m} 2=$ viewdecisionmemo.asp\&id=215\&

69. Phurrough S, Salive M, O'Connor D, Schafer J. Proposed Coverage Decision Memorandum for Lumbar Artificial Disc Replacement. [cited May 25, 2007]. www.cms.hhs.gov/mcd/viewdraftdecisionmemo.asp?from $2=$ viewdraftdecisi onmemo. asp\&id $=197$ \&

70. Centers for Medicare and Medicaid Services (CMS). Health Technology Assessment (HTA) Database: Percutaneous kyphoplasty for vertebral fractures caused by osteoporosis and malignancy. Blue Cross Blue Shield Association (BCBS), Chicago, 2005.

71. Adminastar Federal Pain Management Policy. LCD Database ID Number L28529. Effective Date 01/01/2009.

72. United Healthcare Health and Medical Insurance: www.uhc.com

73. Cigna Health and Medical Insurance: www.cigna.com

74. Aetna Health and Medical Insurance: www.aetna.com/index.htm

75. Anthem Blue Cross Blue Shield (BCBS)
Health and Medical Insurance: www. anthem.com

76. Wilson PR, Caplan RA, Connis RT, Gilbert HC, Grigsby EJ, Haddox JD, Harvey AM, Korevaar WC, Lubenow TR, Simon DL. Practice guidelines for chronic pain management. A report by the American Society of Anesthesiologists Task Force on Pain Management, Chronic Pain Section. Anesthesiology 1997; 86:9951004.

77. Sanders SH, Harden RN, Benson SE, Vicente PJ. Clinical practice guidelines for chronic non-malignant pain syndrome patients II: An evidence-based approach. J Back Musc Rehabil 1999; 13:47-58.

78. Nelemans PJ, Debie RA, DeVet HC, Sturmans F. Injection therapy for subacute and chronic benign low back pain. Spine 2001; 26:501-515.

79. Geurts JW, van Wijk RM, Stolker RJ, Groen GJ. Efficacy of radiofrequency procedures for the treatment of spinal pain: A systematic review of randomized clinical trials. Reg Anesth Pain Med 2001; 26:394-400.

8o. Manchikanti L, Singh V, Vilims BD, Hansen HC, Schultz DM, Kloth DS. Medial branch neurotomy in management of chronic spinal pain: Systematic review of the evidence. Pain Physician 2002; 5:405-418.

81. Niemisto L, Kalso E, Malmivaara A, Seitsalo S, Hurri H. Cochrane Collaboration Back Review Group. Radiofrequency denervation for neck and back pain: A systematic review within the framework of the Cochrane collaboration back review group. Spine 2003, 28:1877-1888.

82. van Tulder MW, Koes B, Malmivaara A. Outcome of non-invasive treatment modalities on back pain: An evidencebased review. Eur Spine J 2006; 15:S64S81.

83. Bogduk N, McGuirk B. Medical Management of Acute and Chronic Low Back Pain. An Evidence-Based Approach: Pain Research and Clinical Management. Elsevier Science BV, Amsterdam, 2002.

84. Bogduk N, McGuirk B. Management of Acute and Chronic Neck Pain. An Evidence-Based Approach. Elsevier, Edinburgh, 2006.

85. Taylor RS, Van Buyten JP, Buchser E. Spinal cord stimulation for chronic back and leg pain and failed back surgery syndrome: A systematic review and analysis of prognostic factors.
Spine 2005; 30:152-160.

86. Koes BW, Scholten RJ, Mens JMA, Bouter LM. Epidural steroid injections for low back pain and sciatica. An updated systematic review of randomized clinical trials. Pain Digest 1999; 9:241-247.

87. Bigos SJ, Boyer OR, Braen GR, Brown K, Deyo R, Haldeman S, Hart JL, Johnson EW, Keller R, Kido D, Liang MH, Nelson RM, Nordin M, Owen BD, Pope MH, Schwartz RK, Stewart DH, Susman J, Triano JJ, Tripp LC, Turk DC, Watts C, Weinstein JN. Acute Low Back Problems in Adults. Clinical Practice Guideline No. 14. AHCPR Publication No. 95-0642. Rockville, Maryland. U.S.A., Agency for Health Care Policy and Research, Public Health Service, U.S., Department of Health and Human Services, December, 1994, pp 1-60.

88. van Tulder MWV, Koes BW, Bouter LM. Conservative treatment of acute and chronic nonspecific low back pain. A systematic review of randomized controlled trials of the most common interventions. Spine 1997; 22:2128-2156.

89. Turner J, Loeser J, Deyo R, Sanders SB. Spinal cord stimulation for patients with failed back surgery syndrome or complex regional pain syndrome: A systemic review of effectiveness and complications. Pain 2004; 108:137147.

90. Airaksinen O, Brox JI, Cedraschi C, Hildebrandt J, Klaber-Moffett J, Kovacs F, Mannion AF, Reis S, Staal JB, Ursin H, Zanoli G. Chapter 4: European guidelines for the management of chronic nonspecific low back pain. Eur Spine 2006; 15:S192-S300.

91. Mailis-Gagnon A, Furlan AD, Sandoval JA, Taylor R. Spinal cord stimulation for chronic pain. Cochrane Database Syst Rev 2004; 3:CDo03783.

92. Turner JA, Sears JM, Loeser JD. Programmable intrathecal opioid delivery systems for chronic non-malignant pain: A systematic review of effectiveness and complications. Clin J Pain 2007; 23:180-195.

93. Turner JA, Loeser JD, Bell KG. Spinal cord stimulation for chronic low back pain. A systematic literature synthesis. Neurosurgery 1995; 37:1088-1096.

94. Taylor RS. Spinal cord stimulation in complex regional pain syndrome and refractory neuropathic back and leg pain/failed back surgery syndrome: Results of a systematic review and meta-analysis. J Pain Symptom Manage 2006; 31:S13-S19. 
95. Taylor RS, Van Buyten JP, Buchser E. Spinal cord stimulation for complex regional pain syndrome: A systematic review of the clinical and cost-effectiveness literature and assessment of prognostic factors. Eur J Pain 2006; 10:91-101.

96. Andersson GB, Mekhail NA, Block JE. Treatment of intractable discogenic low back pain. A systematic review of spinal fusion and intradiscal electrothermal therapy (IDET). Pain Physician 2006; 9:237-248.

97. Appleby D, Andersson G, Totta M. Meta-analysis of the efficacy and safety of intradiscal electrothermal therapy (IDET). Pain Med 2006; 4:308-316.

98. Gibson JN, Waddell G. Surgery for degenerative lumbar spondylosis: Updated Cochrane Review. Spine 2005; 30:2312-2320.

99. Percutaneous Discectomy. Washington State Department of Labor and Industries, Office of Medical Director; February 24,2004

100. Intradiscal Electrothermal Therapy (IDET). Technology Assessment Update. Washington State Department of Labor and Industries, Office of the Medical Director; September 30, 2003.

101. Taylor RS, Taylor RJ, Fritzell P. Balloon kyphoplasty and vertebroplasty for vertebral compression fractures: A comparative systematic review of efficacy and safety. Spine 2006; 31:27472755.

102. Hulme PA, Krebs J, Ferguson SJ, Berlemann U. Vertebroplasty and kyphoplasty: A systematic review of 69 clinical studies. Spine 2006; 31:1983-2001.

103. Staal JB, de Bie R, de Vet HC, Hildebrandt J, Nelemans P. Injection therapy for subacute and chronic low-back pain: An updated Cochrane review. Spine 2009; 34:49-59.

104. Carragee EJ, Hurwitz EL, Cheng I, Carroll LJ, Nordin M, Guzman J, Peloso P, Holm LW, Côté P, Hogg-Johnson S, van der Velde G, Cassidy JD, Haldeman S, Bone and Joint Decade 2000-2010 Task Force on Neck Pain and Its Associated Disorders. Treatment of neck pain: Injections and surgical interventions: Results of the Bone and Joint Decade 2000-2010 Task Force on Neck Pain and Its Associated Disorders. Spine 2008; 33:S153-S169.

105. Wolfer L, Derby R, Lee JE, Lee SH. Systematic review of lumbar provocation discography in asymptomatic subjects with a meta-analysis of false-positive rates. Pain Physician 2008; 11:513538.

106. Gill JB, Kuper M, Chin PC, Zhang Y, Schutt $R$ Jr. Comparing pain reduction following kyphoplasty and vertebroplasty for osteoporotic vertebral compression fractures. Pain Physician 2007; 10:583-590.

107. Jasper JF, Hayek SM. Implanted occipital nerve stimulators. Pain Physician 2008; 11:187-200.

108. Sniderman AD, Furberg CD. Why guideline-making requires reform. JAMA 2009; 301:429-431.

109. Choudhry NK, Stelfox HT, Detsky AS. Relationships between authors of clinical practice guidelines and the pharmaceutical industry. JAMA 2002; 287:612617.

110. Psaty BM, Furberg C. British guidelines on managing hypertension provide evidence, progress, and an occasional missed opportunity. BMJ 1999; 319:589-590.

111. Abdi S, Lucas LF, Datta S. Role of epidural steroids in the management of chronic spinal pain: A systematic review of effectiveness and complications Pain Physician 2005; 8:127-143.

112. Boswell MV, Colson JD, Spillane WF. Therapeutic facet joint interventions: $A$ systematic review of their role in chronic spinal pain management and complications. Pain Physician 2005; 8:101114.

113. Chopra P, Smith HS, Deer TR, Bowman RC. Systematic review of adhesiolysis in managing chronic low back pain. Pain Physician 2005; 8:87-100.

114. Shah RV, Everett CR, McKenzie-Brown AM, Sehgal N. Discography as a diagnostic test for spinal pain: A systematic and narrative review. Pain Physician 2005; 8:187-209.

115. Everett CR, Shah R, Sehgal N, McKenzie-Brown AM. A systematic review of diagnostic utility of selective nerve root blocks. Pain Physician 2005; 8:225233.

116. McKenzie-Brown A, Shah RV, Sehgal N, Everett CR. A systematic review of sacroiliac joint interventions. Pain Physician 2005; 8:115-125.

117. Shaneyfelt TM, Mayo-Smith MF, Rothwangl J. Are guidelines following guidelines? The methodological quality of clinical practice guidelines in the peer reviewed medical literature. JAMA 1999; 281:1900-1905.

118. AGREE Collaboration (Appraisal of
Guidelines, Research, and Evaluation in Europe [AGREE] Collaborative Group). Appraisal of Guidelines for Research \& Evaluation (AGREE) Instrument, September 2001.

119. Field MJ, Lohr KN (eds). Committee to Advise the Public Health Service on Clinical Practice Guidelines, Institute of Medicine. Clinical Practice Guidelines. Directions for a New Program. National Academy Press, Washington, 1990.

120. Guyatt G, Drummond R. Part 1. The basics: Using the medical literature. $1 \mathrm{~A}$. Introduction: The philosophy of evidence-based medicine. In: Users' Guides to the Medical Literature. A Manual for Evidence-Based Clinical Practice. The Evidence-Based Medicine Working Group. AMA Press, 2002, pp 312.

121. Burgers JS, van Everdingen JJ. Beyond the evidence in clinical guidelines. Lancet 2004; 364:392-393.

122. Atkins D, Siegel J, Slutsky J. Making policy when the evidence is in dispute. Health Aff (Millwood) 2005; 24:102113.

123. Ricci S, Celani MG, Righetti E. Development of clinical guidelines: Methodological and practical issues. Neurol Sci 2006; 27:S228-S230.

124. Perlin JB, Kupersmith J. Information technology and the inferential gap. Health Aff 2007; 26:W192-w194.

125. Stewart WF, Shah NR, Selna MJ, Paulus RA, Walker JM. Bridging the inferentia gap: The electronic health record and clinical evidence. Health Aff 2007; 26: w181-w191.

126. Berg AO, Allan JD. Introducing the third U.S. Preventive Services Task Force. Am J Prev Med 2001; 20:S3-S4.

127. West S, King V, Carey T, Lohr K, McKoy N, Sutton S, Lux L. Systems to Rate the Strength of Scientific Evidence. Evidence Report/Technology Assessment No. 47 University of North Carolina: Agency for Healthcare Research and Quality. AHRQ Publication No. 02-E016; April 2002.

128. Higgins JPT, Green S (eds). Cochrane Handbook for Systematic Reviews of Interventions Version 5.0.1 [updated September 2008]. The Cochrane Collaboration, 2008. www.cochrane-handbook.org

129. Altman DG, Schulz KF, Moher D, Egger M, Davidoff F, Elbourne D, Gøtzsche PC, Lang T; CONSORT GROUP (Consolidated Standards of Reporting Trials). The revised CONSORT statement for re- 
porting randomized trials: Explanation and elaboration. Ann Intern Med 2001; 134:663-694.

130. Piaggio G, Elbourne DR, Altman DG, Pocock SJ, Evans SJ, CONSORT Group. Reporting of noninferiority and equivalence randomized trials: An extension of the CONSORT statement. JAMA 2006; 295:1152-1160.

131. Zwarenstein M, Treweek S, Gagnier JJ, Altman DG, Tunis S, Haynes B, Oxman AD, Moher D; CONSORT group; Pragmatic Trials in Healthcare (Practihc) group. Improving the reporting of pragmatic trials: An extension of the CONSORT statement. BMJ 2008; 337: a2390.

132. Stroup DF, Berlin JA, Morton SC, Olkin I, Williamson GD, Rennie D, Moher D, Becker BJ, Sipe TA, Thacker SB. Metaanalysis of observational studies in epidemiology: A proposal for reporting. Meta-analysis of Observational Studies in Epidemiology (MOOSE) group. JAMA 2000; 283:2008-2012.

133. Bossuyt PM, Reitsma JB, Bruns DE, Gatsonis CA, Glasziou PP, Irwig LM, Lijmer JG, Moher D, Rennie D, de Vet HC; STARD Group. Towards complete and accurate reporting of studies of diagnostic accuracy: The STARD initiative. Fam Pract 2004; 21:4-10.

134. Whiting P, Rutjes A, Reitsma J, Bossuyt P, Kleijnen J. The Development of QUADAS: A tool for the quality assessment of studies of diagnostic accuracy included in systematic reviews. $B M C$ Med Res Methodol 2003; 3:25.

135. Atkins D, Eccles M, Flottorp S, Guyatt GH, Henry D, Hill S, Liberati A, O'Connell $D$, Oxman AD, Phillips $B$, Schünemann H, Edejer TT, Vist GE, Williams JW Jr; GRADE Working Group. Systems for grading the quality of evidence and the strength of recommendations I: Critical appraisal of existing approaches. BMC Health Serv Res 2004; 4:38.

136. Guyatt G, Gutterman D, Baumann MH, Addrizzo-Harris D, Hylek EM, Phillips B, Raskob G, Lewis SZ, Schünemann $\mathrm{H}$. Grading strength of recommendations and quality of evidence in clinical guidelines. Report from an American College of Chest Physicians task force. Chest 2006; 129:174-181.

137. Bonica JJ. Definitions and taxonomy of pain. In: Bonica JJ, Loessor JD, Chapman CR, (et al) (eds). The Management of Pain, Second Edition. Lea \& Febiger, Philadelphia, 1990, pp 18-27.

138. Gureje O, von Korff M, Simon GE, Gater
R. Persistent pain and well-being: A World Health Organization study in primary care. JAMA 1998; 280:147-151.

139. Lawrence RC, Helmick CG, Arnett FC. Estimates of the prevalence of arthritis and selected musculoskeletal disorders in the United States. Arthritis Rheum 1998; 41:778-799.

140. Hardt J, Jacobsen C, Goldberg J, Nickel $R$, Buchwald D. Prevalence of chronic pain in a representative sample in the United States. Pain Med 2008; 9:803812.

141. Pappagallo M, Werner M. Epidemiology of chronic pain. In: Palmer C, Booth C (eds). .Chronic Pain A Primer for Physicians. Remedica, Chicago, 2008, pp. 22-33.

142. Manchikanti L, Boswell MV. Evolution of spinal interventional techniques. In: Manchikanti L, Singh V (eds). Interventional Techniques in Chronic Spinal Pain. ASIPP Publishing, Paducah, KY, 2007, pp 1-16.

143. von Korff M, Dworkin SF, Le Resche L, Kruger A. An epidemiologic comparison of pain complaints. Pain 1988; 32:173-183.

144. von Korff M, Dworkin SF, Le Resche L. Graded chronic pain status: An epidemiologic evaluation. Pain 1990; 40:279-291.

145. von Korff M, Ormel J, Keefe FJ, Dworkin SF. Grading the severity of chronic pain. Pain 1992; 50:133-149.

146. Smith BH, Torrance N. Epidemiology of chronic pain. In: McQuay HJ, Kalso E, Moore RA (eds). Systematic Reviews in Pain Research: Methodology Refined. IASP Press, Seattle, 2008, pp 247-274.

147. Harkness EF, Macfarlane GJ, Silman AJ, McBeth J. Is musculoskeletal pain more common now than 40 years ago?: Two population-based cross-sectional studies. Rheumatology (Oxford) 2005; 44:890-895.

148. Stewart WF, Ricci JA, Chee E, Morganstein D, Lipton R. Lost productive time and cost due to common pain conditions in the US workforce. JAMA 2003; 290:2443-2454.

149. von Korff M, Le Resche L, Dworkin SF. First onset of common pain symptoms: A prospective study of depression as a risk factor. Pain 1993; 55:251-258.

150. Sternbach RA. Pain and "hassles" in the United States: Findings of the Nuprin pain report. Pain 1986; 27:69-80.

151. Magni G, Caldieron C, Rigatti-Luchini $\mathrm{S}$, Merskey H. Chronic musculoskele- tal pain and depressive symptoms in the general population. An analysis of the 1st National Health and Nutrition Examination Survey data. Pain 1990; 43:299-307.

152. Magni G, Marchetti M, Moreschi C, Merskey H, Luchini SR. Chronic musculoskeletal pain and depressive symptoms in the National Health and Nutrition Examination I. Epidemiological follow-up study. Pain 1993; 53:163-168.

153. Chronic Pain in America: Roadblocks to Relief, a study conducted by Roper Starch Worldwide for American Academy of Pain Medicine, American Pain Society and Janssen Pharmaceutica, 1999.

154. Mikkelsson M, El-Metwally A, Kautiainen $H$, Auvinen A, Macfarlane GJ, Salminen JJ. Onset, prognosis and risk factors for widespread pain in schoolchildren: A prospective 4-year follow-up study. Pain 2008; 681-687.

155. Martin AL, McGrath PA, Brown SC, Katz J. Children with chronic pain: Impact of sex and age on long-term outcomes. Pain 2007; 128:13-19.

156. Martin BI, Deyo RA, Mirza SK, Turner JA, Comstock BA, Hollingworth W, Sullivan SD. Expenditures and health status among adults with back and neck problems. JAMA 2008; 299:656-664.

157. Hartvigsen J, Frederiksen H, Christensen K. Back and neck pain in seniors - prevalence and impact. Eur Spine 2006; 15:802-806.

158. Kamper SJ, Rebbeck TJ, Maher CG, McAuley JH, Sterling M. Course and prognostic factors of whiplash: A systematic review and meta-analysis. Pain 2008; 138:617-629.

159. Cassidy JD, Carroll LJ, Côté P. The Saskatchewan Health and Back Pain Survey. The prevalence of low back pain and related disability in Saskatchewan adults. Spine 1998; 23:1860-1867.

160. Côté P, Cassidy JD, Carroll L. The Saskatchewan Health and Back Pain Survey. The prevalence of neck pain and related disability in Saskatchewan adults. Spine 1998; 23:1689-1698.

161. Manchikanti L. The epidemiology of low back pain. Pain Physician 2000; 3:167-192.

162. Linton SJ, Hellsing AL, Hallden K. A population based study of spinal pain among 35-45-year old individuals. Spine 1998, 23:1457-1463.

163. Miemelainen R, Videman T, Battie MC. Prevalence and characteristics of up- 
per or mid-back pain in Finnish men. Spine 2006; 31:1846-1849.

164. Bot SD, van der Waal JM, Terwee CB, van der Windt DA, Schellevis FG, Bouter LM, Dekker J. Incidence and prevalence of complaints of the neck and upper extremity in general practice. Ann Rheum Dis 2005; 64:118-123.

165. Hogg-Johnson S, van der Velde G, Carroll LJ, Holm LW, Cassidy JD, Guzman J, Côté P, Haldeman S, Ammendolia C, Carragee E, Hurwitz E, Nordin $\mathrm{M}, \mathrm{Pe}$ loso P; Bone and Joint Decade 20002010 Task Force on Neck Pain and Its Associated Disorders. The burden and determinants of neck pain in the general population: Results of the Bone and Joint Decade 2000-2010 Task Force on Neck Pain and its associated disorders. Spine 2008; 33:S39-S51.

166. Ektor-Andersen J, Isacsson SO, Lindgren $A$, Orbaek $P$. The experience of pain from the shoulder-neck area related to the total body pain, self-experienced health and mental distress. The Malmo Shoulder-Neck Study group. Pain 1999; 82:289-295.

167. Haldeman S, Carroll LJ, Cassidy JD. Introduction/Mandate: The empowerment of people with neck pain. The Bone and Joint Decade 2000-2010 Task Force on Neck Pain and Its Associated Disorders. Spine 2008; 33:S8-S13.

168. Fejer R, Kyvik KO, Hartvigsen J. The prevalence of neck pain in the world population: A systematic critical review of the literature. Eur Spine / 2006; 15:834-848.

169. Bovim G, Schrader H, Sand T. Neck pain in the general population. Spine 1994; 19:1307-1309.

170. Huisstede BM, Wijnhoven HA, BiermaZeinstra SM, Koes BW, Verhaar JA, Picavet $\mathrm{S}$. Prevalence and characteristics of complaints of the arm, neck, and/or shoulder (CANS) in the open population. Clin J Pain 2008; 24:253-259.

171. Chiu TT, Leung AS. Neck pain in Hong Kong: A telephone survey on prevalence, consequences, and risk groups. Spine 2006; 31:E540-E544.

172. Ciancaglini R, Testa M, Radaelli G. Association of neck pain with symptoms of temporomandibular dysfunction in the general adult population. Scand I Rehabil Med 1999; 31:17-22.

173. Westerling D, Jonsson BG. Pain from the neck-shoulder region and sick leave. Scand I Soc Med 1980; 8:131-136.

174. Thelin A, Holmberg S, Thelin N. Func- tioning in neck and low back pain from a 12-year perspective: A prospective population-based study. J Rehabil Med 2008; 40:555-561.

175. Niemi S, Levoska S, Kemilä J, Rekola K, Keinänen-Kiukaanniemi S. Neck and shoulder symptoms and leisure time activities in high school students. J Orthop Sports Phys Ther 1996; 24:25-29.

176. Guez M, Hildingsson C, Nilsson M, Toolanen $\mathrm{G}$. The prevalence of neck pain: A population-based study from northern Sweden. Acta Orthop Scand 2002; 73:455-459.

177. Linton SJ, Ryberg M. Do epidemiological results replicate? The prevalence and health-economic consequences of neck and back pain in the general population. Eur J Pain 2000; 4:347-354.

178. Hartvigsen J, Christensen K, Frederiksen $\mathrm{H}$. Back and neck pain exhibit many common features in old age: A population-based study of 4,486 Danish twins $70-102$ years of age. Spine 2004; 29:576-580.

179. Côté P, Cassidy JD, Carroll LJ, Kristman $\mathrm{V}$. The annual incidence and course of neck pain in the general population: $\mathrm{A}$ population-based cohort study. Pain 2004; 112:267-273.

180. Palmer KT, Syddall H, Cooper C, Coggon D. Smoking and musculoskeletal disorders: Findings from a British national survey. Ann Rheum Dis 2003; 62:33-36.

181. Picavet HS, Schouten JS. Musculoskeletal pain in the Netherlands: Prevalences, consequences and risk groups, the DMC(3)-study. Pain 2003; 102:167-178.

182. Hartvigsen J, Christensen K. Pain in the back and neck are with us until the end: A nationwide interview-based survey of Danish 100-year-olds. Spine 2008; 33:909-913.

183. Hartvigsen J, Petersen HC, Frederiksen $H$, Christensen K. Small effect of genetic factors on neck pain in old age: A study of 2,108 Danish twins 70 years of age and older. Spine 2005; 30:206208. Erratum in Spine 2005; 30:710.

184. Holm LW, Carroll LJ, Cassidy JD, HoggJohnson S, Côté P, Guzman J, Peloso P, Nordin M, Hurwitz E, van der Velde G, Carragee E, Haldeman S; Bone and Joint Decade 2000-2010 Task Force on Neck Pain and Its Associated Disorders. The burden and determinants of neck pain in whiplash-associated disorders after traffic collisions: Results of the Bone and Joint Decade 2000-2010
Task Force on Neck Pain and Its Associated Disorders. Spine 2008; 33:S52S59.

185. Buitenhuis J, de Jong PJ, Jaspers JP, Groothoff JW. Work disability after whiplash: A prospective cohort study. Spine 2009; 34:262-267.

186. Malanga G, Peter J. Whiplash injuries. Curr Pain Headache Rep 2005; 9:322325.

187. Freburger JK, Holmes GM, Agans RP, Jackman AM, Darter JD, Wallace AS, Castel LD, Kalsbeek WD, Carey TS. The rising prevalence of chronic low back pain. Arch Intern Med 2009; 169:251258.

188. Buitenhuis J, de Jong PJ, Jaspers JP, Groothoff JW. Catastrophizing and causal beliefs in whiplash. Spine 2008; 33:2427-2433.

189. Côté P, van der Velde G, Cassidy JD, Carroll LJ, Hogg-Johnson S, Holm LW, Carragee EJ, Haldeman S, Nordin M, Hurwitz EL, Guzman J, Peloso PM; Bone and Joint Decade 2000-2010 Task Force on Neck Pain and Its Associated Disorders. The burden and determinants of neck pain in workers: Results of the Bone and Joint Decade 2000-2010 Task Force on Neck Pain and Its Associated Disorders. Spine 2008; 33:S60-S74.

190. Leroux I, Dionne CE, Bourbonnais R, Brisson C. Prevalence of musculoskeletal pain and associated factors in the Quebec working population. Int Arch Occup Environ Health 2005; 78:379386.

191. Akesson I, Schutz A, Horstmann V, Skerfving S, Moritz U. Musculoskeletal symptoms among dental personnel - lack of association with mercury and selenium status, overweight and smoking. Swed Dent / 2000; 24:23-38.

192. Akesson I, Johnsson B, Rylander L, Moritz U, Skerfving S. Musculoskeletal disorders among female dental personnel - clinical examination and a 5 -year follow-up study of symptoms. Int Arch Occup Environ Health 1999; 72:395403.

193. Finsen L, Christensen H, Bakke M. Musculoskeletal disorders among dentists and variation in dental work. App Ergon 1998; 29:119-125.

194. Rundcrantz BL, Johnsson B, Moritz U. Cervical pain and discomfort among dentists. Epidemiological, clinical and therapeutic aspects. Part 1. A survey of pain and discomfort. Swed Dent J 1990; 14:71-80. 
195. Trinkoff AM, Lipscomb JA, Geiger-Brown J, Brady B. Musculoskeletal problems of the neck, shoulder, back and functional consequences in nurses. Am J Ind Med 2002; 41:170-178.

196. Trinkoff AM, Lipscomb JA, Geiger-Brown J, Storr CL, Brady BA. Perceived physical demands and reported musculoskeletal problems in registered nurses. Am J Prev Med 2003; 24:270-275.

197. Smith DR, Choe MA, Jeon MY, Chae YR, An GJ, Jeong JS. Epidemiology of musculoskeletal symptoms among Korean hospital nurses. Int J Occup Saf Ergon 2005; 11:431-440.

198. Rosecrance JC, Cook TM, Zimmermann $\mathrm{CL}$. Active surveillance for the control of cumulative trauma disorders: A working model in the newspaper industry. J Ortho Sports Phys Ther 1994; 19:267276.

199. Holmström EB, Lindell J, Moritz U. Low back and neck/shoulder pain in construction workers: Occupational workload and psychosocial risk factors. Part 2: Relationship to neck and shoulder pain. Spine 1992; 17:672-677.

200. Côté P, Kristman V, Vidmar M, Van Eerd D, Hogg-Johnson S, Beaton D, Smith PM. The prevalence and incidence of work absenteeism involving neck pain: A cohort of Ontario lost-time claimants. Spine 2008; 33:S192-S198.

201. Palmer KT, Walker-Bone K, Griffin MJ, Syddall H, Pannett B, Coggon D, Cooper C. Prevalence and occupational associations of neck pain in the British population. Scand I Work Environ Health 2001; 27:49-56.

202. Eriksen W, Natvig B, Knardahl S, Bruusgaard D. Job characteristics as predictors of neck pain. A 4-year prospective study. J Occup Environ Med 1999; 41:893-902.

203. Hush JM, Maher CG, Refshauge KM. Risk factors for neck pain in office workers: A prospective study. BMC Musculoskelet Disord 2006; 7:81.

204. Gamperiene M, Stigum H. Work related risk factors for musculoskeletal complaints in the spinning industry in Lithuania. Occup Environ Med 1999; 56:411-416.

205. Carroll LJ, Hogg-Johnson S, van der Velde G, Haldeman S, Holm LW, Carragee EJ, Hurwitz EL, Côté P, Nordin M, Peloso PM, Guzman J, Cassidy JD; Bone and Joint Decade 2000-2010 Task Force on Neck Pain and Its Associated Disorders. Course and prognostic factors for neck pain in the general population:
Results of the Bone and Joint Decade 2000-2010 Task Force on Neck Pain and Its Associated Disorders. Spine 2008; 33:S75-S82.

206. Silverstein BA, Viikari-Juntura E, Kalat J. Use of a prevention index to identify industries at high risk for work-related musculoskeletal disorders of the neck, back, upper extremity in Washington State, 1990-1998. Am J Ind Med 2002; 41:149-169.

207. Borghouts JA, Koes BW, Bouter LM. The clinical course and prognostic factors of non-specific neck pain: A systematic review. Pain 1998; 77:1-13.

208. Holmberg SA, Thelin AG. Primary care consultation, hospital admission, sick leave and disability pension owing to neck and low back pain: A 12-year prospective cohort study in a rural population. BMC Musculoskelet Disord 2006; 7:66.

209. Cassidy JD, Carroll LJ, Côté P, Lemstra M, Berglund A, Nygren A. Effect of eliminating compensation for pain and suffering on the outcome of insurance claims for whiplash injury. N Engl J Med 2000; 342:1179-1186.

210. Carroll LJ, Holm LW, Hogg-Johnson S, Côté P, Cassidy JD, Haldeman S, Nordin M, Hurwitz EL, Carragee EJ, van der Velde G, Peloso PM, Guzman J; Bone and Joint Decade 2000-2010 Task Force on Neck Pain and Its Associated Disorders. Course and prognostic factors for neck pain in whiplash-associated disorders (WAD): Results of the Bone and Joint Decade 2000-2010 Task Force on Neck Pain and Its Associated Disorders. Spine 2008; 33:S83-S92.

211. Cassidy JD, Carroll LJ, Côté P, Frank J. Does multidisciplinary rehabilitation benefit whiplash recovery? Results of a population-based incidence cohort study. Spine 2007; 32:126-131.

212. Drottning M, Staff PH, Sjaastad O. Cervicogenic headache (CEH) after whiplash injury. Cephalalgia 2002; 22:165171.

213. Carroll LJ, Hogg-Johnson S, Côté P, van der Velde G, Holm LW, Carragee EJ, Hurwitz EL, Peloso PM, Cassidy JD, Guzman J, Nordin M, Haldeman S; Bone and Joint Decade 2000_2010 Task Force on Neck Pain and Its Associated Disorders. Course and prognostic factors for neck pain in workers: Results of the Bone and Joint Decade 2000-2010 Task Force on Neck Pain and its Associated Disorders. Spine 2008; 33:S93S100.
214. Singer KP, Edmondston SJ. Introduction: The enigma of the thoracic spine. In Singer KP, Edmondston SJ (eds). Clinical Anatomy and Management of Thoracic Spine, Vol 2. Butterworth Heinemann, Oxford, 2000, pp 3-13.

215. Occhipinti E, Colombini D, Grieco A. Study of distribution and characteristics of spinal disorders using a validated questionnaire in a group of male subjects not exposed to occupational spinal risk factors. Spine 1993; 18:11501159.

216. Edmondston SJ, Singer KP. Thoracic spine: Anatomical and biomechanical considerations for manual therapy. Man Ther 1997; 2:132-143.

217. Milgrom C, Finestone A, Lev B, Wiener M, Floman Y. Overexertional lumbar and thoracic back pain among recruits: A prospective study of risk factors and treatment regimens. J Spinal Disord 1993; 6:187-193.

218. Van der Linden SM, Fahrer H. Occurrence of spinal pain syndromes in a group of apparently healthy and physically fit sportsmen (orienteers). Scand J Rheumatol 1988; 17:475-481.

219. Anderson R, Meeker WC, Wirick BE, Mootz RD, Kirk DH, Adams A. A metaanalysis of clinical trials of spinal manipulation. J Manipulative Physiol Ther 1992; 15:181-194.

220. Deyo RA, Tsui-Wu YJ. Descriptive epidemiology of low-back pain and its related medical care in the United States. Spine 1987; 12:264-268.

221. Deyo RA, Mirza SK, Martin BI. Back pain prevalence and visit rates: Estimates from U.S. national surveys, 2002. Spine 2006; 31:2724-2727.

222. Sternbach RA. Survey of pain in the United States: The Nuprin Pain Report. Clin J Pain 1986; 2:49-53.

223. Verhaak PF, Kerssens JJ, Dekker J, Sorbi MJ, Bensing JM. Prevalence of chronic benign pain disorder among adults: A review of the literature. Pain 1998; 77:231-239.

224. El-Methway A, Salminen JJ, Auvinen A, Kautiainen $\mathrm{H}$, Mikkelsson M. Lower limb pain in a preadolescent population: Prognosis and risk factors for chronicity - a prospective 1 - and 4 year follow-up study. Pediatrics 2005; 116:673-681.

225. Nachemson AL. Newest knowledge of low back pain. A critical look. Clin Orthop 1992; 279:8-20.

226. Leigh JP, Markowitz SB, Fahs M, Shin C, 
Landrigan PJ. Occupational injury and illness in the United States. Estimates of costs, morbidity, and mortality. Arch Inter Med 1997; 157:1557-1568.

227. Rosecrance, JC, Cook TM, Zimmermann CL. Work related musculoskeletal symptoms among construction workers in the pipe trades. Work 1996; 7:1320.

228. Guo HR, Tanaka S, Cameron LL, Seligman PJ, Behrens VJ, Ger J, Wild DK, Putz-Anderson V. Back pain among workers in the United States. National estimates and workers at high risk. AmJ Ind Med 1995; 28:591-602.

229. Frymoyer JW, Pope MH, Clements JG, Wilder DG, MacPherson B, Ashikaga T. Risk factors in low back pain. An epidemiological survey. J Bone Joint Surg Am 1983; 65:218-218.

230. Nagi SZ, Riley LE, Newby LG. A social epidemiology of back pain in a general population. J Chronic Dis 1973; 26:769779.

231. Reisbord LS, Greenland S. Factors associated with self-reported back pain prevalence. A population based study. J Chronic Dis 1985; 38:691-702.

232. Kelsey JL, Golden Al, Mundt DJ. Low back pain/prolapsed lumbar intervertebral disc. Rheum Dis Clin North Am 1990; 163:699-715.

233. Hicks GE, Morone N, Weiner DK. Degenerative lumbar disc and facet disease in older adults: Prevalence and clinical correlates. Spine 2009; 34:1301-1306.

234. Rudy TE, Weiner DK, Lieber SJ, Slaboda J, Boston JR. The impact of chronic low back pain on older adults: A comparative study of patients and controls. Pain 2007; 131:293-301.

235. Shekelle PG, Markovich M, Louie R. An epidemiologic study of episodes of back pain care. Spine 1995; 20:16681673.

236. Anderson GBJ, Svensson HO. The intensity of work recovery in low back pain. Spine 1983; 8:880-887.

237. Gureje O, Simon GE, von Korff M. A cross-national study of the course of persistent pain in primary care. Pain 2001; 92:195-200.

238. Andersson HI, Ejlertsson G, Leden I, Rosenberg C. Chronic pain in a geographically defined general population: Studies of differences in age, gender, social class, and pain localization. Clin J Pain 1993; 9:174-182.

239. Eriksen J, Ekholm O, Sjøgren P, Rasmussen NK. Development of and recov- ery from long-term pain. A 6-year follow-up study of a cross-section of the adult Danish population. Pain 2004; 108:154-162.

240. Kadam UT, Thomas E, Croft PR. Is chronic widespread pain a predictor of allcause morbidity? A 3 year prospective population based study in family practice. J Rheumatol 2005; 32:1341-1348.

241. Stanford EA, Chamber CT, Biesanz JC, Chen $E$. The frequency, trajectories and predictors of adolescent recurrent pain: A population-based approach. Pain 2008; 138:11-21.

242. Cassidy JD, Côté P, Carroll LJ, Kristman $\mathrm{V}$. Incidence and course of low back pain episodes in the general population. Spine 2005; 30:2817-2823.

243. Hestbaek L, Leboeuf-Yde C, Manniche C. Low back pain: What is the long-term course? A review of studies of general patient populations. Eur Spine J 2003; 12:149-165.

244. Croft PR, Lewis M, Papageorgiou AC, Thomas E, Jayson MI, Macfarlane GJ, Silman AJ. Risk factors for neck pain: A longitudinal study in the general population. Pain 2001; 93:317-325.

245. Enthoven P, Skargren E, Oberg B. Clinical course in patients seeking primary care for back or neck pain: A prospective 5 -year follow-up of outcome and health care consumption with subgroup analysis. Spine 2004; 29:24582465.

246. Elders LA, Burdorf A. Prevalence, incidence, and recurrence of low back pain in scaffolders during a 3-year follow-up study. Spine 2004; 29:E101-E106.

247. Croft PR, Papageorgiou AC, Thomas E, Macfarlane GJ, Silman AJ. Short-term physical risk factors for new episodes of low back pain. Prospective evidence from the South Manchester Back Pain Study. Spine 1999; 24:1556-1561.

248. Miedema HS, Chorus AM, Wevers CW, van der Linden S. Chronicity of back problems during working life. Spine 1998; 23:2021-2028.

249. Thomas E, Silman AJ, Croft PR, Papageorgiou AC, Jayson MI, Macfarlane GJ. Predicting who develops chronic low back pain in primary care. A prospective study. Brit Med J 1999; 318:16621667.

250. Mortimer M, Pernold G, Wiktorin C. Low back pain in a general population. Natural course and influence of physical exercise - A 5-year follow-up of the Musculoskeletal Intervention Center-
Norrtälje Study. Spine 2006; 31:30453051.

251. Jones GT, Johnson RE, Wiles NJ, Chaddock C, Potter RG, Roberts C, Symmons DP, Macfarlane GJ. Predicting persistent disabling low back pain in general practice: A prospective cohort study. $\mathrm{Br}$ J Gen Pract 2006; 56:334-341.

252. Kaaria S, Luukkonen R, Riihimaki H, Kirjonen J, Leino-Arjas P. Persistence of low back pain reporting among a cohort of employees in a metal corporation: A study with 5-, 10-, and 28-year follow-ups. Pain 2006; 120:131-137.

253. Leboeuf-Yde C, Gronstvedt A, Borge JA, Lothe J, Magnesen E, Nilsson O, Rosok G, Stig LC, Larsen K. The Nordic back pain subpopulation program: A 1-year prospective multicenter study of outcomes of persistent low-back pain in chiropractic patients. J Manipulative Physiol Ther 2005; 28:90-96.

254. Jacob T, Baras M, Zeev A, Epstein L. A longitudinal, community-based study of low back pain outcomes. Spine 2004; 29:1810-1817.

255. Hestbaek L, Leboeuf-Yde C, Engberg M, Lauritzen T, Bruun NH, Manniche C. The course of low back pain in a general population. Results from a 5 -year prospective study. I Manipulative Physiol Ther 2003; 26:213-219.

256. Szpalski M, Gunzburg R, Balague F, Nordin M, Melot C. A 2-year prospective longitudinal study on low back pain in primary school children. Eur Spine J 2002; 11:459-464.

257. Waxman R, Tennant A, Helliwell P. A prospective follow-up study of low back pain in the community. Spine 2000; 25:2085-2090.

258. Kovacs FM, Fernández C, Cordero A, Muriel A, Gonzalez-Lujan L, Gil del Real MT; Spanish Back Pain Research Network. Non-specific low back pain in primary care in the Spanish National Health Service: A prospective study on clinical outcomes and determinants of management. BMC Health Serv Res 2006; 6:57.

259. Smith BH, Elliott AM, Hannaford PC, Chambers WA, Smith WC. Factors related to the onset and persistence of chronic back pain in the community: Results from a general population follow-up study. Spine 2004; 29:10321040.

260. Stanton TR, Henschke N, Maher CG, Refshauge KM, Latimer J, McAuley JH. After an episode of acute low back pain, recurrence is unpredictable and 
not as common as previously thought. Spine 2008; 33:2923-2928.

261. Bressler HB, Keyes WJ, Rochon PA, Badley $E$. The prevalence of low back pain in the elderly. A systematic review of the literature. Spine 1999; 24:18131819.

262. Ratcliffe GE, Enns MW, Belik S, Sareen J. Chronic pain conditions and suicidal ideation and suicide attempts. An epidemiologic perspective. Clin J Pain 2008; 24:204-210.

263. Merikangas KR, Ames M, Cui L, Stang PE, Ustun TB, von Korff M, Kessler RC. The impact of comorbidity of mental and physical conditions on role disability in the US adult household population. Arch Gen Psychiatry 2007; 64:1180-1188.

264. Cunningham LS, Kelsey JL. Epidemiology of musculoskeletal impairments and associated disability. Am J Public Health 1984; 74:574-579.

265. Bentsen SB, Rustøen T, Wahl AK, Miaskowski C. The pain experience and future expectations of chronic low back pain patients following spinal fusion. J Clin Nurs 2008; 17:153-159.

266. Rivera JJ. Reliability of psychological evaluation in chronic pain in an interventional pain management setting. Pain Physician 2005; 8:375-383.

267. Manchikanti L, Rivera JJ, Pampati V, Damron KS, Beyer CD, Barnhill RC. Effectiveness of clinical guidelines in interventional pain management. Pain Physician 2002; 5:127-132.

268. Manchikanti L, Fellows B, Singh V. Understanding psychological aspects of chronic pain in interventional pain management. Pain Physician 2002; 5:57-82.

269. Manchikanti L, Fellows B, Pampati V, Damron KS, Beyer CD, Barnhill RC. Comparison of psychological status of chronic pain patients with general population. Pain Physician 2002; 5:40-48.

270. Deyo RA, Mirza SK, Turner JA, Martin BI. Overtreating chronic back pain: Time to back off? I Am Board Fam Med 2009; 22:62-68.

271. Deyo RA, Nachemson A, Mirza SK. Spinal-fusion surgery: The case for restraint. N Engl J Med 2004; 350:722726.

272. Fritzell P, Hagg O, Nordwall A. Complications in lumbar fusion surgery for chronic low back pain: Comparison of three surgical techniques used in a prospective randomized study. A report from the Swedish Lumbar Spine Study Group. Eur Spine J 2003; 12:178-189.

273. Thomsen K, Christensen FB, Eiskjaer SP, Hansen ES, Fruensgaard S, Bunger CE. The effect of pedicle screw instrumentation on functional outcome and fusion rates in posterolateral lumbar spinal fusion: A prospective, randomized clinical study. Spine 1997; 22:2813-2822.

274. Maghout-Juratli S, Franklin GM, Mirza SK, Wickizer TM, Fulton-Kehoe D. Lumbar fusion outcomes in Washington State workers' compensation. Spine 2006; 31:2715-2723.

275. Martin BI, Mirza SK, Comstock BA, Gray DT, Kreuter W, Deyo RA. Are lumbar spine reoperation rates falling with greater use of fusion surgery and new surgical technology? Spine 2007; 32:2119-2126.

276. Hart LG, Deyo RA, Cherkin DC. Physician office visits for low back pain. Frequency, clinical evaluation, and treatment patterns from a US national survey. Spine 1995; 20:11-19.

277. Leigh JP, Sheetz RM. Prevalence of back pain among full-time United States workers. BrJ Med 1989; 4:651-657.

278. Manchikanti L, Hirsch JA. Obama health care for all Americans: Practical implications. Pain Physician 2009; 12:289304 .

279. Turk DC. Clinical effectiveness and cost-effectiveness of treatments for patients with chronic pain. Clin J Pain 2002; 18:355-365.

280. Asche CV, Kirkness CS, McAdam-Marx C, Fritz JM. The societal costs of low back pain: Data published between 2001 and 2007. J Pain Palliat Care Pharmacother 2007; 21:25-33.

281. Waddell G. The Back Pain Revolution, Second Edition. Churchill Livingstone, Edinburgh, 2004

282. Nieto R, Miró J, Huguet A. Disability in subacute whiplash patients: Usefulness of the neck disability index. Spine 2008; 33:E630-E635.

283. Saastamoinen $P$, Leino-Arjas $P$, Laaksonen M, Lahelma E. Socio-economic differences in the prevalence of acute, chronic and disabling chronic pain among ageing employees. Pain 2005; 114:364-371.

284. Bunketorp L, Stener-Victorin E, Carlsson J. Neck pain and disability following motor vehicle accidents: $A$ cohort study. Eur Spine J 2005; 14:84-89.

285. Frank AO, De Souza LH, Frank CA. Neck pain and disability: A cross-sectional survey of the demographic and clinical characteristics of neck pain seen in a rheumatology clinic. Int J Clin Pract 2005; 59:173-182.

286. Hartvigsen J, Frederiksen H, Christensen K. Physical and mental function and incident low back pain in seniors: A population-based two-year prospective study of 1,387 Danish twins aged 70 to 100 years. Spine 2006; 31:16281632.

287. Jacob T. Low back pain incident episodes: A community-based study. Spine J 2006; 6:306-310.

288. Hestbaek L, Leboeuf-Yde C, Kyvik KO. Is comorbidity in adolescence a predictor for adult low back pain? A prospective study of a young population. BMC Musculoskelet Disord 2006; 7:29.

289. Ekman M, Jönhagen S, Hunsche E, Jonsson $L$. Burden of illness of chronic low back pain in Sweden: A cross-sectional, retrospective study in primary care setting. Spine 2005; 30:1777-1785.

290. Ritzwoller DP, Crounse L, Shetterly S, Rublee D. The association of comorbidities, utilization and costs for patients identified with low back pain. $B M C$ Musculoskelet Disord 2006; 7:72.

291. Vogt MT, Kwoh CK, Cope DK, Osial TA, Culyba M, Starz TW. Analgesic usage for low back pain: Impact on health care costs and service use. Spine 2005; 30:1075-1081.

292. Webster BS, Verma SK, Gatchel RJ. Relationship between early opioid prescribing for acute occupational low back pain and disability duration, medical costs, subsequent surgery and late opioid use. Spine 2007; 32:2127-2132.

293. Ricci JA, Stewart WF, Chee E, Leotta C, Foley K, Hochberg MC. Back pain exacerbations and lost productive time costs in United States workers. Spine 2006; 31:3052-3060.

294. Morken T, Riise T, Moen B, Bergum O, Hauge SH, Holien S, Langedrag A, Olson HO, Pedersen S, Saue IL, Seljebø GM, Thoppil V. Frequent musculoskeletal symptoms and reduced health-related quality of life among industrial workers. Occup Med 2002; 52:91-98.

295. Centers for Disease Control and Prevention. Prevalence of disabilities and associated health conditions among adults: United States, 1999. MMWR Morb Mortal Wkly Rep 2001; 50:120125.

296. Rizzo JA, Abbott TA 3rd, Berger ML. 
The labor productivity effects of chronic backache in the United States. Med Care 1998; 36:1471-1488.

297. Frymoyer JW, Cats-Baril WL. An overview of the incidences and costs of low back pain. Orthop Clin North Am 1991; 22:263-271.

298. McGorry RW, Webster BS, Snook SH, Hsiang SM. The relation between pain intensity, disability, and the episodic nature of chronic and recurrent low back pain. Spine 2000; 25:834-841.

299. Sach TH, Whynes DK. Measuring indirect costs: Is there a problem? Appl Health Econ Health Policy 2003; 2:135139.

300. White AG, Birnbaum HG, Mareva MN, Daher M, Vallow S, Schein J, Katz N. Direct costs of opioid abuse in an insured population in the United States. J Manag Care Pharm 2005; 11:469-479.

301. Daffner SD, Hilibrand AS, Hanscom BS, Brislin BT, Vaccaro AR, Albert TJ. Impact of neck and arm pain on overall health status. Spine 2003; 28:2030-2035.

302. Dionne CE, Chenard M. Back-related functional limitations among fulltime homemakers: A comparison with women employed full-time outside the home. Spine 2004; 29:1375-1382.

303. Luo X, Pietrobon R, Sun SX, Liu GG, Hey L. Estimates and patterns of direct health care expenditures among individuals with back pain in the United States. Spine 2004; 29:79-86.

304. Ohayon MM, Schatzberg AF. Using chronic pain to predict depressive morbidity in the general population. Arch Gen Psychiatry 2003; 60:39-47.

305. Hurwitz EL, Morgenstern H, Yu F. Crosssectional and longitudinal associations of low-back pain and related disability with psychological distress among patients enrolled in the UCLA LowBack Pain Study. J Clin Epidemiol 2003; 56:463-471.

306. Turner JA, Franklin G, Heagerty PJ, Wu R, Egan K, Fulton-Kehoe D, Gluck JV, Wickizer TM. The association between pain and disability. Pain 2004; 112:307314 .

307. Pai S, Sundaram LJ. The economic burden of low back pain: A review of studies published between 1996 and 2001. Orthop Clin North Am 2004; 35:1-5.

308. Maetzel A, Li L. The economic burden of low back pain: A review of studies published between 1996 and 2001. Best Pract Res Clin Rheumatol 2002; 16:2330.
309. Bell G, Kidd D, North R. Cost-effectiveness analysis of spinal cord stimulation in treatment of failed back surgery syndrome. J Pain Symp Manage 1997; 13:286-295.

310. Lind BK, Abrams C, Lafferty WE, Diehr PK, Grembowski DE. The effect of complementary and alternative medicine claims on risk adjustment. Med Care 2006; 44:1078-1084.

311. Katz JN. Lumbar disc disorders and lowback pain: Socioeconomic factors and consequences. J Bone Joint Surg Am 2006: 88:S21-S24.

312. de Lissovoy G, Brown RE, Halpern M, Hassenbusch SJ, Ross E. Cost-effectiveness of long-term intrathecal morphine therapy for pain associated with failed back surgery syndrome. Clin Ther 1997; 19:96-112.

313. Dagenais S, Caro J, Haldeman S. A systematic review of low back pain cost of illness studies in the United States and internationally. Spine J 2008; 8:8-20.

314. Maniadakis N, Gray A. The economic burden of back pain in the UK. Pain 2000; 84:95-103.

315. Walker BF, Muller R, Grant WD. Low back pain in Australian adults: The economic burden. Asia Pac J Public Health 2003; 15:79-87.

316. Jhawar BS, Fuchs CS, Colditz GA, Stampfer MJ. Cardiovascular risk factors for physician-diagnosed lumbar disc herniation. Spine / 2006; 6:684691.

317. Carroll LJ, Cassidy JD, Côté P. Frequency, timing, and course of depressive symptomatology after whiplash. Spine 2006; 31:E551-E556.

318. Dersh J, Gatchel RJ, Mayer T, Polatin P, Temple OR. Prevalence of psychiatric disorders in patients with chronic disabling occupational spinal disorders. Spine 2006; 31:1156-1162.

319. Paulozzi LJ, Budnitz DS, Yongli X. Increasing deaths from opioid analgesics in the United States. Pharmacoepidemiol Drug Saf 2006; 15:618-627.

320. Nock MK, Borges G, Bromet EJ, Alonso $J$, Angermeyer $M$, Beautrais A, Bruffaerts R, Chiu WT, de Girolamo G, Gluzman S, de Graaf R, Gureje O, Haro JM, Huang Y, Karam E, Kessler RC, Lepine $J P$, Levinson D, Medina-Mora ME, Ono Y, Posada-Villa J, Williams D. Cross-national prevalence and risk factors for suicidal ideation, plans and attempts. BrJ Psychiatry 2008; 192:98-105.

321. Kessler RC, Angermeyer M, Anthony
JC, de Graaf R, Demyttenaere K, Gasquet I, DE Girolamo G, Gluzman S, Gureje O, Haro JM, Kawakami N, Karam A, Levinson D, Medina Mora ME, Oakley Browne MA, Posada-Villa J, Stein D), Adley Tsang CH, Aguilar-Gaxiola S, Alonso J, Lee S, Heeringa S, Pennell BE, Berglund P, Gruber MJ, Petukhova M, Chatterji S, Ustün TB. Lifetime prevalence and age-of-onset distributions of mental disorders in the World Health Organization's World Mental Health Survey Initiative. World Psychiatry 2007; 6:168-176

322. Smith BH, Torrance N, Bennett MI, Lee A). Health and quality of life associated with chronic pain of predominantly neuropathic origin in the community. Clin J Pain 2007; 23:143-149.

323. Weiner BK. Spine update: The biopsychosocial model and spine care. Spine 2008; 33:219-223.

324. Gatchel RJ, Turk DC. Criticisms of the biopsychosocial model in spine care: Creating and then attacking a straw person. Spine 2008; 33:2831-2836.

325. Weinstein JN, Lurie JD, Olson PR, Bronner KK, Fisher ES. United States' trends and regional variations in lumbar spine surgery: 1992-2003. Spine 2006; 31:2707-2714.

326. McCrory DC, Turner DA, Patwardhan $M B$, Richardson WL. Spinal fusion for degenerative disc disease affecting the lumbar spine (draft evidence report/technology review prepared for the Medicare Coverage Advisory Committee meeting), 2006; www.cms.hhs. gov/determinationprocess/downloads/id41ta.pdf

327. Manchikanti L, McMahon EB. Physician refer thyself: Is Stark II, Phase III the final voyage? Health policy update. Pain Physician 2007; 10:725-741.

328. Friedly J, Chan L, Deyo R. Geographic variation in epidural steroid injection use in Medicare patients. / Bone Joint Surg Am 2008; 90:1730-1737.

329. Manchikanti L. The growth of interventional pain management in the new millennium: A critical analysis of utilization in the Medicare population. Pain Physician 2004; 7:465-482.

330. Engel GL. The need for a new medical model: A challenge for biomedicine. Science 1977; 196:129-136.

331. White P. Biopsychosocial Medicine: An Integrated Approach to Understanding Illness. Oxford University Press, Oxford, 2005. 
332. Rosenberg CE. They tyranny of diagnosis: Specific entities and individual experiences. Millbank Quart 2002; 80:237-260.

333. Covington EC. Psychogenic pain-what it means, why it does not exist, and how to diagnose it. Pain Med 2000; 1:287-294.

334. Gagliese L, Katz J. Medically unexplained pain is not caused by psychopathology. Pain Res Manage 2000; 5:251-257.

335. Hendler N, Bergson C, Morrison C. Overlooked physical diagnoses in chronic pain patients involved in litigation. Part 2. The addition of MRI, nerve blocks, 3-D CT, and qualitative flow meter. Psychosomatics 1996; 37:509-517.

336. Hendler NH, Kolodny AL. Using medication wisely in chronic pain. Patient Care 1992; 26:125-139.

337. Pang WW, Mok MS, Lin ML, Chang DP, Hwang MH. Application of spinal pain mapping in the diagnosis of low back pain-analysis of 104 cases. Acta Anaesthesiol Sin 1998; 36:71-74.

338. Manchikanti L, Singh V, Pampati V, Damron K, Barnhill R, Beyer C, Cash K. Evaluation of the relative contributions of various structures in chronic low back pain. Pain Physician 2001; 4:308316.

339. Yin W, Bogduk N. The nature of neck pain in a private pain clinic in the United States. Pain Med 2008; 9:196-203.

340. Bogduk N. Principles of diagnostic blocks. In: Slipman C, Derby R, Simeone FA, Mayer TG (eds). Interventional Spine: An Algorithmic Approach. Saunders Elsevier, Philadelphia, 2008, pp 187-192.

341. Buckley FP. Regional anesthesia with local anesthetics. In: Loeser JD (ed). Bonica's Management of Pain, 3rd Edition. Lippincott Williams \& Wilkins, Philadelphia, 2001, pp 1893-1952.

342. Bonica JJ. Local anesthesia and regional blocks. In: Wall PD, Melzack R (eds). Textbook of Pain, 2nd Edition. Churchill Livingstone, Edinburgh, 1989, pp 724743.

343. Bonica JJ, Buckley FP. Regional analgesia with local anesthetics. In: Bonica JJ (ed). The Management of Pain, Vol. II. Lea \& Febiger, Philadelphia, 1990; pp 1883-1966.

344. Boas RA. Nerve blocks in the diagnosis of low back pain. Neurosurg Clin N Am 1991; 2:807-816.

345. Bonica JJ, Butler SH. Local anaesthesia and regional blocks. In: Wall PD, Melzack R (eds). Textbook of Pain, 3rd Edition. Churchill Livingstone, Edinburgh, 1994, pp 997-1023.

346. Barnsley L, Lord S, Bogduk N. Comparative local anaesthetic blocks in the diagnosis of cervical zygapophysial joint pain. Pain 1993; 55:99-106.

347. Bogduk N. Diagnostic nerve blocks in chronic pain. Best Pract Res Clin Anaesthesiol 2002; 16:565-578.

348. Lord SM, Barnsley L, Bogduk N. The utility of comparative local anesthetic blocks versus placebo-controlled blocks for the diagnosis of cervical zygapophysial joint pain. Clin J Pain 1995; 11:208-213.

349. Cavanaugh JM, Ozaktay AC, Yamashita T, Avramov A, Getchell TV, King Al. Mechanisms of low back pain: A neurophysiologic and neuroanatomic study. Clin Orthop 1997; 335:166-180.

350. Bogduk N, Wilson AS, Tynan W. The human lumbar dorsal rami. J Anat 1982; 134:383-397.

351. Dreyfuss P, Schwarzer AC, Lau P, Bogduk N. Specificity of lumbar medial branch and $\mathrm{L}_{5}$ dorsal ramus blocks. Spine 1997; 22:895-902.

352. Kaplan M, Dreyfuss P, Halbrook B, Bogduk N. The ability of lumbar medial branch blocks to anesthetize the zygapophysial joint. Spine 1998; 23:18471852.

353. Cavanaugh JM, Lu Y, Chen C, Kallakuri $\mathrm{S}$. Pain generation in lumbar and cervical facet joints. J Bone Joint Surg Am 2006; 88 Suppl 2:63-67.

354. Hirsch C, Ingelmark BE, Miller M. The anatomical basis for low back pain: Studies on the presence of sensory nerve endings in ligamentous, capsular and intervertebral disc structures in the human lumbar spine. Acta Orthop Scand 1963; 33:1-17.

355. Mooney V, Robertson J. The facet syndrome. Clin Orthop 1976; 115:149-156.

356. McCall IW, Park WM, O'Brien JP. Induced pain referral from posterior lumbar elements in normal subjects. Spine 1979; 4:441-446.

357. Fairbank JC, Park WM, McCall IW, O'Brien JP. Apophyseal injection of local anesthetic as a diagnostic aid in primary low-back pain syndromes. Spine 1981; 6:598-605.

358. Marks R. Distribution of pain provoked from lumbar facet joints and related structures during diagnostic spinal infiltration. Pain 1989; 39:37-40.
359. Fukui S, Ohseto K, Shiotani M, Ohno K, Karasawa H, Naganuma Y. Distribution of referral pain from the lumbar zygapophyseal joints and dorsal rami. Clin J Pain 1997; 13:303-307.

360. Windsor RE, King FJ, Roman SJ, Tata N, Cone-Sullivan LA, Thampi S, Acebey M, Gilhool JJ, Rao R, Sugar R. Electrical stimulation induced lumbar medial branch referral patterns. Pain Physician 2002; 5:347-353.

361. Boswell MV, Singh V, Staats PS, Hirsch JA. Accuracy of precision diagnostic blocks in the diagnosis of chronic spinal pain of facet or zygapophysial joint origin: A systematic review. Pain Physician 2003; 6:449-456.

362. Sehgal N, Shah RV, McKenzie-Brown A, Everett CR. Diagnostic utility of facet (zygapophysial) joint injections in chronic spinal pain: A systematic review of evidence. Pain Physician 2005; 8:211-224.

363. Bogduk N. International Spinal Injection Society guidelines for the performance of spinal injection procedures. Part 1. Zygapophysial joint blocks. Clin J Pain 1997; 13:285-302.

364. Manchukonda R, Manchikanti KN, Cash KA, Pampati V, Manchikanti L. Facet joint pain in chronic spinal pain: An evaluation of prevalence and false-positive rate of diagnostic blocks. J Spinal Disord Tech 2007; 20:539-545.

365. Manchikanti L, Boswell MV, Singh V, Pampati V, Damron KS, Beyer CD. Prevalence of facet joint pain in chronic spinal pain of cervical, thoracic, and lumbar regions. BMC Musculoskelet Disord 2004; 5:15.

366. Manchikanti L, Pampati V, Fellows B, Pakanati RR. Prevalence of lumbar facet joint pain in chronic low back pain. Pain Physician 1999; 2:59-64.

367. Manchikanti L, Pampati V, Fellows B, Baha A. The inability of the clinical picture to characterize pain from facet joints. Pain Physician 2000; 3:158-166.

368. Manchikanti L, Hirsch JA, Pampati V. Chronic low back pain of facet (zygapophysial) joint origin: Is there a difference based on involvement of single or multiple spinal regions? Pain Physician 2003; 6:399-405.

369. Manchikanti L, Singh V, Pampati V, Damron K, Beyer C, Barnhill R. Is there correlation of facet joint pain in lumbar and cervical spine? Pain Physician 2002; 5:365-371.

370. Schwarzer AC, Aprill CN, Derby R, Fortin 
J, Kine G, Bogduk N. The relative contributions of the disc and zygapophyseal joint in chronic low back pain. Spine 1994; 19:801-806.

371. Schwarzer AC, Aprill CN, Derby R, Fortin J, Kine G, Bogduk N. Clinical features of patients with pain stemming from the lumbar zygapophyseal joints. Is the lumbar facet syndrome a clinical entity? Spine 1994; 10:1132-1137.

372. Schwarzer AC, Wang SC, Bogduk N, McNaught PJ, Laurent R. Prevalence and clinical features of lumbar zygapophysial joint pain: A study in an Australian population with chronic low back pain. Ann Rheum Dis 1995; 54:100-106.

373. Manchikanti L, Manchukonda R, Pampati V, Damron KS, McManus CD. Prevalence of facet joint pain in chronic low back pain in postsurgical patients by controlled comparative local anesthetic blocks. Arch Phys Med Rehabil 2007; 88:449-455.

374. Nath S, Nath CA, Pettersson K. Percutaneous lumbar zygapophysial (facet) joint neurotomy using radiofrequency current, in the management of chronic low back pain. A randomized doubleblind trial. Spine 2008; 33:1291-1297.

375. Manchikanti L, Singh V, Falco FJ, Cash KA, Pampati V. Lumbar facet joint nerve blocks in managing chronic facet joint pain: One-year follow-up of a randomized, double-blind controlled trial: Clinical Trial NCTo0355914. Pain Physician 2008; 11:121-132.

376. Manchikanti L, Singh V, Pampati V. Are diagnostic lumbar medial branch blocks valid? Results of 2-year follow up. Pain Physician 2003; 6:147-153.

377. Dreyfuss $P$, Baker R, Leclaire R, Fortin L, Lambert R, Bergeron Y, Rossignol $M$. Radiofrequency facet joint denervation in the treatment of low back pain: A placebo-controlled clinical trial to assess efficacy. Spine 2002; 27:556-567.

378. Schwarzer AC, Derby R, Aprill CN, Fortin J, Kine G, Bogduk N. The value of the provocation response in lumbar zygapophysial joint injections. Clin J Pain 1994; 10:309-313.

379. Merskey H, Bogduk N. Lumbar zygapophysial joint pain. In: Classification of Chronic Pain. Descriptions of Chronic Pain Syndromes and Definition of Pain Terms, 2nd ed. Task Force on Taxonomy of the International Association for the Study of Pain. IASP Press, Seattle, 1994, pp 181-182.

380. Manchikanti L, Damron KS, Rivera J,
McManus C, Jackson S, Barnhill R, Martin J. Evaluation of effect of sedation as a confounding factor in the diagnostic validity of lumbar facet joint pain: A prospective, randomized, doubleblind, placebo-controlled evaluation. Pain Physician 2004; 7:411-417.

381. Manchikanti L, Pampati V, Damron KS, McManus CD, Jackson SD, Barnhill RC, Martin JC. The effect of sedation on diagnostic validity of facet joint nerve blocks: An evaluation to assess similarities in population with involvement in cervical and lumbar regions. Pain Physician 2006; 9:47-52.

382. Manchikanti L, Pampati V, Fellows B, Rivera J, Damron K, Beyer C, Cash K. Influence of psychological factors on the ability of diagnose chronic low back pain of facet joint origin. Pain Physician 2001; 4:349-357.

383. Manchikanti L, Cash KA, Pampati V, Fellows B. Influence of psychological variables on the diagnosis of facet joint involvement in chronic spinal pain. Pain Physician 2008; 11:145-160.

384. Manchikanti L, Singh V, Fellows B, Pampati V. Evaluation of influence of gender, occupational injury, and smoking on chronic low back pain of facet joint origin: A subgroup analysis. Pain Physician 2002; 5:30-35.

385. Manchikanti L, Manchikanti K, Cash KA, Singh V, Giordano J. Age-related prevalence of facet joint involvement in chronic neck and low back pain. Pain Physician 2008; 11:67-75.

386. Manchikanti KN, Manchikanti L, Damron KS, Pampati V, Fellows B. Increasing deaths from opioid analgesics in the United States: An evaluation in an interventional pain management practice. J Opioid Manage 2008; 4:271-283

387. Manchikanti L, Singh V. An algorithmic approach to diagnosis and management of low back pain. In: Manchikanti L, Slipman CW, Fellows B (eds). Interventional Pain Management: Low Back Pain - Diagnosis and Treatment. ASIPP Publishing, Paducah, KY, 2002, pp 597604.

388. Bogduk N, Holmes S. Controlled zygapophysial joint blocks: The travesty of cost-effectiveness. Pain Med 2000; 1:24-34.

389. Bogduk N. Diagnosing lumbar zygapophysial joint pain. Pain Med 2005; 6:139-142.

390. Windsor RE, Storm S, Sugar R. Prevention and management of complications resulting from common spinal injections. Pain Physician 2003; 6:473-484.

391. Manchikanti L, Schultz DM, Singh V, Falco FJ. Lumbar facet joint interventions. In: Manchikanti L, Singh V (eds). Interventional Techniques in Chronic Spinal Pain. ASIPP Publishing, Paducah, KY, 2007; pp 253-276.

392. Orpen NM, Birch NC. Delayed presentation of septic arthritis of a lumbar facet joint after diagnostic facet joint injection. J Spinal Disord Tech 2003; 16:285287.

393. Alcock E, Regaard A, Browne J. Facet joint injection: A rare form cause of epidural abscess formation. Pain 2003; 103:209-210.

394. Falagas ME, Bliziotis IA, Mavrogenis AF, Papagelopoulos PJ. Spondylodiscitis after facet joint steroid injection: A case report and review of the literature. Scand J Infect Dis 2006; 38:295-299.

395. Dizdar O, Alyamac E, Onal IK, Uzun O. Group B streptococcal facet joint arthritis: Case report. Spine 2005; 30: E414-E416.

396. Ogura T, Mikami Y, Hase H, Mori M, Hayashida T, Kubo T. Septic arthritis of a lumbar facet joint associated with epidural and paraspinal abscess. Orthopedics 2005; 28:173-175.

397. Magee M, Kannangara S, Dennien B, Lonergan R, Emmett L, van der Wall $\mathrm{H}$. Paraspinal abscess complicating facet joint injection. Clin Nucl Med 2000; 25:71-73.

398. Doita M, Nishida K, Miyamoto H, Yoshiya S, Kurosaka M, Nabeshima Y. Septic arthritis of bilateral lumbar facet joints: Report of a case with MRI findings in the early stage. Spine 2003; 28:E198E202.

399. Cook NJ, Hanrahan P, Song S. Paraspinal abscess following facet joint injection. Clin Rheumatol 1999; 18:52-53.

400. Coscia MF, Trammell TR. Pyogenic lumbar facet joint arthritis with intradural extension: A case report. I Spinal Disord Tech 2002; 15:526-528.

401. Benyamin RM, Vallejo R, Kramer J, Rafeyan. Corticosteroid induced psychosis in the pain management setting. Pain Physician 2008; 11:917-920.

402. Thomson SJ, Lomax DM, Collett BJ. Chemical meningism after lumbar facet joint block with local anaesthetic and steroids. Anaesthesia 1993; 46:563564.

403. Berrigan T. Chemical meningism after lumbar facet joint block. Anaesthesia 
1992; 47:905-906.

404. Manchikanti L, Cash KA, Moss TL, Pampati V. Effectiveness of protective measures in reducing risk of radiation exposure in interventional pain management: A prospective evaluation. Pain Physician 2003; 6:301-305.

405. Manchikanti L, Cash KA, Moss TL, Pampati V. Radiation exposure to the physician in interventional pain management. Pain Physician 2002; 5:385-393.

406. Manchikanti L, Cash K, Moss T, Rivera J, Pampati V. Risk of whole body radiation exposure and protective measures in fluoroscopically guided interventional techniques: A prospective evaluation. BMC Anesthesiol 2003; 3:2.

407. Zhou Y, Singh N, Abdi S, Wu J, Crawford J, Furgang F. Fluoroscopy radiation safety for spine interventional pain procedures in university teaching hospitals. Pain Physician 2005; 8:49-53.

408. Raj PP, Shah RV, Kaye AD, Denaro S, Hoover JM. Bleeding risk in interventional pain practice: Assessment, management, and review of the literature. Pain Physician 2004; 7:3-51.

409. Hancock MJ, Maher CG, Latimer J, Spindler MF, McAuley JH, Laslett M, Bogduk N. Systematic review of tests to identify the disc, SIJ or facet joint as the source of low back pain. Eur Spine / 2007; 16:1539-1550.

410. Schwarzer AC, Wang SC, O’Driscoll D, Harrington T, Bogduk N, Laurent R. The ability of computed tomography to identify a painful zygapophysial joint in patients with chronic low back pain. Spine 1995; 20:907-912.

411. Rubinstein SM, van Tulder M. A best-evidence review of diagnostic procedures for neck and low-back pain. Best Pract Res Clin Rheumatol 2008; 22:471-482.

412. Raymond J, Dumas JM. Intra-articular facet block. Diagnostic tests or therapeutic procedure? Radiology 1989; 151:333-336.

413. Bogduk N. Lumbar medial branch blocks. In: Practice Guidelines for Spinal Diagnostic and Treatment Procedures, 1st edition. International Spine Intervention Society, San Francisco, 2004, pp 47-65.

414. Bogduk N. Diskography. APS J 1994; 3:149-154.

415. Merskey H, Bogduk N. Lumbar discogenic pain. In: Classification of Chronic Pain. Descriptions of Chronic Pain Syndromes and Definition of Pain Terms, 2nd ed. Task Force on Taxonomy of the International Association for the Study of Pain. IASP Press, Seattle, 1994, pp 180-181.

416. Bogduk N. Lumbar disc stimulation (provocation discography). In: Practice Guidelines for Spinal Diagnostic and Treatment Procedures, 1st edition. International Spine Intervention Society, 2004, pp 20-46.

417. Bogduk N. The anatomy of the lumbar intervertebral disc syndrome. Med J Aust 1976; 1:878-881.

418. Wiberg $\mathrm{G}$. Back pain in relation to the nerve supply of the intervertebral disc. Acta Orthop Scand 1947; 19:211-221.

419. Bogduk N, Tynan W, Wilson AS. The nerve supply to the human lumbar intervertebral discs. J Anat 1981; 132:3956.

420. McCarthy PW, Carruthers B, Martin D, Petts P. Immunohistochemical demonstration of sensory nerve fibers and endings in lumbar intervertebral discs of the rat. Spine 1991; 16:653-655.

421. Cavanaugh JM, Kallakuri S, Ozaktay AC. Innervation of the rabbit lumbar intervertebral disc and posterior longitudinal ligament. Spine 1995; 20:20802085.

422. Roof PG. Innervation of annulus fibrosus and posterior longitudinal ligament. Arch Neurol Psychiatry 1940; 44:100-103.

423. Zhang Y, Kerns JM, Anderson DG, Lee YS, Chen EY, Tannoury C, An HS. Sensory neurons and fibers from multiple spinal cord levels innervate the rabbit lumbar disc. Am J Phys Med Rehabil 2006; 85:865-871.

424. Malinsky J. The ontogenetic development of nerve terminations in the intervertebral discs of man. Acta Anat 1959; 38:96-113.

425. Yoshizawa H, O’Brien JP, Thomas-Smith W, Trumper M. The neuropathology of intervertebral discs removed for low back pain. J Pathol 1980; 132:95-104.

426. Peng B, Wu W, Hou S, Li P, Zhang C, Yang $Y$. The pathogenesis of discogenic low back pain. J Bone Joint Surg $\mathrm{Br}$ 2005; 87:62-67.

427. Freemont AJ, Peacock TE, Goupille P, Hoyland JA, O'Brien J, Jayson MI. Nerve ingrowth into diseased intervertebral disc in chronic back pain. Lancet 1997; 350:178-181.

428. Coppes MH, Marani E, Thomeer RT, Oudega M, Groen GJ. Innervation of annulus fibrosus in low back pain. Lancet 1990; 336:189-190.

429. Coppes MH, Marani E, Thomeer RT,
Groen GJ. Innervation of “painful” lumbar discs. Spine 1997; 22:2342-2350.

430. Nakamura S, Takahashi K, Takahashi Y, Morinaga T, Shimada Y, Moriya H. Origin of nerves supplying the posterior portion of lumbar intervertebral discs in rats. Spine 1996; 21:917-924.

431. Morinaga T, Takahashi K, Yamagata M, Chiba T, Tanaka K, Takahashi Y, Nakamura S, Suseki K, Moriya H. Sensory innervation to the anterior portion of lumbar intervertebral disc. Spine 1996; 21:1848-1851.

432. Ohtori S, Takahashi Y, Takahashi K, Yamagata M, Chiba T, Tanaka K, Hirayama J, Moriya H. Sensory innervation of the dorsal portion of the lumbar intervertebral disc in rats. Spine 1999; 24:2295-2299.

433. Fagan A, Moore R, Vernon Roberts B, Blumbergs P, Fraser R. The innervation of the intervertebral disc: A quantitative analysis. Spine 2003; 28:25702576.

434. Brisby H. Pathology and possible mechanisms of nervous system response to disc degeneration. J Bone Joint Surg Am 2006; 88 Suppl 2:68-71.

435. Palmgren T, Gronblad M, Virri J, Kaapa E, Karaharju E. An immunohistochemical study of nerve structures in the anulus fibrosus of human normal lumbar intervertebral discs. Spine 1999; 24:2075-2079.

436. Ashton IK, Roberts S, Jaffray DC, Polak $J M$, Eisenstein SM. Neuropeptides in the human intervertebral disc. J Orthop Res 1994; 12:186-192.

437. Shinohara H. Lumbar disc lesion, with special reference to the histological significance of nerve endings of the lumbar discs. J Jap Orthop Assoc 1970; 44:553-570.

438. Roberts S, Eisenstein SM, Menage J, Evans EH, Ashton IK. Mechanoreceptors in intervertebral discs. Spine 1995; 24:2645-2651.

439. Aoki Y, Ohtori S, Takahashi K, Ino H, Takahashi Y, Chiba T, Moriya H. Innervation of the lumbar intervertebral disc by nerve growth factor-dependent neurons related to inflammatory pain. Spine 2004; 29:1077-1081.

440. Palmgren T, Gronblad M, Virri J, Seitsalo S, Ruuskanen M, Karaharju E. Immunohistochemical demonstration of sensory and autonomic nerve terminals in herniated lumbar disc tissue. Spine 1996; 21:1301-1306.

441. Ohtori S, Takahashi K, Chiba T, Yamaga- 
ta M, Sameda H, Moriya H. Sensory innervation of the dorsal portion of the lumbar intervertebral discs in rats. Spine 2001; 26:946-950.

442. Ohtori S, Inoue G, Koshi T, Ito T, Doya $\mathrm{H}$, Moriya H, Takahashi K. Substance P-saporin down-regulates substance $P$ receptor immunoreactive sensory dorsal root ganglion neurons innervating the lumbar intervertebral discs in rats. Spine 2006; 31:2987-2991.

443. Larsson K, Rydevik B, Olmarker K. Disc related cytokines inhibit axonal outgrowth from dorsal root ganglion cells in vitro. Spine 2005; 30:621-624.

444. Kang JD, Georgescu HI, McIntyre-Larkin L, Stefanovic-Racic M, Donaldson WF 3 rd, Evans $\mathrm{CH}$. Herniated lumbar intervertebral discs spontaneously produce matrix metalloproteinases, nitric oxide, interleukin-6, and prostaglandin E2. Spine 1996; 21:271-277.

445. Ahmed M, Bjurholm A, Kreicbergs A, Schultzberg M. Neuropeptide $Y$, tyrosine hydroxylase and vasoactive intestinal polypeptide-immunoreactive nerve fibers in the vertebral bodies, discs, dura mater, and spinal ligaments of the rat lumbar spine. Spine 1993; 18:268-273.

446. Ashton IK, Eisenstein SM. The effect of substance $\mathrm{P}$ on proliferation and proteoglycan deposition of cells derived from rabbit intervertebral disc. Spine 1996; 21:421-426.

447. O’Neill CW, Kurgansky ME, Derby R, Ryan DP. Disc stimulation and patterns of referred pain. Spine 2002; 27:27762781.

448. Derby R, Eek B, Lee SH, Seo S, Kim BJ. Comparison of intradiscal restorative injections and intradiscal electrothermal treatment (IDET) in the treatment of low back pain. Pain Physician 2004; 7:63-66.

449. Mixter WJ, Barr JS. Rupture of the intervertebral disc with involvement of the spinal canal. N Eng J Med 1934; 211:210-215.

450. Rosen S, Falco F. Radiofrequency stimulation of intervertebral discs. Pain Physician 2003; 6:435-438.

451. Schwarzer AC, Aprill CN, Derby R, Fortin J, Kine G, Bogduk N. The prevalence and clinical features of internal disc disruption in patients with chronic low back pain. Spine 1995; 20:1878-1883.

452. Ohnmeiss DD, Vanharanta H, Ekholm J. Relationship of pain drawings to invasive tests assessing intervertebral disc pathology. Eur Spine J 1999; 8:126-131.

453. Mixter WJ, Ayers JB. Herniation or rupture of the intervertebral disc into the spinal canal. N Engl J Med 1935; 213:385-395.

454. Aoki Y, Takahashi Y, Ohtori S, Moriya H, Takahashi K. Distribution and immunocytochemical characterization of dorsal root ganglion neurons innervating the lumbar intervertebral disc in rats: A review. Life Sci 2004; 74:2627-2642.

455. Freemont AJ, Watkins A, Le Maitre C, Baird P, Jeziorska M, Knight MT, Ross ER, O'Brien JP, Hoyland JA. Nerve growth factor expression and innervation of the painful intervertebral disc. J Pathol 2002; 197:286-292.

456. Burke JG, Watson RW, McCormack D, Dowling FE, Walsh MG, Fitzpatrick JM. Intervertebral discs which cause low back pain secrete high levels of proinflammatory mediators. J Bone Joint Surg Br 2002; 84:196-201.

457. Burke JG, G Watson RW, Conhyea D, McCormack D, Dowling FE, Walsh MG, Fitzpatrick JM. Human nucleus pulposus can respond to a pro-inflammatory stimulus. Spine 2003; 28:2685-2693.

458. Crock HV. A reappraisal of intervertebral disc lesions. Med J Aust 1970; 1:983-989.

459. Ohnmeiss DD, Vanharanta H, Ekholm J. Degree of disc disruption and lower extremity pain. Spine 1997; 22:16001605.

460. Wheeler AH, Murrey DB. Chronic lumbar spine and radicular pain: Pathophysiology and treatment. Curr Pain Headache Rep 2002; 6:97-105.

461. Milette PC, Fontaine S, Lepanto L, Breton G. Radiating pain to the lower extremities caused by lumbar disc rupture without spinal nerve root involvement. Am J Neuroradiol 1995; 16:16051615.

462. Crock HV. Isolated lumbar disc resorption as a cause of nerve root canal stenosis. Clin Orthop 1976; 115:109-115.

463. Videman T, Nurminen M. The occurrence of anular tears and their relation to lifetime back pain history: A cadaveric study using barium sulfate discography. Spine 2004; 29:2668-2676.

464. Kang JD, Stefanovic-Racic M, McIntyre LA, Georgescu HI, Evans CH. Toward a biochemical understanding of human intervertebral disc degeneration and herniation. Contributions of nitric oxide, interleukins, prostaglandin E2, and matrix metalloproteinases. Spine
1997; 22:1065-1073.

465. Tanaka N, Ishida T, Hukuda S, Horiike K. Purification of a low-molecular-weight phospholipase $A(2)$ associated with soluble high-molecular-weight acidic proteins from rabbit nucleus pulposus and its comparison with a rabbit splenic group lla phospholipase A(2). J Biochem (Tokyo) 2000; 127:985-991.

466. Miyahara K, Ishida T, Hukuda S, Horiike $\mathrm{K}$, Okamoto M, Tojo H. Human group II phospholipase $A_{2}$ in normal and diseased intervertebral discs. Biochim Biophys Acta 1996; 1316:183-190.

467. Nygaard OP, Mellgren SI, Osterud B. The inflammatory properties of contained and noncontained lumbar disc herniation. Spine 1997; 22:2484-2488.

468. Ashton IK, Walsh DA, Polak JM, Eisenstein SM. Substance $P$ in intervertebral discs. Binding sites on vascular endothelium of the human annulus fibrosus. Acta Orthop Scand 1994; 65:635-639.

469. Igarashi T, Kikuchi S, Shubayev V, Myers RR. Exogenous tumor necrosis factor-alpha mimics nucleus pulposus-induced neuropathology. Molecular, histologic, and behavioral comparisons in rats. Spine 2000; 25:2975-2980.

470. Séguin CA, Pilliar RM, Roughley PJ, Kandel RA. Tumor necrosis factor-alpha modulates matrix production and catabolism in nucleus pulposus tissue. Spine 2005; 30:1940-1948.

471. Ohtori S, Inoue G, Ito T, Koshi T, Ozawa T, Doya H, Saito T, Moriya H, Takahash K. Tumor necrosis factor-immunoreactive cells and PGP 9.5-immunoreactive nerve fibers in vertebral endplates of patients with discogenic low back pain and modictype 1 or type 2 changes on MRI. Spine 2006; 31:1026-1031.

472. McCarron RF, Wimpee MW, Hudkins PG, Laros GS. The inflammatory effects of nucleus pulposus: A possible element in the pathogenesis of low back pain. Spine 1987; 12:760-764.

473. Olmarker K, Nordborg C, Larsson K, Rydevik B. Ultrastructural changes in spinal nerve roots induced by autologous nucleus pulposus. Spine 1996; 27:411-414.

474. Olmarker K, Rydevik B, Nordborg C. Autologous nucleus pulposus induces neurophysiologic and histologic changes in porcine cauda equina nerve roots. Spine 1993; 18:1425-1432.

475. Igarashi T, Kikuchi S, Shubayev V, Myers RR. 2000 Volvo Award winner in basic science studies: Exogenous tumor necrosis factor-alpha mimics nu- 
cleus pulposus-induced neuropathology. Molecular, histologic, and behavioral comparisons in rats. Spine 2000; 25:2975-2980.

476. Homma Y, Brull SJ, Zhang JM. A comparison of chronic pain behavior following local application of tumor necrosis factor alpha to the normal and mechanically compressed lumbar ganglia in the rat. Pain 2002; 95:239-246.

477. Kawakami M, Tamaki T, Hashizume H, Weinstein JN, Meller ST. The role of phospholipase $A_{2}$ and nitric oxide in pain-related behavior produced by an allograft of intervertebral disc material to the sciatic nerve of the rat. Spine 1997; 22:1074-1079.

478. Olmarker K, Rydevik B. Selective inhibition of tumor necrosis factor-alpha prevents nucleus pulposus-induced thrombus formation, intraneural edema, and reduction of nerve conduction velocity: Possible implications for future pharmacologic treatment strategies of sciatica. Spine 2001; 26:863869.

479. Saal JS, Franson RC, Dobrow R, Saal JA, White AH, Goldthwaite N. High levels of inflammatory phospholipase A2 activity in lumbar disc herniations. Spine 1990; 15:674-678.

480. Olmarker K, Rydevik B, Holm S. Edema formation in spinal nerve roots induced by experimental, graded compression: An experimental study on the pig cauda equina with special reference to differences in effects between rapid and slow onset of compression. Spine 1989; 14:569-573.

481. Olmarker K, Rydevik B, Holm S, Bagge $U$. Effects of experimental graded compression on blood flow in spinal nerve roots: A vital microscopic study on the porcine cauda equina. J Orthop Res 1989; 7:817-823.

482. Olmarker K, Holm S, Rydevik B. Importance of compression onset rate for the degree of impairment of impulse propagation in experimental compression injury of the porcine cauda equina. Spine 1990; 35:416-419.

483. Rydevik BL. The effects of compression on the physiology of nerve roots. J Manipul Physiol Ther 1992; 1:62-66.

484. Olmarker K, Holm S, Rosenqvist AL, Rydevik B. Experimental nerve root compression. Presentation of a model for acute, graded compression of the porcine cauda equina, with analysis of neural and vascular anatomy. Spine
1992; 16:61-69.

485. Yabuki S, Kikuchi S, Olmarker K, Myers RR. Acute effects of nucleus pulposus on blood flow and endoneurial fluid pressure in rat dorsal root ganglia. Spine 1998; 23:2517-2523.

486. Yabuki S, Igarashi T, Kikuchi S. Application of nucleus pulposus to the nerve root simultaneously reduces blood flow in dorsal root ganglion and corresponding hindpaw in the rat. Spine 2000; 25:1471-1476.

487. Zucherman J, Derby R, Hsu K, Picetti G, Kaiser J, Schofferman J, Goldthwaite N, White A. Normal magnetic resonance imaging with abnormal discography. Spine 1988; 13:1355-1359.

488. Guyer RD, Ohnmeiss DD; NASS. Lumbar discography. Spine / 2003; 3:S11S27.

489. Deyo RA, Rainville J, Kent DL. What can the history and physical examination tell us about low back pain? JAMA 1992; 268:760-765.

490. Vroomen PC, de Krom MC, Knottnerus JA. Diagnostic value of history and physical examination in patients suspected of sciatica due to disc herniation: A systematic review. I Neurol 1999; 246:899-906.

491. Devillé WL, van der Windt DA, Dzaferagi A, Bezemer PD, Bouter LM. The test of Lasègue: Systematic review of the accuracy in diagnosing herniated discs. Spine 2000; 25:1140-1147.

492. Pneumaticos SG, Chatziioannou SN, Hipp JA, Moore WH, Esses SI. Low back pain: Prediction of short-term outcome of facet joint injection with bone scintigraphy. Radiology 2006; 238:693698.

493. Young S, Aprill C, Laslett M. Correlation of clinical examination characteristics with three sources of chronic low back pain. Spine J 2003; 3:460-465.

494. Laslett M, Oberg B, Aprill CN, McDonald B. Centralization as a predictor of provocation discography results in chronic low back pain, and the influence of disability and distress on diagnostic power. Spine J 2005; 5:370-380.

495. Laslett M, April CN, McDonald B, Oberg B. Clinical predictors of lumbar provocation discography: A study of clinical predictors of lumbar provocation discography. Eur Spine J 2006; 15:14731484.

496. van den Hoogen HM, Koes BW, van Eijk JT, Bouter LM. On the accuracy of history, physical examination, and eryth- rocyte sedimentation rate in diagnosing low back pain in general practice. A criteria-based review of the literature. Spine 1995; 20:318-327.

497. Maigne JY, Lapeyre E, Morvan G, Chatellier G. Pain immediately upon sitting down and relieved by standing up is often associated with radiologic lumbar instability or marked anterior loss of disc space. Spine 2003; 28:1327-1334.

498. Yrjama M, Tervonen O, Vanharanta $\mathrm{H}$. Ultrasonic imaging of lumbar discs combined with vibration pain provocation compared with discography in the diagnosis of internal anular fissures of the lumbar spine. Spine 1996; 21:571575 .

499. Adams MA, Dolan P, Hutton WC. The stages of disc degeneration as revealed by discograms. J Bone Joint Surg BR 1986; 68:36-41.

500. Yasuma T, Ohno R, Yamauchi Y. Falsenegative lumbar discograms: Correlation of discographic and histologic findings in postmortem and surgical specimens. J Bone Joint Surg AM 1988; 70:1279-1290.

501. Yu SW, Haughton VM, Sether LA, Wagner $M$. Comparison of MR and discography in detecting radial tears of the annulus: A post-mortem study. AJNR Am J Neuroradiol 1989; 10:1077-1081.

502. Saternus KS, Bornscheuer HH. Comparative radiologic and pathologic-anatomic studies on the value of discography in the diagnosis of acute intravertebral disk injuries in the cervical spine. Fortschr Geb Rontgenstr Nuklearmed 1983; 139:651-657.

503. Viikari-Juntura E, Raininko R, Videman T, Porkka L. Evaluation of cervical disc degeneration with ultralow field MRI and discography. An experimental study on cadavers. Spine 1989; 14:616619.

504. Antti-Poika I, Soini J, Tallroth K, Yrjonen T, Konttinen YT. Clinical relevance of discography combined with CT scanning. A study of 100 patients. J Bone Joint Surg Br 1990; 72:480-485.

505. Agorastides ID, Lam KS, Freeman BJ, Mulholland RC. The Adams classification for cadaveric discograms: Interand intra-observer error in the clinical setting. Eur Spine I 2002; 11:76-79.

506. Sachs BL, Vanharanta H, Spivey MA, Guyer RD, Videman T, Rashbaum RF, Johnson RG, Hochschuler SH, Mooney $V$. Dallas discogram description. A new classification of $\mathrm{CT} /$ discography in low 
back disorders. Spine 1987; 12:287294.

507. Gresham JL, Miller R. Evaluation of the lumbar spine by diskography and its use in selection of proper treatment of the herniated disk syndrome. Clin Orthop 1969; 67:29-41.

508. Brodsky AE, Binder WF. Lumbar discography: Its value in diagnosis and treatment of lumbar disc lesions. Spine 1979; 4:110-120.

509. Birney TJ, White JJ Jr, Berens D, Kuhn G. Comparison of MRI and discography in the diagnosis of lumbar degenerative disease. J Spin Disord 1992; 5:417423.

510. Southern EP, Fye MA, Panjabi MM, Patel TC, Cholewicki J. Disc degeneration: A human cadaveric study correlation magnetic resonance imaging and quantitative discomanometry. Spine 2000; 25:2171-2175.

511. Simmons EH, Segil CM. An evaluation of discography in the localization of symptomatic levels in discogenic disease of the spine. Clin Orthop 1975; 108:57-69.

512. Abdelwahab IF, Gould ES. The role of diskography after negative postmyelography CT scans: Retrospective review. AJNR Am J Neuroradiol 1988; 9:187-190.

513. Jackson RP, Glah JJ. Foraminal and extraforaminal lumbar disc herniation: Diagnosis and treatment. Spine 1987; 12:577-585.

514. Grubb SA, Lipscomb HJ, Guilford WB. The relative value of lumbar roentgenograms, metrizamide myelography, and discography in the assessment of patients with chronic low back syndrome. Spine 1987; 12:282-286.

515. Wiley JJ, Macnab I, Wortzman G. Lumbar discography and its clinical applications. Can J Surg 1968; 11:280-289.

516. Lehmer SM, Dawson MH, O’Brien JP. Delayed pain response after lumbar discography. Eur Spine J 1994; 3:28-31.

517. Milette PC, Raymond J, Fontaine S. Comparison of high-resolution computed tomography with discography in the evaluation of lumbar disc herniations. Spine 1990; 15:525-533.

518. Lim CH, Jee WH, Son BC, Kim DH, Ha KY, Park CK. Discogenic lumbar pain: Association with MR imaging and CT discography. Eur J Radiol 2005; 54:431-437.

519. Gibson MJ, Buckley J, Mawhinney R, Mulholland RC, Worthington BS. Mag- netic resonance imaging and discography in the diagnosis of disc degeneration: A comparative study of 50 discs. J Bone Joint Surg BR 1986; 68:369-373.

520. Schneiderman G, Flannigan B, Kingston S, Thomas J, Dillin WH, Watkins RG. Magnetic resonance imaging in the diagnosis of disc degeneration: Correlation with discography. Spine 1987; 12:276-282.

521. Horton WC, Daftari TK. Which disc as visualized by magnetic resonance imaging is actually a source of pain? A correlation between magnetic resonance imaging and discography. Spine 1992; $17: \mathrm{S}_{164}-\mathrm{S} 171$.

522. Huang TS, Zucherman JF, Hsu KY, Shapiro M, Lentz D, Gartland J. Gadopentetate dimeglumine as an intradiscal contrast agent. Spine 2002; 27:839843.

523. Shin DA, Kim HI, Jung JH, Shin DG, Lee JO. Diagnostic relevance of pressurecontrolled discography. J Korean Med Sci 2006; 21:911-916.

524. Schellhas KP, Pollei SR, Gundry CR, Heithoff KB. Lumbar disc high-intensity zone. Correlation of magnetic resonance imaging and discography. Spine 1996; 21:79-86.

525. Saifuddin A, Braithwaite I, White J, Taylor BA, Renton P. The value of lumbar spine magnetic resonance imaging in the demonstration of anular tears. Spine 1998; 23:453-457.

526. Smith BM, Hurwitz EL, Solsberg D, Rubinstein D, Corenman DS, Dwyer AP, Kleiner J. Interobserver reliability of detecting lumbar intervertebral disc highintensity zone on magnetic resonance imaging and association of high-intensity zone with pain and anular disruption. Spine 1998; 23:2074-2080.

527. Lappalainen AK, Kääpä E, Lamminen A, Laitinen OM, Gronblad M. The diagnostic value of contrast-enhanced magnetic resonance imaging in the detection of experimentally induced anular teras in sheep. Spine 2002; 27:2806-2810.

528. Ricketson R, Simmons JW, Hauser BO. The prolapsed intervertebral disc. The high-intensity zone with discography correlation. Spine 1996; 21:27582762.

529. Peng B, Hou S, Wu W, Zhang C, Yang Y. The pathogenesis and clinical significance of a high-intensity zone (HIZ) of lumbar intervertebral disc on MR imaging in the patient with discogenic low back pain. Eur Spine J 2006; 15:583-
587.

530. Carragee EJ, Paragiodakis SJ, Khurana S. Lumbar high-intensity zone and discography in subjects without low back problems. Spine 2000; 25:2987-2992.

531. Lam KS, Carlin D, Mulholland RC. Lumbar disc high-intensity zone: The value and significance of provocative discography in the determination of the discogenic pain source. Eur Spine I 2000; 9:36-41.

532. Lei D, Rege A, Koti M, Smith FW, Wardlaw D. Painful disc lesion: Can modern biplanar magnetic resonance imaging replace discography? J Spinal Disord Tech 2008; 21:430-435.

533. O’Neill C, Kurgansky M, Kaiser J, Lau W. Accuracy of MRI for diagnosis of discogenic pain. Pain Physician 2008; 11:311326.

534. Scuderi GJ, Brusovanik GV, Golish SR, Demeo R, Hyde J, Hallab N, Vaccaro AR. A critical evaluation of discography in patients with lumbar intervertebral disc disease. Spine J 2008; 8:624-629.

535. Derincek A, Mehbod A, Schellhas K, Pinto M, Transfeldt E. Discography: Can pain in a morphologically normal disc be due to an adjacent abnormal disc? Arch Orthop Trauma Surg 2007; 127:699-703.

536. Byun WM, Ahn SH, Ahn MW. Significance of perianular enhancement associated with anular tears on magnetic resonance imagings in diagnosis of radiculopathy. Spine 2008; 33:24402443.

537. Derby R, Howard MW, Grant JM, Lettice J, Van Peteghem PK, Ryan DP. The ability of pressure-controlled discography to predict surgical and nonsurgical outcomes. Spine 1999; 24:364-371.

538. O’Neill C, Kurgansky M. Subgroups of positive discs on discography. Spine 2004; 29:2134-2139.

539. Derby R, Lee SH, Kim BJ, Chen Y, Aprill C, Bogduk N. Pressure-controlled lumbar discography in volunteers with low back pain symptoms. Pain Med 2005; 6:213-221.

540. Derby R, Kim BJ, Lee SH, Chen Y, Seo KS, Aprill C. Comparison of discographic findings in asymptomatic subject discs and negative discs of chronic LBP patients: Can discography distinguish asymptomatic discs among morphologically abnormal discs? Spine J 2005; 5:389-394.

541. Derby R, Kim BJ, Chen Y, Seo KS, Lee $\mathrm{SH}$. The relation between annular dis- 
ruption on computed tomography scan and pressure-controlled diskography. Arch Phys Med Rehabil 2005; 86:15341538.

542. Manchikanti L, Singh V, Pampati V, Fellows B, Beyer C, Damron K, Cash K. Provocative discography in low back pain patients with or without somatization disorder: A randomized prospective evaluation. Pain Physician 2001; 4:227-239.

543. Knottnerus JA, van Weel C, Muris JW. Evaluation of diagnostic procedures. BMJ 2002; 324:477-480.

544. Fraser RD, Osti OL, Vernon-Roberts B. Discitis after discography. J Bone Joint Surg 1987; 69-B:26-35.

545. Schreck RI, Manion WL, Kambin P, Sohn M. Nucleus pulposus pulmonary embolism. A case report. Spine 1997; 22:927-928.

546. Tsuji N, Igarashi S, Koyama T. Spinal epidural abscess. No Shinkei Geka 1987; 15:1079-1085.

547. Junila J, Niinimäki T, Tervonen O. Epidural abscess after lumbar discography. Spine 1997; 22:2191-2193.

548. Willems PC, Jacobs W, Duinkerke ES, De Kleuver M. Lumbar discography: Should we use prophylactic antibiotics? A study of 435 consecutive discograms and a systematic review of the literature. I Spinal Disord Tech 2004; 17:243-247.

549. Guiboux JP, Cantor JB, Small SD, Zervos $M$, Herkowitz HN. The effect of prophylactic antibiotics on iatrogenic intervertebral disc infections. A rabbit model. Spine $1995 ; 20: 685-688$.

550. Koroglu A, Acar O, Ustun ME, Tiras B, Eser 0 . The penetration of cefoperazone and sulbactam into the lumbar intervertebral discs. J Spinal Disord 2001; 14:453-454.

551. Boswell M, Wolfe J. Intrathecal cefazolin-induced seizures following attempted discography. Pain Physician 2004; 7:103-106.

552. Johnson RG. Does discography injure normal discs? An analysis of repeat discograms. Spine 1989; 14:424-426.

553. Reitman CA, Hipp JA, Kirking BC, Haas S, Esses SI. Posterior annular strains during discography. I Spinal Disord 2001; 14:347-352.

554. Cho DC, Sung JK. Traumatic subacute spinal subdural hematoma successfully treated with lumbar drainage: Case report. J Spinal Disord Tech 2009;
22:73-76.

555. Carragee EJ, Chen Y, Tanner CM, Hayward C, Rossi M, Hagle C. Can discography cause long-term back symptoms in previously asymptomatic subjects? Spine 2000; 25:1803-1808.

556. Carragee EJ, Tanner CM, Khurana S, Hayward C, Welsh J, Date E, Truong T, Rossi M, Hagle C. The rates of falsepositive lumbar discography in select patients without low back symptoms. Spine 2000; 25:1373-1380.

557. Carragee EJ, Alamin TF, Miller J, Grafe M. Provocative discography in volunteer subjects with mild persistent low back pain. Spine J 2002; 2:25-34.

558. Carragee EJ, Chen Y, Tanner CM, Truong T, Lau E, Brito JL. Provocative discography in patients after limited lumbar discectomy: A controlled, randomized study of pain response in symptomatic and asymptomatic subjects. Spine 2000; 25:3065-3071.

559. Carragee EJ, Tanner CM, Yang B, Brito JL, Truong T. False-positive findings on lumbar discography. Reliability of subjective concordance assessment during provocative disc injection. Spine 1999; 24:2542-2547.

560. Holt EP Jr. The question of lumbar discography. J Bone Joint Surg Am 1968; 50:720-726.

561. Simmons JW, Aprill CN, Dwyer AP, Brodsky AE. A reassessment of Holt's data on: "The question of lumbar discography." Clin Orthop 1988; 237:120-124.

562. Carragee EJ, Alamin TF, Carragee JM. Low-pressure positive discography in subjects asymptomatic of significant low back pain illness. Spine 2006; 31:505-509.

563. Carragee EJ, Lincoln T, Parmar VS, Alamin T. A gold standard evaluation of the "discogenic pain" diagnosis as determined by provocative discography. Spine 2006; 31:2115-2123.

564. Seo KS, Derby R, Date ES, Lee SH, Kim $\mathrm{BJ}$, Lee $\mathrm{CH}$. Invitro measurement of pressure differences using manometry at various injection speeds during discography. Spine J 2007; 7:68-73.

565. Simmons JW, Emery SF, McMillin JN, Landa D, Kimmich SJ. Awake discography. A comparison study with magnetic resonance imaging. Spine 1991; 16: S216-S221.

566. Walsh TR, Weinstein JN, Spratt KF, Lehmann TR, Aprill C, Sayre H. Lumbar discography in normal subjects. J Bone
Joint Surg AM 1990; 72:1081-1088.

567. Massie WK, Steven DB. A critical evaluation of discography. J Bone Joint Surg Am 1967; 49A:1243-1244.

568. Cohen SP. Sacroiliac joint pain: A comprehensive review of anatomy, diagnosis and treatment. Anesth Analg 2005; 101:1440-1453.

569. Maigne JY, Aivakiklis A, Pfefer F. Results of sacroiliac joint double block and value of sacroiliac pain provocation test in 54 patients with low back pain. Spine 1996; 21:1889-1892.

570. Irwin RW, Watson T, Minick RP, Ambrosius WT. Age, body mass index, and gender differences in sacroiliac joint pathology. Am J Phys Med Rehabil 2007; 86:37-44.

571. Schwarzer AC, Aprill CN, Bogduk M. The sacroiliac joint in chronic low back pain. Spine 1995; 20:31-37.

572. Maigne JY, Planchon CA. Sacroiliac joint pain after fusion. A study with anesthetic blocks. Eur Spine J 2005; 14:654658.

573. Merskey H, Bogduk N. Sacroiliac joint pain. In: Classification of Chronic Pain: Descriptions of Chronic Pain Syndromes and Definition of Pain Terms, 2nd ed. Task Force on Taxonomy of the International Association for the Study of Pain. IASP Press, Seattle, 1994, pp 190-191.

574. Bogduk N. Sacroiliac joint blocks. In: Practice Guidelines for Spinal Diagnos tic and Treatment Procedures, 1st edition. International Spine Intervention Society, San Francisco, 2004, pp 6686.

575. Forst SL, Wheeler MT, Fortin JD, Vilensky JA. The sacroiliac joint: Anatomy, physiology and clinical significance. Pain Physician 2006; 9:61-67.

576. Song IH, Carrasco-Fernández J, Rudwaleit $M$, Sieper J. The diagnostic value of scintigraphy in assessing sacroiliitis in ankylosing spondylitis: A systematic literature research. Ann Rheum Dis 2008; 67:1535-1540.

577. Laslett M, Young SB, Aprill CN, MCDonald B. Diagnosing painful sacroiliac joints: A validity study of a McKenzie evaluation and sacroiliac provocation tests. Aust J Physiother 2003; 49:8997.

578. van der Wurff P, Buijs EJ, Groen GJ. A multitest regimen of pain provocation tests as an aid to reduce unnecessary minimally invasive sacroiliac joint procedures. Arch Phys Med Rehabil 2006; 
87:10-14.

579. Hansen HC, Helm S. Sacroiliac joint pain and dysfunction. Pain Physician 2003; 6:179-189.

580. Rosenberg JM, Quint TJ, de Rosayro AM. Computerized tomographic localization of clinically-guided sacroiliac joint injections. Clin J Pain 2000; 16:1821.

581. Hansen $\mathrm{H}$. Is fluoroscopy necessary for sacroiliac joint injections? Pain Physician 2003; 6:155-158.

582. Fortin J, Tolchin R. Sacroiliac arthrograms and post-arthrography computerized tomography. Pain Physician 2003; 6:287-290.

583. Fortin JD, Vilensky JA, Merkel GF. Can the sacroiliac joint cause sciatica? Pain Physician 2003; 6:269-271.

584. Peloso PMJ, Gross A, Haines T, Trinh K, Goldsmith $\mathrm{CH}$, Burnie SJ, Cervical Overview Group. Medicinal and injection therapies for mechanical neck disorders. Cochrane Database Syst Rev 2007; 3:CDooo319.

585. Saskatchewan Workers' Compensation Board. Statistical Supplement 2005. www.wcbsask.com/WCBPortal/ShowProperty/WCBRepository/formsPublications/publications/annualPubs/ 2005 StatisticalSummary//pdfContent. Accessed date: October 15, 2008.

586. Spitzer WO, Leblanc FE, Dupuis M. Scientific approach to the assessment and management of activity related spinal disorders. Spine 1987; 7:S1-59.

587. Bogduk N. The clinical anatomy of the cervical dorsal rami. Spine 1982; 7:319330.

588. Ohtori S, Takahashi K, Chiba T, Yamagata M, Sameda H, Moriya H. Sensory innervation of the cervical facet joints in rats. Spine 2001; 26:147-150.

589. Barnsley L, Bogduk N. Medial branch blocks are specific for the diagnosis of cervical zygapophyseal joint pain. Reg Anesth 1993; 18:343-350.

590. Zhang J, Tsuzuki N, Hirabayashi S, Saiki K, Fujita K. Surgical anatomy of the nerves and muscles in the posterior cervical spine. Spine 2003; 28:13791384 .

591. Chen C, Lu Y, Kallakuri S, Patwardhan A, Cavanaugh JM. Distribution of A-delta and C-fiber receptors in the cervical facet joint capsule and their response to stretch. J Bone Joint Surg Am 2006; 88:1087-1816.

592. Manchikanti L, Manchikanti K, Damron
K, Pampati V. Effectiveness of cervical medial branch blocks in chronic neck pain: A prospective outcome study. Pain Physician 2004; 7:195-201.

593. Sapir DA, Gorup JM. Radiofrequency medial branch neurotomy in litigant and non-litigant patients with cervical whiplash. Spine 2001; 26:E268-E273.

594. Govind J, King W, Bailey B, Bogduk N. Radiofrequency neurotomy for the treatment of third occipital headache. J Neurol Neurosurg Psychiatry 2003; 74:88-93.

595. McDonald G, Lord S, Bogduk N. Longterm follow-up of patients treated with cervical radiofrequency neurotomy for chronic spinal pain. Neurosurgery 1999; 45:61-67.

596. Manchikanti L, Singh V, Falco FJ, Cash KA, Fellows B. Cervical medial branch blocks for chronic cervical facet joint pain: A randomized double-blind, controlled trial with one-year follow-up. Spine 2008; 33:1813-1820.

597. Lord S, Barnsley L, Wallis B, McDonald G, Bogduk N. Percutaneous radio-frequency neurotomy for chronic cervical zygapophyseal-joint pain. N Engl J Med 1996; 335:1721-1726.

598. Barnsley L. Percutaneous radiofrequency neurotomy for chronic neck pain: Outcomes in a series of consecutive patients. Pain Med 2005; 6:282286.

599. Wallis B, Lord S, Bogduk N. Resolution of psychological distress of whiplash patients following treatment by radiofrequency neurotomy: A randomized, double-blind, placebo-controlled trial. Pain 1997; 73:15-22.

6oo. Manchikanti L, Singh V, Rivera J, Pampati, V. Prevalence of cervical facet joint pain in chronic neck pain. Pain Physician 2002; 5:243-249.

601. Speldewinde G, Bashford G, Davidson I. Diagnostic cervical zygapophyseal joint blocks for chronic cervical pain. Med J Aust 2001; 174:174-176.

602. Manchikanti L, Manchikanti K, Pampati V, Brandon D, Giordano J. The prevalence of facet joint-related chronic neck pain in postsurgical and non-postsurgical patients: A comparative evaluation. Pain Pract 2008; 8:5-10.

603. Lord SM, Barnsley L, Wallis BJ, Bogduk N. Chronic cervical zygapophysial joint pain with whiplash: A placebo-controlled prevalence study. Spine 1996; 21:1737-1744.

604. Barnsley L, Lord SM, Wallis BJ, Bog- duk N. The prevalence of chronic cervical zygapophysial joint pain after whiplash. Spine 1995; 20:20-26.

605. Barnsley L, Lord S, Wallis B, Bogduk N. False-positive rates of cervical zygapophysial joint blocks. Clin J Pain 1993; 9:124-130.

606. Manchikanti L, Pampati V, Damron KS, McManus CD, Jackson SD, Barnhill RC, Martin JC. The effect of sedation on diagnostic validity of facet joint nerve blocks: An evaluation to assess similarities in population with involvement in cervical and lumbar regions (ISRCTNo: 76376497). Pain Physician 2006; 9:4752

607. Merskey H, Bogduk N. Cervical zygapophysial joint pain. In: Classification of Chronic Pain. Descriptions of Chronic Pain Syndromes and Definition of Pain Terms, 2nd ed. Task Force on Taxonomy of the International Association for the Study of Pain. IASP Press, Seattle, 1994, pp 108-109.

608. Bogduk N. Cervical medial branch blocks. In: Practice Guidelines for Spinal Diagnostic and Treatment Procedures, 1st edition. International Spine Intervention Society, 2004, pp 112-137.

609. Merskey H, Bogduk N. Cervical discogenic pain. In: Classification of Chronic Pain. Descriptions of Chronic Pain Syndromes and Definition of Pain Terms, 2nd ed. Task Force on Taxonomy of the International Association for the Study of Pain. IASP Press, Seattle, 1994, p 108.

610. Bogduk N. Cervical disc stimulation (provocation discography). In: Practice Guidelines for Spinal Diagnostic and Treatment Procedures, 1st edition. International Spine Intervention Society, 2004, pp 95-111.

611. Falco FJE, Irwin L, Zhu J, Kim D, Onyewu CO. Cervical discography. In: Manchikanti L, Singh V (eds). Interventional Techniques in Chronic Spinal Pain. ASIPP Publishing, Paducah, KY, 2007, pp 567-580.

612. Schellhas KP, Smith MD, Gundry $C R$, Pollei SR. Cervical discogenic pain: Prospective correlation of magnetic resonance imaging and discography in asymptomatic subjects and pain sufferers. Spine 1996; 21:300-311.

613. Sneider SE, Winslow OP Jr., Prylor TH. Cervical diskography: Is it relevant? JAMA 1963; 185:163-165.

614. Zheng Y, Liew SM, Simmons ED. Value of magnetic resonance imaging and discography in determining the level of 
cervical discectomy and fusion. Spine 2004; 29:2140-2145.

615. Sohn HM, You JW, Lee JY. The relationship between disc degeneration and morphologic changes in the intervertebral foramen of the cervical spine: A cadaveric MRI and CT study. J Korean Med Sci 2004; 19:101-106.

616. Dai L. Disc degeneration and cervical instability. Correlation of magnetic resonance imaging with radiography. Spine 1998; 23:1734-1738.

617. Siebenrock KA, Aebi M. Cervical discography in discogenic pain syndrome and its predictive value for cervical fusion. Arch Orthop Trauma Surg 1994; 113:199-203.

618. Motimaya A, Arici M, George D, Ramsby $G$. Diagnostic value of cervical discography in the management of cervical discogenic pain. Conn Med 2000; 64:395-398.

619. Smith GW, Nichols P Jr. Technique for cervical discography. Radiology 1957; 68:718-720.

620. Smith GW. The normal cervical diskogram; with clinical observations. Am J Roentgenol Radium Ther Nucl Med 1959; 81:1006-1010.

621. Cloward RB. Cervical diskography. A contribution to the etiology and mechanism of neck, shoulder and arm pain. Ann Surg 1959; 150:1052-1064.

622. Cloward RB. Cervical discography. Technique, indications and use in the diagnosis of ruptured cervical discs. AJR 1958; 79:563-574.

623. Cloward RB. Cervical discography. Acta Radiol Diagn (Stockh) 1963; 1:675688.

624. Holt EP Jr. Fallacy of cervical discography. Report of 50 cases in normal subjects. JAMA 1964; 188:799-801.

625. Klafta LA Jr., Collis JS Jr. An analysis of cervical discography with surgical verification. J Neurosurg 1969; 30:38-41.

626. Klafta LA Jr., Collis JS Jr. The diagnostic inaccuracy of the pain response in cervical discography. Cleve Clin Q 1969; 36:35-39.

627. Roberts S, Evans H, Trivedi J, Menage J. Histology and pathology of the human intervertebral disc. J Bone Joint Surg Am 2006; 88:S10-S14.

628. Oda J, Tanaba H, Tsuzuki N. Intervertebral disc changes with aging of human cervical vertebra. From the neonate to the eighties. Spine 1988; 13:1205-1211. 629. Roth DA. Cervical analgesic discogra- phy. A new test for the definitive diagnosis of the painful disc syndrome. JAMA 1976; 235:1713-1714.

630. Kofoed H. Thoracic outlet syndrome. Clin Orthop Rel Res 1981; 156:145-148.

631. Parfenchuck TA, Janssen ME. A correlation of cervical magnetic resonance imaging and discography/computed tomographic discograms. Spine 1994; 19:2819-2825.

632. Meyer RR. Cervical diskography. A help or hindrance in evaluating neck, shoulder, arm pain? Am J Roentgenol Radium Ther Nucl Med 1963; 90:1208-1215.

633. Stuck RM. Cervical discography. Am J Roentgenol Radium Ther Nucl Med 1961; 86:975-982.

634. Kikuchi S, Macnab I, Moreau P. Localisation of the level of symptomatic cervical disc degeneration. J Bone Joint Surg Br 1981; 63-B:272-277.

635. Cohen SP, Hurley RW. The ability of diagnostic spinal injections to predict surgical outcomes. Anesth Analg 2007; 105:1756-1775.

636. Schoelles K, Reston J, Treadwell J, Noble M, Snyder D. Spinal fusion and discography for chronic low back and uncomplicated lumbar degenerative disc disease. Health Technology Assessment. Washington State Health Care Authority; October 19, 2007.

637. Ohnmeiss DD, Guyer RD, Mason SL. The relation between cervical discographic pain responses and radiographic images. Clin J Pain 2000; 16:1-5.

638. Grubb SA, Kelly CK. Cervical discography: Clinical implications from 12 years experience. Spine 2000; 25:13821389.

639. Lownie SP, Ferguson GG. Spinal subdural empyema complicating cervical discography. Spine 1989; 14:1415-1417.

640. Laun A, Lorenz R, Agnoli NL. Complications of cervical discography. J Neurosurg Sci 1981; 25:17-20.

641. Weingarten TN, Hooten WM, Huntoon MA. Septic facet joint arthritis after a corticosteroid facet injection. Pain Med 2006; 7:52-56.

642. Connor PM, Darden BV II. Cervical discography complications and clinical efficacy. Spine 1993; 18:2035-2038.

643. Zeidman SM, Thompson K, Ducker TB. Complications of cervical discography: Analysis of 4400 diagnostic disc injections. Neurosurgery 1995; 37:414-417.

644. Palit M, Schofferman J, Goldthwaite N, Reynolds J, Kerner M, Keaney D, Law-
rence-Miyasaki L. Anterior discectomy and fusion for the management of neck pain. Spine 1999; 24:2224-2228.

645. Bogduk N, Aprill C. On the nature of neck pain, discography, and cervical zygapophyseal joint blocks. Pain 1993; 54:213-217.

646. Manchikanti L, Schultz DM, Falco FJ, Singh V. Thoracic facet joint interventions. In: Manchikanti L, Singh V (eds). Interventional Techniques in Chronic Spinal Pain. ASIPP Publishing, Paducah, KY, 2007, pp 277-294.

647. Manchikanti L, Pampati VS. Research designs in interventional pain management: Is randomization superior, desirable or essential? Pain Physician 2002; 5:275-284.

648. Stolker RJ, Vervest AC, Groen GJ. Percutaneous facet denervation in chronic thoracic spinal pain. Acta Neurochir 1993; 122:82-90.

649. Dreyfuss P, Tibiletti C, Dreyer SJ. Thoracic zygapophyseal joint pain patterns: A study in normal volunteers. Spine 1994; 19:807-811.

650. Fukui S, Ohseto K, Shiotani M. Patterns of pain induced by distending the thoracic zygapophyseal joints. Reg Anesth 1997; 22:332-336.

651. Stolker RJ, Vervest AC, Groen GJ. Parameters in electrode positioning in thoracic percutaneous facet denervation: An anatomical study. Acta Neurochir 1994; 128:32-39.

652. Stolker RJ, Vervest AC, Groen GJ. The treatment of chronic thoracic segmental pain by radiofrequency percutaneous partial rhizotomy. I Neurosurg 1994; 80:986-992.

653. Stolker RJ, Vervest AC, Ramos LM, Groen GJ. Electrode positioning in thoracic percutaneous partial rhizotomy: An anatomical study. Pain 1994; 57:241-251.

654. Dreyfuss P, Tibiletti C, Dreyer S. Sobel J. Thoracic zygapophyseal pain: A review and description of an intraarticular block technique. Pain Digest 1994; 4:44-52.

655. Chua WH, Bogduk N. The surgical anatomy of thoracic facet denervation. Acta Neurochir 1995; 136:140-144.

656. Stolker RJ, Vervest AC, Groen GJ, De Ruiter JW, Hansen L. On the innervation of the dorsal compartment of the thoracic spine. In: Stolker RJ, Vervest AC (eds). Pain Management by Radiofrequency Procedures in the Cervical 
and Thoracic Spine: A Clinical and Anatomical Study. Utrecht, Thesis, 1994, pp 133-144.

657. Stilwell DL. The nerve supply of the vertebral column and its associated structures in the monkey. Anat $\operatorname{Rec} 1956$; 125:139-169.

658. Manchikanti L, Singh V, Pampati VS, Beyer CD, Damron KS. Evaluation of the prevalence of facet joint pain in chronic thoracic pain. Pain Physician 2002; 5:354-359.

659. Manchikanti L, Singh V, Falco FJE, Cash KA, Pampati V. Effectiveness of thoracic medial branch blocks in managing chronic pain: A preliminary report of a randomized, double-blind controlled trial; Clinical trial NCTo0355706. Pain Physician 2008; 11:491-504.

660. Manchikanti L, Manchikanti KN, Manchukonda R, Pampati V, Cash KA. Evaluation of therapeutic thoracic medial branch block effectiveness in chronic thoracic pain: A prospective outcome study with minimum 1-year follow up. Pain Physician 2006; 9:97-105.

661. Dreyfuss P, Kaplan M, Dreyer SJ. Zygapophyseal joint injection techniques in the spinal axis. In: Lennard TA (ed). Pain Procedures in Clinical Practice, 2nd ed. Hanley \& Belfus, Inc., Philadelphia, PA, 2000, pp 276-308.

662. Tzaan W, Tasker R. Percutaneous radiofrequency facet rhizotomy-experience with 118 procedures and reappraisal of its value. Can J Neurol Sci 2000; 27:125-130.

663. Sluijter ME. Thoracic pain and thoracic procedures. In: Radiofrequency. Part 2: Thoracic and Cervical Region, Headache and Facial Pain. FlivoPress, Switzerland, 2003, pp 143-158.

664. Horlocker TT, Wedel DJ, Benzon H, Brown DL, Enneking FK, Heit JA, Mulroy MF, Rosenquist RW, Rowlingson J, Tryba M, Yuan CS. Regional anesthesia in the anticoagulated patient: Defining the risks (the second ASRA Consensus Conference on Neuraxial Anesthesia and Anticoagulation). Reg Anesth Pain Med 2003; 28:172-197.

665. Manchikanti L. Role of neuraxial steroids in interventional pain management. Pain Physician 2002; 5:182-199.

666. Merskey H, Bogduk N. Thoracic zygapophysial joint pain. In: Classification of Chronic Pain. Descriptions of Chronic Pain Syndromes and Definition of Pain Terms, 2nd ed. Task Force on Taxonomy of the International Association for the Study of Pain. IASP Press, Seattle, 1994, pp 116-117.

667. Bogduk N. Thoracic medial branch blocks. In: Practice Guidelines for Spinal Diagnostic and Treatment Procedures, 1st edition. International Spine Intervention Society (ISIS), San Francisco, 2004, pp 330-346.

668. Schellhas KP, Pollei SR, Dorwart RH. Thoracic discography. A safe and reliable technique. Spine 1994; 19:21032109.

669. Wood KB, Schellhas KP, Garvey TA, Aeppli D. Thoracic discography in healthy individuals. A controlled prospective study of magnetic resonance imaging and discography in asymptomatic and symptomatic individuals. Spine 1999; 24:1548-1555.

670. Bogduk N. Thoracic provocation discography. In: Practice Guidelines for Spinal Diagnostic and Treatment Procedures, 1st edition. International Spine Intervention Society (ISIS), San Francisco, 2004, pp 287-294.

671. Merskey H, Bogduk N. Thoracic discogenic pain. In: Classification of Chronic Pain. Descriptions of Chronic Pain Syndromes and Definition of Pain Terms, 2nd ed. Task Force on Taxonomy of the International Association for the Study of Pain. IASP Press, Seattle, 1994, p 116.

672. Merskey H, Bogduk N. Thoracic spinal or radicular pain syndromes. In: Classification of Chronic Pain. Descriptions of Chronic Pain Syndromes and Definition of Pain Terms, 2nd ed. Task Force on Taxonomy of the International Association for the Study of Pain. IASP Press, Seattle, 1994, pp 112-119.

673. Bennet GJ. Update on the neurophysiology of pain transmission and modulation: Focus on the NMDA-receptor. J Pain Symptom Manage 2000; 19:S2S6.

674. Millan MJ. The induction of pain: An integrative review. Prog Neurobiol 1999; 57:1-164.

675. Turk DC. Combining somatic and psychosocial treatment for chronic pain patients: Perhaps $1+1$ does $=3$. Clin J Pain 2001; 17:281-283.

676. Smith BH, Gribbin M. Etiology, prevention, treatment, and disability management of chronic pain. Introduction. Clin J Pain 2001; 17:S1-S4.

677. Rucker KS. Chronic Pain Evaluation. Butterworth/ Heinemann, Boston 2001.
678. Coccharella L, Andersson GBJ (eds). Pain. In: Guides to the Evaluation of Permanent Impairment, Fifth Edition. American Medical Association, Chicago, IL, 2000, pp 565-591.

679. Bogduk N. Low Back Pain. In: Clinical Anatomy of Lumbar Spine and Sacrum. 4 th edition. Churchill Livingstone, New York, 2005, pp 183-216.

680. Bogduk N, McGuirk B. Causes and sources of chronic low back pain. In: Medical Management of Acute and Chronic Low Back Pain. An EvidenceBased Approach: Pain Research and Clinical Management, Vol. 13. Elsevier Science BV, Amsterdam, 2002, pp 115126.

681. Bogduk N, McGuirk B. Sources and causes of neck pain. In: Management of Acute and Chronic Neck Pain. An Evidence-Based Approach. Elsevier, Edinburgh, 2006, pp 9-20.

682. Ebraheim NA, Elgafy $H$, Semaan HB. Computed tomographic findings in patients with persistent sacroiliac pain after posterior iliac graft harvesting. Spine 2000; 25:2047-2051.

683. Katz V, Schofferman J, Reynolds J. The sacroiliac joint: A potential cause of pain after lumbar fusion to the sacrum. J Spinal Disord Tech 2003; 16:96-99.

684. Schofferman J, Reynolds J, Herzog R, Covington E, Dreyfuss P, O'Neill C. Failed back surgery: Etiology and diagnostic evaluation. Spine J 2003; 3:400403.

685. Atlas SJ, Deyo RA, Keller RB, Chapin AM, Patrick DL, Long JM, Singer DE. The Maine Lumbar Spine Study, Part II. 1 -year outcomes of surgical and nonsurgical management of sciatica. Spine 1996; 21:1777-1786.

686. Waguespack A, Schofferman J, Slosar P, Reynolds J. Etiology of long-term failures of lumbar spine surgery. Pain Med 2002; 3:18-22.

687. Sampath P, Bendebba M, Davis JD, Ducker T. Outcome in patients with cervical radiculopathy. Prospective, multicenter study with independent clinical review. Spine 1999; 24:591-597.

688. Waddell G, Kummel EG, Lotto WN, Graham JD, Hall H, McCulloch JA. Failed lumbar disc surgery and repeat surgery following industrial injury. J Bone Joint Surg Am 1979; 61:201-207.

689. Lieberman IH. Disc bulge bubble: Spine economics 101. Spine J 2004; 4:609613.

690. Weinstein JN, Tosteson TD, Lurie JD, 
Tosteson AN, Hanscom B, Skinner JS, Abdu WA, Hilibrand AS, Boden SD, Deyo RA. Surgical vs nonoperative treatment for lumbar disk herniation: The Spine Patient Outcomes Research Trial (SPORT): A randomized trial. JAMA 2006; 296:2441-2450.

691. Deyo RA, Mirza SK. Trends and variations in the use of spine surgery. Clin Orthop Relat Res 2006; 443:139-146.

692. Logroscino C, Sgrambiglia R. Pointillart V. Intermediate follow-up after treatment of degenerative disc disease with Bryan Cervical Disc Prosthesis: Single level and bilevel. Spine 2003; 28:26732678.

693. Ross JS, Robertson JT, Frederickson RC, Petrie JL, Obuchowski N, Modic MT, deTribolet N. Association between peridural scar and recurrent radicular pain after lumbar discectomy: Magnetic resonance evaluation. Neurosurgery 1996; 38:855-863.

694. Fritsch EW, Heisel J, Rupp S. The failed back surgery syndrome. Reasons, intraoperative findings, and long-term results: A report of 182 operative treatments. Spine 1996; 21:626-633.

695. Malter AD, Larson EB, Urban N, Deyo RA. Cost-effectiveness of lumbar discectomy for the treatment of herniated intervertebral disc. Spine 1996; 21:1048-1054.

696. Brox JI, Sørensen R, Friis A, Nygaard $\varnothing$, Indahl A, Keller A, Ingebrigtsen T, Eriksen HR, Holm I, Koller AK, Riise R, Reikerås 0 . Randomized clinical trial of lumbar instrumented fusion and cognitive intervention and exercises in patients with chronic low back pain and disc degeneration. Spine 2003; 28:1913-1921.

697. Tosteson AN, Skinner JS, Tosteson TD, Lurie JD, Andersson GB, Berven S, Grove MR, Hanscom B, Blood EA, Weinstein JN. The cost effectiveness of surgical versus nonoperative treatment for lumbar disc herniation over two years: Evidence from the Spine Patient Outcomes Research Trial (SPORT). Spine 2008; 33:2108-2115.

698. Hacker RJ, Miller CG. Failed anterior cervical foraminotomy. I Neurosurg Spine 2003; 98:126-130.

699. Osterman H, Sund R, Seitsalo S, Keskimaki I. Risk of multiple reoperations after lumbar discectomy: A populationbased study. Spine 2003; 28:621-627.

700. Bono CM, Lee CK. Critical analysis of trends in fusion for degenerative disc disease over the past 20 years: Influ- ence of technique of fusion rate and clinical outcome. Spine 2004; 29:455463.

701. Cherkin DC, Deyo RA, Loeser JD, Bush T, Waddell G. An international comparison of back surgery rates. Spine 1994; 19:1201-1206.

702. Law JD, Lehman RAW, Kirsch WM. Reoperation after lumbar intervertebral disc surgery. J Neurosurg 1978; 48:259263.

703. Cowan JA Jr, Dimick JB, Wainess R, Upchurch GR Jr, Chandler WF, La Marca F. Changes in the utilization of spinal fusion in the United States. Neurosurgery 2006; 59:15-20.

704. Gray DT, Deyo RA, Kreuter W, Mirza SK, Heagerty PJ, Comstock BA, Chan L. Population-based trends in volumes and rates of ambulatory lumbar spine surgery. Spine 2006; 31:1957-1963.

705. Kuntz KM, Snider RK, Weinstein JN, Pope MH, Katz JN. Cost-effectiveness of fusion with and without instrumentation for patients with degenerative spondylolisthesis and spinal stenosis. Spine 2000; 25:1132-1139.

706. Glassman SD, Carreon LY, Djurasovic M, Dimar JR, Johnson JR, Puno RM, Campbell MJ. Lumbar fusion outcomes stratified by specific diagnostic indication. Spine J 2009; 9:13-21.

707. Bogduk N, Lord S. Cervical zygapophysial joint pain. Neurosurg $Q 1998$; 8:107-117.

708. Manchikanti L, Schultz DM, Falco FJ, Singh V. Cervical facet joint interventions. In: Manchikanti L, Singh V (eds). Interventional Techniques in Chronic Spinal Pain. ASIPP Publishing, Paducah, KY, 2007, pp 295-320.

709. Slipman CW, Bhat AL, Gilchrist RV, Isaac Z, Chou L, Lenrow DA. A critical review of the evidence for the use of zygapophysial injections and radiofrequency denervation in the treatment of low back pain. Spine J 2003; 3:310316.

710. Bogduk N. A narrative review of intraarticular corticosteroid injections for low back pain. Pain Med 2005; 6:287296.

711. Bogduk N. Diagnostic blocks: A truth serum for malingering. Clin J Pain 2004; 20:409-414.

712. Carette S, Marcoux S, Truchon R, Grondin C, Gagnon J, Allard Y, Latulippe M. A controlled trial of corticosteroid injections into facet joints for chronic low back pain. N Engl / Med 1991;
325:1002-1007.

713. Marks RC, Houston T, Thulbourne T. Facet joint injection and facet nerve block. A randomized comparison in 86 patients with chronic low back pain. Pain 1992; 49:325-328.

714. Nash TP. Facet joints. Intra-articular steroids or nerve blocks? Pain Clinic 1990; 3:77-82.

715. Lilius G, Laasonen EM, Myllynen P, Harilainen A, Gronlund G. Lumbar facet joint syndrome. A randomized clinical trial. J Bone Joint Surg Br 1989; 71:681684.

716. Fuchs S, Erbe T, Fischer HL, Tibesku CO. Intraarticular hyaluronic acid versus glucocorticoid injections for nonradicular pain in the lumbar spine. J Vasc Interv Radiol 2005; 16:1493-1498.

717. Barnsley L, Lord SM, Wallis BJ, Bogduk $\mathrm{N}$. Lack of effect of intra-articular corticosteroids for chronic pain in the cervical zygapophyseal joints. N Engl J Med 1994; 330:1047-1050.

718. Marks RC, Semple AJ. Spinal anaesthesia after facet joint injection. Anaesthesia 1988; 43:65-66.

719. Heckmann JG, Maihofner C, Lanz S, Rauch C, Neundorfer B. Transient tetraplegia after cervical facet joint injection for chronic neck pain administered without imaging guidance. Clin Neurol Neurosurg 2006; 108:709-711.

720. Simopoulos TT, Kraemer JJ, Glazer P, Bajwa ZH. Vertebral osteomyelitis: A potentially catastrophic outcome after lumbar epidural steroid injection. Pain Physician 2008; 11:693-697.

721. Sehgal A, Valentine JM. Lumbar radiculopathy after zygapophyseal joint injection. Br J Anaesth 2007; 99:412-414.

722. Manchikanti L, Pampati V, Bakhit C, Rivera J, Beyer C, Damron K, Barnhill R. Effectiveness of lumbar facet joint nerve blocks in chronic low back pain: A randomized clinical trial. Pain Physician 2001; 4:101-117.

723. Manchikanti L, Manchikanti K, Manchukonda R, Cash KA, Damron KS, Pampati V, McManus CD. Evaluation of lumbar facet joint nerve blocks in the management of chronic low back pain: A preliminary report of a randomized, double-blind controlled trial: Clinical Trial NCToo0355914. Pain Physician 2007; 10:425-440.

724. Manchikanti L, Damron KS, Cash KA, Manchukonda R, Pampati V. Thera- 
peutic cervical medial branch blocks in managing chronic neck pain: A preliminary report of a randomized, double-blind, controlled trial: Clinical Trial NCTo033272. Pain Physician 2006; 9:333-346.

725. Manchikanti L, Manchikanti KN, Damron KS, Pampati V. Effectiveness of cervical medial branch blocks in chronic neck pain: A prospective outcome study. Pain Physician 2004; 7:195-202.

726. Verrills $P$, Mitchell B, Vivian D, Nowesenitz G, Lovell B, Sinclair C. The incidence of intravascular penetration in medial branch blocks: Cervical, thoracic, and lumbar spines. Spine 2008; 33: E174-E177.

727. van Kleef M, Barendse GA, Kessels A, Voets HM, Weber WE, de Lange S. Randomized trial of radiofrequency lumbar facet denervation for chronic low back pain. Spine 1999; 24:1937-1942.

728. Gallagher J, Vadi PLP, Wesley JR. Radiofrequency facet joint denervation in the treatment of low back pain - A prospective controlled double-blind study to assess efficacy. Pain Clinic 1994; 7:193-198.

729. Sanders M, Zuurmond WWA. Percutaneous intraarticular lumbar facet joint denervation in the treatment of low back pain: A comparison with percutaneous extra-articular lumbar facet denervation. Pain Clinic 1999; 11:329335.

730. Leclaire R, Fortin L, Lambert R, Bergeron YM, Rossignol M. Radiofrequency facet joint denervation in the treatment of low back pain: A placebo-controlled clinical trial to assess efficacy. Spine 2001; 26:1411-1416.

731. Buijs EJ, van Wijk RM, Geurts JW, Weeseman RR, Stolker RJ, Groen GG. Radiofrequency lumbar facet denervation: A comparative study of the reproducibility of lesion size after 2 current radiofrequency techniques. Reg Anesth Pain Med 2004; 9:400-407.

732. Haspeslagh SR, Van Suijlekom HA, Lame IE, Kessels AG, van Kleef M, Weber WE. Randomised controlled trial of cervical radiofrequency lesions as a treatment for cervicogenic headache [ISRCTNo7444684]. BMC Anesthesiol 2006; 6:1.

733. Van Wijk RM, Geurts JW, Wynne HJ, Hammink E, Buskens E, Lousberg R, Knape JT, Groen GJ. Radiofrequency denervation of lumbar facet joints in the treatment of chronic low back pain: A randomized, double-blind, sham le- sion-controlled trial. Clin J Pain 2005; 21:335-344.

734. Shin WR, Kim HI, Shin DG, Shin DA. Radiofrequency neurotomy of cervical medial branches for chronic cervicobrachialgia. J Korean Med Sci 2006; 21:119-125.

735. Birkenmaier C, Veihelmann A, Trouillier H, Hausdorf J, Devens C, Wegener B, Jansson V, von Schulze Pellengahr C. Percutaneous cryodenervation of lumbar facet joints: A prospective clinical trial. Int Orthop 2007; 31:525-530.

736. Staender M, Maerz U, Tonn JC, Steude U. Computerized tomography-guided kryorhizotomy in 76 patients with lumbar facet joint syndrome. J Neurosurg Spine 2005; 3:444-449.

737. Mogalles AA, Dreval' ON, Akatov OV, Kuznetsov AV, Rynkov IP, Plotnikov VM, Minaev VP. Percutaneous laser denervation of the zygapophyseal joints in the pain facet syndrome. Zh Vopr Neirokhir Im N N Burdenko 2004; 1:20-25.

738. Martinez-Suarez JE, Camblor L, Salva $S$, De Jongh WA. Thermocoagulation of lumbar facet joints. Experience in 252 patients. Revista de la Sociedad Espanola del Dolor 2005; 12:425-428.

739. Gofeld M, Jitendra J, Faclier G. Radiofrequency facet denervation of the lumbar zygapophysial joints: 10-year prospective clinical audit. Pain Physician 2007; 10:291-300.

740. Schaerer JP. Radiofrequency facet rhizotomy in the treatment of chronic neck and low back pain. Int Surg 1978; 63:53-59.

741. Dreyfuss P, Halbrook B, Pauza K, Joshi A, McLarty J, Bogduk N. Efficacy and validity of radiofrequency neurotomy for chronic lumbar zygapophysial joint pain. Spine 2000; 25:1270-1277.

742. Schofferman J, Kine G. Effectiveness of repeated radiofrequency neurotomy for lumbar facet pain. Spine 2004; 29:2471-2473.

743. Vad V, Cano W, Basrai D, Lutz G, Bhat A. Role of radiofrequency denervation in lumbar zygapophyseal joint synovitis in baseball pitchers: A clinical experience. Pain Physician 2003; 6:307-312.

744. North RB, Han M, Zahurak M, Kidd DH. Radiofrequency lumbar facet denervation: Analysis of prognostic factors. Pain 1994; 57:77-83.

745. Mikeladze G, Espinal R, Finnegan R, Routon J, Martin D. Pulsed radiofrequency application in treatment of chronic zygapophyseal joint pain.
Spine J 2003; 3:360-362.

746. Lindner R, Sluijter ME, Schleinzer W. Pulsed radiofrequency treatment of the lumbar medial branch for facet pain: A retrospective analysis. Pain Med 2006; 7:435-439.

747. Jerosch J. Facet syndrome. 2. Percutaneous facet coagulation. Chirurgische Praxis 2005; 65:43-55.

748. Bogduk N. Lumbar radiofrequency neurotomy. Clin J Pain 2006; 22:409.

749. Bogduk N. Point of view Re. Nath et al. Percutaneous lumbar zygapophysial (facet) joint neurotomy using radiofrequency current, in the management of chronic low back pain. A randomized double-blind trial. Spine 2008; 33:1291-1298.

750. Kornick C, Kramarich SS, Lamer TJ, Todd Sitzman B. Complications of lumbar facet radiofrequency denervation. Spine 2004; 29:1352-1354.

751. Kornick CA, Kramarich SS, Sitzman BT, Marshall KA, Santiago-Palma J, Lamer TJ. Complication rate associated with facet joint radiofrequency denervation procedures. Pain Med 2002; 3:175176.

752. Manchikanti L, Singh V. Review of chronic low back pain of facet joint origin. Pain Physician 2002; 5:83-101.

753. Bogduk N, Christophidis N, Cherry D. Epidural use of steroids in the management of back pain. Report of working party on epidural use of steroids in the management of back pain. National Health and Medical Research Council. Canberra, Commonwealth of Australia, 1994; pp 1-76.

754. Singh V, Manchikanti L. Role of caudal epidural injections in the management of chronic low back pain. Pain Physician 2002; 5:133-148.

755. Manchikanti L, Pampati V, Fellows B, Bakhit CE. The diagnostic validity and therapeutic value of lumbar facet joint nerve blocks with or without adjuvant agents. Curr Rev Pain 2000; 4:337344.

756. Manchikanti L, Pampati V, Damron KS, McManus $C D$, Jackson SD, Barnhill RC, Martin JC. A randomized, prospective, double-blind, placebo-controlled evaluation of the effect of sedation on diagnostic validity of cervical facet joint pain. Pain Physician 2004; 7:301-309.

757. Botwin KB, Guirguis R. Cervical interlaminar epidural steroid injections. In: Manchikanti L, Singh V (eds.) Inter- 
ventional Techniques in Chronic Spinal Pain, ASIPP Publishing, Paducah KY 2007; pp 401-422.

758. Botwin KB, Vettichira S. Thoracic interlaminar epidural steroid injections. In: Manchikanti L, Singh V (eds). Interventional Techniques in Chronic Spinal Pain. ASIPP Publishing, Paducah, KY, 2007, pp 383-400.

759. Botwin KB. Lumbar interlaminar epidural steroid injections. In: Manchikanti L, Singh V (eds). Interventional Techniques in Chronic Spinal Pain. ASIPP Publishing, Paducah KY 2007; pp 355382.

760. Manchikanti L, Singh V. Caudal epidural injections. In: Manchikanti L, Singh $\mathrm{V}$ (eds.) Interventional Techniques in Chronic Spinal Pain. ASIPP Publishing, Paducah, KY, 2007, pp 331-354.

761. Manchikanti L, Schultz DM, Racz GB. Lumbar transforaminal epidural injections. In: Manchikanti L, Singh V (eds). Interventional Techniques in Chronic Spinal Pain. ASIPP Publishing, Paducah, KY, 2007, pp 423-454.

762. Manchikanti L, Schultz DM, Racz GB. Cervical transforaminal epidural injections. In: Manchikanti L, Singh V (eds). Interventional Techniques in Chronic Spinal Pain. ASIPP Publishing, Paducah, KY, 2007, pp 455-478.

763. Koes BW, Scholten RJ, Mens JM, Bouter LM. Efficacy of epidural steroid injections for low-back pain and sciatica: A systematic review of randomized clinical trials. Pain 1995; 63:279-288.

764. Rozenberg S. Glucocorticoid therapy in common lumbar spinal disorders. Rev Rhum Engl Ed 1998; 65:649-655.

765. Watts RW, Silagy CA. A meta-analysis on the efficacy of epidural corticosteroids in the treatment of sciatica. Anaesth Intensive Care 1995; 23:564569.

766. Armon C, Argoff CE, Samuels J, Backonja MM; Therapeutics and Technology Assessment Subcommittee of the American Academy of Neurology. Assessment: Use of epidural steroid injections to treat radicular lumbosacral pain: Report of the Therapeutics and Technology Assessment Subcommittee of the American Academy of Neurology. Neurology 2007; 68:723-729.

767. Boswell M, Hansen $H$, Trescot A, Hirsch J. Epidural steroids in the management of chronic spinal pain and radiculopathy. Pain Physician 2003; 6:319-334.
768. Bush K, Hillier S. A controlled study of caudal epidural injections of triamcinolone plus procaine for the management of intractable sciatica. Spine 1991; 16:572-575.

769. Manchikanti L, Singh V, Cash KA, Pampati V, Damron KS, Boswell MV. Preliminary results of randomized, equivalence trial of fluoroscopic caudal epidural injections in managing chronic low back pain: Part 2. Disc herniation and radiculitis. Pain Physician 2008; 11:801-815.

770. Dashfield AK, Taylor MB, Cleaver JS, Farrow D. Comparison of caudal steroid epidural with targeted steroid placement during spinal endoscopy for chronic sciatica: A prospective, randomized, double-blind trial. $\mathrm{Br} / \mathrm{An}$ aesth 2005; 94:514-559.

771. Mathews JA, Mills SB, Jenkins VM, Grimes SM, Morkel MJ, Mathews W, Scott CM, Sittampalam Y. Back pain and sciatica: Controlled trials of manipulation, traction, sclerosant and epidural injections. Brit J Rheumatol 1987; 26:416-423.

772. Breivik H, Hesla PE, Molnar I, Lind B. Treatment of chronic low back pain and sciatica. Comparison of caudal epidural injections of bupivacaine and methylprednisolone with bupivacaine followed by saline. In: Bonica JJ, Albe-Fesard D (eds). Advances in Pain Research and Therapy. Raven Press, New York, 1976, pp 927-932.

773. Hesla PE, Breivik H. Epidural analgesia and epidural steroid injection for treatment of chronic low back pain and sciatica. Tidsskr Nor Laegeforen 1979; 99:936-939.

774. Manchikanti L, Singh V, Cash KA, Pampati V, Datta S. Preliminary results of randomized, equivalence trial of fluoroscopic caudal epidural injections in managing chronic low back pain: Part 3. Post surgery syndrome. Pain Physician 2008; 11:817-831.

775. Revel M, Auleley GR, Alaoui S, Nguyen M, Duruoz T, Eck-Michaud S, Roux C, Amor B. Forceful epidural injections for the treatment of lumbosciatic pain with post-operative lumbar spinal fibrosis. Rev Rhum Engl Ed 1996; 63:270-277.

776. Manchikanti L, Cash KA, McManus CD, Pampati V, Abdi S. Preliminary results of randomized, equivalence trial of fluoroscopic caudal epidural injections in managing chronic low back pain: Part 4. Spinal stenosis. Pain Physician
2008; 11:833-848.

777. Ciocon JO, Galindo-Ciocon D, Amaranath L, Galindo D. Caudal epidural blocks for elderly patients with lumbar canal stenosis. J Am Geriatr Soc 1994; 42:593-596.

778. Botwin K, Brown LA, Fishman M, Rao S. Fluoroscopically guided caudal epidural steroid injections in degenerative lumbar spine stenosis. Pain Physician 2007; 10:547-558.

779. Huntoon MA, Burgher AH. Back to the future: The end of the steroid century? Pain Physician 2008; 11:713-716.

780. Manchikanti L, Cash KA, McManus CD, Pampati V, Smith HS. Preliminary results of randomized, equivalence trial of fluoroscopic caudal epidural injections in managing chronic low back pain: Part 1. Discogenic pain without disc herniation or radiculitis. Pain Physician 2008; 11:785-800.

781. Manchikanti L, Singh V, Rivera JJ, Pampati V, Beyer CD, Damron KS, Barnhill RC. Effectiveness of caudal epidural injections in discogram positive and negative chronic low back pain. Pain Physician 2002; 5:18-29.

782. Manchikanti L, Pampati V, Rivera JJ, Beyer C, Damron K, Barnhill R. Caudal epidural injections with Sarapin or steroids in chronic low back pain. Pain Physician 2001; 4:322-335.

783. Manchikanti L, Pakanati RR, Pampati V. Comparison of three routes of epidural steroid injections in low back pain. Pain Digest 1999; 9:277-285.

784. Stitz MY, Sommer HM. Accuracy of blind versus fluoroscopically guided caudal epidural injection. Spine 1999; 24:1371-1376.

785. MacLean CA, Bachman DT. Documented arterial gas embolism after spinal epidural injection. Ann Emerg Med 2001; 38:592-595.

786. Yue WM, Tan SB. Distant skip level discitis and vertebral osteomyelitis after caudal epidural injection: A case report of a rare complication of epidural injections. Spine 2003; 28:E209-E211.

787. Botwin KP, Gruber RD, Bouchlas CG, Torres-Ramos FM, Hanna A, Rittenberg J, Thomas SA. Complications of fluoroscopically guided caudal epidural injections. Am J Phys Med Rehabil 2001; 80:416-424.

788. Mateo E, Lopez-Alarcon MD, Moliner S, Calabuig E, Vivo M, De Andres J, Grau F. Epidural and subarachnoid pneumo- 
cephalus after epidural technique. Eur J Anesthesiol 1999; 16:413-417.

789. Katz JA, Lukin R, Bridenbaugh PO, Gunzenhauser L. Subdural intracranial air: An unusual cause of headache after epidural steroid injection. Anesthesiology 1991; 74:615-618.

790. Kusher FH, Olson JC. Retinal hemorrhage as a consequence of epidural steroid injection. Arch Opthalmol 1995; 113:309-313.

791. Pizzimenti JJ, Daniel KP. Central serous chorioretinopathy after epidural steroid injection. Pharmacotherapy 2005; 25:1141-1146.

792. Fogel GR, Cunningham PY 3rd, Esses SI. Spinal epidural lipomatosis: Case reports, literature review and metaanalysis. Spine J 2005; 5:202-211.

793. Tanaka A, Nakazawa S, Nishikawa K, Saito S. Spinal cord infarction following multiple epidural injections. Pain Clinic 2004; 16:207-211.

794. Hooten WM, Kinney MO, Huntoon MA. Epidural abscess and meningitis after epidural corticosteroid injection. Mayo Clin Proc 2004; 79:682-686.

795. Manchikanti L, Cash KA, Pampati V, McManus CD, Damron KS. Evaluation of fluoroscopically guided caudal epidural injections. Pain Physician 2004; 7:81-92.

796. Manchikanti L, Bakhit CE, Pampati V. The role of epidurography in caudal neuroplasty. Pain Digest 1998; 8:277281.

797. Botwin KP, Freeman ED, Gruber RD, Torres-Ramos FM, Bouchlas C, Sanelli JT, Hanna AF. Radiation exposure to a physician performing fluoroscopically guided caudal epidural steroid injections. Pain Physician 2001; 4:343-348.

798. Manchikanti L, Schultz DM, Racz GB. Lumbar transforaminal epidural injections. In: Manchikanti L, Singh V (eds). Interventional Techniques in Chronic Spinal Pain, ASIPP Publishing, Paducah, KY, 2007, pp 423-454.

799. Manchikanti L, Pampati V, Beyer CD, Damron KS, Cash KA, Moss TL. The effect of neuraxial steroids on weight and bone mass density: A prospective evaluation. Pain Physician 2000; 3:357366.

80o. Brill S, Swartz A, Brill G. Epidural steroid injections do not induce weight gain. Curr Drug Saf 2007; 2:113-116.

801. Young WF. Transient blindness after lumbar epidural steroid injection: A case report and literature review. Spine 2002; 27:E476-E477.

802. Browning DJ. Acute retinal necrosis following epidural steroid injections. Am J Ophthalmol 2003; 136:192-194.

803. lida T, Spaide RF, Negrao SG, Carvalho CA, Yannuzzi LA. Central serous chorioretinopathy after epidural corticosteroid injection. Am J Ophthalmol 2001; 132:423-425.

804. McAllister RK, McDavid AJ, Meyer TA, Bittenbinder TM. Recurrent persistent hiccups after epidural steroid injection and analgesia with bupivacaine. Anesth Analg 2005; 100:1834-1836.

805. Everett CR, Baskin MN, Novoseletsky $D$, Speach D, Patel R. Flushing as a side effect following lumbar transforaminal epidural steroid injection. Pain Physician 2004; 7:427-429.

806. Ozdemir O, Calisaneller T, Yildirim E, Altinors N. Acute intracranial subdural hematoma after epidural steroid injection: A case report. J Manipulative Physiol Ther 2007; 30:536-538.

807. Markham JW, Lynge HN, Stahlman GE. The syndrome of spontaneous spinal epidural hematoma. Report of three cases. J Neurosurg 1967; 26:334-341.

808. Stoll A, Sanchez M. Epidural hematoma after epidural block: Implications for its use in pain management. Surg Neurol 2002; 57:235-240.

809. LaBan MM, Kasturi G, Wang IM. Epidural corticosteroid injections precipitating epidural hematomas with spinal paresis. Am J Phys Med Rehabil 2007; 86:66-167.

810. Manchikanti L. Pharmacology of neuraxial steroids. In Manchikanti L, Singh $\mathrm{V}$ (eds). Interventional Techniques in Chronic Spinal Pain. ASIPP Publishing, Paducah, KY, 2007, pp 167-184.

811. Nelson DA, Landau WM. Intraspinal steroids: History, efficacy, accidentality, and controversy with review of United States Food and Drug Administration reports. I Neurol Neurosurg Psychiatry 2001; 70:433-443.

812. Carette S, Leclaire R, Marcoux S, Morin F, Blaise GA, St-Pierre A, Truchon R, Parent $\mathrm{F}$, Levesque J, Bergeron $\mathrm{V}$, Montminy $P$, Blanchette C. Epidural corticosteroid injections for sciatica due to herniated nucleus pulposus. N Engl I Med 1997; 336:1634-1640.

813. Cuckler JM, Bernini PA, Wiesel SW, Booth RE Jr, Rothman RH, Pickens GT. The use of epidural steroid in the treatment of radicular pain. I Bone Joint
Surg 1985; 67:63-66.

814. Snoek W, Weber H, Jorgensen B. Double-blind evaluation of extradural methylprednisolone for herniated lumbar disc. Acta Orthop Scand 1977; 48:635-641.

815. Arden NK, Price C, Reading I, Stubbing J, Hazelgrove J, Dunne C, Michel M, Rogers P, Cooper C, WEST Study Group. A multicentre randomized controlled trial of epidural corticosteroid injections for sciatica: The WEST study. Rheumatology (Oxford) 2005; 44:1399-1406.

816. Wilson-MacDonald J, Burt G, Griffin D, Glynn C. Epidural steroid injection for nerve root compression: A randomized, controlled trial. J Bone Joint Surg Br 2005; 87-B:352-355.

817. Campbell MJ, Carreon LY, Glassman SD, McGinnis MD, Elmlinger BS. Correlation of spinal canal dimensions to efficacy of epidural steroid injection in spinal stenosis. J Spinal Disord Tech 2007; 20:168-171.

818. Butterman GR. The effect of spinal steroid injections for degenerative disc disease. Spine J 2004; 4:495-505.

819. Stav A, Ovadia L, Sternberg A, Kaadan M, Weksler N. Cervical epidural steroid injection for cervicobrachialgia. Acta Anaesthesiol Scand 1993; 37:562-566.

820. Castagnera L, Maurette P, Pointillart V, Vital JM, Erny P, Senegas J. Long term results of cervical epidural steroid injection with and without morphine in chronic cervical radicular pain. Pain 1994; 58:239-243.

821. Pasqualucci A, Varrassi G, Braschi A, Peduto VA, Brunelli A, Marinangeli F, Gori F, Colò F, Paladini A, Mojoli F. Epidural local anesthetic plus corticosteroid for the treatment of cervical brachial radicular pain: Single injection versus continuous infusion. Clin J Pain 2007; 23:551-557.

822. Price C, Arden N, Coglan L, Rogers P. Cost-effectiveness and safety of epidural steroids in the management of sciatica. Health Technol Assess 2005; 9:158 , iii.

823. Botwin KP, Castellanos R, Raos, Hanna AF, Torres-Ramos FM, Gruber RD, Bouchlas CG, Fuoco GS. Complications of fluoroscopically guided interlaminar cervical injections. Arch Phys Med Rehabil 2003; 84:627-633.

824. Cicala RS, Westbrook L, Angel JJ. Side effects and complications of cervical epidural steroid injections. I Pain Symptom Manage 1989; 4:64-66. 
825. Derby R, Lee SH, Kim BJ, Chen Y, Seo KS. Complications following cervical epidural steroid injections by expert interventionalists in 2003. Pain Physician 2004; 7:445-449.

826. Waldman SD. Complications of cervical epidural nerve block with steroids: A prospective study of 790 consecutive blocks. Reg Anaesth 1989; 14:149-151.

827. Huang RC, Shapiro GS, Lim M, Sandhu HS, Lutz GE, Herzog RJ. Cervical epidural abscess after epidural steroid injection. Spine 2004; 29:E7-E9.

828. Waldman SD. Cervical epidural abscess after cervical epidural nerve block with steroids. Anesth Analg 1991; 72:717718.

829. Kricun R, Shoemaker El, Chovanes GI, Stephens HW. Epidural abscess of the cervical spine: MR findings in five cases. AJR Am J Roentgenol 1992; 158:1145-1149.

830. Papadakis CE, Chimona TS, Skoulakis CE, Prokopakis EP, Kyrmizakis DE, Velegrakis GA. Cervical prevertebral abscess owing to injection of corticosteroids. J Otolaryngol 2005; 34:254257.

831. Tang H, Lin H, Liu Y, Li CM. Spinal epidural abscess-experience with 46 patients and evaluation of prognostic factors. J Infect 2002; 45:76-81.

832. Anand S, Maini L, Agarwal A, Sing T, Dhal AK, Dhaon BK. Spinal epidural abscess - a report of six cases. Int Orthop 1999; 23:175-177.

833. Elias M. Cervical epidural abscess following trigger point injection. J Pain Symptom Manage 1991; 9:71-72.

834. Ho KY. Vascular uptake of contract despite negative aspiration in interlaminar cervical epidural injection. Pain Physician 2006; 9:267-268.

835. Williams KN, Jackowski A, Evans PJ. Epidural haematoma requiring surgical decompression following repeated cervical epidural steroid injections for chronic pain. Pain 1990; 42:197-199.

836. Yagi S, Hida K, Iwasaki Y, Abe H, Akino $M$, Saito H. Cervical epidural hematoma caused by cervical twisting after epidural anesthesia: A case report. No Shinkei Geka 1998; 26:235-242.

837. Reitman CA, Watters W 3 rd. Subdural hematoma after cervical steroid injection. Spine 2002; 27:E174-E176.

838. Mendelson J, Muppidi S, Silberstein S. Multiple intracerebral hemorrhages after cervical epidural injections. Neurology 2008; 70:2415-2416.
839. Oberoi G. Inadvertent subdural spread complicating injection of cervical epidural steroid with local anaesthetic. Anaesth Intensive Care 2004; 32:846.

840. Russo MA. Inadvertent subdural spread complicating cervical epidural steroid injection. Anaesth Intensive Care 2004; 32:145-146.

841. Bansal S, Turtle MJ. Inadvertent subdural spread complicating cervical epidural steroid injection with local anaesthetic agent. Anaesth Intensive Care 2003; 31:570-572.

842. Hodges SD, Castleberg RL, Miller T, Ward R, Thornburg C. Cervical epidural steroid injection with intrinsic spinal cord damage. Two case reports. Spine 1998; 23:2137-2142.

843. Arpa J, Lara M, Cruz Martinez A, Perez Jimenez A. Cervical spinal cord infarction caused by the use of epidural morphine. Neurologia 1992; 7:240-241.

844. Racz GB, Heavner JE. Cervical spinal canal loculation and secondary ischemic cord injury--PVCS--perivenous counter spread--danger sign! Pain Pract 2008; 8:399-403.

845. Simopoulos T, Peeters-Asdourian C. Pneumocephalus after cervical epidural steroid injection. Anesth Analg 2001; 92:1576-1577.

846. Dietrich CL, Smith CE. Epidural granuloma and intracranial hypotension resulting from cervical epidural steroid injection. Anesthesiology 2004; 100:445447.

847. Bromage RP, Benumof JL. Paraplegia following intracord injection during attempted epidural anesthesia under general anesthesia. Reg Anesth Pain Med 1998; 23:104-107.

848. Bilir A, Gulec S. Cauda equina syndrome after epidural steroid injection: A case report. / Manipulative Physiol Ther 2006; 29:492-494.

849. Sabel M, Felsberg J, Neuen-Jacob E, Lichota A, Schnitzler A, Herdmann J. Enlargement of a chronic aseptic lumbar epidural abscess by intraspinal injections - a rare cause of progressive paraparesis. Zentralbl Neurochir 2000; 61:111-114.

850. Parlier-Cuau C, Carlier RY, David P, Silva M, Doyon D. Subdural abscess. Rare complication of epidural infiltration: Apropos of a case and review of the literature. J Radiol 1993; 74:205-209.

851. Hooten WM, Mizerak A, Carns PE. Discitis after lumbar epidural corticosteroid injection: A case report and analysis of the case report literature. Pain
Med 2006; 7:46-51.

852. Hawley JS, Ney JP, Swanberg MM. Subarachnoid pneumocephalus from epidural steroid injection. Headache 2005 ; 45:247-248.

853. DePalma MJ, Bhargava A, Slipman CW. A critical appraisal of the evidence for selective nerve root injection in the treatment of lumbosacral radiculopathy. Arch Phys Med Rehabil 2005; 86:14771483.

854. Jeong HS, Lee JW, Kim SH, Myung JS, Kim JH, Kang HS. Effectiveness of transforaminal epidural steroid injection by using a preganglionic approach: A prospective randomized controlled study. Radiology 2007; 245:584-590.

855. Karppinen J, Malmivaara A, Kurunlahti M, Kyllönen E, Pienimäki T, Nieminen P, Ohinmaa A, Tervonen O, Vanharanta H. Periradicular infiltration for sciatica: A randomized controlled trial. Spine 2001; 26:1059-1067.

856. Karppinen J, Ohinmaa A, Malmivaara A, Kurunlahti M, Kyllönen E, Pienimäki T, Nieminen P, Tervonen O, Vanharanta $\mathrm{H}$. Cost effectiveness of periradicular infiltration for sciatica: Subgroup analysis of a randomized controlled trial. Spine 2001; 26:2587-2595.

857. Riew KD, Yin Y, Gilula L, Bridwell KH, Lenke LG, Lauryssen C, Goette K. The effect of nerve-root injections on the need for operative treatment of lumbar radicular pain. A prospective, randomized, controlled, double-blind study. J Bone Joint Surg Am 2000; 82-A:15891593.

858. Riew KD, Park JB, Cho YS, Gilula L, Patel A, Lenke LG, Bridwell KH. Nerve root blocks in the treatment of lumbar radicular pain. A minimum five-year follow-up. J Bone Joint Surg Am 2006; 88:1722-1725.

859. Vad VB, Bhat AL, Lutz GE, Cammisa F. Transforaminal epidural steroid injections in lumbosacral radiculopathy: $\mathrm{A}$ prospective randomized study. Spine 2002; 27:11-16.

860. Glaser SE, Falco F. Paraplegia following a thoracolumbar transforaminal epidural steroid injection. Pain Physician 2005; 8:309-314.

861. Manchikanti L, Cash KA, Pampati V, Damron KS, McManus CD. Evaluation of lumbar transforaminal epidural injections with needle placement and contrast flow patterns: A prospective, descriptive report. Pain Physician 2004; 7:217-223.

862. Botwin KP, Gruber RD, Bouchlas CG, 
Torres-Ramos FM, Freeman TL, Slaten WK. Complications of fluoroscopically guided transforaminal lumbar epidural injections. Arch Phys Med Rehabil 2000; 81:1045-1050.

863. Furman MB, O’Brien EM, Zgleszewski TM. Incidence of intravascular penetration in transforaminal lumbosacral epidural steroid injections. Spine 2000; 25:2628-2632.

864. Houten JK, Errico TJ. Paraplegia after lumbosacral nerve root block: Report of three cases. Spine J 2002; 2:70-75.

865. Huston CW, Slipman CW, Garvin C. Complications and side effects of cervical and lumbosacral selective nerve root injections. Arch Phys Med Rehabil 2005; 86:277-283.

866. Cohen SP, Maine DN, Shockey SM, Kudchadkar S, Griffith S. Inadvertent disk injection during transforaminal epidural steroid injection: Steps for prevention and management. Pain Med 2008; 9:688-694.

867. Puljak L, Kojundzic SL, Hogan QH, Sapunar D. Lidocaine injection into the rat dorsal root ganglion causes neuroinflammation. Anesth Analg 2009; 108:1021-1026.

868. Boonen S, Van Distel G, Westhovens R, Dequeker J. Steroid myopathy induced by epidural triamcinolone injection. Brit J Rheumatol 1995; 34:385-386.

869. Sandberg DI, Lavyne MH. Symptomatic spinal epidural lipomatosis after local epidural corticosteroid injections: Case report. Neurosurgery 1999; 45:162165.

870. Clinkscales A, Cleary JD. Steroid-induced avascular necrosis. Ann Pharmacother Pharmacother 2002; 36:1105.

871. Mikhail GR, Sweet LC, Mellinger RC. Parenteral long-acting corticosteroid effect on hypothalamic pituitary adrenal function. Ann Allergy 1973; 31:337343.

872. Belozer M, Wang G. Epidural adhesiolysis for the treatment of back pain. Health Technol Assess 2004; 5:1-19.

873. Viesca C, Racz G, Day M. Spinal techniques in pain management: Lysis of adhesions. Anesthesiol Clin North America 2003; 21:745-766.

874. Manchikanti L, Bakhit CE. Percutaneous lysis of epidural adhesions. Pain Physician 2000; 3:46-64.

875. Manchikanti L, Saini B, Singh V. Lumbar epidural adhesiolysis. In: Manchikanti L, Slipman CW, Fellows B (eds). Interventional Pain Management: Low Back
Pain - Diagnosis and Treatment. ASIPP Publishing, Paducah, KY, 2002, pp 353390.

876. Veihelmann A, Devens C, Trouiller H, 886. Manchikanti L, Singh V. Epidural lyBirkenmaier C, Gerdesmeyer L, Refior HJ. Epidural neuroplasty versus physiotherapy to relieve pain in patients with sciatica: A prospective randomized blinded clinical trial. J Orthop Science 2006; 11:365-369.

877. Heavner JE, Racz GB, Raj P. Percutaneous epidural neuroplasty. Prospective evaluation of $0.9 \% \mathrm{NaCl}$ versus $10 \%$ $\mathrm{NaCl}$ with or without hyaluronidase. Reg Anesth Pain Med 1999; 24:202207.

878. Manchikanti L, Rivera J, Pampati V, Damron KS, McManus CD, Brandon $D E$, Wilson SR. One day lumbar epidural adhesiolysis and hypertonic saline neurolysis in treatment of chronic low back pain: A randomized double blind trial. Pain Physician 2004; 7:177-186.

879. Gerdesmeyer L, Lampe R, Veihelmann A, Burgkart R, Gobel M, Gollwitzer H, Wagner K. Chronic radiculopathy. Use of minimally invasive percutaneous epidural neurolysis according to Racz. Der Schmerz 2005; 19:285-295.

880. Manchikanti L, Pakanati R, Bakhit CE, Pampati V. Role of adhesiolysis and hypertonic saline neurolysis in management of low back pain. Evaluation of modification of Racz protocol. Pain Digest 1999; 9:91-96.

881. Manchikanti L, Pampati V, Bakhit CE, Pakanati RR. Non-endoscopic and endoscopic adhesiolysis in post lumbar laminectomy syndrome. A one-year outcome study and cost effective analysis. Pain Physician 1999; 2:52-58.

882. Manchikanti L, Pampati V, Fellows B, Rivera JJ, Beyer CD, Damron KS. Role of one day epidural adhesiolysis in management of chronic low back pain: A randomized clinical trial. Pain Physician 2001; 4:153-166.

883. Racz GB, Heavner JE, Raj PP. Percutaneous epidural neuroplasty. Prospective one-year follow up. Pain Digest 1999; 9:97-102.

884. Gerdesmeyer L, Rechl H, Wagenpfeil S, Ulmer M, Lampe R, Wagner K. Minimally invasive epidural neurolysis in chronic radiculopathy. A prospective controlled study to prove effectiveness. Der Orhopade 2003; 32:869-876.

885. Manchikanti L, Heavner JE, Racz GB. Percutaneous lysis of lumbar epidural adhesions. In: Manchikanti L, Singh
$\mathrm{V}$ (eds). Interventional Techniques in Chronic Spinal Pain. ASIPP Publishing, Paducah, KY, 2007, pp 479-506. sis of adhesions and myeloscopy. Curr Pain Headache Rep 2002; 6:427-435.

887. Lucas JS, Ducker TB, Perot PL. Adverse reactions to intrathecal saline injections for control of pain. J Neurosurg 1975; 42:557-561.

888. Gill JB, Heavner JE. Visual impairment following epidural fluid injections and epiduroscopy: A review. Pain Med $2005 ; 6: 367-374$.

889. Manchikanti L, Boswell MV, Rivera JJ, Pampati V, Damron KS, McManus CD, Brandon DE, Wilson SR. A randomized, controlled trial of spinal endoscopic adhesiolysis in chronic refractory low back and lower extremity pain. BMC Anesthesiol 2005; 5:10.

890. Avellanal M, Diaz-Reganon G. Interlaminar approach for epiduroscopy in patients with failed back surgery syndrome. Br J Anaesth 2008; 101:244249.

891. Geurts JW, Kallewaard JW, Richardson J, Groen GJ. Targeted methylprednisolone acetate/hyaluronidase/clonidine injection after diagnostic epiduroscopy for chronic sciatica: A prospective, 1 year follow-up study. Reg Anesth Pain Med 2002; 27:343-352.

892. Richardson J, McGurgan P, Cheema S, Prasad R, Gupta S. Spinal endoscopy in chronic low back pain with radiculopathy. A prospective case series. Anaesthesia 2001; 56:454-460.

893. Manchikanti L, Pakanati, RR, Pampati V, Fellows B. The value and safety of epidural endoscopic adhesiolysis. Am J Anesthesiol 2000; 27:275-279.

894. Manchikanti L, Heavner JE, Boswell MV. Endoscopic lumbar epidural adhesiolysis. In: Manchikanti L, Singh V (eds). Interventional Techniques in Chronic Spinal Pain. ASIPP Publishing, Paducah, KY, 2007, pp 507-526.

895. Holmström B, Rawal N, Axelsson K, Nydahl PA. Risk of catheter migration during combined spinal epidural block: Percutaneous epiduroscopy study. Anesth Analg 1995; 80:747-753.

896. Amirikia A, Scott IU, Murray TG, Halperin LS. Acute bilateral visual loss associated with retinal hemorrhages following epiduroscopy. Arch Ophthalmol 2000; 118:287-289.

897. Tabandeh H. Intraocular hemorrhages associated with endoscopic spinal sur- 
gery. Am J Ophthalmol 2000; 129:688690.

898. Heavner JE, Wyatt DE, Bosscher HA. Lumbosacral epiduroscopy complicated by intravascular injection. Anesthesiology 2007; 107:347-350.

899. Vallejo R, Benyamin RM, Kramer J, Stanton G, Joseph NJ. Pulsed radiofrequency denervation for the treatment of sacroiliac joint syndrome. Pain Med 2006; 7:429-434.

900. Cohen SP, Abdi S. Lateral branch blocks as a treatment for sacroiliac joint pain: A pilot study. Reg Anesth Pain Med 2003; 28:113-119.

901. Burnham RS, Yasui Y. An alternate method of radiofrequency neurotomy of the sacroiliac joint: A pilot study of the effect of pain, function, and satisfaction. Reg Anesth Pain Med 2007; 32:12-19.

902. Cohen SP, Hurley RW, Buckenmaier CC 3rd, Kurihara C, Morlando B, Dragovich A. Randomized placebo-controlled study evaluating lateral branch radiofrequency denervation for sacroiliac joint pain. Anesthesiology 2008; 109:279-288

903. Freeman BJ. IDET: A critical appraisal of the evidence. Eur Spine J 2006; 15:448457.

904. Freeman BJ, Mehdian R. Intradiscal electrothermal therapy, percutaneous discectomy, nucleoplasty: What is the current evidence? Curr Pain Headache Rep 2008; 12:14-21.

905. Pauza KJ, Howell S, Dreyfuss P. A randomized, placebo-controlled trial of intradiscal electrothermal therapy for the treatment of discogenic low back pain. Spine J 2004; 4:27-35.

906. Freeman BJ, Fraser RD, Cain CM, Hall DJ, Chapple DC. A randomized, double blind, controlled trial: Intradiscal electrothermal therapy versus placebo for the treatment of chronic discogenic low back pain. Spine 2005; 30:2369-2377.

907. Andersson GB, Mekhail NA, Block JE. Intradiscal electrothermal therapy (IDET). Spine 2006; 31:1402-1403.

908. Gibson JA, Waddell G. Letter to the editor. Spine 2006; 31:1402-1403.

909. Karasek M, Bogduk N. Twelve-month follow-up of a controlled trial of intradiscal thermal anuloplasty for back pain due to internal disc disruption. Spine 2000; 25:2601-2607.

910. Bogduk N, Karasek M. Two-year followup of a controlled trial of intradiscal electrothermal anuloplasty for chronic low back pain resulting from internal disc disruption. Spine J 2002; 2:343350.

911. Gerszten PC, Welch WC, McGrath PM, Willis SL. A prospective outcomes study of patients undergoing intradiscal electrothermy (IDET) for chronic low back pain. Pain Physician 2002; 5:360364.

912. Saal JA, Saal JS. Intradiscal electrothermal treatment for chronic discogenic low back pain: Prospective outcome study with a minimum 2-year followup. Spine 2002; 279:966-973.

913. Saal JA, Saal JS. Intradiscal electrothermal treatment for chronic discogenic low back pain: A prospective outcome study with minimum 1-year follow-up. Spine 2000; 25:2622-2627.

914. Saal JS, Saal JA. Management of chronic discogenic low back pain with a thermal intradiscal catheter. A preliminary report. Spine 2000; 25:382-388.

915. Cohen SP, Larkin T, Abdi S, Chang A, Stojanovic M. Risk factors for failure and complications of intradiscal electrothermal therapy: A pilot study. Spine 2003; 28:1142-1147.

916. Freedman VA, Martin LG, Schoeni RF. Recent trends in disability and functioning among older adults in the United States. JAMA 2002; 288:3137-3146.

917. Lee MS, Cooper G, Lutz GE, Lutz C, Hong HM. Intradiscal Electrothermal Therapy (IDET) for treatment of chronic lumbar discogenic pain: A minimum 2year clinical outcome study. Pain Physician 2003; 6:443-448.

918. Lutz C, Lutz GE, Cooke PM. Treatment of chronic lumbar diskogenic pain with intradiscal electrothermal therapy: $A$ prospective outcome study. Arch Phys Med Rehabil 2003; 84:23-28.

919. Davis TT, Delamarter RB, Sra P, Goldstein TB. The IDET procedure for chronic discogenic low back pain. Spine 2004; 29:752-756.

920. Derby R, Lee SH, Seo KS, Kazala K, Kim BJ, Kim MJ. Efficacy of IDET for relief of leg pain associated with discogenic low back pain. Pain Practice 2004; 4:281-285.

921. Mekhail N, Kapural L. Intradiscal thermal annuloplasty for discogenic pain: An outcome study. Pain Practice 2004; 4:84-90.

922. Kapural L, Mekhail N, Korunda Z, Basali A. Intradiscal thermal annuloplasty for the treatment of lumbar discogen- ic pain in patients with multilevel degenerative disc disease. Anesth Analg 2004; 99:472-476.

923. Bryce DA, Nelson J, Glurich I, Berg RL. Intradiscal electrothermal annuloplasty therapy: A case series study leading to new considerations. WMJ 2005; 104:39-46.

924. Maurer P, Block JE, Squillante D. Intradiscal electrothermal therapy (IDET) provides effective symptom relief in patients with discogenic low back pain. $J$ Spinal Disord Tech 2008; 21:55-62.

925. Nunley PD, Jawahar A, Brandao SM, Wilkinson K. Intradiscal electrothermal therapy (IDET) for low back pain in Worker's Compensation patients: Can it provide a potential answer? Longterm results. J Spinal Disord Tech 2008; 21:11-18.

926. Ergun R, Sekerci Z, Bulut H, Dolgun H. Intradiscal electrothermal treatment for chronic discogenic low back pain: A prospective outcome study of $39 \mathrm{pa}$ tients with Oswestry Disability Index at 18 month follow up. Neurol Res 2008; 30:411-416.

927. Kapural L, Hayek S, Malak O, Arrigain S, Mekhail N. Intradiscal thermal annuloplasty versus intradiscal radiofrequency ablation for the treatment of discogenic pain: A prospective matched control trial. Pain Med 2005; 6:425-431.

928. Saal JA. Complications related to intradiscal electrothermal therapy: Technical considerations and prevention. Semin Spine Surg 2002; 14:163-165.

929. Lee J, Lutz GE, Campbell D, Rodeo SA, Wright T. Stability of the lumbar spine after intradiscal electrothermal therapy. Arch Phys Med Rehabil 2001; 82:120-122.

930. Ackerman WE. Cauda equina syndrome after intradiscal electrothermal therapy. Reg Anaesth Pain Med 2002; 27:622.

931. Eckel TS, Ortiz AO. Intradiscal electrothermal therapy in the treatment of discogenic low back pain. Tech Vasc Interv Radiol 2002; 5:217-222.

932. Djurasovic M, Glassman SD, Dimar JR 2nd, Johnson JR. Vertebral osteonecrosis associated with the use of intradiscal electrothermal therapy. A case report. Spine 2002; 27:E325-E328.

933. Scholl BM, Theiss SM, Lopez-Ben R, Kraft M. Vertebral osteonecrosis related to intradiscal electrothermal therapy: A case report. Spine 2003; 28:E161E164. 
934. Wetzel FT. Cauda equina syndrome from intradiscal electrothermal therapy. Neurology 2001; 56:1607.

935. Orr RD, Thomas S. Intradural migration of broken IDET catheter causing a radiculopathy. J Spinal Disord Tech 2005; 18:185-187.

936. Cohen SP, Larkin T, Polly DW Jr. A giant herniated disc following intradiscal electrothermal therapy. J Spinal Disord Tech 2002; 15:537-541.

937. Saal J. IDET related complications: A multi-center study of 1675 treated patients with a review of the FDA MDR Data Base. Paper presented at: 16th Annual North American Spine Society; October 31-November 3, 2001; Seattle WA.

938. Hsia AW, Isaac K, Katz JS. Cauda equina syndrome from intradiscal electrothermal therapy. Neurology 2000; 55:320.

939. Wang JC, Kabo JM, Tsou PM, Halevi L, Shamie AN. The effect of uniform heating on the biomechanical properties of the intervertebral disc in a porcine model. Spine J 2005; 5:64-70.

940. Pollintine P, Findlay G, Adams MA. Intradiscal electrothermal therapy can alter compressive stress distributions inside degenerated intervertebral discs. Spine 2005; 30:E134-E139.

941. Kloth DS, Fenton DS, Andersson GB, Block JE. Intradiscal electrothermal therapy (IDET) for the treatment of discogenic low back pain: Patient selection and indications for use. Pain Physician 2008; 11:659-668.

942. Kapural L, Ng A, Dalton J, Mascha E, Kapural M, de la Garza M, Mekhail N. Intervertebral disc biacuplasty for the treatment of lumbar discogenic pain: Results of a six-month follow-up. Pain Med 2008; 9:60-67.

943. Kapural L. Letter to the editor: Intervertebral disk cooled bipolar radiofrequency (intradiskal biacuplasty) for the treatment of lumbar diskogenic pain: 12 month follow up of the pilot study. Pain Med 2008; 9:407-408.

944. Finch PM, Price LM, Drummond PD. Radiofrequency heating of painful annular disruptions: One-year outcomes. I Spinal Disord Tech 2005; 18:6-13.

945. Gibson JNA, Waddell G. Surgical interventions for lumbar disc prolapse. Cochrane Database Syst Rev 2009; (1): CDoo1350.

946. Waddell G, Gibson A, Grant I. Surgical treatment of lumbar disc prolapse and degenerative lumbar disc disease. In: Nachemson AL, Jonsson E (eds). Neck and Back Pain: The Scientific Evidence of Causes, Diagnosis and Treatment. Lippincott Williams \& Wilkins, Philadelphia, 2000, pp 305-326.

947. Gibson JN, Grant IC, Waddell G. The Cochrane review of surgery for lumbar disc prolapse and degenerative lumbar spondylosis. Spine 1999; 24:18201832.

948. Revel M, Payan C, Vallee C, Laredo JD, Lassale B, Roux C, Carter H, Salomon C, Delmas E, Roucoules J. Automated percutaneous lumbar discectomy versus chemonucleolysis in the treatment of sciatica. A randomized multicenter trial. Spine 1993; 18:1-7.

949. Krugluger J, Knahr K. Chemonucleolysis and automated percutaneous discectomy-a prospective randomized comparison. Int Orthop 2000; 24:167-169.

950. Chatterjee S, Foy PM, Findlay GF. Report of a controlled clinical trial comparing automated percutaneous lumbar discectomy and microdiscectomy in the treatment of contained lumbar disc herniation. Spine 1995; 20:734738.

951. Haines SJ, Jordan N, Boen JR, Nyman JA, Oldridge NB, Lindgren BR; LAPDOG/ LEAPDOG Investigators. Discectomy strategies for lumbar disc herniation: Results of the LAPDOG trial. / Clin Neurosci 2002; 9:411-417.

952. Shapiro S. Long-term follow-up of 57 patients undergoing automated percutaneous discectomy. J Neurosurg 1995; 83:31-33.

953. Grevitt MP, McLaren A, Shackleford IM, Mulholland RC. Automated percutaneous lumbar discectomy. An outcome study. J Bone Joint Surg Br 1995; 77:626-629.

954. Onik G, Mooney V, Maroon JC, Wiltse L, Helms C, Schweigel J, Watkins R, Kahanovitz N, Day A, Morris J, McCullough JA, Reicher M, Croissant P, Dunsker S, Davis GW, Brown C, Hochschuler S, Saul T, Ray C. Automated percutaneous discectomy: A prospective multiinstitutional study. Neurosurgery 1990; 26:228-232.

955. Davis GW, Onik G, Helms C. Automated percutaneous discectomy. Spine 1991; 16:359-363.

956. Maroon JC, Allen AC. A retrospective study of 1,054 APLD cases: A twenty month clinical follow-up at 35 US centers. I Neurol Orthop Med Surg 1989;
10:335-337.

957. Teng GJ, Jeffery RF, Guo JH, He SC, Zhu $H Z$, Wang XH, Wu YZ, Lu JM, Ling XL, Qian Y, Zhang YM, Zhu MJ, Guan L, He $X M$. Automated percutaneous lumbar discectomy: A prospective multi-institutional study. J Vasc Interv Radiol 1997; 8:457-463.

958. Bonaldi G, Belloni G, Prosetti D, Moschini L. Percutaneous discectomy using Onik's method: 3 years' experience. Neuroradiology 1991; 33:516-519.

959. Degobbis A, Crucil M, Alberti M, Bortolussi A. A long-term review of 50 patients out of 506 treated with automated percutaneous nucleotomy according to Onik for lumbar-sacral disc herniation. Acta Neurochir Suppl 2005; 92:103-105.

960. Gill K, Blumenthal SL. Automated percutaneous discectomy. Long-term clinical experience with the Nucleotome system. Acta Orthop Scand Suppl 1993; 251:30-33.

961. Rezaian SM, Ghista DN. Percutaneous discectomy: Technique, indications, and contraindications, 285 cases and results. J Neurol Orthop Med Surg $1995 ; 16: 1-6$.

962. Marks RA. Transcutaneous lumbar diskectomy for internal disk derangement: A new indication. South Med J 2000; 93:885-890.

963. Bernd L, Schiltenwolf M, Mau H, Schindele S. No indications for percutaneous lumbar discectomy? Int Orthop 1997; 21:164-168.

964. Bosacco SJ, Bosacco DN, Berman AT, Cordover A, Levenberg RJ, Stellabotte J. Functional results of percutaneous laser discectomy. Am J Orthop 1996; 25:825-828.

965. Choy DS. Percutaneous laser disc decompression (PLDD): 12 years experience with 752 procedures in 518 patients. J Clin Laser Med Surg 1998; 16:325-331.

966. Nerubay J, Caspi I, Levinkopf M. Percutaneous carbon dioxide laser nucleolysis with 2- to 5-year followup. Clin Orthop Relat Res 1997; 337:45-48.

967. Ascher PW. Laser trends in minimally invasive treatment: Atherosclerosis, disk herniations. I Clin Laser Med Surg 1991; 9:49-57.

968. Casper GD, Hartman VL, Mullins LL. Results of a clinical trial of the holmium: YAG laser in disc decompression utilizing a side-firing fiber: A two-year follow-up. Lasers Surg Med 1996; 19:90- 
96.

969. Botsford JA. Radiological considerations: Patient selection for percutaneous laser disc decompression. J Clin Laser Med Surg 1994; 12:255-259.

970. Knight M, Goswami A. Lumbar percutaneous KTP532 wavelength laser disc decompression and disc ablation in the management of discogenic pain. J Clin Laser Med Surg 2002; 20:9-13.

971. Grönemeyer DH, Buschkamp H, Braun M, Schirp S, Weinsheimer PA, Gevargez A. Image-guided percutaneous laser disk decompression for herniated lumbar disks: A 4-year follow-up in 200 patients. J Clin Laser Med Surg 2003; 21:131-138

972. Zhao DQ, Du F, Yang J, Zheng YB. Cohort-controlled study on percutaneous laser decompression in treating lumbar disc herniation. Chin J Clin Rehabil 2005; 9:202-203.

973. Tassi GP. Comparison of results of 500 microdiscectomies and 500 percutaneous laser disc decompression procedures for lumbar disc herniation. Photomed Laser Surg 2006; 24:694-697.

974. Mayer HM, Brock M: Percutaneous endoscopic discectomy: Surgical technique and preliminary results compared to microsurgical discectomy. J Neurosurg 1993; 78:216-225.

975. Epstein NE. Nerve root complications of percutaneous laser-assisted diskectomy performed at outside institutions: A technical note. J Spinal Disord 1994; 7:510-512.

976. Epstein NE. Laser-assisted diskectomy performed by an internist resulting in cauda equina syndrome. I Spinal Disord 1999; 12:77-79.

977. Ohnmeiss DD, Guyer RD, Hochschuler $\mathrm{SH}$. Laser disc decompression. The importance of proper patient selection. Spine 1994; 19:2054-2058.

978. Chen YC, Lee SH, Chen D. Intradiscal pressure study of percutaneous disc decompression with nucleoplasty in human cadavers. Spine 2003; 28:661665.

979. Chen YC, Lee SH, Saenz Y, Lehman NL. Histologic findings of disc, end plate and neural elements after coblation of nucleus pulposus: An experimental nucleoplasty study. Spine / 2003; 3:466470.

980. Singh V, Piryani C, Liao K, Nieschultz S. Percutaneous disc decompression using coblation (nucleoplasty) in the treatment of chronic discogenic pain.
Pain Physician 2002; 5:250-259.

981. Sharps LS, Isaac Z. Percutaneous disc decompression using Nucleoplasty. Pain Physician 2002; 5:121-126.

982. Welch WC, Gerszten PC. Alternative strategies for lumbar discectomy: intradiscal electrothermy and nucleoplasty. Neurosurg Focus 2002; 13:E7.

983. Singh V, Piryani C, Liao K. Role of percutaneous disc decompression using coblation in managing chronic discogenic low back pain: A prospective, observational study. Pain Physician 2004; 7:419-425.

984. Singh V, Piryani C, Liao K. Evaluation of percutaneous disc decompression using coblation in chronic back pain with or without leg pain. Pain Physician 2003; 6:273-280.

985. Marin FZ. CAM versus nucleoplasty. Acta Neurochir Suppl 2005; 92:111-114.

986. Mirzai H, Tekin I, Yaman O, Bursali A. The results of nucleoplasty in patients with lumbar herniated disc: A prospective clinical study of 52 consecutive patients. Spine / 2007; 7:88-92.

987. Al-Zain F, Lemcke J, Killeen T, Meier U, Eisenschenk A. Minimally invasive spinal surgery using nucleoplasty: A 1year follow-up study. Acta Neurochir (Wien) 2008; 150:1257-1262.

988. Bhagia SM, Slipman CW, Nirschl M, Isaac Z, El-Abd O, Sharps LS, Garvin C. Side effects and complications after percutaneous disc decompression using coblation technology. Am J Phys Med Rehabil 2006; 85:6-13.

989. Alo KM, Wright RE, Sutcliffe J, Brandt SA. Percutaneous lumbar discectomy: Clinical response in an initial cohort of fifty consecutive patients with chronic radicular pain. Pain Pract 2004; 4:1929.

990. Alo KM, Wright RE, Sutcliffe J, Brandt SA. Percutaneous lumbar discectomy: One-year follow-up in an initial cohort of fifty consecutive patients with chronic radicular pain. Pain Pract 2005; 5:116-124.

991. Lierz P, Alo KM, Felleiter P. Percutaneous lumbar discectomy using the Dekompressor System under CT-control. Pain Pract 2009; 9:216-220.

992. Amoretti N, David P, Grimaud A, Flory P, Hovorka I, Roux C, Chevallier P, Bruneton JN. Clinical follow-up of 50 patients treated by percutaneous lumbar discectomy. Clin Imaging 2006; 30:242244.

993. Domsky R, Goldberg M, Hirsh RA, Scar- inge D, Toriman MC. Critical failure of a percutaneous discectomy probe requiring surgical removal during disc decompression. Reg Anesth Pain Med 2006; 31:177-179.

994. Oakley J, Prager J. Spinal cord stimulation: Mechanism of action. Spine 2002; 22:2574-2583.

995. Taylor RS, Taylor RJ, Van Buyten JP, Buchser E, North R, Bayliss S. The cost effectiveness of spinal cord stimulation in the treatment of pain: A systematic review of the literature. J Pain Symptom Manage 2004; 27:370-378.

996. Bala MM, Riemsma RP, Nixon J, Kleijnen J. Systematic review of the (cost-) effectiveness of spinal cord stimulation for people with failed back surgery syndrome. Clin J Pain 2008; 24:757-758.

997. Manca A, Kumar K, Taylor RS, Jacques L, Eldabe S, Meglio M, Molet J, Thomson S, O'Callaghan J, Eisenberg E, Milbouw G, Buchser E, Fortini G, Richardson J, Taylor RJ, Goeree R, Sculpher MJ. Quality of life, resource consumption and costs of spinal cord stimulation versus conventional medical management in neuropathic pain patients with failed back surgery syndrome (PROCESS trial). Eur J Pain 2008; 12:10471058.

998. Kumar K, Malik S, Demeria D. Treatment of chronic pain with spinal cord stimulation versus alternative therapies: Cost-effectiveness analysis. Neurosurgery 2002; 51:106-115.

999. North RB, Kidd D, Shipley J, Taylor RS. Spinal cord stimulation versus reoperation for failed back surgery syndrome: A cost effectiveness and cost utility analysis based on a randomized, controlled trial. Neurosurgery 2007; 61:361-368.

1000. Cameron T. Safety and efficacy of spinal cord stimulation for the treatment of chronic pain: A 20-year literature review. J Neurosurg 2004; 100:S254-S67.

1001. Kumar K, Taylor RS, Jacques L, Eldabe S, Meglio M, Molet J, Thomson S, O'Callaghan J, Eisenberg E, Milbouw G, Buchser E, Fortini G, Richardson J, North RB. The effects of spinal cord stimulation in neuropathic pain are sustained: A 24-month follow-up of the prospective randomized controlled multicenter trial of the effectiveness of spinal cord stimulation. Neurosurgery 2008; 63:762-770.

1002. Kumar K, Taylor RS, Jacques L, Eldabe S, Meglio M, Molet J, Thomson S, O’Callaghan J, Eisenberg E, Milbouw 
G, Buchser E, Fortini G, Richardson J, North RB. Spinal cord stimulation versus conventional medical management for neuropathic pain: A multicentre randomised controlled trial in patients with failed back surgery syndrome. Pain 2007; 132:179-188.

1003. North RB, Kidd DH, Farrokhi F, Piantadosi SA. Spinal cord stimulation versus repeated lumbosacral spine surgery for chronic pain: A randomized, controlled trial. Neurosurgery 2005; 56:98-107.

1004. Van Buyten JP, Van Zundert J, Vueghs P, Vanduffel L. Efficacy of spinal cord stimulation: 10 years of experience in a pain centre in Belgium. Eur J Pain 2001; 5:299-307.

1005. Kumar K, Toth C. The role of spinal cord stimulation in the treatment of chronic pain postlaminectomy. Curr Pain Headache Rep 1998; 2:85-92.

1006. De La Porte C, Van de Kelft E. Spinal cord stimulation in failed back surgery syndrome. Pain 1993; 52:55-61.

1007. Devulder J, De Laat M, Van Bastelaere M, Rolly G. Spinal cord stimulation: A valuable treatment for chronic failed back surgery patients. J Pain Symptom Manage 1997; 13:296-301.

1008. North RB, Ewend MG, Lawton MT, Kidd $\mathrm{DH}$, Piantadosi S. Failed back surgery syndrome: 5-year follow-up after spinal cord stimulator implantation. Neurosurgery 1991; 28:692-699.

1009. Dario A. Treatment of failed back surgery syndrome. Neuromodulation 2001; 4:105-110.

1010. De La Porte C, Siegfried J. Lumbosacral spinal fibrosis (spinal arachnoiditis). Its diagnosis and treatment by spinal cord stimulation. Spine 1983; 8:593603.

1011. Burchiel KJ, Anderson VC, Brown FD, Fessler RG, Friedman WA, Pelofsky S, Weiner RL, Oakley J, Shatin D. Prospective, multicenter study of spinal cord stimulation for relief of chronic back and extremity pain. Spine 1996; 21:2786-2794.

1012. Ohnmeiss DD, Rashbaum RF, Bogdanffy GM. Prospective outcome evaluation of spinal cord stimulation in patients with intractable leg pain. Spine 1996; 21:1344-1350.

1013. Bagger JP, Jensen BS, Johannsen G. Long-term outcome of spinal cord electrical stimulation in patients with refractory chest pain. Clin Cardiol 1998; 21:286-288.

1014. Quigley DG, Arnold J, Eldridge PR, Cam- eron H, Mclvor K, Miles JB, Varma TR. Long-term outcome of spinal cord stimulation and hardware complications. Stereotact Funct Neurosurg 2003; 81:50-56.

1015. Winkelmüller $\mathrm{M}$, Winkelmüller W. Longterm effects of continuous intrathecal opioid treatment in chronic pain of nonmalignant etiology. J Neurosurg 1996; 85:458-467.

1016. Roberts LJ, Finch PM, Goucke CR, Price LM. Outcome of intrathecal opioids in chronic non-cancer pain. Eur J Pain 2001; 5:353-361.

1017. Deer TR, Caraway DL, Kim CK, Dempsey CD, Stewart CD, McNeil KF. Clinical experience with intrathecal bupivacaine in combination with opioid for the treatment of chronic pain related to failed back surgery syndrome and metastatic cancer pain of the spine. Spine J 2002; 2:274-278.

1018. Thimineur MA, Kravitz E, Vodapally MS. Intrathecal opioid treatment for chronic non-malignant pain: A 3 year prospective study. Pain 2004; 109:242249.

1019. Shaladi A, Saltari MR, Piva B, Crestani F, Tartari S, Pinato P, Michelleto G, Dall'Ara R. Continuous intrathecal morphine infusion in patients with vertebral fractures due to osteoporosis. Clin J Pain 2007; 23:511-517.

1020. Mueller-Schwefe G, Hassenbusch SJ, Reig E. Cost-effectiveness of intrathecal therapy for pain. Neuromodulation 1999; 2:77-84.

1021. Deer TR. Intrathecal drug delivery systems. In: Manchikanti L, Singh V (eds). Interventional Techniques in Chronic Spinal Pain. ASIPP Publishing, Paducah KY, 2008, pp 613-628.

1022. Paice, J, Penn R, Shott S. Intraspinal morphine for chronic pain: A retrospective, multicenter study. J Pain Symptom Manage 1996; 11:71-80.

1023. Daniell H. Hypogonadism in men consuming sustained-action oral opioids. J Pain 2002; 3:377-384.

1024. Coffey R, Burchiel K. Inflammatory mass lesions associated with intrathecal drug infusion catheters: Report and observations on 41 patients. Neurosurgery 2002; 50:78-86.

1025. McMillan MR, Doud T, Nugent W. Catheter-associated masses in patients receiving intrathecal analgesic therapy. Anesth Analg 2003; 96:186-190.

1026. Yaksh TL, Horais KA, Tozier NA, Allen JW, Rathbun M, Rossi SS, Sommer C,
Meschter C, Richter PJ, Hildebrand KR. Chronically infused intrathecal morphine in dogs. Anesthesiology 2003; 99:174-187.

1027. Gradert TL, Baze WB, Satterfield W, Hildebrand K, Johansen M, Hassenbusch S. Safety of chronic intrathecal morphine infusion in a sheep model. Anesthesiology 2003; 99:188-198.

1028. International Classification of Diseases, gth Revision - Clinical Modification, ICD-9-CM. American Medical Association, Chicago, 2009.

1029. Manchikanti L. The role of evaluation and management services in pain management. Pain Physician 1999; 2:1032.

1030. H.R. 2015. Balanced Budget Act of 1997. P.L. 105-33, August 5, 1997.

1031. Quinn C. Issues of medical necessity. A medical director's guide to good faith adjudication. Am J Managed Care 1997; 3:883-888.

1032. Jacobson PD, Asch S, Glassman PA, Model KE, Hernandez JB. Defining and implementing medical necessity in Washington State and Oregon. Inquiry 1997; 34:143-154.

1033. Centers for Medicare and Medicaid Services (CMS) Billing Guide. Medicare Part B. NHIC Corp., March 2009.

1034. Garner BA (ed). Black's Law Dictionary, 8th Edition. Thomson West, St. Paul, 2004.

1035. American Medical Association. Model Managed Care Contract, Second Edition. 2000. www.ama-assn.org/ama/ upload $/ \mathrm{mm} / 395 /$ modelmgdcare.pdf

1036. Manchikanti L, Boswell MV, Manchukonda R, Cash KA, Giordano. Influence of prior opioid exposure on diagnostic facet joint nerve blocks. J Opioid Manage 2008; 4:351-360.

1037. Manchikanti L, Pampati V, Damron $K$. The role of placebo and nocebo effects of perioperative administration of sedatives and opioids in interventional pain management. Pain Physician 2005; 8:349-355.

1038. Donelson R, Aprill C, Medcalf R, Grant W. A prospective study of centralization of lumbar and referred pain. A predictor of symptomatic discs and anular competence. Spine 1997; 22:11151122.

1039. Malhotra G, Abbasi A, Rhee M. Complications of transforaminal cervical epidural steroid injections. Spine 2009; 34:731-739. 
1040. Lee JH, Lee JK, Seo BR, Moon SJ, Kim JH, Kim SH. Spinal cord injury produced by direct damage during cervical transforaminal epidural injection. Reg Anesth Pain Med 2008; 33:377-379.

1041. Scanlon GC, Moeller-Bertram T, Romanowsky SM, Wallace MS. Cervical transforaminal epidural steroid injections. More dangerous than we think? Spine 2007; 32:1249-1256.

1042. Windsor RE, Storm S, Sugar S, Nagula D. Cervical transforaminal injection: Review of the literature, complications, and a suggested technique. Pain Physician 2003; 6:457-465.

1043. Furman MB, Giovanniollo MT, O’Brien $E M$. Incidence of intravascular penetration in transforaminal cervical epidural steroid injections. Spine 2003; 28:2125.

1044. Muro K, O’Shaughnessy B, Ganju A. Infarction of the cervical spinal cord following multilevel transforaminal epidural steroid injection: Case report and review of the literature. J Spinal Cord Med 2007; 30:385-388.

1045. Suresh S, Berman J, Connell DA. Cerebellar and brainstem infarction as a complication of CT-guided transforaminal cervical nerve root block. Skeletal Radiol 2007; 36:449-452.

1046. Bogduk N, Dreyfuss P, Baker R, Yin W, Landers M, Hammer M, Aprill C. Complications of spinal diagnostic and treatment procedures. Pain Med 2008; 9:S11-S34.

1047. Kaplan MS, Cunniff J, Cooke J, Collins JG. Intravascular uptake during fluoroscopically guided cervical interlaminar steroid injection at 66-7: A case report. Arch Phys Med Rehabil 2008; 89:553558.

1048. Beckman WA, Mendez RJ, Paine GF, Mazzilli MA. Cerebellar herniation after cervical transforaminal epidural injection. Reg Anesth Pain Med 2006; 31:282-285.

1049. Huntoon MA. Cervical spine: Case presentation, complications, and their prevention. Pain Med 2008; 9:S35-S40.

1050. Ludwig MA, Burns SP. Spinal cord infarction following cervical transforaminal epidural injection: A case report. Spine 2005; 30:E266-E268.

1051. Rowlingson JC, Kirschenbaum LP. Epidural analgesic techniques in the management of cervical pain. Anesth Analg 1986; 65:938-942.

1052. Ferrante FM, Wilson SP, lacobo C, Orav EJ, Rocco AG, Lipson S. Clinical classi- fication as a predictor of therapeutic outcome after cervical epidural steroid injection. Spine 1993; 18:730-736.

1053. Grenier B, Castagnera L, Maurette P, Erny P, Senegas J. Chronic cervico-brachial neuralgia treated by cervical epidural injection of corticosteroids. Longterm results. Ann Fr Anesth Reanim 1995; 14:484-488.

1054. Proano FA, Morgan PJ, Hymes JA, Rosenblatt RM, Weiss JA. Cervical steroid epidural block for treatment of cervical herniated intervertebral discs. Pain 1990; 5 :S87.

1055. Cicala RS, Thoni K, Angel JJ. Long-term results of cervical epidural steroid injections. Clin J Pain 1989; 5:143-145.

1056. Schimmer BP, Parker KL. Adrenocorticotropic hormone; adrenocortical steroids and their synthetic analogs; inhibitors of the synthesis and actions of adrenocortical hormones. In: Hardman JG, Limbird LE (eds). Goodman \& Gilman, The Pharmacological Basis of Therapeutics, Tenth Edition. McGrawHill, New York, 2001, pp 1649-1679.

1057. McEvoy GK, Snow EK, Miller J, Kester L, Welsh OH. AHFS Drug Information 2009. American Society of Health System Pharmacists, Bethesda, 2009.

1058. Maillefert JF, Aho S, Huguenin MC, Chatard C, Peere T, Marquignon MF, Lucas B, Tavernier C. Systemic effects of epidural dexamethasone injections. Revue du Rhumatisme 1995; 62:429432.

1059. Ward A, Watson J, Wood P, Dunne C, Kerr D. Glucocorticoid epidural for sciatica: Metabolic and endocrine sequelae. Rheumatology 2002; 41:68-71.

1060. Weissman DE, Dufer D, Vogel V, Abeloff MD. Corticosteroid toxicity in neurooncology patients. J Neurooncol 1987; 5:125-128.

1061. Delaney TJ, Rowlingson JC, Carron H, Butler A. Epidural steroid effects on nerves and meninges. Anesth Analg 1980; 58:610-614.

1062. Mackinnon SE, Hudson AR, Gentili F, Kline DG, Hunter D. Peripheral nerve injection injury with steroid agents. Plast Reconstr Surg 1982; 69:482-489.

1063. Chino N, Awad EA, Kottke FJ. Pathology of propylene glycol administered by perineural and intramuscular injection in rats. Arch Phys Med Rehab 1974; 55:33-38.

1064. Benzon HT, Gissen AJ, Strichartz GR, Avram MJ, Covino BG. The effect of polyethylene glycol on mammalian nerve impulses. Anesth Analg 1987; 66:553-559.

1065. Abram SE, Marsala M, Yaksh TL. Analgesic and neurotoxic effects of intrathecal corticosteroids in rats. Anesthe siology 1994; 81:1198-1205.

1066. Latham JM, Fraser RD, Moore RJ, Blumbergs PC, Bogduk N. The pathologic effects of intrathecal betamethasone. Spine 1997; 22:1558-1562.

1067. Robustelli della Cuna FS, Mella M, Magistrali G, Ricci M, Losurdo A, Goglio AM. Stability and compatibility of methylprednisolone acetate and ropivacaine hydrochloride in polypropylene syringes for epidural administration. Am J Health Syst Pharm 2001; 58:1753-1756.

1068. Swai EA, Rosen M. An attempt to develop a model to study the effects of intrathecal steroids. Eur / Anaesthesiol 1986; 3:127-136.

1069. Dunbar SA, Manikantan P, Philip J. Epidural infusion pressure in degenerative spinal disease before and after epidural steroid therapy. Anesth Analg 2002; 94:417-420.

1070. Slucky AV, Sacks MS, Pallares VS, Malinin TI, Eismont FJ. Effects of epidural steroids on lumbar dura material properties. J Spin Disord 1999; 12:331-340.

1071. Stanczak J, Blankenbaker DG, De Smet AA, Fine J. Efficacy of epidural injections of Kenalog and Celestone in the treatment of lower back pain. AJR Am J Roentgenol 2003; 181:1255-1258.

1072. Noe CE, Haynsworth RF Jr. Comparison of epidural depo-medrol vs. aqueous betamethasone in patients with low back pain. Pain Pract 2003; 3:222225.

1073. Tiso RL, Cutler T, Catania JA, Whalen K. Adverse central nervous system sequelae after selective transforaminal block: The role of corticosteroids. Spine / 2004; 4:468-474.

1074. Benzon HT, Chew TL, McCarthy RJ, Benzon HA, Walega DR. Comparison of the particle sizes of different steroids and the effect of dilution. Anesthesiology 2007; 106:331-338.

1075. Derby R, Lee SH, Date ES, Lee JH, Lee $\mathrm{CH}$. Size and aggregation of corticosteroids used for epidural injections. Pain Med 2008; 9:227-234.

1076. Huntoon MA. Complications associated with chronic steroid use. In: Neal JM, Rathmell JP (eds)S. Complications in Regional Anesthesia \& Pain Medicine. Saunders, Philadelphia, PA, 2007, 
pp 331-339.

1077. Nelson D. Dangers from methylprednisolone acetate therapy by intraspinal injection. Arch Neurol 1988; 45:804806.

1078. Huntoon MC, Martin DP. Paralysis after transforaminal epidural injection and previous spinal surgery. Reg Anesth Pain Med 2004; 29:494-495.
1079. Huntoon MA. Anatomy of the cervical intervertebral foramina: Vulnerable arteries and ischemic neurologic injuries after transforaminal epidural injections. Pain 2005; 117:104-111.

1080. Jacobs A, Pullan PT, Potter JM, Shenfield GM. Adrenal suppression following extradural steroids. Anaesthesia 1983; 38:953-956.
1081. Kay JK, Findling JW, Raff H. Epidural triamcinolone suppresses the pituitary adrenal axis in human subjects. Anesth Analg 1994; 79:501-505.

1082. Hsu D, Fu P, Gyermek L, Tan C. Comparison of plasma cortisol and ACTH profile after a single lumbar epidural dose of triamcinolone $40 \mathrm{mg}, 80 \mathrm{mg}$ respectively in low back pain patients. Anesth Analg 1996; 82:S191. 